UNIVERSIDADE DE SÃO PAULO

ESCOLA DE ENGENHARIA DE SÃO CARLOS

PROGRAMA DE PÓS-GRADUAÇÃO EM ENGENHARIA DE TRANSPORTES

MARCELO MONARI

Método para definição de rede de rotas cicláveis em áreas urbanas de cidades de pequeno porte: um estudo de caso para a cidade de Bariri-SP

SÃO CARLOS 



\title{
Método para definição de rede de rotas cicláveis em áreas urbanas de cidades de pequeno porte: um estudo de caso para a cidade de Bariri-SP
}

\author{
VERSÃO CORRIGIDA \\ A versão original encontra-se na Escola de Engenharia de São Carlos
}

Dissertação apresentada ao Programa de Pósgraduação em Engenharia de Transportes da Escola de Engenharia de São Carlos, Universidade de São Paulo, como parte dos requisitos necessários para obtenção do título de Mestre em Ciências.

Área de concentração: Infraestrutura de Transportes - Geomática

Orientador: Prof. Associado Paulo C. L. Segantine 
AUTORIZO A REPRODUCÃO TOTAL OU PARCIAL DESTE TRABALHO, POR QUALQUER MEIO CONVENCIONAL OU ELETRONICO, PARA FINS DE ESTUDO E PESQUISA, DESDE QUE CITADA A FONTE.

Ficha catalográfica elaborada pela Biblioteca Prof. Dr. Sérgio Rodrigues Fontes da EESC/USP com os dados inseridos pelo(a) autor(a).

M734mari, Marcelo

Método para definição de rede de rotas cicláveis em áreas urbanas de cidades de pequeno porte: um estudo de caso para a cidade de Bariri-SP / Marcelo Monari; orientador Paulo César Lima Segantine. São Carlos, 2018.

Dissertação (Mestrado) - Programa de Pós-Graduação em. Engenharia de Transportes e Ârea de Concentração em Infraestrutura de Transportes -- Escola de Engenharia de São Carlos da Universidade de São Paulo, 2018.

1. Bicicleta. 2. Transporte cicloviário. 3. Mobilidade urbana. 4. Rotas cicláveis. 5. Cidades de pequeno porte. 6 . Nível de estresse. 7. Declividade. 8. Infraestrutura cicloviária. I. Título. 


\section{FOLHA DE JULGAMENTO}

Candidato: Engenheiro MARCELO MONARI.

Título da dissertaçäo: "Método para definição de rede de rotas cicláveis em áreas urbanas de cidades de pequeno porte: um estudo de caso parta a cidade de BaririSP".

Data da defesa: 11/05/2018.

Comissão Julgadora:

Prof. Associado Paulo Cesar Lima Segantine (Orientador)

(Escola de Engenharia de Säo Carlos/EESC)

Profa. Dra. Maria Teresa Françoso

(Universidade Estadual de Campinas/UNICAMP)

Prof. Dr. Fernando Hideki Hirose

(Universidade Federal de São Carlos/UFSCar)
Resultado:

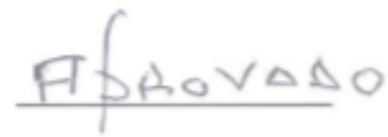

Aprovado

APRONADO

Coordenadora do Programa de Pós-Graduaçăo em Engenharia de Transportes:

Profe. Associada Ana Paula Camargo Larocca

Presidente da Comissão de Pós-Graduação:

Prof. Associado Luis Fernando Costa Alberto 

Aos meus pais, Márcio e Márcia, e aos meus amigos, dedico este trabalho. 



\section{AGRADECIMENTOS}

Aos meus pais, Márcio Augusto Monari e Márcia Regina da Silva, por todo o incentivo, sacrifício, carinho e amor, sem os quais este trabalho não poderia ser desenvolvido.

Ao prof. Paulo César Lima Segantine pela ótima orientação, e pelo respeito, amizade e companheirismo. Agradeço acima de tudo pela confiança depositada em mim para a elaboração deste trabalho, fornecendo os estímulos para uma possível carreira acadêmica.

À Escola de Engenharia de São Carlos por todos os recursos e infraestrutura disponibilizados para a realização do mestrado.

Aos professores e funcionários do Departamento de Engenharia de Transportes por toda a ajuda e ensinamentos, em especial ao prof. Irineu da Silva e ao técnico em mensuração Paulo Sérgio Batista.

A todos os meus amigos, tanto de Bariri quanto de São Carlos, que de alguma maneira contribuíram para a realização deste trabalho.

À Coordenação de Aperfeiçoamento de Pessoal de Nível Superior (CAPES) pela concessão da bolsa de estudo. 



\section{RESUMO}

MONARI, M. Método para definição de rede de rotas cicláveis em áreas urbanas de cidades de pequeno porte: um estudo de caso para a cidade de Bariri-SP. 2018. 206 p. Dissertação (Mestrado em Engenharia de Transportes). Escola de Engenharia de São Carlos, Universidade de São Paulo. São Carlos, 2018.

A Lei $\mathrm{n}^{\circ}$ 12.587, de 3 de janeiro de 2012, obriga a todos os municípios brasileiros com população superior a 20 mil habitantes a elaborarem um plano de mobilidade urbana integrado e compatível com seus respectivos planos diretores ou neles inseridos, priorizando os modos de transporte não motorizados. Apesar da exigência legal, muitos municípios brasileiros, principalmente os de pequeno porte, não dispõem de diretrizes para o desenvolvimento de sistemas cicloviários. O objetivo deste trabalho é elaborar um método para definição de rede de rotas cicláveis em áreas urbanas de cidades de pequeno porte, cuja ideia central é avaliar segmentos viários com relação a fatores que influenciam no uso da bicicleta como modo de transporte urbano, tais como declividade, disponibilidade de espaço e influência exercida pelos veículos motorizados. O método proposto é subdividido em cinco etapas: (1) caracterização da área de estudo; (2) análise dos polos geradores de tráfego por bicicletas; (3) avaliação da compatibilidade das vias com o transporte cicloviário; (4) identificação das rotas cicláveis; e (5) definição da rede. Os modelos escolhidos para a verificação do perfil topográfico e para a avaliação da qualidade de serviço das vias de tráfego para o transporte cicloviário são, respectivamente, o modelo da AASHTO (1999) e o modelo de Sorton e Walsh (1994). Foi realizado um estudo de caso na cidade de Bariri-SP. Os resultados mostram que as rotas cicláveis identificadas priorizam segmentos com infraestrutura cicloviária pré-existente, assim como locais que necessitam de facilidades para ciclistas, como ciclofaixas e ciclovias, e dispõem de espaço para sua inserção. Quanto aos espaços compartilhados, nota-se uma tendência de que as rotas cicláveis sejam compostas por segmentos com boas avaliações globais de nível de estresse. A rede de rotas cicláveis definida para a cidade de Bariri-SP é formada por 19 eixos viários distribuídos de maneira a atender toda a área delimitada para estudo.

Palavras-chave: Bicicleta. Transporte cicloviário. Mobilidade urbana. Rotas cicláveis. Cidade de pequeno porte. Ciclovia. Ciclofaixa. Nível de estresse. Infraestrutura cicloviária. Declividade. 



\begin{abstract}
MARCELO, M. Method for the definition of cycling routes network in urban areas of small-sized cities: a case study for the city of Bariri-SP. 2018. 206 p. Dissertation (M. Sc. in Transportation Engineering). São Carlos School of Engineering, University of São Paulo. São Carlos, 2018.
\end{abstract}

The law 12.587 of January 3rd, 2012, enforces every Brazilian city over 20,000 inhabitants to elaborate an urban mobility plan integrated and compatible with their respective master plans, giving priority to non-motorized transportation modes. Despite legal enforcement, many Brazilian cities, mainly the small ones, are not given proper guidelines to develop cycling systems. This research's goal is to elaborate a method to define a cycling routes network in urban areas of small-sized cities, whose main point is to assess road segments according to factors that influence the bicycle use as an urban transportation mode, such as slope, space availability to stand cycling transportation as well as motorized vehicles influence on bicycle traffic. The proposed method splits into five steps: (1) study area characterization; (2) analysis of bicycle traffic generator poles; (3) evaluation of the streets compatibility with bicycle transportation; (4) cycling routes identification; (5) network definition. The chosen models for topographic verification and service quality ratings of the roads for cycling transportation are, respectively, the AASHTO's (1999) model and the Sorton and Walsh's (1994) model. A case study was carried out in the city of Bariri-SP. The results of the proposed method's application show that the identified cycling routes prioritize road segments with cycling infrastructure already existent, as well as places in need of cycling facilities, such as cycle lanes and cycle paths, that have available space to accommodate them. Concerning shared spaces, there's a trend that cycling routes are composed of segments with good global stress level evaluations. The cycling routes network defined in the city of Bariri-SP is made up by 19 road axes widespread to serve the whole area delimited for study.

Keywords: Bicycle. Cycling. Urban mobility. Cycling routes. Small-sized city. Bike path. Bike lane. Level of stress. Cycling infrastructure. Slope. 



\section{LISTA DE TABELAS}

Tabela 3.1: Limites de extensão de trechos em aclive (AASHTO, 1999)..............................58

Tabela 3.2: Limites de extensão de trechos em aclive (AASHTO, 2012)...............................58

Tabela 3.3: Critério para verificação do perfil topográfico para ciclovias (GEIPOT, 2001a). 59

Tabela 3.4: Interpretação para avaliação global do nível de estresse. 66

Tabela 3.5: LTS para ciclofaixas contíguas à faixa de estacionamento. ....................................68

Tabela 3.6: LTS para ciclofaixas não contíguas à faixa de estacionamento. ........................... 68

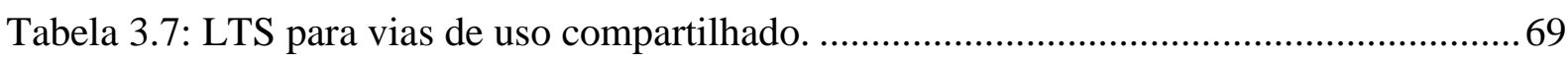

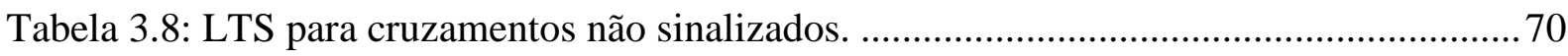

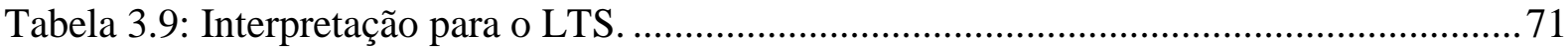

Tabela 3.10: Fatores relacionados ao pavimento - Epperson-Davis (1994)...........................73

Tabela 3.11: Fatores relacionados à localização - Epperson-Davis (1994)............................ 74

Tabela 3.12: Classificação dos segmentos viários de acordo com seu ICV - Epperson-Davis (1994).

Tabela 3.13: Sistema de pontuação para avaliação do nível de serviço - Dixon (1996)......... 76

Tabela 3.14: Interpretação para as faixas de nível de serviço - Dixon (1996).........................78

Tabela 3.15: Nível de serviço para bicicletas de Landis et al. (1997) ...................................... 80

Tabela 3.16: Fator de ajustamento para veículos pesados - BCI............................................ 81

Tabela 3.17: Fator de ajustamento para estacionamentos - BCI. ........................................... 82

Tabela 3.18: Fator de ajustamento para conversões à direita - BCI. ....................................... 82

Tabela 3.19: Compatibilidade das vias com o transporte cicloviário - BCI. ........................... 82

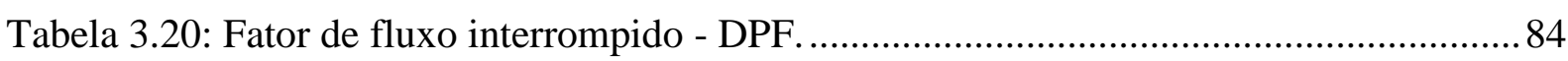

Tabela 3.21: Nível de serviço para vias de uso compartilhado - FHWA (2006b)...................85

Tabela 3.22: Interpretação para as faixas de nível de serviço - FHWA (2006)...................... 85

Tabela 4.1: Máximos comprimentos em aclive para a verificação do perfil topográfico das vias

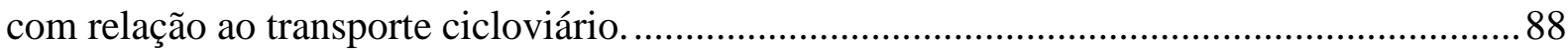

Tabela 4.2: Fator relacionado à infraestrutura cicloviária....................................................95

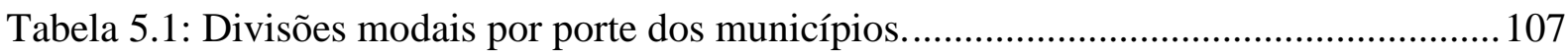

Tabela 5.2: Fator de equivalência em veículos de passeio - HBS........................................ 114

Tabela 5.3: Estimativas das velocidades médias dos veículos (ID: 1-10)............................ 117

Tabela 5.4: Estimativas das velocidades médias dos veículos (ID: 11-20)......................... 117

Tabela A1: Receptores GNSS utilizados no levantamento. ............................................... 161

Tabela B1: Av. XV de Novembro (I) x Rua Santa Cruz (II). ............................................. 165 
Tabela B2: Av. XV de Novembro (I) x Rua Prudente de Moraes (II).................................. 166

Tabela B3: Av. XV de Novembro (I) x Rua Rui Barbosa (II).......................................... 167

Tabela B4: Av. José Jorge Resegue (I) x Rua Rui Barbosa (II) - (a).................................. 168

Tabela B5: Av. José Jorge Resegue (I) x Rua Rui Barbosa (II) - (b).................................. 169

Tabela B6: Av. José Jorge Resegue (I) x Rua Rui Barbosa (II) - (c) ................................. 170

Tabela B7: Av. José Jorge Resegue (I) x Rua Prudente de Moraes (II). .............................. 171

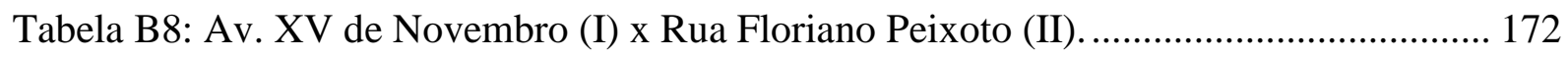

Tabela B9: Av. José Jorge Resegue (I) x Rua Floriano Peixoto (II). ................................... 173

Tabela B10: Rua 7 de Setembro (I) x Rua Antônio C. Baricelo (II). ................................... 174

Tabela B11: Rua 7 de Setembro (I) x Rua Vitório E. Prearo (II). ....................................... 175

Tabela B12: Rua 7 de Setembro (I) x Av. João Lemos (II). ................................................ 176

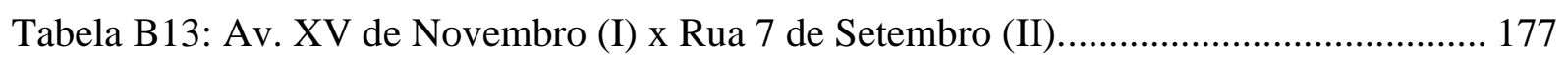

Tabela B14: Av. Claudionor Barbieri (I) x Rua 7 de Setembro (II). ................................... 178

Tabela B15: Av. Claudionor Barbieri (I) x Av. Sérgio Furcin (II)..................................... 179

Tabela B16: Av. Claudionor Barbieri (I) x Av. Francisco Munhoz Cegarra (II). .................. 180

Tabela B17: Av. Claudionor Barbieri (I) x Rua Rui Barbosa (II). ..................................... 181

Tabela B18: Av. Claudionor Barbieri (I) x Rua Santa Cruz (II) ........................................ 182

Tabela B19: Av. Dr. Antônio Galízia (I) x Rua Prudente de Moraes (II). ............................ 183

Tabela B20: Av. Francisco Munhoz Cegarra (I) x Av. Centenário (II) - (a). ....................... 184

Tabela B21: Av. Francisco Munhoz Cegarra (I) x Av. Centenário (II) - (b)........................ 185

Tabela B22: Av. Sérgio Furcin (I) x Av. Padre João Eid (II) - (a)...................................... 186

Tabela B23: Av. Sérgio Furcin (I) x Av. Padre João Eid (II) - (b) . .................................... 187

Tabela B24: Av. Sérgio Furcin (I) x Av. Padre João Eid (II) - (c)...................................... 188

Tabela B25: Av. Sérgio Furcin (I) x Av. Padre João Eid (II) - (d) . .................................... 189

Tabela B26: Av. Padre João Eid (I) x Rua Luís Furlaneto (II) ........................................... 190

Tabela B27: Rua Luís Furlaneto (I) x Estrada Municipal Fernando Romero (II) - (a)........ 191

Tabela B28: Rua Luís Furlaneto (I) x Estrada Municipal Fernando Romero (II) - (b)......... 192

Tabela B29: Av. XV de Novembro (I) x Av. Sérgio Furcin (II) - (a)................................... 193

Tabela B30: Av. XV de Novembro (I) x Av. Sérgio Furcin (II) - (b) ................................... 194

Tabela B31: Av. XV de Novembro (I) x Av. Sérgio Furcin (II) - (c) .................................. 195

Tabela B32: Av. João Lemos (I) x Rua Euclides G. Corrêa (II) - (a) ................................... 196

Tabela B33: Av. João Lemos (I) x Rua Euclides G. Corrêa (II) - (b) ................................... 197

Tabela B34: Av. João Lemos (I) x Rua Euclides G. Corrêa (II) - (c) . .................................. 198

Tabela B35: Av. João Lemos (I) x Rua Euclides G. Corrêa (II) - (d) .................................. 199 
Tabela B36: Rua Vitório E. Prearo (I) x Rua Euclides G. Corrêa (II) - (a).......................... 200

Tabela B37: Rua Vitório E. Prearo (I) x Rua Euclides G. Corrêa (II) - (b) ...........................201

Tabela B38: Estrada Perimetral Pref. Domingos Antônio Fortunato (I)............................... 202

Tabela B39: Estrada Perimetral Pref. Domingos Antônio Fortunato (I) ............................... 203

Tabela C1: Tempos cronometrados para amostras aleatórias de veículos (1).......................205

Tabela C2: Tempos cronometrados para amostras aleatórias de veículos (2)....................... 206 



\section{LISTA DE FIGURAS}

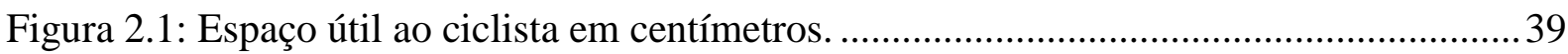

Figura 2.2: Espaço compartilhado entre ciclistas e pedestres. ................................................ 40

Figura 2.3: Espaço compartilhado entre bicicletas e automóveis............................................ 41

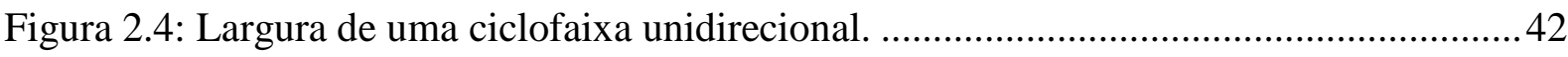

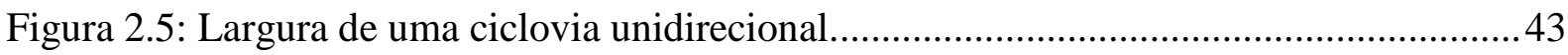

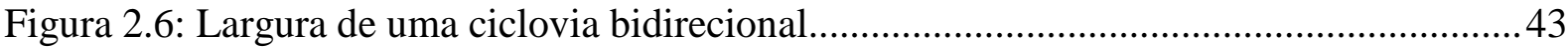

Figura 2.7: Diagrama de infraestrutura cicloviária para vias urbanas................................... 44

Figura 3.1: Critério para verificação do perfil topográfico das vias (FHWA, 1977)..............57

Figura 3.2: Critério para verificação do perfil topográfico das vias (AUSTROADS, 2014)...60

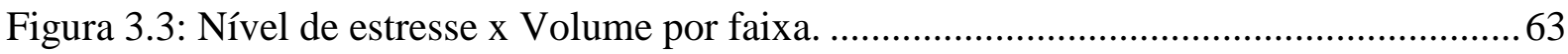

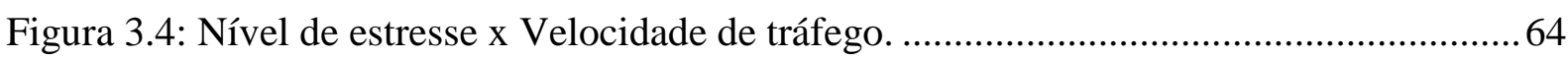

Figura 3.5: Nível de estresse x Largura da faixa externa. ..................................................... 65

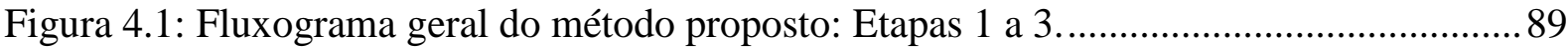

Figura 4.2: Fluxograma geral do método proposto: Etapas 4 e 5 .......................................... 90

Figura 4.3: Verificação do perfil topográfico (AASHTO, 1999)........................................... 94

Figura 4.4: Verificação da necessidade de facilidades para ciclistas (LTSA, 2004)...............96

Figura 5.1: Localização do município de Bariri-SP (SIRGAS2000). .................................... 100

Figura 5.2: Bariri-SP: Zonas de tráfego e sistema viário. .................................................... 101

Figura 5.3: Bariri-SP: Pontos de parada dos ônibus urbanos e infraestrutura cicloviária

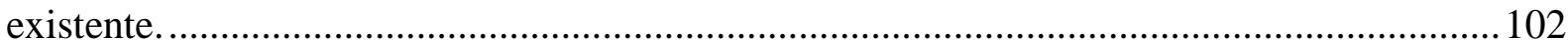

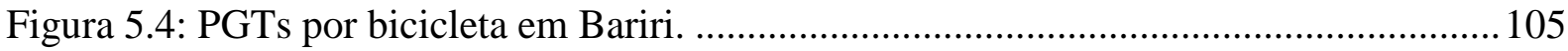

Figura 5.5: Pontos levantados com o auxílio da tecnologia GNSS..................................... 110

Figura 5.6: Relação entre alturas geométrica, altitude ortométrica e ondulação geoidal.......112

Figura 5.7: Interseções selecionadas para contagens volumétricas..................................... 113

Figura 5.8: Trechos selecionados para estimativas das velocidades. ................................... 116

Figura 6.1: Linhas de desejo até os PGTs por bicicleta...................................................... 122

Figura 6.2: Elevações dentro dos limites urbanos de Bariri-SP. .......................................... 123

Figura 6.3: Classes de declividade para verificação do perfil topográfico das vias............... 124

Figura 6.4: Avaliações individuais das variáveis do nível de estresse. ................................ 126

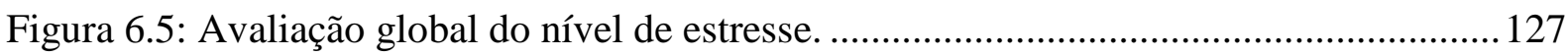

Figura 6.6: Facilidades necessárias à circulação de ciclistas................................................. 129

Figura 6.7: Rotas cicláveis - Umuarama Clube .............................................................. 130 


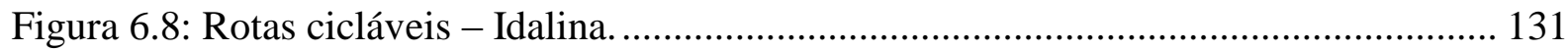

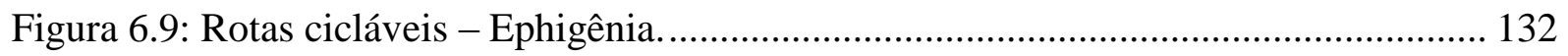

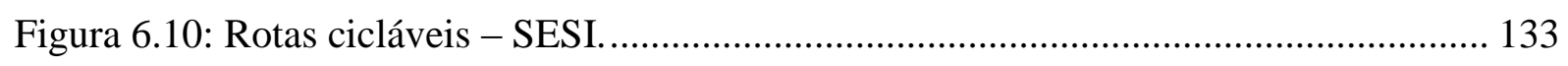

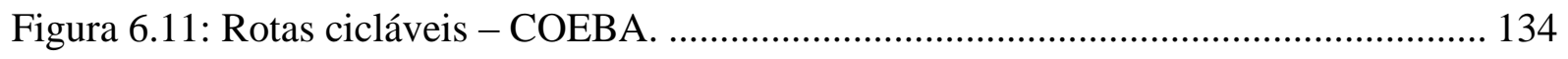

Figura 6.12: Rotas cicláveis - Plásticos Bariri. .............................................................. 135

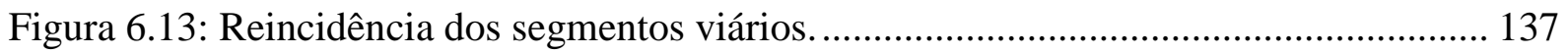

Figura 6.14: Eixos viários potencialmente cicláveis em Bariri-SP..................................... 138

Figura 6.15: Cobertura dos eixos viários potencialmente cicláveis (1) .............................. 139

Figura 6.16: Cobertura dos eixos viários potencialmente cicláveis (2) . .............................. 140

Figura 6.17: Cobertura dos eixos viários potencialmente cicláveis (3).............................. 141

Figura 6.18: Cobertura dos eixos viários potencialmente cicláveis (4) . .............................. 142

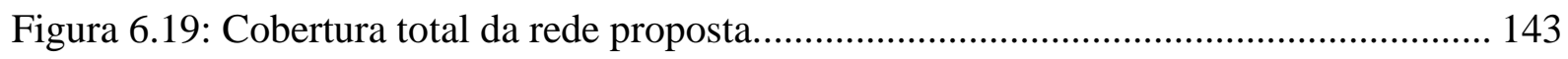

Figura A1: Equipamentos utilizados para o nivelamento com auxílio da tecnologia GNSS. 161

Figura B1: Av. XV de Novembro (I) x Rua Santa Cruz (II). ............................................. 165

Figura B2: Av. XV de Novembro (I) x Rua Prudente de Moraes (II) . ................................. 166

Figura B3: Av. XV de Novembro (I) x Rua Rui Barbosa (II). ......................................... 167

Figura B4: Av. José Jorge Resegue (I) x Rua Rui Barbosa (II) - (a) . ................................. 168

Figura B5: Av. José Jorge Resegue (I) x Rua Rui Barbosa (II) - (b) .................................. 169

Figura B6: Av. José Jorge Resegue (I) x Rua Rui Barbosa (II) - (c) . ................................. 170

Figura B7: Av. José Jorge Resegue (I) x Rua Prudente de Moraes (II)................................ 171

Figura B8: Av. XV de Novembro (I) x Rua Floriano Peixoto (II). ...................................... 172

Figura B9: Av. José Jorge Resegue (I) x Rua Floriano Peixoto (II) ..................................... 173

Figura B10: Rua 7 de Setembro (I) x Rua Antônio C. Baricelo (II)..................................... 174

Figura B11: Rua 7 de Setembro (I) x Rua Vitório E. Prearo (II)......................................... 175

Figura B12: Rua 7 de Setembro (I) x Av. João Lemos (II). .............................................. 176

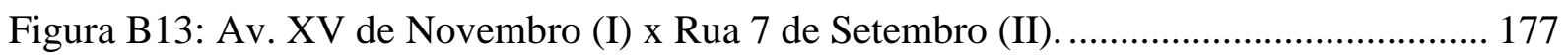

Figura B14: Av. Claudionor Barbieri (I) x Rua 7 de Setembro (II) ........................................ 178

Figura B15: Av. Claudionor Barbieri (I) x Av. Sérgio Furcin (II). ...................................... 179

Figura B16: Av. Claudionor Barbieri (I) x Av. Francisco Munhoz Cegarra (II)................... 180

Figura B17: Av. Claudionor Barbieri (I) x Rua Rui Barbosa (II) ...................................... 181

Figura B18: Av. Claudionor Barbieri (I) x Rua Santa Cruz (II) ........................................ 182

Figura B19: Av. Dr. Antônio Galízia (I) x Rua Prudente de Moraes (II).............................. 183

Figura B20: Av. Francisco Munhoz Cegarra (I) x Av. Centenário (II) - (a)......................... 184

Figura B21: Av. Francisco Munhoz Cegarra (I) x Av. Centenário (II) - (b)......................... 185 
Figura B22: Av. Sérgio Furcin (I) x Av. Padre João Eid (II) - (a). ..................................... 186

Figura B23: Av. Sérgio Furcin (I) x Av. Padre João Eid (II) - (b). .................................... 187

Figura B24: Av. Sérgio Furcin (I) x Av. Padre João Eid (II) - (c). ..................................... 188

Figura B25: Av. Sérgio Furcin (I) x Av. Padre João Eid (II) - (d). .................................... 189

Figura B26: Av. Padre João Eid (I) x Rua Luís Furlaneto (II) ............................................ 190

Figura B27: Rua Luís Furlaneto (I) x Estrada Municipal Fernando Romero (II) - (a).......... 191

Figura B28: Rua Luís Furlaneto (I) x Estrada Municipal Fernando Romero (II) - (b).......... 192

Figura B29: Av. XV de Novembro (I) x Av. Sérgio Furcin (II) - (a) .................................... 193

Figura B30: Av. XV de Novembro (I) x Av. Sérgio Furcin (II) - (b)................................. 194

Figura B31: Av. XV de Novembro (I) x Av. Sérgio Furcin (II) - (c) .................................. 195

Figura B32: Av. João Lemos (I) x Rua Euclides G. Corrêa (II) - (a).................................. 196

Figura B33: Av. João Lemos (I) x Rua Euclides G. Corrêa (II) - (b) ................................... 197

Figura B34: Av. João Lemos (I) x Rua Euclides G. Corrêa (II) - (c).................................. 198

Figura B35: Av. João Lemos (I) x Rua Euclides G. Corrêa (II) - (d) .................................... 199

Figura B36: Rua Vitório E. Prearo (I) x Rua Euclides G. Corrêa (II) - (a). ......................... 200

Figura B37: Rua Vitório E. Prearo (I) x Rua Euclides G. Corrêa (II) - (b). ......................... 201

Figura B38: Estrada Perimetral Pref. Domingos Antônio Fortunato (I).............................. 202

Figura B39: Estrada Perimetral Pref. Domingos Antônio Fortunato (I). ................................ 203 



\section{LISTA DE ABREVIATURAS}

AASHTO: American Association of State Highway Transportation Officials Acob: Área de cobertura

Atot: Área total

ANTP: Associação Nacional de Transportes Públicos

ASTER: Advanced Spaceborne Thermal Emission and Reflection Radiometer

BCI: Bicycle Compatibility Index

BLOS: Bicycle Level of Service

BNAT: Bicycle Network Analysis Tool

BNDES: Banco Nacional de Desenvolvimento Econômico e Social

BSL: Bicycle Stress Level

CET: Companhia de Engenharia de Tráfego

CM: Caminho Mínimo

COEBA: Cooperativa Educacional de Bariri

CTB: Código de Trânsito Brasileiro

DNIT: Departamento Nacional de Infraestrutura de Transportes

EESC: Escola de Engenharia de São Carlos

EGM96: Earth Gravitational Model (1996)

EUA: Estados Unidos da América

FGSV: Forschungsgesellschaft für Straßen und Verkehrswesen

FHWA: Federal Highway Administration

GEIPOT: Grupo Executivo de Integração da Política de Transportes

GNSS: Global Navigation Satellite System

HCM: Highway Capacity Manual

HPMS: Highway Performance Monitoring System

IBGE: Instituto Brasileiro de Geografia e Estatística

ICV: Índice de Compatibilidade da Via

INPE: Instituto de Pesquisas Espaciais

Lcc: Largura do canteiro central

Lfe: Largura da faixa externa

LTS: Level of Traffic Stress

LTSA: Land Transport Safety Authority

MDE: Modelo Digital de Elevação 
NASA: National Aeronautics and Space Administration

NBR: Norma Brasileira

NE: Nível de Estresse

NGA: National Geospatial-Intelligence

NSB: Nível de Serviço para Bicicletas

OSM: Open Street Map

PGT: Polo Gerador de Tráfego

QGIS: QauntumGIS

RBMC: Rede Brasileira de Monitoramento Contínuo

RINEX: Receiver Independent Exchange

RTK: Real Time Kinematic

SESI: Serviço Social da Indústria

SIG: Sistema de Informação Geográfica

SIRGAS2000: Sistema de Referência Geocêntrico para as Américas (2000)

SRTM: Shuttle Radar Topographic Mission

SUPLOS: Shared-Use Path Level of Service

TRB: Transportation Research Board

UTM: Universal Transversa de Mercator

UUM: Unidade Urbanística Mínima

VDM: Volume Diário Médio

VHP: Volume no Horário de Pico

WGS84: World Geodetic System (1984) 


\section{SUMÁRIO}

1 INTRODUÇÃO ...........................................................................................................29

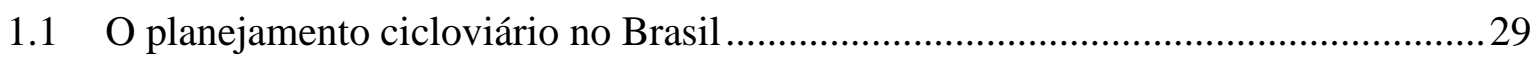

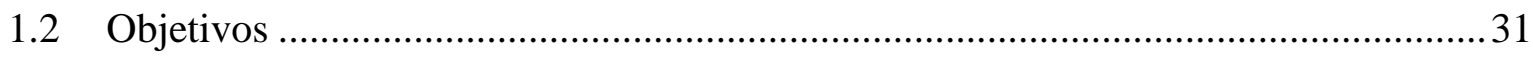

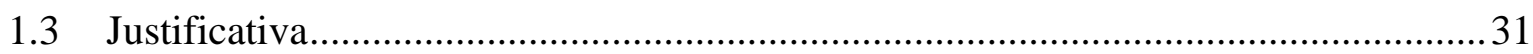

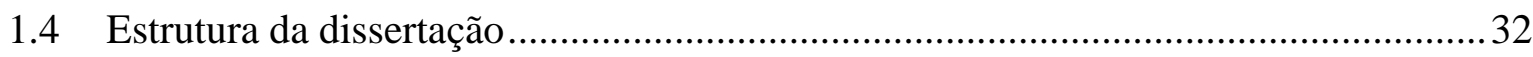

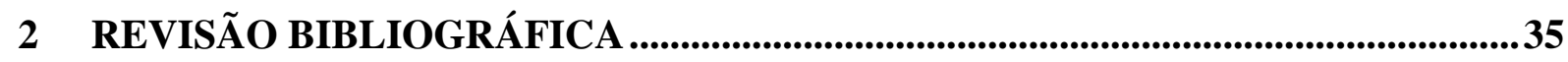

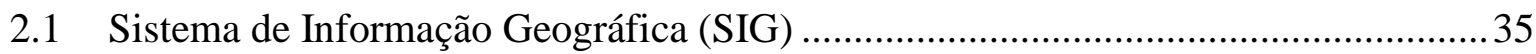

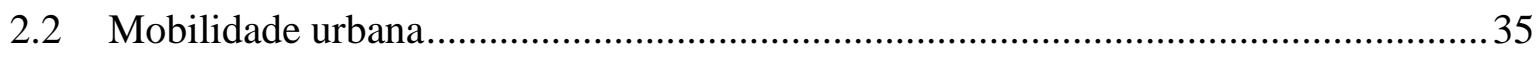

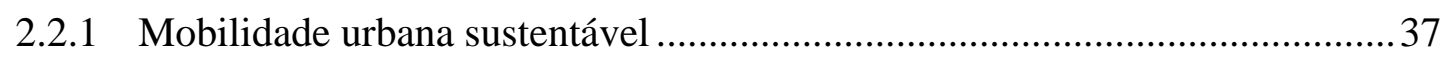

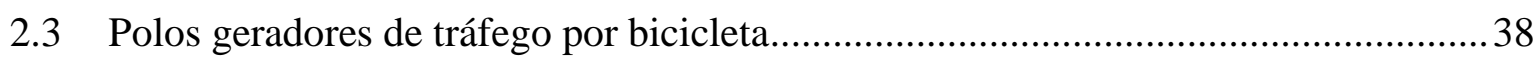

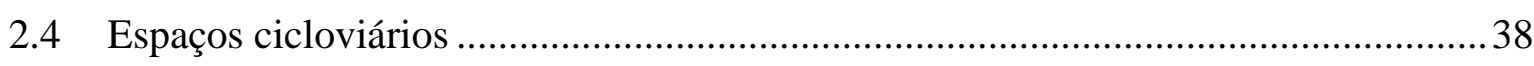

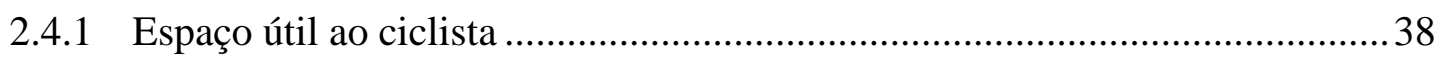

2.4.2 Alternativas viárias para o tráfego de bicicletas ........................................... 39

2.4.3 Critérios para inserção de facilidades para ciclistas ..................................... 43

2.4.4 Relação de equivalência entre as alternativas viárias para ciclistas ............... 44

2.4.5 Disponibilidade de espaço para inserção de facilidades para ciclistas ...........46

2.5 Fatores que influenciam no uso da bicicleta como modo de transporte urbano.........47

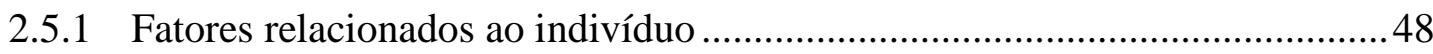

2.5.2 Fatores relacionados ao percurso.......................................................... 49

2.5.3 Fatores relacionados ao destino da viagem .............................................50

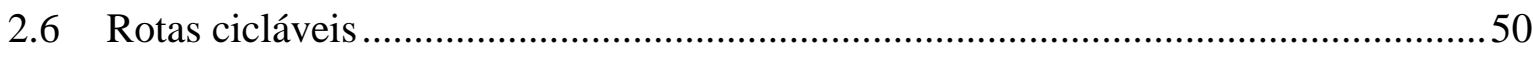

3 MODELOS DE AVALIAÇÃO DA COMPATIBILIDADE DAS VIAS COM O TRANSPORTE CICLOVIÁRIO .......................................................................................55

3.1 Verificação do perfil topográfico das vias para o transporte cicloviário ...................56

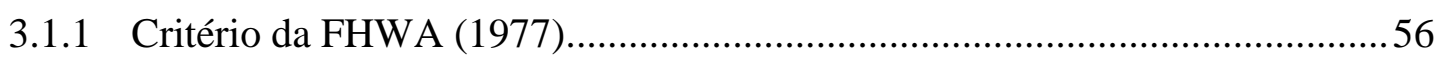

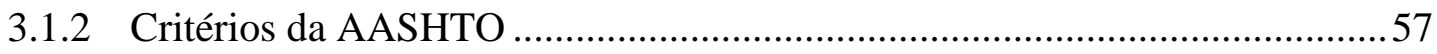




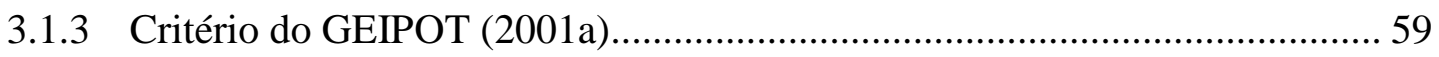

3.1.4 Critério do Austroads (2014) ................................................................... 59

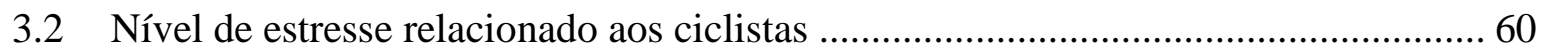

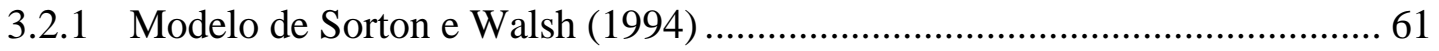

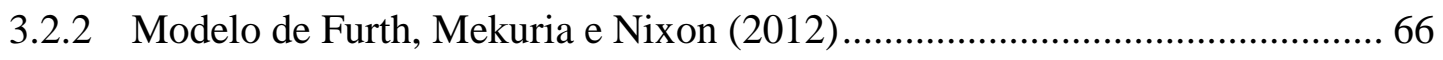

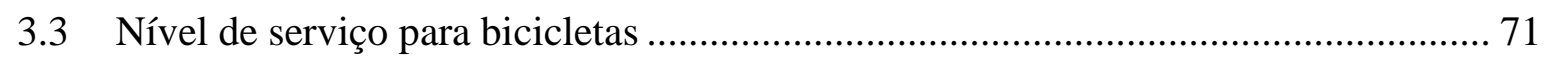

3.3.1 Índice de Condição da Via (ICV) de Epperson-Davis (1994) ....................... 73

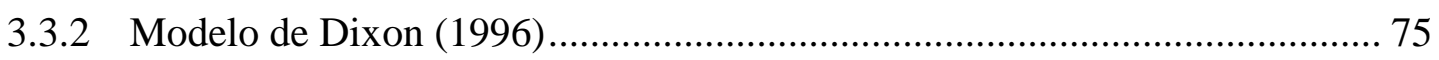

3.3.3 Nível de Serviço para Bicicletas (NSB) de Landis et al. (1997).................... 79

3.3.4 Bicycle Compatibility Index (BCI) de Harkey et al. (1998) ......................... 80

3.3.5 Shared-Use Path Level of Service (SUPLOS) da FHWA (2006b)................ 83

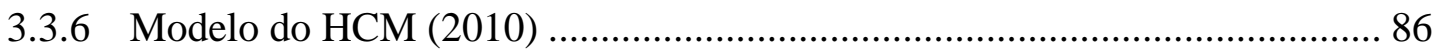

\section{MÉTOdO PARA DEFINIÇÃO DE REDE DE ROTAS CICLÁVEIS EM ÁREAS URBANAS DE CIDADES DE PEQUENO PORTE...................................................... 87}

4.1 Etapa 1: Caracterização da área de estudo............................................................. 91

4.2 Etapa 2: Análise dos polos geradores de tráfego por bicicleta ............................... 92

4.3 Etapa 3: Avaliação da compatibilidade das vias com o transporte cicloviário.......... 93

4.3.1 Verificação do perfil topográfico (AASHTO, 1999) ................................... 93

4.3.2 Avaliação da qualidade de serviço das vias (SORTON; WALSH, 1994) ..... 94

4.3.3 Verificação da necessidade de facilidades para ciclistas (LTSA, 2004)........ 95

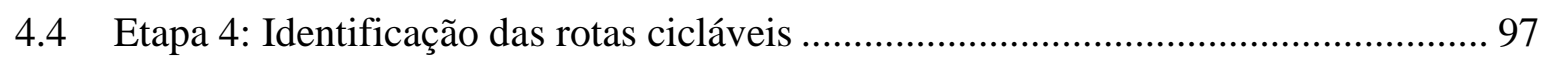

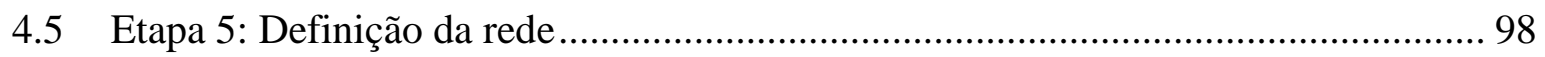

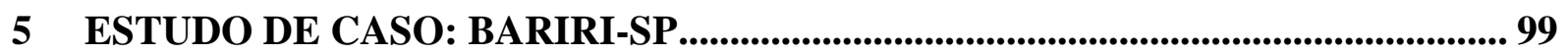

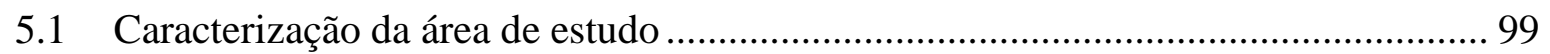

5.2 Análise dos polos geradores de tráfego por bicicleta ............................................ 103

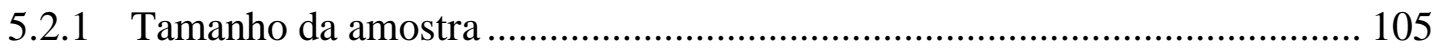

5.3 Avaliação da compatibilidade das vias com o transporte cicloviário ...................... 108 
5.3.1 Nivelamento com auxílio da tecnologia GNSS ....................................... 108

5.3.2 Volumes e velocidades dos veículos motorizados ....................................112

5.3.3 Larguras das faixas externas das vias de tráfego ........................................ 117

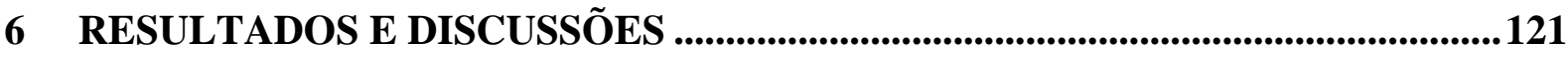

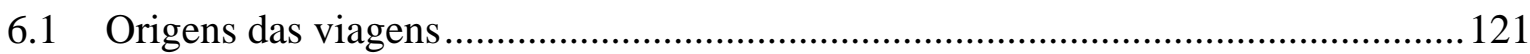

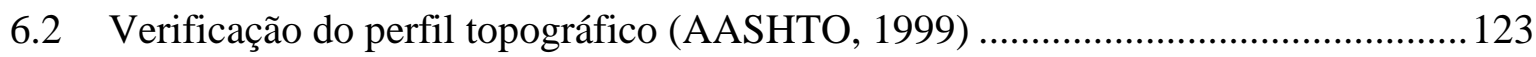

6.3 Avaliação da qualidade de serviço das vias (SORTON; WALSH, 1994) ................ 125

6.3.1 Avaliações individuais do nível de estresse ........................................... 125

6.3.2 Avaliação global do nível de estresse................................................... 127

6.4 Verificação da necessidade de facilidades para ciclistas...................................... 128

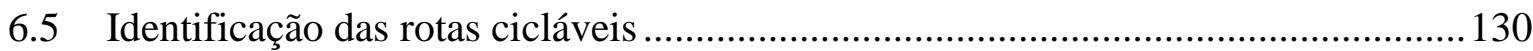

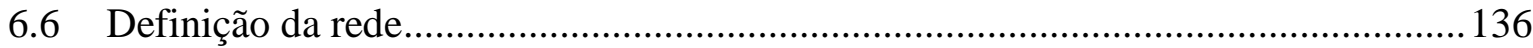

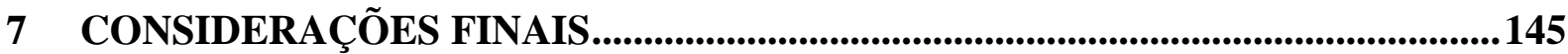

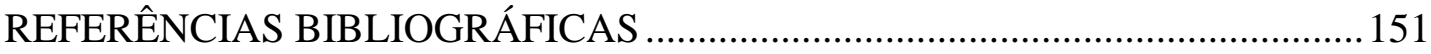

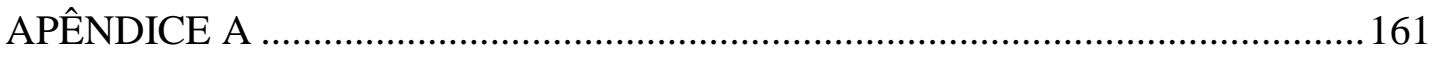

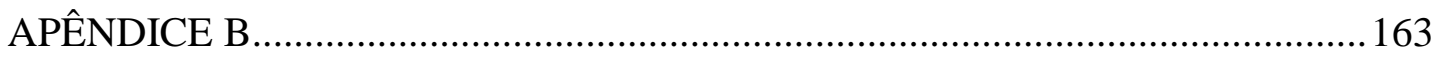

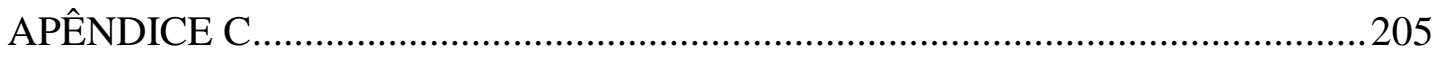





\section{INTRODUÇÃO}

O transporte cicloviário, nas últimas décadas, tem sido tema de grande discussão entre autoridades da área de transportes. Os benefícios sociais trazidos pela utilização da bicicleta fazem com que este modo de transporte se apresente como uma solução interessante para a diminuição dos problemas ocasionados pelo uso intensivo do automóvel como, por exemplo, congestionamentos e poluição atmosférica.

As vantagens proporcionadas pelo uso da bicicleta encontradas na literatura são muitas: baixos custos de aquisição e manutenção, menores perturbação ambiental e necessidade de espaço público se comparadas com os modos de transporte motorizados, além de benefícios à saúde do usuário. Entretanto, apesar de todos estes pontos positivos, muitas questões ainda são levantadas a respeito de como aumentar a utilização da bicicleta como modo de transporte urbano (PUCHER; DILL; HANDY, 2009).

O transporte cicloviário é muito popular em países socialmente desenvolvidos, como Holanda, Alemanha, Dinamarca etc., e está aos poucos evoluindo também em países emergentes, como China, Índia, Colômbia e, não diferentemente, o Brasil. No entanto, a sociedade brasileira, de maneira geral, ainda julga o uso da bicicleta como uma característica da população de baixa renda (NERI, 2012; TUCKER; MANAUGH, 2016).

Apesar dos aspectos culturais e das características geográficas (relevo, clima etc.) de um determinado país serem importantes para a popularização do transporte cicloviário no mesmo, políticas governamentais também exercem grande influência nesta questão. Na Holanda, por exemplo, além de inúmeras medidas pró-utilização da bicicleta, foram implementadas também medidas que restringem a utilização do automóvel. Esta combinação é justamente o que faz com que o uso da bicicleta neste país seja tão intenso (PUCHER; BUEHLER, 2008).

\subsection{O planejamento cicloviário no Brasil}

No Brasil, as primeiras ações voltadas ao planejamento cicloviário ocorreram em meados da década de 70, como consequência de problemas originados pelo aumento nos preços 
dos combustíveis, fato conhecido como $1^{\circ}$ Choque do Petróleo (MINISTÉRIO DAS CIDADES, 2007).

Em março de 1976, o Grupo Executivo de Integração da Política de Transportes (GEIPOT) publicou o manual "Planejamento Cicloviário - Uma Política para as Bicicletas". Este documento foi durante muito tempo a principal referência na literatura técnica voltada ao transporte cicloviário no país, apresentando diretrizes às diversas etapas de planejamento e operação de sistemas cicloviários (GEIPOT, 2001a).

Em julho de 2001, foi publicado, também pelo GEIPOT, o primeiro documento contendo resultados de uma extensa coleta de dados referente à utilização da bicicleta em território nacional, intitulado "Planejamento Cicloviário: Diagnóstico Nacional". A pesquisa foi realizada em aproximadamente 60 municípios brasileiros, enfatizando informações sobre infraestrutura e demais elementos inclusos na elaboração de sistemas cicloviários (GEIPOT, 2001b).

A partir dos resultados deste relatório, pôde ser desenvolvido, em dezembro de 2001, o "Manual do Planejamento Cicloviário", que consiste em uma atualização do documento elaborado em 1976. O manual apresenta diretrizes para uma política nacional voltada ao incentivo ao uso da bicicleta, enfatizando abordagens práticas sobre o planejamento cicloviário no Brasil (GEIPOT, 2001a; KIRNER, 2006).

Em setembro de 2005 foi criado o "Programa Brasileiro de Mobilidade por Bicicleta Bicicleta Brasil”, cuja função é incluir a bicicleta como elemento fundamental na promoção da mobilidade urbana nos municípios brasileiros. Desta forma, em 2007, foi desenvolvido o “Caderno de referência para elaboração de Plano de Mobilidade por Bicicleta nas Cidades", fornecendo diretrizes aos municípios que têm a intenção de elaborar planos cicloviários integrados aos demais modos de transporte existentes (MINISTÉRIO DAS CIDADES, 2007).

Em 2007, a Associação Nacional de Transportes Públicos (ANTP) publicou o manual intitulado "Transporte Cicloviário". Trata-se do sétimo volume de uma série de cadernos técnicos desenvolvidos com apoio do Banco Nacional de Desenvolvimento Econômico e Social (BNDES). Neste documento são fornecidos subsídios técnicos para a construção e ampliação de espaços cicloviários urbanos, isto é, diretrizes para projetos e orientações para a gestão do transporte cicloviário (BICALHO, 2007; PRESADA, 2007). 
Apesar de todos os esforços apresentados, nota-se uma carência de projetos voltados aos ciclistas em território nacional. Desta forma, é de extrema importância que sejam elaboradas cada vez mais políticas de incentivo ao uso da bicicleta, assim como diretrizes voltadas ao transporte cicloviário passíveis de serem aplicadas às cidades brasileiras.

\subsection{Objetivos}

O objetivo deste trabalho é desenvolver, propor e aplicar um método para definição de rede de rotas cicláveis em áreas urbanas de cidades de pequeno porte. Este processo deve ser realizado por meio da análise simultânea dos seguintes fatores que influenciam no uso da bicicleta como modo de transporte urbano: relevo da área de estudo, qualidade de serviço das vias para acomodar o transporte cicloviário, existência ou possibilidade de inserção de facilidades para ciclistas e distância da viagem. O estudo de caso é realizado para a cidade de Bariri-SP.

\subsection{Justificativa}

Nas últimas décadas, as transformações climáticas e o risco de esgotamento dos recursos naturais têm trazido à tona a importância de projetos voltados aos modos de transporte não motorizados. Apesar disso, o transporte cicloviário necessita de alguns estímulos para ser inserido em ambientes urbanos. Assim, quando sistemas cicloviários são dispostos nos locais adequados, torna-se maior a chance de as pessoas utilizarem a bicicleta em seus deslocamentos diários (KAMARGIANNI, 2015).

De acordo com o Instituto Brasileiro de Geografia e Estatística (IBGE, 2016), entendese por município de pequeno porte como qualquer município cuja população urbana é inferior a 100 mil habitantes. Nestes municípios, de maneira geral, as configurações urbanas compactas e as pequenas distâncias de viagem fazem com que se torne inviável a implantação de um sistema de transporte coletivo que funcione de maneira eficiente. Além disso, o poder de compra de uma grande parcela da população destes municípios não permite que a mesma tenha acesso aos modos de transporte motorizados, como automóveis e motocicletas. Assim, as 
autoridades em transportes têm constantemente enfatizado a necessidade de priorização dos modos de transporte não motorizados nestes municípios.

A Lei $n^{\circ} 12.587$, de 3 de janeiro de 2012, exige que todos os municípios com população superior a 20 mil habitantes elaborem planos de mobilidade urbana compatíveis com seus respectivos planos diretores. Além disso, nos municípios sem transporte público coletivo, este plano de mobilidade deve enfatizar os modos de transporte não motorizados (BRASIL, 2012).

Apesar da exigência legal, nem todos os municípios brasileiros receberam a instrumentalização adequada (recursos financeiros, contratação de funcionários etc.) para se organizarem e aderirem à nova proposta. Desta forma, o prazo inicialmente estipulado aos municípios para a elaboração do plano de mobilidade urbana, que era de 3 anos, foi prorrogado para 6.

Os métodos clássicos encontrados na literatura para o planejamento de redes cicloviárias baseiam-se em pesquisas origem-destino. No entanto, a grande maioria dos municípios brasileiros, principalmente os de pequeno e médio porte, não dispõe destas informações, devido ao seu alto custo. Logo, o desenvolvimento de métodos alternativos voltados à implantação de redes cicloviárias que possam ser aplicados às pequenas cidades brasileiras se apresenta como um processo extremamente importante, servindo de suporte técnico aos projetos municipais.

O município escolhido para a realização do estudo de caso é Bariri-SP. Esta escolha é justificada pela facilidade do levantamento de informações junto à prefeitura local e aos polos geradores de tráfego por bicicleta. Além disso, a familiarização com o local de estudo permite uma melhor análise dos resultados encontrados, evitando erros que poderiam ser cometidos pelo desconhecimento das características do sistema viário local.

\subsection{Estrutura da dissertação}

O conteúdo abordado em cada um dos capítulos desta dissertação é apresentado a seguir.

No capítulo 1 é realizada uma breve introdução a respeito do planejamento cicloviário no Brasil. Além disso, são apresentados os objetivos, a justificativa e a estrutura da dissertação.

No capítulo 2 é apresentada a fundamentação teórica, isto é, toda a revisão da literatura necessária para o desenvolvimento deste trabalho. Dentre os tópicos discutidos, destacam-se os 
conceitos de mobilidade urbana sustentável e polo gerador de tráfego por bicicletas, os espaços cicloviários, os fatores que influenciam no uso da bicicleta como modo de transporte urbano e os métodos já existentes para a identificação de rotas cicláveis em áreas urbanas.

No capítulo 3, também de caráter teórico, são apresentadas algumas ferramentas para analisar a compatibilidade das vias com o transporte cicloviário, isto é, modelos para a verificação do perfil topográfico e para a avaliação do nível de serviço e/ou nível de estresse relacionados aos ciclistas.

No capítulo 4 é detalhado o método proposto por este trabalho para definição de rede de rotas cicláveis em áreas urbanas de cidades de pequeno porte.

No capítulo 5 é apresentado o estudo de caso para a cidade de Bariri-SP, isto é, toda a metodologia utilizada para o levantamento de informações necessárias à aplicação do método proposto por este trabalho.

No capítulo 6 são apresentados os resultados da aplicação do método proposto por este trabalho à cidade de Bariri-SP.

No capítulo 8 apresentam-se as considerações finais, além de serem discutidas as limitações deste trabalho com sugestões para trabalhos futuros. 


\section{REVISÃO BIBLIOGRÁFICA}

\subsection{Sistema de Informação Geográfica (SIG)}

De acordo com Segantine (2001), entende-se por Sistema de Informação Geográfica ou SIG como um sistema capaz de manipular informações geográficas, ou seja, informações às quais podem ser atribuídas coordenadas segundo um determinado sistema de referência. Tratase de uma tecnologia que tem apresentado, nas últimas décadas, um enorme impacto em todos os campos do conhecimento que analisam dados distribuídos espacialmente, auxiliando na investigação de fenômenos de diversas áreas como Engenharia, Geologia, Hidrografia etc.

Os principais produtos gerados pelos SIGs são mapas, planilhas, tabelas e demais documentos capazes de representar os dados espaciais manipulados. Geralmente, esta representação é de caráter visual, permitindo ao usuário a identificação de elementos de acordo com a sua localização espacial de maneira georreferenciada. Desta forma, segundo Segantine (2001), o usuário é capaz de buscar informações e associá-las às entidades gráficas e vice-versa.

A evolução constante das funções desempenhadas pelos SIGs tem os configurado como ferramentas indispensáveis para a engenharia de transportes. De acordo com Silva (1998), esta tecnologia permite, por exemplo, simular o comportamento do tráfego, auxiliando os planejadores e demais autoridades em transportes a tomarem decisões frente a projetos de maneira mais rápida e flexível. Além disso, a crescente interação entre os SIGs e as técnicas de manipulação de dados espaciais, como a tecnologia GNSS, a Fotogrametria Digital e o Sensoriamento Remoto, tem expandido consideravelmente seu uso em trabalhos na área de geomática.

\subsection{Mobilidade urbana}

De acordo com Affonso (2002), o conceito de mobilidade é interpretado como o conjunto de respostas dadas por indivíduos e agentes econômicos às suas necessidades por deslocamentos, de acordo com as características do espaço físico e a complexidade das atividades nele desenvolvidas. Desta forma, os indivíduos podem fazer uso de meios de 
transporte motorizados (coletivos ou individuais) ou não motorizados (bicicletas, carroças, a pé etc.).

Quando a interação dos fluxos de deslocamento se dá no espaço urbano, define-se o conceito de mobilidade urbana. Trata-se, portanto, de uma característica das cidades diretamente relacionada, entre outros fatores, ao desenvolvimento socioeconômico e à organização dos sistemas de transporte ao longo das mesmas.

O processo de expansão das cidades, ocasionado pelo aumento populacional, ocorre muitas vezes sem o planejamento necessário, promovendo a fragmentação do espaço urbano. Desta forma, grande parte da população economicamente menos favorecida se vê obrigada a ocupar bairros periféricos, distantes dos centros urbanos e dos seus locais de trabalho e lazer, aumentando a necessidade de implantação de infraestruturas de transporte que garantam deslocamentos de maneira segura e eficiente. No entanto, a política adotada pela maioria das cidades ao redor do mundo, e não diferentemente pelas cidades brasileiras, baseia-se em garantir a fluidez e o espaço necessário à circulação de automóveis. Além disso, é importante destacar que esta lógica não se resume apenas às cidades de grande porte, uma vez que as cidades menores tendem a reproduzir tal modelo de desenvolvimento (BOARETO, 2008; KNEIB, 2012).

Os custos de implantação de infraestruturas próprias à utilização dos automóveis têm se apresentado cada vez mais elevados, comprometendo os orçamentos públicos (LEE; SENER; JONES, 2015). Somando-se a isto, outras externalidades negativas causadas pela utilização deste modo de transporte, como iniquidade social e danos ao meio ambiente, têm estimulado as autoridades em transportes na busca por soluções alternativas para suprir a necessidade da população por deslocamentos diários (CARVALHO 2016).

O grande desafio dos planejadores em transportes, portanto, reside em elaborar diretrizes capazes de reverterem a matriz modal atual, a qual se baseia nos deslocamentos motorizados individuais, a partir da priorização e da valorização dos modos de transporte coletivos e não motorizados (KNEIB, 2012). É neste contexto em que são apresentadas perspectivas sustentáveis para a mobilidade urbana. 


\subsubsection{Mobilidade urbana sustentável}

Entende-se por mobilidade urbana sustentável como o desenvolvimento de espaços urbanos capazes de promoverem o equilíbrio entre a satisfação da carência humana por deslocamentos e a proteção ao meio ambiente, garantindo acesso com padrões aceitáveis a bens e atividades (ACKER; GOODWIN; WITLOX, 2016). De acordo com a literatura, a mobilidade urbana sustentável pode ser analisada sob três diferentes aspectos: econômico, social e ambiental.

Com relação ao aspecto econômico, a mobilidade urbana sustentável pode ser promovida por meio do equilíbrio econômico-financeiro entre os sistemas de transporte, com ênfase para o transporte coletivo. Políticas de financiamento dos custos deste serviço pelo poder público são de fundamental importância para a existência de um sistema de transporte público urbano de qualidade a um preço de tarifa justo (CARVALHO, 2016).

Com relação ao aspecto social, a mobilidade urbana sustentável pode ser promovida garantindo-se a acessibilidade universal aos serviços de transporte e a equidade nas condições de deslocamento entre indivíduos de diferentes classes sociais. Algumas medidas que contribuem para isto são: equilíbrio entre os modos de transporte, eficiência de recursos energéticos, uso de tecnologias para o transporte sustentável, diminuição das necessidades de deslocamento com maior adensamento das cidades, uso das telecomunicações, maior ocupação dos automóveis, integração entre os diferentes modos de transporte etc. (COSTA, 2003).

Com relação ao aspecto ambiental, um importante instrumento para a promoção da mobilidade urbana sustentável é aquele conhecido por transporte ativo, ou seja, qualquer modo de transporte não motorizado movido à propulsão humana, com destaque para o transporte cicloviário e para os deslocamentos a pé (LITMAN, 2015). Além disso, deve-se buscar o aumento da participação do transporte público na matriz modal de deslocamentos.

Neste contexto, torna-se necessária a inclusão do transporte cicloviário em uma política abrangente de mobilidade, estimulando o uso de bicicletas em substituição ao transporte motorizado individual ou como complemento do transporte coletivo (BICALHO, 2007). 


\subsection{Polos geradores de tráfego por bicicleta}

De acordo com Kneib (2004), entende-se por polos geradores de tráfego (PGTs) como instalações capazes de causar impactos no sistema viário, promovendo a ocupação ou a transformação da paisagem urbana em um curto período. Dentre os vários exemplos de PGTs, merecem destaque: indústrias, escolas, universidades, hospitais, shopping centers, clubes, parques, igrejas etc.

Os PGTs podem ser classificados de acordo com diversos critérios como natureza das atividades que desempenham, tamanho das edificações, número de deslocamentos que atraem etc. Além disso, cada PGT possui uma determinada área de influência dentro do local onde está inserido, cujos limites são traçados, dentre outros fatores, pela facilidade de acesso e pelas características socioeconômicas da população que reside ou frequenta as regiões periféricas ao polo (PORTUGAL; GOLDNER, 2003).

Neste contexto, define-se polo gerador de tráfego por bicicleta como qualquer empreendimento ou atividade que gera grande atração de viagens por bicicleta. A identificação e a inclusão dos PGTs por bicicleta no planejamento de redes de transporte cicloviário têm como objetivo facilitar o acesso dos ciclistas pertencentes à área de influência destas instalações a seus locais de trabalho, estudo e lazer.

\subsection{Espaços cicloviários}

O tráfego de bicicletas em áreas urbanas pode ocorrer de maneira compartilhada com outros modos de transporte ou por meio de infraestruturas próprias à circulação dos ciclistas. Para garantir que este processo seja realizado de maneira segura é necessário, entre outros fatores, verificar a disponibilidade de espaço urbano para comportar o transporte cicloviário.

\subsubsection{Espaço útil ao ciclista}

Para acomodar as dimensões básicas da bicicleta e garantir a manutenção do equilíbrio dos ciclistas é necessário espaço físico para sua circulação e eventuais manobras. Desta forma, 
o espaço útil ao ciclista, de acordo com o Ministério das Cidades (2007), é o seguinte: largura de $1,00 \mathrm{~m}$, comprimento de $1,75 \mathrm{~m}$ e altura de $2,25 \mathrm{~m}$.

Apesar de todas as modificações estruturais sofridas pela bicicleta nos últimos anos e do surgimento de diversos novos modelos deste veículo, sua dimensão longitudinal permanece a mesma, isto é, 1,75 m. A largura útil de 1,00 m resulta da largura do guidão $(0,60 \mathrm{~m})$, acrescida do espaço necessário ao movimento dos braços e pernas (0,20 m para cada lado). Por medidas de segurança, adota-se também um espaço para manobras de 0,25 m para cada lado. Quanto à altura, é também adotado um gabarito de 0,25 m à dimensão mínima de 2,00 m, resultando em 2,25 m (MINISTÉRIO DAS CIDADES, 2007). A Figura 2.1 ilustra estas dimensões.

Figura 2.1: Espaço útil ao ciclista em centímetros.
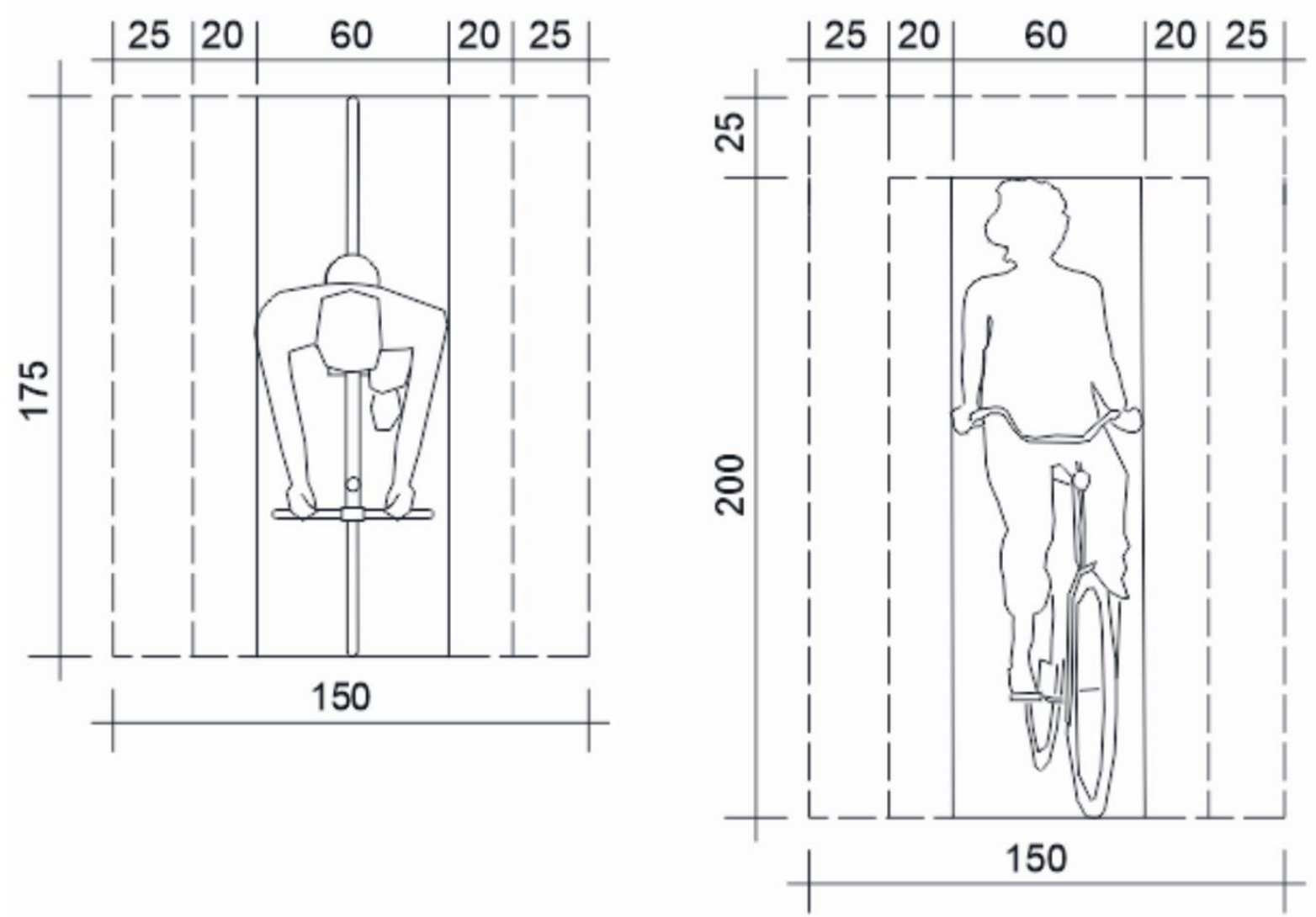

Fonte: Adaptado de MINISTÉRIO DAS CIDADES (2007, p. 99).

\subsubsection{Alternativas viárias para o tráfego de bicicletas}

De acordo com Litman et al. (2000), os três principais tipos de infraestrutura cicloviária que podem ser implantados em áreas urbanas são os seguintes: espaços compartilhados entre bicicletas e veículos motorizados, ou entre ciclistas e pedestres, espaços parcialmente 
segregados dos demais modos de transporte (ciclofaixas) e espaços completamente segregados dos demais modos de transporte (ciclovias). A seguir são apresentadas as principais características de cada uma destas alternativas viárias.

\subsubsection{Espaços compartilhados}

O compartilhamento de espaço entre bicicletas e outros modos de transporte é a solução mais adotada no planejamento cicloviário, pois geralmente não requer mudanças estruturais significativas no sistema viário e possui menores custos de implantação e manutenção em relação aos demais tipos de infraestrutura cicloviária. Entretanto, para que este processo ocorra de maneira segura, alguns critérios devem ser verificados.

O uso compartilhado do espaço urbano entre ciclistas e pedestres pode ocorrer ao longo de um passeio, como apresenta a Figura 2.2. Para que isto aconteça, este local deve apresentar as seguintes características: ser definido prioritariamente como passeio de pedestres nos planos diretores de transportes, não possuir qualquer dispositivo de separação física entre o tráfego de pedestres e ciclistas e, por último, apresentar sinalização adequada, alertando sobre a situação de espaço compartilhado (MINISTÉRIO DAS CIDADES, 2007).

Figura 2.2: Espaço compartilhado entre ciclistas e pedestres.

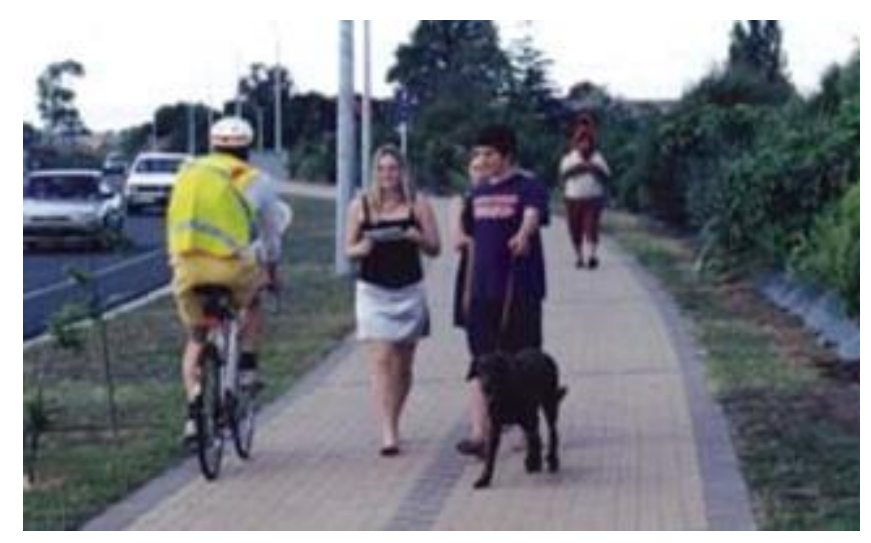

Fonte: LTSA (2004, p. 41).

De acordo com Toole (2010), a largura ideal de um passeio compartilhado entre ciclistas e pedestres, considerando-se o fluxo de tráfego bidirecional, é de 3,00 m. Em locais com baixa circulação de pedestres, no entanto, são admissíveis 2,40 m. Estes valores só são representativos de passeios com boas condições do pavimento. 
Os espaços compartilhados entre bicicletas e automóveis, como apresentado pela Figura 2.3, devem apresentar baixos volumes e velocidades de tráfego de veículos motorizados, situações que ocorrem, de maneira geral, em vias residenciais locais (LITMAN et al., 2000).

Figura 2.3: Espaço compartilhado entre bicicletas e automóveis.

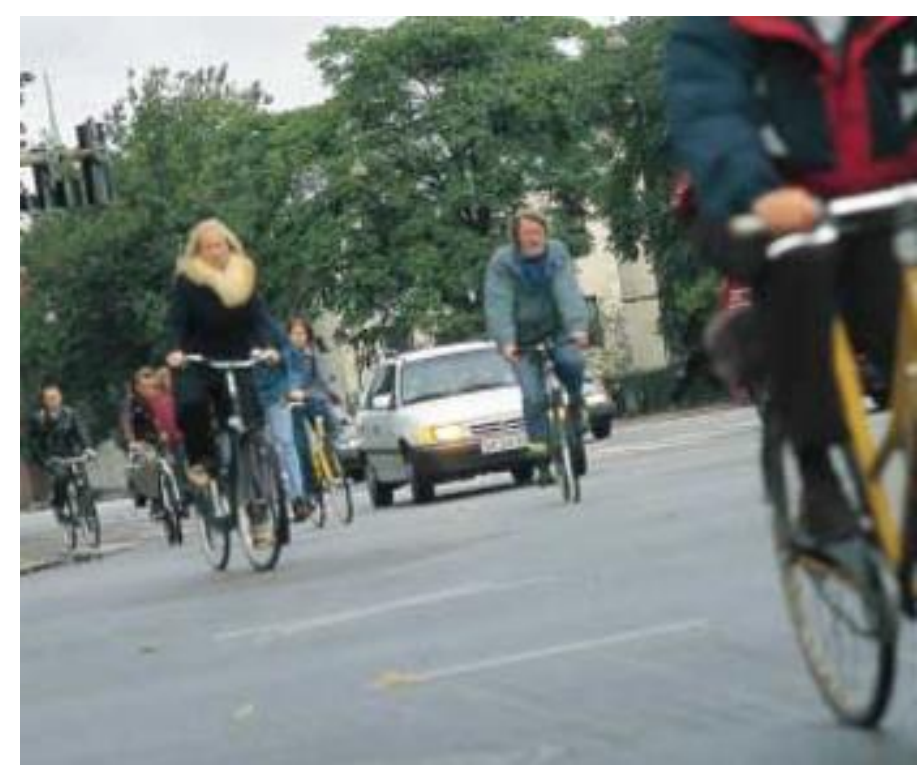

Fonte: JENSEN (2000, p. 15).

Neste contexto, é introduzido o conceito de via ciclável, isto é, qualquer via de tráfego compartilhado que recebe o tratamento adequado (sinalização, iluminação etc.) para a circulação segura das bicicletas (GEIPOT, 2001a).

Segundo Toole (2010), a largura efetiva ideal para uma faixa de uso compartilhado entre bicicletas e veículos motorizados é de 4,30 m. Em vias de tráfego com larguras efetivas menores que este valor não é descartada a possibilidade de se acomodar o transporte cicloviário. No entanto, uma série de medidas devem ser adotadas, como sinalização e inserção de equipamentos que promovam a diminuição da velocidade de tráfego dos veículos motorizados.

\subsubsection{Ciclofaixas}

De acordo com o Ministério das Cidades (2007), entende-se por ciclofaixa como o espaço próprio à circulação de ciclistas contíguo à pista de rolamento de veículos motorizados 
e identificado por meio de pintura ou dispositivos delimitadores. A Figura 2.4 ilustra as dimensões necessárias à implantação de uma ciclofaixa unidirecional.

Figura 2.4: Largura de uma ciclofaixa unidirecional.

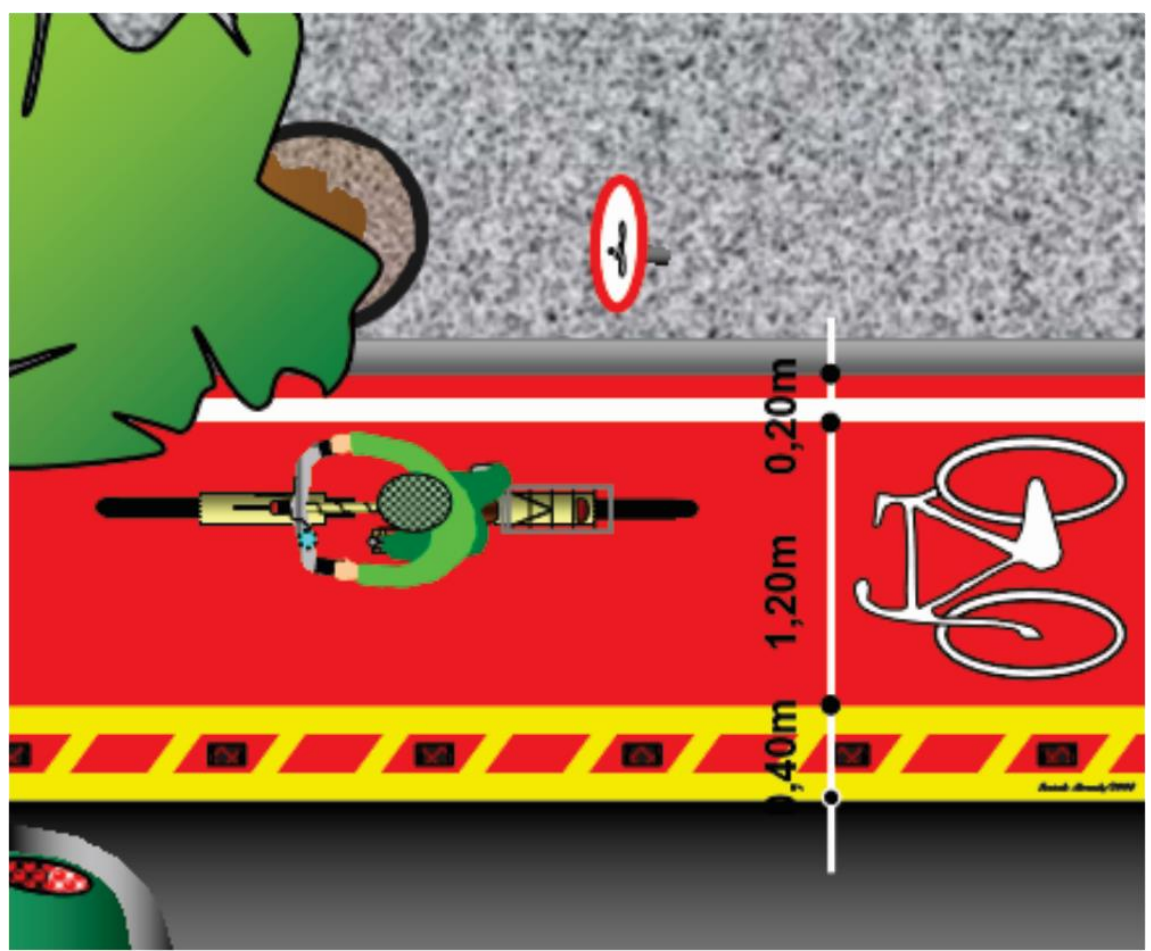

Fonte: GEIPOT (2001a, p. 38).

A largura interna mínima de uma ciclofaixa unidirecional, segundo o GEIPOT (2001a), é de 1,20 m. Além disso, deve ser a ela acrescida uma faixa de separação do tráfego motorizado de no mínimo 0,40 m, sendo recomendado 0,60 m. Deve ser também considerada uma faixa separadora entre a ciclofaixa e meio-fio da ordem de $0,20 \mathrm{~m}$, resultando em uma largura total de 1,80 m. Vale destacar ainda que as ciclofaixas podem ser dispostas também de maneira bidirecional, dependendo do sentido de circulação do tráfego motorizado e da disponibilidade de espaço para sua inserção, embora esta alternativa não seja muito empregada pelas autoridades em transportes dos municípios brasileiros.

\subsubsection{Ciclovias}

De acordo com o Ministério das Cidades (2007), entende-se por ciclovia como o espaço próprio à circulação de ciclistas totalmente segregado dos demais modos de transporte. Esta 
alternativa viária pode ser implantada em canteiros centrais, em calçadas laterais à pista de rolamento, ou ainda possuir um traçado independente do sistema viário. Assim como as ciclofaixas, as ciclovias podem ser unidirecionais ou bidirecionais.

De acordo com Ministério das Cidades (2007), as ciclovias unidirecionais devem possuir largura mínima de 2,00 m, como ilustra a Figura 2.5.

Figura 2.5: Largura de uma ciclovia unidirecional.

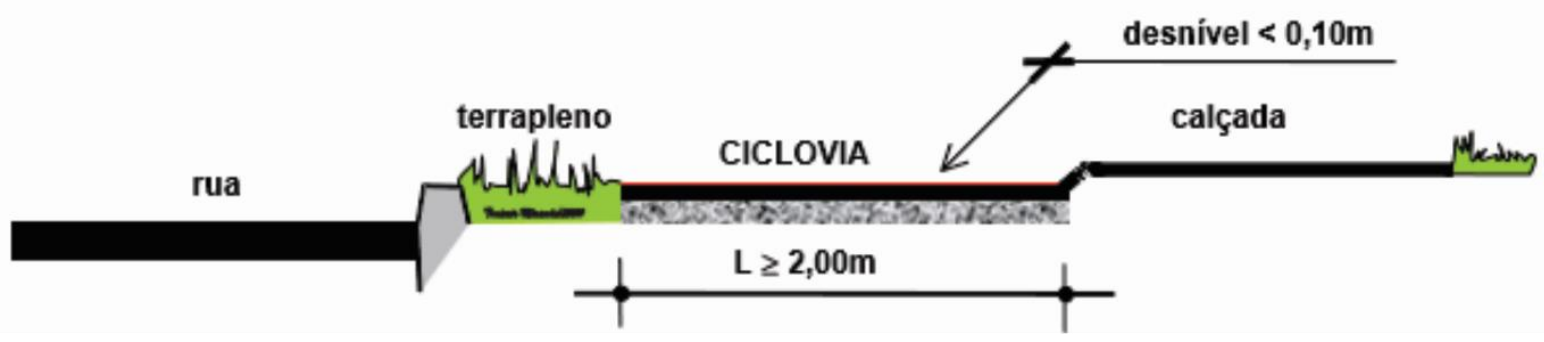

Fonte: MINISTÉRIO DAS CIDADES (2007, p. 111).

As ciclofaixas bidirecionais, por sua vez, devem possuir largura mínima de 2,50 m, sendo recomendáveis 3,00 m (MINISTÉRIO DAS CIDADES, 2007). A Figura 2.6 ilustra estas dimensões.

Figura 2.6: Largura de uma ciclovia bidirecional.

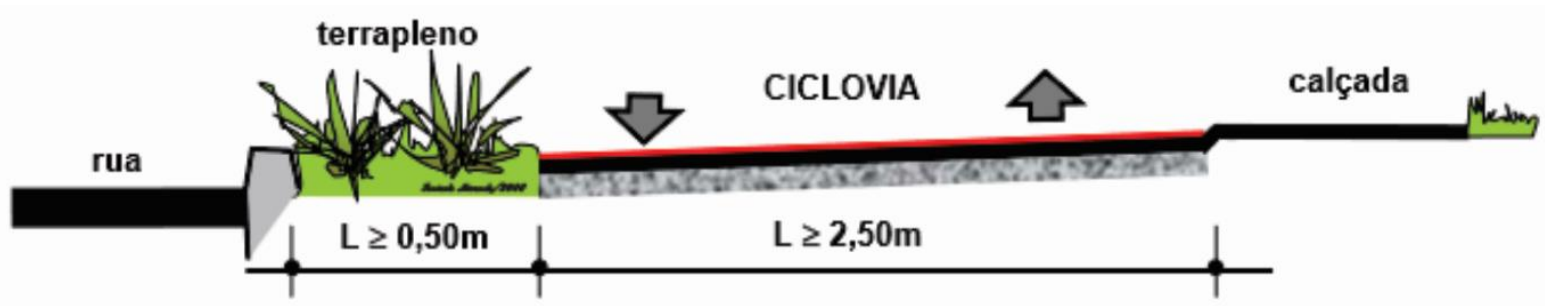

Fonte: MINISTÉRIO DAS CIDADES (2007, p. 113).

\subsubsection{Critérios para inserção de facilidades para ciclistas}

A inserção de facilidades para ciclistas é realizada de forma a contribuir com a segurança dos mesmos, separando-os do intenso tráfego de automóveis, veículos pesados e motocicletas. Desta forma, os critérios de separação entre o tráfego de bicicletas e o de veículos motorizados encontrados na literatura baseiam-se majoritariamente em duas variáveis: volume e velocidade de tráfego dos veículos motorizados. 
A Figura 2.7, adaptada de Cycle Network and Route Planning Guide (LTSA, 2004), exemplifica como o volume e a velocidade de veículos motorizados condicionam a inserção de infraestruturas próprias à circulação de ciclistas em vias urbanas. Quanto maiores estas variáveis, maior também deve ser o grau de separação entre o tráfego de veículos motorizados e o de bicicletas. Nota-se que mesmo em locais com pequenos volumes de veículos motorizados pode ser desejável esta separação.

Figura 2.7: Diagrama de infraestrutura cicloviária para vias urbanas.

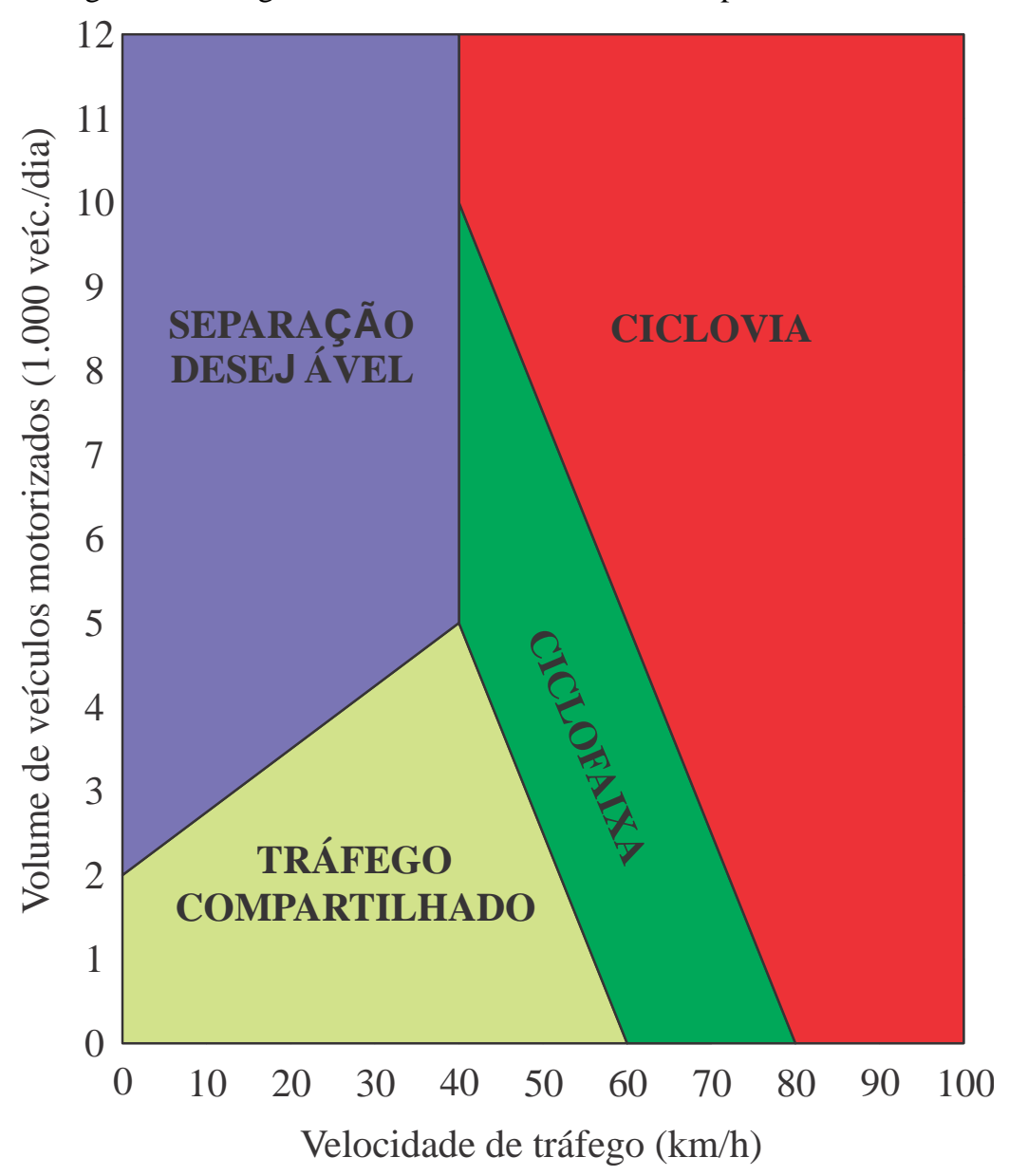

Fonte: Adaptado de LTSA (2004, p. 35).

\subsubsection{Relação de equivalência entre as alternativas viárias para ciclistas}

O diagrama proposto pela LTSA (2004) para inserção de facilidades para ciclistas sugere que o critério para a separação entre o tráfego de bicicletas e o de veículos motorizados baseia-se em uma hierarquia entre os espaços cicloviários. Desta forma, segundo Segadilha (2014), diversos pesquisadores definem a seguinte ordem decrescente de preferência entre os ciclistas por estes espaços: (1) ciclovias, (2) ciclofaixas e (3) vias cicláveis. 
Com base nesta hierarquia, alguns estudos têm sido desenvolvidos na tentativa de propor uma relação de equivalência entre os diversos tipos de infraestrutura cicloviária. Em outras palavras, significa dizer que o comprimento $\mathrm{X}$ de um segmento viário compartilhado entre bicicletas e automóveis oferece as mesmas condições de segurança e conforto aos ciclistas que um comprimento $\mathrm{Y}$ deste mesmo segmento se provido de ciclofaixa, e que um comprimento $\mathrm{Z}$ deste mesmo segmento se provido de ciclovia, sendo $\mathrm{X}<\mathrm{Y}<\mathrm{Z}$.

Stinson e Bhat (2003) conduziram uma pesquisa de preferência declarada com o objetivo de avaliar a influência de diversos fatores na escolha das rotas pelos ciclistas. Os resultados desta pesquisa demonstraram que os ciclistas se dispõem a desviar das rotas mais curtas para trafegarem por locais com facilidades ao transporte cicloviário, como ciclofaixas e ciclovias, e por vias compartilhadas com baixos volumes de veículos motorizados.

Broach, Gliebe e Dill (2009) desenvolveram um estudo em Portland (EUA) com o objetivo de entender como os diferentes tipos de infraestrutura cicloviária estimulam a utilização da bicicleta. Os autores concluíram que ambientes dotados de facilidades para ciclistas encorajam os mesmos a aumentarem suas distâncias de viagem. Desta forma, por meio dos resultados da pesquisa, foi possível propor a seguinte relação de equivalência para as alternativas viárias aos ciclistas: 1,00 unidade de distância para ciclofaixas ou vias locais (baixos volumes e velocidades de veículos motorizados) equivale a:

- 1,22 para vias compartilhadas entre ciclistas e pedestres;

- 1,35 para ciclovias;

- 0,82 para vias arteriais com volume de veículos diário variando entre 10.000 e 20.000 ;

- 0,42 para vias arteriais com volume de veículos diário variando entre 20.000 e 30.000;

- $\quad$ 0,14 para vias cujo volume de veículos diário é superior a 30.000.

Larsen e El-Geneidy (2011), por meio da aplicação de questionários online a aproximadamente 3.000 ciclistas da cidade de Montreal (Canadá), avaliaram como as características de cada um dos tipos de infraestrutura cicloviária afetam no processo de escolha das rotas pelos ciclistas. Os resultados desta pesquisa, gerados com o auxílio de análises estatísticas, demonstraram que os ciclistas que utilizam facilidades completamente segregadas do tráfego de veículos motorizados (ciclovias) têm suas distâncias de viagem aumentadas, em média, em $71 \%$ em relação aos ciclistas que trafegam por vias compartilhadas. Já os ciclistas que trafegam por ciclofaixas acrescem às suas distâncias de viagem um percentual médio de 
$31 \%$ em relação aos ciclistas que trafegam por vias compartilhadas. Estes valores também podem ser utilizados para quantificar a relação de equivalência entre os diversos tipos de infraestrutura cicloviária.

\subsubsection{Disponibilidade de espaço para inserção de facilidades para ciclistas}

Após verificada a necessidade de inserção de ciclofaixas ou ciclovias em determinados locais, é preciso analisar a viabilidade física, isto é, a disponibilidade de espaço em passeios, seções transversais das vias ou canteiros centrais para sua construção e manutenção. A seguir são apresentadas as dimensões mínimas de cada um destes espaços para acomodar tais alternativas de infraestrutura cicloviária.

\subsubsection{Passeios}

De acordo com o Ministério das Cidades (2007), a inserção de uma infraestrutura cicloviária junto aos passeios é feita com uma série de limitações como, por exemplo, apresentar-se no mesmo nível de circulação dos pedestres, dispor de projeto de drenagem compatível com o de todo o passeio, apresentar sinalização identificadora do tráfego de bicicletas etc. Como já apresentado na seção 2.4.2.3, as larguras mínimas de uma ciclovia unidirecional e de uma bidirecional são, respectivamente, de 2,00 m e 2,50 m.

A largura recomendável para um passeio público, segundo o Departamento Nacional de Infraestrutura de Transportes (DNIT, 2010), é de 1,50 m, que consiste na largura necessária a um cadeirante para efetuar manobras. No entanto, é admissível uma largura mínima de 1,20 m.

Gondim (2010) atenta ainda para a influência da arborização nos padrões de circulação dos ciclistas. Segundo a autora, estes tendem a se distanciar de maneira diferenciada conforme os canteiros estejam no nível da faixa própria à circulação de bicicletas ou dispostos de maneira elevada. Esta distância também se altera levando-se em conta a seção do canteiro e as dimensões do tronco da espécie arbórea. Desta forma, a NBR 12255:1990 estabelece que estes canteiros devem possuir larguras mínimas de 0,80 m (ABNT, 1990). Portanto, conclui-se que passeios 
capazes de comportar ciclovias unidirecionais e bidirecionais devem possuir, respectivamente, larguras mínimas de 4,00 m e 4,50 m.

\subsubsection{Seções transversais das vias}

A inserção de ciclofaixas adjacentes à pista de rolamento dos veículos motorizados depende, entre outros fatores, da largura efetiva desta pista. A largura interna mínima de uma ciclofaixa unidirecional, como apresentado na seção 2.4.2.2, é de 1,20 m.

De acordo com o DNIT (2010), a largura da pista de rolamento desejável para áreas urbanas é de 3,60 m, sendo admissíveis 3,30 m. Portanto, conclui-se que uma via de tráfego capaz de acomodar ciclofaixas unidirecionais deve possuir seção transversal com largura efetiva superior a $4,50 \mathrm{~m}$.

\subsubsection{Canteiros centrais}

A separação entre o tráfego de bicicletas e o de veículos motorizados pode ocorrer também por meio da inserção de infraestruturas cicloviárias em canteiros centrais. Neste sentido, é interessante avaliar a disponibilidade de espaço para acomodação de ciclovias bidirecionais, garantindo aos ciclistas a integridade de seus percursos de ida e volta.

A largura desejável a uma ciclovia bidirecional, como apresentado na seção 2.4.2.3, é de 3,00 m, sendo admissíveis 2,50 m. O Ministério das Cidades (2007) atenta que, para casos de desnível lateral (terrapleno) maior que 0,10 m, é necessário adotar-se um acréscimo de 0,50 m. Portanto, a largura ideal de um canteiro central capaz de acomodar uma ciclovia bidirecional varia entre 3,00 e $3,50 \mathrm{~m}$.

\subsection{Fatores que influenciam no uso da bicicleta como modo de transporte urbano}

Os fatores que influenciam no uso da bicicleta como modo de transporte urbano, de acordo com a Federal Highway Administration (FHWA, 2006a), podem ser classificados de 
três maneiras distintas: (1) fatores relacionados ao indivíduo, (2) fatores relacionados ao percurso e (3) fatores relacionados ao destino da viagem.

\subsubsection{Fatores relacionados ao indivíduo}

O uso da bicicleta como modo de transporte por um determinado individuo é influenciado por vários fatores relacionados às características do próprio indivíduo e às suas preferências. Dentre alguns exemplos destes fatores, podem ser citados: gênero, idade, renda e ocupação, distância de viagem e percepções de segurança no tráfego.

Em países como Alemanha, Dinamarca e Holanda, os diversos programas de incentivo à utilização da bicicleta, desenvolvidos pelos próprios governos destes países, contribuem para a distribuição homogênea de ciclistas entre as diferentes classes sociais, sendo a idade um dos poucos fatores pessoais limitantes ao uso da bicicleta. No Brasil, entretanto, pesquisas realizadas para a caracterização da demanda cicloviária existente demonstram a predominância de ciclistas do sexo masculino, em idade economicamente ativa e pertencentes às classes sociais e econômicas mais desfavorecidas (PUCHER; BUEHLER, 2008; SOUSA, 2012).

De acordo com o Ministério das Cidades (2007), a bicicleta é um veículo cujo raio de ação é limitado, decorrente do próprio modo de tração do veículo. Desta forma, a distância de viagem, apesar de ser uma característica do percurso, configura-se como um dos fatores relacionados ao indivíduo, sendo ponderado de acordo com o condicionamento físico do mesmo e com a facilidade de acesso aos seus destinos de viagem.

A tolerância de ciclistas às distâncias de viagem por bicicleta tem sido tema abordado por diversos trabalhos. De acordo com McNeil (2011), vários autores têm procurado estimar o quanto estes ciclistas estão dispostos a pedalar antes de substituírem a bicicleta por outro modo de transporte. O GEIPOT (2001a) sugere que as distâncias ideais para viagens urbanas por bicicleta não devem ser superiores a 7,5 km.

Tucker e Manaugh (2016) apresentam uma abordagem alternativa para a quantificação das distâncias ideais para viagens urbanas por bicicleta: na escolha das rotas para viagens não recreacionais, os ciclistas buscam caminhos que, simultaneamente, minimizem o tempo de viagem e proporcionem conforto. Desta forma, é aceitável que alguns desvios sejam feitos com o intuito de evitar segmentos viários com baixa qualidade operacional ao transporte cicloviário. 
Os autores propõem, portanto, que estes desvios não sejam maiores do que $25 \%$ da distância mínima de viagem.

As percepções individuais de segurança no tráfego também desempenham um importante papel na seleção da bicicleta como modo de transporte urbano. Ciclistas que compartilham a via com outros modos de transporte estão sujeitos a quedas, colisões e outros acidentes causados por aberturas de portas e manobras de ultrapassagem. Além disso, a ausência de equipamentos que promovam a iluminação adequada das vias onde trafegam os ciclistas contribui para um cenário de preocupação, principalmente em períodos noturnos, com o risco de assaltos e outros ataques (FHWA, 1992; FHWA, 2006a; NERI, 2012).

\subsubsection{Fatores relacionados ao percurso}

Os fatores que influenciam no uso da bicicleta relacionados ao percurso são os aspectos do meio físico comuns a todos os ciclistas, embora não sejam ponderados igualmente pelos mesmos. Dentre alguns exemplos, destacam-se: relevo, condições climáticas e existência de infraestruturas próprias ao transporte cicloviário.

$\mathrm{O}$ fato de a bicicleta ser um modo de transporte não motorizado movido à propulsão humana faz com que os ciclistas procurem despender o mínimo de energia na realização de suas viagens. Desta forma, vias com declividades acentuadas, irregularidades no pavimento e ondulações fortes do terreno são alguns fatores que podem desestimular o uso da bicicleta. A tendência natural é o projeto de sistemas cicloviários ao longo de rotas que suavizem a declividade (GEIPOT, 2001a).

As condições climáticas de um determinado local também atuam como fatores limitantes ao transporte cicloviário, ou seja, chuva, frio ou calor intensos e ventos dominantes são algumas das intempéries que desestimulam o uso da bicicleta. De acordo com a FHWA (1992), as condições climáticas ideais ao uso da bicicleta são: médias de temperaturas mínimas e máximas entre $18^{\circ} \mathrm{C}$ e $28^{\circ} \mathrm{C}$, e precipitações mensuráveis com ocorrências menores do que em 60 dias por ano.

A existência de alternativas de infraestrutura viária próprias ao uso da bicicleta também atua como um fator de influência na escolha pelo modo de transporte cicloviário. Entretanto, Dill e Carr (2003) atentam para o fato de que uma rede cicloviária ser composta por grandes 
extensões de ciclofaixas e ciclovias não é o suficiente para que hajam elevadas taxas de utilização da bicicleta no espaço urbano. É necessário que estas tipologias estejam inseridas em ligações de grande movimento e que sejam dispostas de maneira contínua, garantindo um nível homogêneo de segurança por toda a rede.

\subsubsection{Fatores relacionados ao destino da viagem}

A inserção de infraestruturas cicloviárias para estimular o uso da bicicleta não se limita às vias de tráfego, mas deve ser expandida também aos locais de destino das viagens. Estacionamentos próprios às bicicletas, vestiários, chuveiros, armários, oficinas de manutenção etc., são alguns dos exemplos de instalações junto a estes locais de destino que auxiliam no desenvolvimento do transporte cicloviário (FHWA, 2006a).

\subsection{Rotas cicláveis}

De acordo com o Ministério das Cidades (2007), entende-se por rota ciclável como um caminho que promove a ligação entre um par origem-destino de maneira segura aos ciclistas, isto é, por meio da sinalização adequada e do tratamento de interseções. Esta ligação pode ser feita de maneira compatível com o sistema viário ou possuir traçado independente.

A construção de rotas cicláveis pode incluir diversos tipos de infraestrutura cicloviária: ciclovias, ciclofaixas ou vias de uso compartilhado. Entretanto, Affonso, Badini e Gouvêa (2003) ressaltam a importância da retomada do conceito de vias compartilhadas, promovendo um espaço mais humano de circulação. Desta forma, é possível contribuir para a formação de sistemas cicloviários até mesmo em locais cujo crescimento se deu de forma espontânea, sem planejamento prévio, como ocorre na maioria das cidades brasileiras de pequeno porte.

A maioria dos estudos relacionados ao processo de escolha das rotas pelos ciclistas é conduzida utilizando-se pesquisas de preferência declarada. Neste modelo de pesquisa são apresentados cenários hipotéticos aos entrevistados, cada um deles representando uma combinação diferente entre os atributos a serem avaliados. De acordo com as escolhas feitas pelos entrevistados é possível, por meio de métodos estatísticos, estimar parâmetros associados 
aos atributos avaliados (ZACHARIAS; ZHANG, 2016). Dentre os trabalhos que se utilizam de pesquisas de preferência declarada voltadas ao transporte cicloviário, destacam-se: Bovy e Bradley (1985), Axhausen e Smith (1986), Hopkinson e Wardman (1996), Ortúzar, Iacobelli e Valeze (2000), Stinson e Bhat (2003), Hunt e Abraham (2007), Tilahun, Levinson e Krizek (2007), Caulfield, Brick e McCarthy (2012) etc.

O método de preferência revelada também é comumente utilizado em pesquisas voltadas ao transporte cicloviário para prever o comportamento dos ciclistas no processo de escolha das rotas. Neste modelo de pesquisa, avalia-se a preferência dos entrevistados entre cenários reais, permitindo a identificação de maneira direta dos atributos mais atrativos dentre os avaliados (ZACHARIAS; ZHANG, 2016). Alguns trabalhos que se utilizam de pesquisas de preferência revelada voltadas ao transporte cicloviário são: Lott, Tardiff e Lott (1978), Calgary (1993), Antonakos (1994), Aultman, Hall e Baetz (1997), Hyodo, Suzuki e Takahashi (2000), Menghini et al. (2010) etc.

A evolução dos SIGs, em especial ao longo das últimas duas décadas, tem possibilitado o desenvolvimento de trabalhos voltados à identificação de rotas cicláveis em áreas urbanas por meio da análise simultânea de diversos fatores que influenciam no uso da bicicleta. O desafio de grande parte destes trabalhos é justamente identificar trajetos que minimizem condições adversas ao ciclismo e que, ao mesmo tempo, sejam compatíveis com as linhas de desejo de viagens dos ciclistas (ISEKI; TINGSTROM, 2013; BUEHLER; DILL, 2015).

Drucker (2003) desenvolveu um trabalho voltado à análise dos segmentos viários que oferecem maiores riscos de acidentes aos praticantes do ciclismo esportivo da cidade de Redlands, Califórnia (EUA). Para isto, foram combinados atributos das declividades das vias e dados georreferenciados de acidentes envolvendo ciclistas. Os resultados permitiram identificar as rotas mais seguras à prática do ciclismo esportivo.

Klobucar e Fricker (2007) desenvolveram um método para identificação de rotas cicláveis intitulado Bicycle Network Analysis Tool (BNAT). De acordo com os autores, cada segmento de um determinado sistema viário possui um custo, representado matematicamente pelo produto entre o comprimento deste segmento e seu respectivo Bicycle Compatibility Index (BCI), índice de compatibilidade da via com o transporte cicloviário desenvolvido por Harkey et al. (1998). Desta forma, a rota ciclável é identificada de maneira que a somatória dos custos dos segmentos que conectam o par origem-destino de interesse seja mínima. O estudo de caso, 
conduzido para a cidade de West Lafayette (EUA), permitiu a identificação dos locais com maior necessidade de melhoramentos para acomodar o tráfego de bicicletas.

Lowry et al. (2012) basearam-se no trabalho de Klobucar e Fricker (2007) para o desenvolvimento de seu próprio método para identificação de rotas cicláveis. A diferença entre estes dois trabalhos é que Lowry et al. (2012), ao invés de empregarem o BCI na ponderação de cada segmento viário, utilizaram-se do Bicycle Level of Stress (BLOS), indicador da compatibilidade das vias com o transporte cicloviário proposto pelo Highway Capacity Manual (HCM). Além disso, os autores também propõem uma equação para quantificar a acessibilidade de ciclistas a destinos de viagens específicos. O estudo de caso, conduzido à comunidade de Moscow (EUA), demonstrou que a adequação da bicicleta no espaço urbano aumenta à medida que mais destinos de viagens são alcançados por meio de rotas cicláveis compostas por segmentos com maiores níveis de serviço.

Furth e Merkuria (2013) basearam-se no mesmo raciocínio que Klobucar e Fricker (2007) para a elaboração de um método para identificação de rotas cicláveis. A diferença principal entre estes dois trabalhos é que Furth e Merkuria (2013), ao invés de empregarem o BCI na ponderação de cada segmento viário, utilizaram-se do índice de compatibilidade da via com o transporte cicloviário desenvolvido pelos próprios autores, intitulado Level of Traffic Stress (LTS). O estudo de caso, realizado na cidade de San Jose (EUA), mostrou que algumas das rotas cicláveis identificadas, apesar de mais seguras à circulação de ciclistas, possuem extensões expressivamente maiores do que as rotas de menor distância.

No Brasil, alguns trabalhos recentes têm sido desenvolvidos na tentativa de elaborar diretrizes para a identificação de rotas cicláveis. Apesar destes trabalhos basearem-se nos mesmos procedimentos daqueles apresentados pela literatura internacional, os resultados encontrados, de maneira geral, são insatisfatórios. Um dos principais motivos para que isto aconteça é a baixa qualidade de serviço das vias das cidades brasileiras para acomodar o transporte cicloviário.

Kirner (2006) propôs um método para definição de rotas cicláveis em áreas urbanas de cidades brasileiras de porte médio. De acordo com a autora, devem ser realizadas entrevistas e pesquisas de preferência declarada junto aos ciclistas que frequentam polos geradores de tráfego por bicicleta, com o intuito de identificar os segmentos viários onde existe maior demanda potencial de viagens pelo transporte cicloviário. Os segmentos selecionados devem ser avaliados quanto ao nível de serviço pelo Método de Dixon (1996), e os que apresentarem 
piores resultados devem receber o melhoramento necessário para integrarem as rotas cicláveis. O estudo de caso, realizado para a cidade de São Carlos (SP), mostrou que os níveis de serviço atribuídos às 11 vias analisadas são considerados inaceitáveis ao transporte cicloviário.

Magalhães, Campos e Bandeira (2015) desenvolveram um método para identificação de redes de rotas cicláveis em áreas urbanas baseado em um algoritmo de busca de caminhos mínimos. A cada um dos segmentos viários do local de estudo (Montes Claros, MG) foi atribuído um custo, representado matematicamente pelo produto entre o comprimento do segmento e seu respectivo nível de serviço avaliado pelo Método de Dixon (1996). Oito rotas cicláveis foram identificadas ligando-se alguns dos polos geradores de tráfego por bicicletas da área de estudo entre si, e a cada uma delas foi feita a verificação do perfil topográfico das vias pelo critério proposto pela AASHTO (1999). Os resultados mostraram que os níveis de serviço atribuídos às vias analisadas são considerados inadequados ao transporte cicloviário.

Cardoso e Campos (2016) elaboraram um método para o planejamento de sistemas cicloviários baseado em cinco parâmetros que influenciam na escolha das rotas pelos ciclistas: largura efetiva, declividade e presença de estacionamentos nas vias, e velocidade e volume médio de tráfego de veículos motorizados. Estas variáveis, ponderadas igualmente, permitem o cálculo de um índice intitulado Índice de Adequação do Segmento para viagens por bicicleta. Os autores propõem que devem ser identificados os caminhos mínimos entre os polos geradores de viagens da área de estudo e que cada um dos segmentos que compõem estes caminhos mínimos deve ser avaliado quanto ao índice de adequação, visando identificar os segmentos inadequados ao uso da bicicleta e, se possível, substituí-los. O estudo de caso demonstrou um exemplo de aplicação do método para a identificação de uma rota ciclável entre dois polos geradores de tráfego por bicicleta na cidade de Nova Iguaçu (RJ). 
$54 \mid P$ á g i n a 


\section{MODELOS DE AVALIAÇÃO DA COMPATIBILIDADE DAS VIAS COM O TRANSPORTE CICLOVIÁRIO}

A utilização da bicicleta como modo de transporte urbano, como discutido no capítulo 2 deste trabalho, é influenciada por diversos fatores relacionados às percepções de conforto e segurança dos ciclistas, assim como às características do espaço físico. Desta forma, a análise destes fatores permite avaliar a compatibilidade das vias de tráfego de uma determinada área de estudo com o transporte cicloviário.

O relevo é frequentemente citado na literatura como um dos fatores que mais exercem influência no uso da bicicleta como modo de transporte urbano. Neste contexto, diversos trabalhos têm sido desenvolvidos, desde a década de 70, com o objetivo de quantificar classes de declividades relacionadas à verificação do perfil topográfico das vias de tráfego para acomodar o transporte cicloviário.

Diversos modelos têm sido desenvolvidos também com o intuito de quantificar a qualidade operacional das vias urbanas para promoção do transporte cicloviário. De acordo com a abordagem proposta por cada um destes modelos, eles podem ser classificados de duas maneiras distintas: (1) modelos de avaliação do nível de estresse ao qual o ciclista está submetido ao trafegar por uma determinada via e (2) modelos de avaliação do nível de serviço das vias relacionado ao uso da bicicleta.

O conjunto de variáveis de entrada necessárias à aplicação da maioria dos modelos de avaliação da qualidade de serviço das vias ao transporte cicloviário, de maneira geral, é muito semelhante. Dentre estas variáveis, destacam-se: volume e velocidade dos veículos motorizados, largura efetiva das vias de tráfego, existência de infraestrutura cicloviária, condições do pavimento, composição do tráfego etc. A principal diferença entre estes modelos, no entanto, é a maneira como cada um deles pondera os parâmetros de entrada (PARKIN; WARDMAN; PAGE, 2007).

A seguir são apresentados os principais modelos encontrados na literatura para a verificação do perfil topográfico e para a avaliação da qualidade de serviço das vias para o transporte cicloviário. 


\subsection{Verificação do perfil topográfico das vias para o transporte cicloviário}

Grandes declividades podem atuar como fatores desestimulantes ao uso da bicicleta. No caso das rampas ascendentes, exige-se que os ciclistas realizem maior esforço físico e, consequentemente, necessitem de mais tempo para completarem suas viagens. Já no caso das rampas descendentes, grandes inclinações das vias fazem com que os ciclistas tenham dificuldade em controlar a velocidade da bicicleta, prejudicando, em muitos casos, a manutenção do equilíbrio (NYENHUIS, 2012).

De acordo com Winters et al. (2010), não existe um consenso entre os planejadores em transportes com relação ao grau de inclinação a partir do qual a via é considerada inadequada ao ciclismo. Ciclistas menos experientes costumam optar por trajetos compostos por vias planas, enquanto ciclistas mais experientes tendem a escolher rotas mais diretas, dando menor importância aos desníveis a serem vencidos (STINSON; BHAT, 2005).

A seguir são apresentados os principais trabalhos encontrados na literatura voltados à elaboração de critérios para a verificação do perfil topográfico das vias com relação ao transporte cicloviário.

\subsubsection{Critério da FHWA (1977)}

Os primeiros esforços voltados à verificação do perfil topográfico das vias com relação ao transporte cicloviário foram apresentados pelo manual Safety \& Location Criteria for Bicycle Facilities, o qual documenta estudos realizados por pesquisadores da Universidade da Califórnia, em Davis (EUA). De acordo com estes estudos, todo o processo de análise da compatibilidade do perfil longitudinal das vias com o transporte cicloviário pode ser quantificado em função de duas variáveis: grau de inclinação da rampa e o seu respectivo comprimento. Esta quantificação, no entanto, pode variar de acordo com a idade e com a condição física de potenciais ciclistas (FHWA, 1975).

Neste contexto, dois anos mais tarde, a própria FHWA (1977) desenvolveu um critério para auxiliar no planejamento de sistemas cicloviários, baseando-se, entre outros fatores, no consumo de energia por parte dos ciclistas ao trafegarem por vias com diferentes inclinações e na distância de visibilidade adequada para se promover a circulação das bicicletas de maneira 
eficiente e segura. O valor máximo para o grau de inclinação das rampas considerado neste critério é de $11 \%$, como apresenta a Figura 3.1.

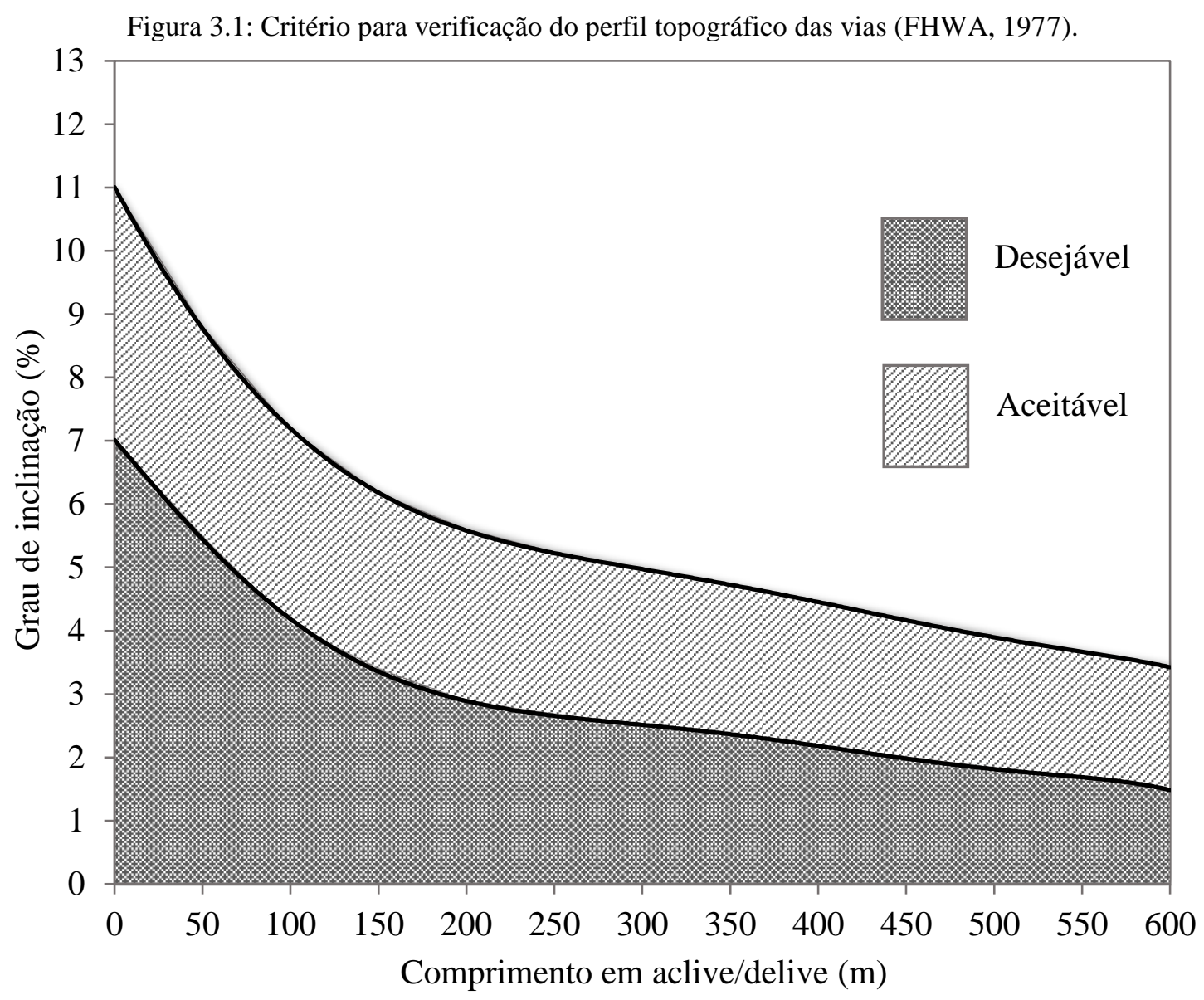

Fonte: Adaptado de FHWA (1977, p. 43).

O critério proposto pela FHWA (1977) manteve-se por mais de uma década como a principal ferramenta para verificação do perfil topográfico das vias para o transporte cicloviário.

\subsubsection{Critérios da AASHTO}

No início dos anos 90, foi publicado pela Association of State Highway and Transportation Officials (AASHTO) o manual Guide for the Development of Bicycle Facilities, o qual propõe uma série de procedimentos para o planejamento de sistemas cicloviários. Desde então, diversas edições deste manual têm sido publicadas com o intuito de incorporar os avanços do planejamento cicloviário ao longo dos anos. 
De acordo com a AASHTO (1999), as inclinações ideais das vias para o uso da bicicleta não devem exceder 3\%, sendo aceitáveis até 5\%. No entanto, dependendo-se das características físicas da área de estudo, nem sempre é possível mudar o greide da via de maneira a garantir estas inclinações. Desta forma, o método proposto pela AASHTO (1999) sugere que, nestes casos, as rampas sejam avaliadas de acordo com seus respectivos comprimentos em aclive.

A Tabela 3.1 apresenta os limites de extensão admissível dos trechos em aclive para vias cujas inclinações são superiores a 5\%, de acordo com AASHTO (1999).

Tabela 3.1: Limites de extensão de trechos em aclive (AASHTO, 1999).

\begin{tabular}{c|c}
\hline Aclive $(\%)$ & $\mathrm{L}_{\text {máximo }}(\mathrm{m})$ \\
\hline $5,00-6,00$ & 240 \\
$6,01-7,00$ & 120 \\
$7,01-8,00$ & 90 \\
$8,01-9,00$ & 60 \\
$9,01-10,00$ & 30 \\
$>10,00$ & 15 \\
\hline
\end{tabular}

Fonte: Adaptado de AASHTO (1999, p.39).

A versão mais recente do manual da AASHTO, publicada em 2012, baseia-se em uma revisão de edições anteriores realizada por Toole (2010). O procedimento para verificação do perfil topográfico das vias para o transporte cicloviário nesta nova edição permanece o mesmo, alterando-se apenas os limites de extensão admissível dos trechos em aclive para vias cujo grau de inclinação excede 5\%, como apresenatdo pela Tabela 3.2.

Tabela 3.2: Limites de extensão de trechos em aclive (AASHTO, 2012).

\begin{tabular}{c|c}
\hline Aclive $(\%)$ & $\mathrm{L}_{\text {máximo }}(\mathrm{m})$ \\
\hline $5,00-8,30$ & 60 \\
$8,31-10,00$ & 9 \\
$10,01-12,50$ & 3 \\
\hline
\end{tabular}

Fonte: Adaptado de TOOLE (2010, p. 150).

Os estudos desenvolvidos pela AASHTO ao longo das últimas três décadas também serviram de ponto de partida para diversos outros trabalhos que propõem critérios para a 
verificação do perfil topográfico das vias para o transporte cicloviário (JENSEN et al., 2000; GEIPOT, 2001a; AUSTROADS, 2014).

\subsubsection{Critério do GEIPOT (2001a)}

Todos os tipos de infraestrutura cicloviária devem manter uma adequada distância de visibilidade para promover a circulação das bicicletas de maneira eficiente e segura. No caso das ciclofaixas ou das vias de tráfego compartilhado, a viabilidade técnica para sua implantação está diretamente ligada às características geométricas do sistema viário, dentre elas, o greide. O mesmo não ocorre com as ciclovias, uma vez que estas facilidades podem possuir um traçado independente do sistema viário.

Desta forma, o GEIPOT (2001a) apresenta valores para a verificação das rampas normais (desejáveis) e máximas (admissíveis), em função do desnível a ser vencido, para o caso das ciclovias, como apresenta a Tabela 3.3.

Tabela 3.3: Critério para verificação do perfil topográfico para ciclovias (GEIPOT, 2001a).

\begin{tabular}{c|c|c}
\hline \multirow{2}{*}{ Desnível a ser vencido $(\mathrm{m})$} & \multicolumn{2}{|c}{ Rampa } \\
\cline { 2 - 3 } & Normal (\%) & Máxima (\%) \\
\hline 2 & 5,0 & 10,0 \\
4 & 2,5 & 5,0 \\
6 & 1,7 & 3,3 \\
\hline
\end{tabular}

Fonte: Adaptado de GEIPOT (2001a, p. 43).

\subsubsection{Critério do Austroads (2014)}

Em 2011 foi publicada a primeira edição do manual Cycling Aspects of Austroads Guides, elaborado pelo grupo australiano de planejadores em transportes intitulado Austroads. Dentre as informações presentes neste manual, destaca-se o procedimento para a verificação do perfil topográfico das vias para o transporte cicloviário extremamente semelhante àquele proposto pelos manuais da AASHTO, com exceção dos diferentes limites de extensão sugeridos para os trechos em aclive (AUSTROADS, 2014). 
A segunda e mais recente edição do manual australiano foi publicada em abril de 2014, e apresenta uma versão revisada destes limites, como apresenta a Figura 3.2.

Figura 3.2: Critério para verificação do perfil topográfico das vias (AUSTROADS, 2014).

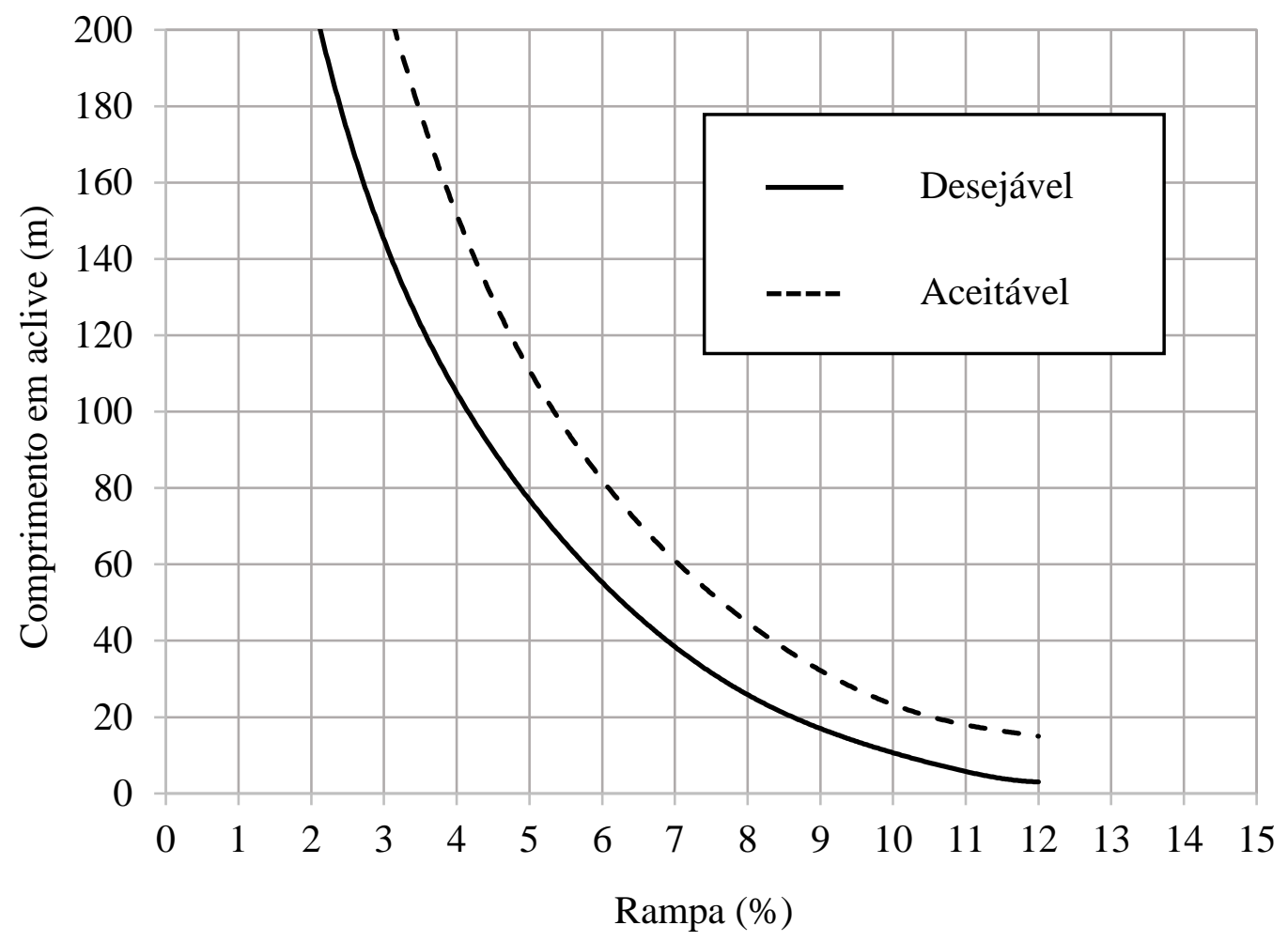

Fonte: Adaptado de AUSTROADS (2014, p. 96).

Uma observação importante deve ser feita a respeito de todos os critérios apresentados anteriormente que se baseiam em limites de extensão de trechos em aclive: normalmente, o cálculo de uma inclinação é feito por meio da divisão entre o desnível e a distância entre os pontos de tangência de uma determinda seção íngreme isolada. No entanto, onde existem rampas consecutivas com diferentes graus de inclinação (todas com o mesmo sentido), ou curvas verticais com grandes raios, o comprimento em aclive deve ser calculado com base no pontos de interseção entre curvas verticais consecutivas (AUSTROADS, 2014).

\subsection{Nível de estresse relacionado aos ciclistas}

O termo estresse pode ser definido como uma mudança, física ou psicológica, de um estado calmo para um estado de excitação, provocada por reações de um determinado indivíduo a situações onde o mesmo se sente ameaçado ou desconfortável (HEALY, 2000). 
Entende-se por estresse relacionado ao transporte cicloviário como o conjunto de respostas dadas pelos ciclistas frente às condições de conforto e segurança proporcionadas pelo espaço onde trafegam. Em outras palavras, trata-se de uma combinação entre as percepções de perigo de cada indivíduo, as características geométricas da via e outros fatores associados ao uso da bicicleta próximo ao tráfego de veículos motorizados, como barulho e emissão de fumaça (FURTH; MERKURIA; NIXON, 2012).

Os dois principais trabalhos encontrados na literatura que propõem avaliações para o nível de estresse relacionado ao transporte cicloviário são: Bicycle Stress Level (BSL), desenvolvido por Sorton e Walsh (1994), e Level of Traffic Stress (LTS), desenvolvido por Furth, Mekuria e Nixon (2012). Ambos os métodos classificam os ciclistas em quatro grupos de acordo com diferentes critérios entre si, de forma que a avaliação do nível de estresse ao qual um determinado ciclista está submetido ao trafegar pela via considere a experiência do próprio ciclista.

A seguir são apresentados os detalhes de cada um destes dois principais modelos para avaliação do nível de estresse relacionado ao transporte cicloviário.

\subsubsection{Modelo de Sorton e Walsh (1994)}

O ponto de partida para a elaboração do modelo de Sorton e Walsh (1994), segundo os próprios autores, foi o trabalho desenvolvido pelo grupo australiano Geelong Planning Committee, em 1978, cujo objetivo era definir o conceito de estresse relacionado ao ciclismo e avaliar a adequação de vias urbanas ao transporte cicloviário. Entretanto, o método proposto pelo grupo australiano possuía uma série de limitações como, por exemplo, o fato de não considerar os diferentes grupos de ciclistas existentes, o que, consequentemente, impediu que fosse verificado o grau de dificuldade, sob a ótica dos próprios ciclistas, ao trafegarem pelas vias avaliadas.

Desta forma, Sorton e Walsh (1994) classificam os ciclistas em quatro grupos distintos:

1) Ciclistas crianças: grupo composto por crianças de até 12 anos de idade, as quais frequentam a escola primária e possuem pouco conhecimento das leis de trânsito. Recomenda-se que os ciclistas pertencentes a este grupo sempre viajem sob a supervisão 
de um responsável ou em vias próximas do local onde residem. Geralmente não utilizam a bicicleta para viagens utilitárias, mas sim para lazer;

2) Ciclistas jovens: grupo composto por jovens entre 13 e 17 anos, cujos níveis de experiência relativos à utilização da bicicleta podem variar muito. Grande parte dos ciclistas pertencentes a este grupo está acostumada a trafegar por vias urbanas;

3) Ciclistas casuais: grupo composto por ciclistas que utilizam a bicicleta de maneira pouco frequente, seja para viagens utilitárias ou por lazer. Muitos dos ciclistas pertencentes a este grupo tendem a evitar vias cujo tráfego de veículos motorizados é intenso; e

4) Ciclistas experientes: grupo composto por ciclistas cuja experiência permite que os mesmos trafeguem por vias arteriais e coletoras, ou seja, utilizando-se de rotas mais diretas e que, consequentemente, sofrem maior influência do tráfego de veículos motorizados.

O modelo para avaliação do nível de estresse proposto por Sorton e Walsh (1994) baseia-se em três variáveis de entrada: volume de veículos motorizados em horário de pico, velocidade dos veículos motorizados e largura da faixa externa da via de tráfego. Os autores alertam ainda para a possibilidade, numa segunda fase de avaliação, de outros fatores serem inclusos, como a presença de estacionamentos e a porcentagem de veículos pesados que trafegam pela via.

A cada uma das três variáveis principais consideradas no modelo deve ser atribuído um valor de nível de estresse que varia de 1 a 5 , sendo 1 a melhor condição e 5 a pior. Estes valores são obtidos por meio de limites propostos pelos autores para a avaliação individual de cada um dos fatores, como detalhado a seguir.

\subsubsection{Volume de tráfego x Nível de estresse}

O volume de tráfego dos veículos motorizados é um dos principais indicadores da compatibilidade do uso da bicicleta na via. Sabe-se, no entanto, que existe uma grande oscilação deste volume durante um período de $24 \mathrm{~h}$. Desta forma, duas medidas podem ser utilizadas para quantificar esta variável: o volume médio diário (VMD) e o volume no horário de pico (VHP). 
Os valores de VHP podem ser determinados, para áreas urbanas, considerando-se uma porcentagem representativa do VMD, usualmente entre 8 e 12\% (DNIT, 2010). Desta forma, a relação direta entre o VMD e o VHP é dada pela Equação 3.1, com VHP em veíc./h, sendo k uma constante referente a esta porcentagem representativa do VMD.

$$
\mathrm{VHP}=\mathrm{k} * \mathrm{VMD}
$$

O volume de veículos motorizados que trafega por faixa é obtido dividindo-se o VHP pelo número de faixas contínuas na via. Para intuito de simplificação, aceita-se que em vias de duplo sentido o volume de tráfego seja dividido igualmente entre as duas faixas de tráfego, isto é, $50 \%$ do VHP para cada uma delas.

A avaliação do nível de estresse em relação ao volume de tráfego em horário de pico pode ser feita com o auxílio da Figura 3.3.

Figura 3.3: Nível de estresse x Volume por faixa.

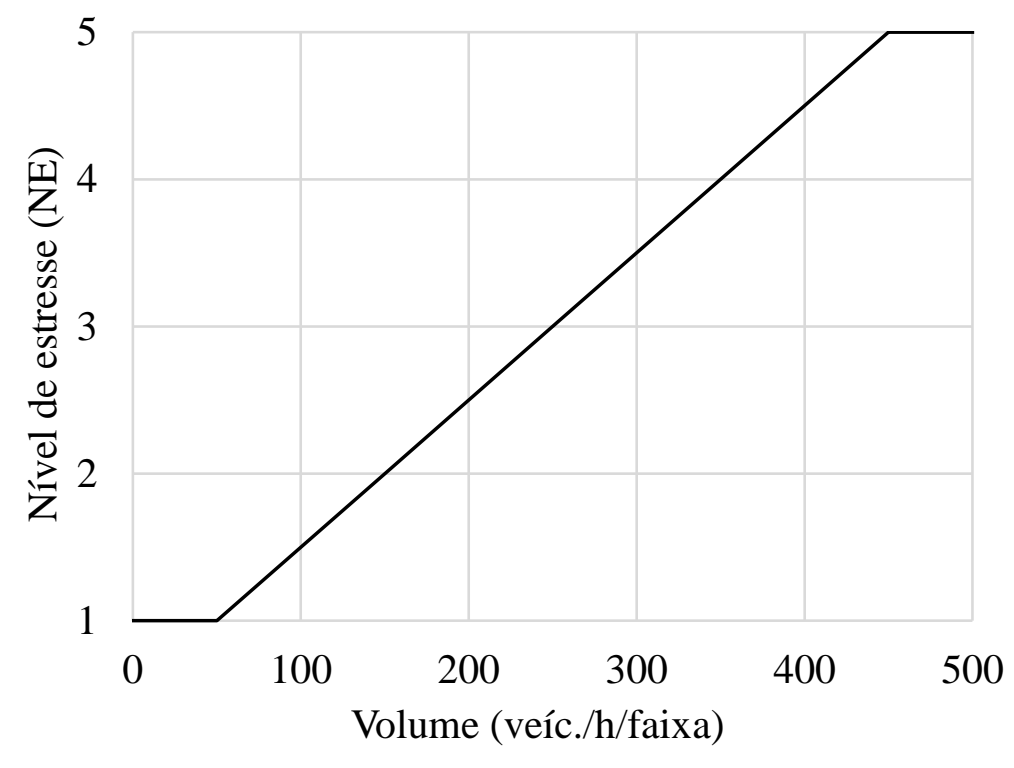

Fonte: Adaptado de SORTON e WALSH (1994, p. 22).

\subsubsection{Velocidade de tráfego x Nível de Estresse}

A velocidade de tráfego dos veículos motorizados, quando muito alta, pode causar efeitos negativos aos ciclistas, como, por exemplo, a perda de equilíbrio durante o movimento. Desta forma, o aumento da velocidade dos automóveis obriga os ciclistas a prestarem mais 
atenção durante o percurso, e, consequentemente, aumenta o nível de estresse ao qual estão submetidos.

A avaliação do nível de estresse em relação à velocidade de tráfego pode ser feita com o auxílio da Figura 3.4.

Figura 3.4: Nível de estresse x Velocidade de tráfego.

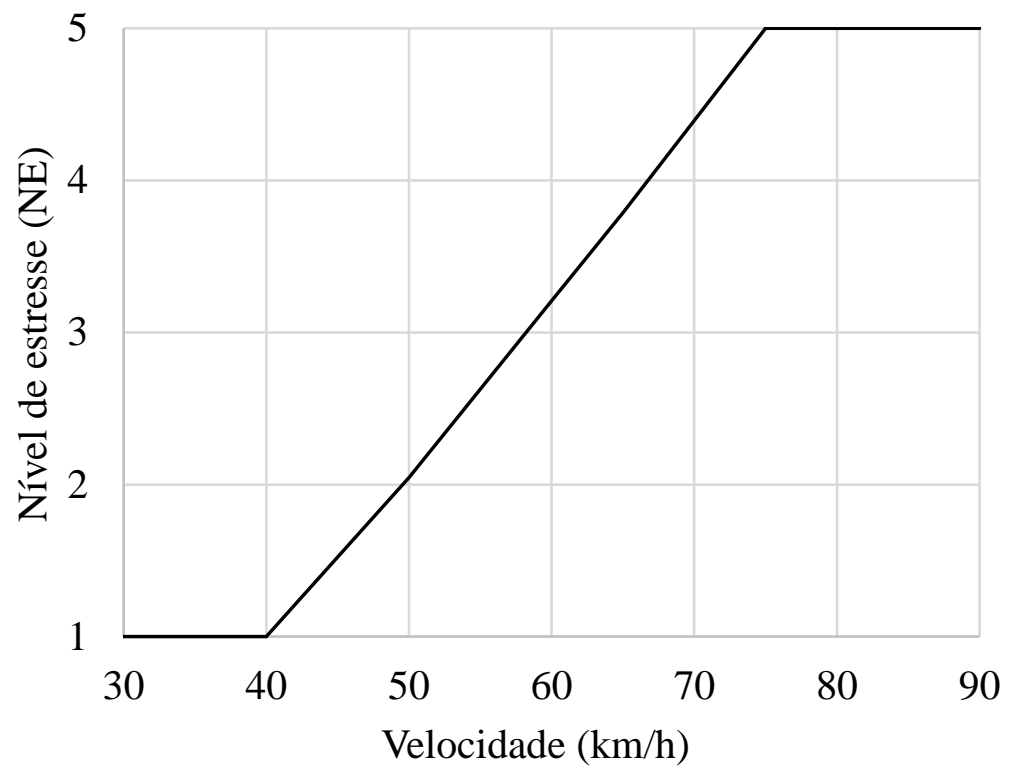

Fonte: Adaptado de SORTON e WALSH (1994, p. 23).

\subsubsection{Largura da faixa externa x Nível de estresse}

De acordo com Sorton e Walsh (1994), a largura da faixa externa pode ser medida como a distância entre o meio-fio ou a sarjeta e a primeira pista de tráfego adjacente a eles. Em casos onde é permitido o estacionamento lateral paralelo à pista de tráfego, a largura da faixa externa é medida a partir do veículo estacionado ou da faixa de estacionamento até a primeira linha da pista de tráfego adjacente a eles.

A avaliação do nível de estresse em relação à largura da faixa externa pode ser feita com o auxílio da Figura 3.5. 
Figura 3.5: Nível de estresse x Largura da faixa externa.

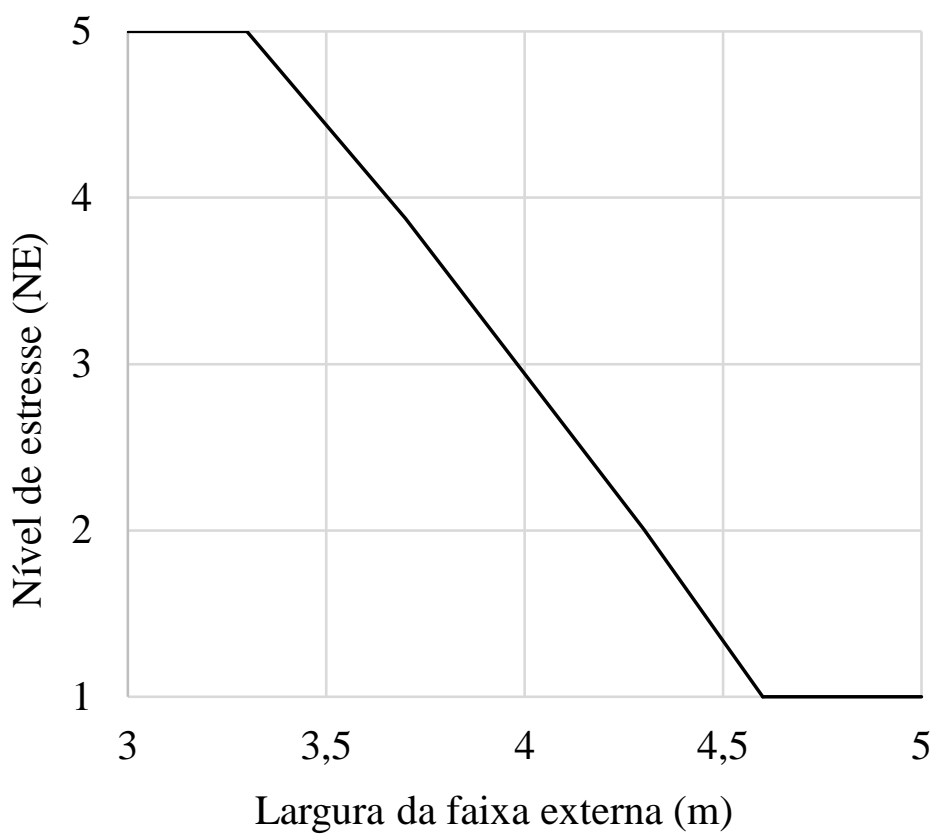

Fonte: Adaptado de SORTON e WALSH (1994, p. 22).

\subsubsection{Avaliação global do nível de estresse}

A avaliação global do nível de estresse pode ser obtida por meio da média aritmética das três avaliações individuais. A interpretação sugerida para cada um dos níveis de estresse é apresentada pela Tabela 3.4.

Dentre as vantagens de utilização do modelo proposto por Sorton e Walsh (1994), destaca-se a facilidade de coleta das variáveis de entrada e de aplicação do próprio modelo. Além disso, a interpretação para a avaliação global do nível de estresse apresentada pelos autores indica a compatibilidade das vias com cada grupo de ciclista.

Com relação às desvantagens, é importante destacar que o modelo deixa de fora, numa primeira fase de avaliação, algumas variáveis importantes, como condições do pavimento, composição do tráfego e existência de facilidades para ciclistas. Além disso, a avaliação do nível de estresse proposta por Sorton e Walsh (1994) não considera as interseções e demais descontinuidades das vias urbanas, mas apenas os segmentos viários que as compõem. 
Tabela 3.4: Interpretação para avaliação global do nível de estresse.

\begin{tabular}{l|l}
\hline \multicolumn{1}{c|}{ Nível de estresse } & \multicolumn{1}{c}{ Interpretação } \\
\hline 1 (Muito Baixo) & $\begin{array}{l}\text { Via razoavelmente segura para todos os tipos de ciclistas, com } \\
\text { exceção de crianças com idade inferior a 10 anos. }\end{array}$ \\
\hline 2 (Baixo) & $\begin{array}{l}\text { Via capaz de acomodar ciclistas experientes e casuais. Podem } \\
\text { precisar de eventuais alterações* ou incluir condições } \\
\text { compensatórias** para acomodar ciclistas jovens. }\end{array}$ \\
\hline 3 (Moderado) & $\begin{array}{l}\text { Via capaz de acomodar ciclistas experientes. Podem incluir } \\
\text { condições compensatórias** para acomodar ciclistas casuais. } \\
\text { Não é recomendada para ciclistas jovens. }\end{array}$ \\
\hline 5 (Alto) & $\begin{array}{l}\text { Via que pode precisar de alterações* ou incluir condições } \\
\text { compensatórias** para acomodar ciclistas experientes. Não é } \\
\text { recomendada para ciclistas casuais ou jovens. }\end{array}$ \\
\hline
\end{tabular}

*Alterações: alargamento de vias, inserção de vias pavimentadas etc.

** Condições compensatórias: alargamento de faixas, pavimentação, construção de ciclofaixas, diminuição do volume de tráfego etc.

Fonte: SORTON e WALSH (1994, p. 19).

\subsubsection{Modelo de Furth, Mekuria e Nixon (2012)}

O modelo desenvolvido por Furth, Mekuria e Nixon (2012), intitulado Level of Traffic Stress (LTS), propõe uma classificação para segmentos viários e interseções composta por quatro níveis de estresse relacionados ao transporte cicloviário, sendo 1 o melhor nível e 4 o pior. Os critérios adotados e os respectivos valores limites para a classificação de cada um destes níveis baseiam-se em diretrizes apresentadas pelo manual holandês Design Manual for Bicycle Traffic (GROOT, 2007). 
O modelo elaborado por Furth, Mekuria e Nixon (2012), assim como o de Sorton e Walsh (1994), atribui a cada um dos níveis de estresse os respectivos grupos de ciclistas capazes de tolerá-los. Desta forma, o LTS baseia-se na classificação da população adulta proposta por Geller (2006):

1) "Fortes e destemidos": ciclistas potencialmente dispostos a trafegar em praticamente qualquer situação de tráfego;

2) "Entusiastas e confiantes": ciclistas potencialmente dispostos a trafegar em vias movimentadas, desde que providas de facilidades ou de espaço necessário à circulação de bicicletas;

3) "Interessados, mas preocupados": ciclistas potenciais que se sentem desconfortáveis ao trafegar por vias com altas velocidades e volumes de veículos motorizados; e

4) "Desinteressados": adultos que não demonstram interesse em utilizar a bicicleta como modo de transporte.

A seguir são apresentados os principais critérios para avaliação do nível de estresse para ciclofaixas, vias de tráfego compartilhado e cruzamentos não sinalizados de acordo com o procedimento proposto por Furth, Mekuria e Nixon (2012).

\subsubsection{Nivel de estresse para ciclofaixas}

As variáveis utilizadas para avaliar o nível de estresse ao qual o ciclista está submetido ao trafegar por uma ciclofaixa, de acordo com o LTS, são: velocidade de tráfego dos veículos motorizados, disponibilidade de espaço, presença de estacionamento lateral paralelo à via e interrupções de fluxo ao longo da ciclofaixa. A avaliação final do LTS é representada pela pior avaliação individual entre estes diversos critérios analisados.

O procedimento para avaliação do LTS para ciclofaixas contíguas às faixas de estacionamentos de veículos motorizados é apresentado pela Tabela 3.5. Já o procedimento para avaliação do LTS para ciclofaixas não contíguas às faixas de estacionamentos de veículos motorizados é apresentado pela Tabela 3.6. 
Tabela 3.5: LTS para ciclofaixas contíguas à faixa de estacionamento.

\begin{tabular}{|c|c|c|c|c|c|}
\hline & Critério & LTS 1 & LTS 2 & LTS 3 & LTS 4 \\
\hline \multirow{4}{*}{ 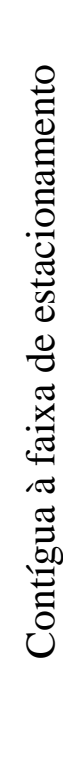 } & Número de faixas de tráfego por direção & 1 & - & $\geq 2$ & - \\
\hline & $\begin{array}{l}\text { Alcance do meio-fio (soma das larguras } \\
\text { da ciclofaixa e da faixa de } \\
\text { estacionamento, incluindo sarjeta } \\
\text { pavimentada) em metros }\end{array}$ & $\geq 4,60$ & $\begin{array}{l}4,11- \\
4,59^{*}\end{array}$ & $\leq 4,10$ & - \\
\hline & $\begin{array}{l}\text { Limite de velocidade (permitido ou } \\
\text { aferido) em } \mathrm{km} / \mathrm{h}\end{array}$ & $\leq 40$ & $41-50$ & $51-64$ & $\geq 65$ \\
\hline & $\begin{array}{lcccc}\text { Interrupção } & \text { de fluxo } & \text { ao longo da } \\
\text { ciclofaixa } & \text { (comum } & \text { em } & \text { zonas } \\
\text { comerciais) } & & & & \end{array}$ & Rara & - & Frequente & - \\
\hline
\end{tabular}

*Em vias cujos limites de velocidade não ultrapassam $40 \mathrm{~km} / \mathrm{h}$, localizadas em áreas não comerciais, é atribuído LTS 2 independentemente do alcance do meio-fio.

Fonte: Adaptado de FURTH, MEKURIA e NIXON (2012, p. 18).

Tabela 3.6: LTS para ciclofaixas não contíguas à faixa de estacionamento.

\begin{tabular}{|c|c|c|c|c|c|}
\hline & Critério & LTS 1 & LTS 2 & LTS 3 & LTS 4 \\
\hline \multirow{4}{*}{ 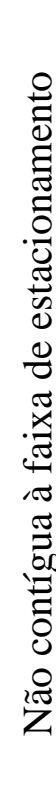 } & Número de faixas de tráfego por direção & 1 & $\begin{array}{l}\text { 2, com } \\
\text { faixa } \\
\text { separadora }\end{array}$ & $\begin{array}{c}\geq 2, \text { ou } \\
\text { sem faixa } \\
\text { separadora }\end{array}$ & - \\
\hline & $\begin{array}{l}\begin{array}{l}\text { Alcance do meio-fio (largura da } \\
\text { ciclofaixa, incluindo } \\
\text { pavimentada) em metros }\end{array} \\
\text { sarjeta }\end{array}$ & $\geq 1,80$ & $<1,80$ & - & - \\
\hline & $\begin{array}{l}\text { Limite de velocidade (permitido ou } \\
\text { aferido) } \mathrm{em} \mathrm{km} / \mathrm{h}\end{array}$ & $\leq 50$ & - & $51-64$ & $\geq 65$ \\
\hline & $\begin{array}{l}\begin{array}{l}\text { Interrupção } \\
\text { ciclofaixa } \\
\text { comerciais) }\end{array} \\
\text { (comum }\end{array}$ & Rara & - & Frequente & - \\
\hline
\end{tabular}


O volume de veículos motorizados, no caso das ciclofaixas, não é identificado como uma variável de grande importância, pois o tráfego de ciclistas se dá em facilidades exclusivas. Desta forma, é mais conveniente avaliar o número de faixas de tráfego por direção, cujo aumento promove maiores variações na velocidade de tráfego e nas manobras de ultrapassagem, afetando a segurança dos ciclistas que trafegam de maneira contígua à via de tráfego (FURTH; MEKURIA; NIXON, 2012).

\subsubsection{Nivel de estresse para vias de uso compartilhado}

As variáveis utilizadas para avaliar o nível de estresse ao qual o ciclista está submetido ao trafegar por vias de uso compartilhado, de acordo com o LTS, são: velocidade de tráfego dos veículos motorizados e número de faixas de tráfego por direção, como apresenta a Tabela 3.7. É válido destacar ainda que, de acordo com Furth, Mekuria e Nixon (2012), uma via compartilhada sem faixa de separação dos sentidos de fluxo disposta no centro da via é menos estressante se comparada a uma via compartilhada que dispõe deste equipamento de sinalização horizontal. Isto é justificado pelo fato de que a ausência desta faixa faz com que os motoristas se posicionem ao centro da via, reservando as margens ao tráfego de bicicletas.

Tabela 3.7: LTS para vias de uso compartilhado.

\begin{tabular}{c|c|c|c|c}
\hline \multirow{2}{*}{$\begin{array}{c}\text { Limite de } \\
\text { velocidade } \\
(\mathrm{km} / \mathrm{h})\end{array}$} & $\begin{array}{c}\text { Sem faixa } \\
\text { separadora }\end{array}$ & 1 & 2 & $\geq 3$ \\
\cline { 2 - 5 }$\leq 40$ & LTS 1 & LTS 2 & LTS 3 & LTS 4 \\
50 & LTS 2 & LTS 3 & LTS 4 & LTS 4 \\
$\geq 55$ & LTS 4 & LTS 4 & LTS 4 & LTS 4 \\
\hline
\end{tabular}

Fonte: Adaptado de FURTH, MEKURIA e NIXON (2012, p. 21).

\subsubsection{Nível de estresse para cruzamentos não sinalizados}

As variáveis utilizadas para avaliar o nível de estresse ao qual o ciclista está submetido ao trafegar por cruzamentos não sinalizados, de acordo com o LTS, são: velocidade de tráfego 
dos veículos motorizados e número de faixas de tráfego por direção da via a ser cruzada, como apresenta a Tabela 3.8 .

Tabela 3.8: LTS para cruzamentos não sinalizados.

\begin{tabular}{c|c|c|c}
\hline \multirow{2}{*}{$\begin{array}{c}\text { Limite de } \\
\text { velocidade da via a }\end{array}$ ser cruzada $(\mathrm{km} / \mathrm{h})$} & \multicolumn{3}{|c}{ Número de faixas de tráfego, por direção, da via a ser cruzada } \\
\cline { 2 - 4 } & $\leq 3$ & $4-5$ & $\geq 6$ \\
\hline 40 & LTS 1 & LTS 2 (1)* & LTS 4 (2)* \\
50 & LTS 1 & LTS 2 & LTS 4 (3)* \\
55 & LTS 2 & LTS 3 & LTS 4 \\
$\geq 65$ & LTS 3 & LTS 4 & LTS 4 \\
\hline
\end{tabular}

*Valores em parênteses se aplicam em casos de existência de refúgios para pedestres em canteiros centrais.

Fonte: Adaptado de FURTH, MEKURIA e NIXON (2012, p. 27).

\subsubsection{Interpretação do LTS}

As interpretações sugeridas por Furth, Mekuria e Nixon (2012) para cada um dos LTS são apresentadas pela Tabela 3.9.

Dentre as vantagens de utilização do modelo proposto por Furth, Mekuria e Nixon (2012), destaca-se o fato de que o mesmo propõe diferentes avaliações para facilidades exclusivas aos ciclistas e para vias de uso compartilhado, incorporando a cada uma delas as respectivas variáveis consideradas relevantes. Além disso, diferentemente do modelo proposto por Sorton e Walsh (1994), o LTS propõe uma avaliação para cruzamentos não sinalizados.

Com relação às desvantagens, é válido destacar que o modelo deixa de fora variáveis importantes, como condições do pavimento e composição do tráfego. Além disso, para a avaliação do nível de estresse ao qual o ciclista está submetido ao trafegar por vias de tráfego compartilhado, o modelo não considera o volume de veículos motorizados, um dos principais indicadores da compatibilidade das vias urbanas com o transporte cicloviário. 
Tabela 3.9: Interpretação para o LTS.

\begin{tabular}{l|l}
\hline Nível de estresse & \multicolumn{1}{c}{ Interpretação } \\
\hline LTS 1 & $\begin{array}{l}\text { A via apresenta baixos níveis de estresse relacionados ao tráfego, } \\
\text { demandando pouca atenção dos ciclistas e se apresentando como uma } \\
\text { interessante alternativa ao transporte cicloviário. Adequada a quase } \\
\text { todos os ciclistas, incluindo crianças hábeis a cruzar interseções. } \\
\text { Pode apresentar facilidades exclusivas para ciclistas. Em casos de } \\
\text { tráfego compartilhado, a diferença de velocidades entre bicicletas e } \\
\text { veículos motorizados é pequena. Em casos onde é permitido } \\
\text { estacionamento lateral paralelo, ciclistas possuem amplo espaço } \\
\text { operacional, evitando conflitos com aberturas de portas dos } \\
\text { automóveis. Interseções seguras. }\end{array}$ \\
\hline LTS 2 & $\begin{array}{l}\text { A via apresenta baixos níveis de estresse relacionados ao tráfego, } \\
\text { porém demanda mais atenção do que o esperado no caso de crianças. } \\
\text { Pode apresentar facilidades exclusivas para ciclistas. Em casos de } \\
\text { tráfego compartilhado, a interação entre bicicletas e veículos } \\
\text { motorizados ocorre ocasionalmente, mas a diferença de velocidades } \\
\text { entre estes modos de transporte é pequena. Caso uma ciclofaixa seja } \\
\text { disposta entre a faixa de tráfego a faixa reservada à conversão a } \\
\text { direita, a prioridade deve ser dada ao tráfego de bicicletas. } \\
\text { Cruzamentos são seguros à maioria dos ciclistas adultos. }\end{array}$ \\
\hline LTS 3 4 & $\begin{array}{l}\text { A disposição de ciclofaixas contíguas à faixa de tráfego pode } \\
\text { requerer pequena interação com o tráfego de veículos motorizados, } \\
\text { cuja velocidade de circulação é moderadamente alta. Em casos de } \\
\text { tráfego compartilhado, a interação entre bicicletas e automóveis } \\
\text { ocorre de maneira moderada. Cruzamentos podem ser relativamente } \\
\text { estressantes, mas ainda são considerados seguros à maioria dos } \\
\text { ciclistas adultos. }\end{array}$ \\
\hline $\begin{array}{l}\text { a disposição de ciclofaixas contíguas à faixa de tráfego pode } \\
\text { cuja velocidade de circulação é alta. Em casos de tráfego } \\
\text { compartilhado, a interação entre bicicletas e automóveis ocorre de } \\
\text { maneira frequente. Cruzamentos considerados perigosos. }\end{array}$ \\
\hline a
\end{tabular}

Fonte: FURTH, MEKURIA e NIXON (2012, p. 14).

\subsection{Nível de serviço para bicicletas}

O HCM define nível de serviço relacionado aos veículos motorizados como uma medida qualitativa capaz de descrever condições operacionais dentro de um fluxo de tráfego, baseando- 
se em variáveis como velocidade, tempo de viagem, liberdade de manobra, interrupções de tráfego e percepções de conforto por parte dos motoristas e passageiros (TRB, 2010).

O conceito de nível de serviço apresentado pelo HCM pode ser expandido ao transporte cicloviário. Desta forma, entende-se por nível de serviço para bicicletas como uma medida capaz de descrever a qualidade operacional oferecida aos ciclistas que trafegam por vias urbanas, isto é, as condições existentes à circulação de bicicletas. A avaliação do nível de serviço pode ser feita para o tráfego ao longo de facilidades como ciclofaixas e ciclovias, e, em alguns casos, até mesmo para vias de uso compartilhado (PROVIDELO, 2011).

Os modelos para avaliação do nível de serviço para bicicletas podem ser classificados de diferentes maneiras. LaMondia e Moore (2015) subdividem estes modelos em quatro grupos distintos, de acordo com a maneira como cada um deles pondera os fatores avaliados:

1) Modelos baseados em índices: são aqueles que avaliam o nível de serviço para bicicletas por meio de uma equação, onde a cada um dos fatores avaliados é atribuído um único peso;

2) Modelos de interação: são métodos semelhantes aos baseados em índices, porém utilizam-se de equações mais complexas, como regressões não lineares, permitindo interações entre os diferentes fatores avaliados;

3) Modelos de pontuação: são aqueles nos quais pontos são atribuídos aos segmentos viários de acordo com as condições de cada fator avaliado ao longo do mesmo. Fatores mais importantes são ponderados com mais pontos. O nível de serviço para bicicletas é avaliado de acordo com a somatória final destes pontos; e

4) Modelos de escala: são métodos semelhantes aos de pontuação, porém o nível de serviço para bicicletas é avaliado de acordo com a média dos pontos atribuídos a cada fator, e não de acordo com a somatória final, fazendo com que cada um destes fatores seja ponderado de maneira idêntica.

A seguir são apresentados os principais modelos encontrados na literatura para avaliação do nível de serviço para bicicletas. 


\subsection{1 Índice de Condição da Via (ICV) de Epperson-Davis (1994)}

O modelo para avaliação da qualidade do serviço das vias para o transporte cicloviário desenvolvido por Epperson-Davis é conhecido como Índice de Condição da Via (ICV). O ponto de partida para a elaboração deste modelo foi outro trabalho desenvolvido pelo próprio Davis, no final da década de 80 , cujo objetivo era relacionar as condições de segurança das vias com registros de ocorrência de acidentes e demais conflitos envolvendo ciclistas (EPPERSON, 1994).

O cálculo do ICV é feito por meio da Equação 3.2, apresentada a seguir.

$$
\mathrm{ICV}=\left[\frac{\mathrm{VMD}}{(\mathrm{f} * 3100)}\right]+\left(\frac{\mathrm{V}}{48}\right)+\left\{\left(\frac{\mathrm{V}}{48}\right) *[(4,25-\mathrm{L}) * 1,635]\right\}+\sum \mathrm{FP}+\sum \mathrm{FL}
$$

Em que:

VMD: volume médio diário (veíc./h);

f: número de faixas de tráfego;

V: velocidade de tráfego permitida $(\mathrm{km} / \mathrm{h})$;

L: largura da faixa externa (m); e

FP e FL: fatores relacionados, respectivamente, ao pavimento e à localização.

Os valores de FP e FL são apresentados, respectivamente, pelas Tabelas 3.10 e 3.11.

Tabela 3.10: Fatores relacionados ao pavimento - Epperson-Davis (1994).

\begin{tabular}{l|c}
\hline \multicolumn{1}{c|}{ Fator } & Valor do FP \\
\hline Rachaduras & 0,50 \\
Remendos & 0,25 \\
Desgaste provocado pelo uso & 0,25 \\
Buracos & 0,25 a $0,50^{*}$ \\
Acostamento irregular & 0,25 a $0,50^{*}$ \\
Cruzamento com ferrovia & 0,25 \\
Existência de equipamentos de drenagem & 0,50 \\
\hline
\end{tabular}

*Valor atribuído de acordo com a gravidade do fator. 
Tabela 3.11: Fatores relacionados à localização - Epperson-Davis (1994).

\begin{tabular}{l|c}
\hline \multicolumn{1}{c|}{ Fator } & Valor do FL \\
\hline 1. Movimentação transversal à via & 0,75 \\
\hline Estacionamento em ângulo & 0,25 \\
Estacionamento paralelo & 0,25 \\
Faixa de conversão à direita & 0,50 \\
Canteiro central (ininterrupto) & 0,35 \\
Canteiro central (com baias de conversão à esquerda) & 0,20 \\
Faixa central para conversão & 0,75 \\
Acostamento pavimentado ou ciclovia & 0,50 \\
\hline 2. Alinhamento da via & 0,20 \\
\hline Declividade acentuada & 0,35 \\
Declividade moderada & 0,50 \\
Curvas horizontais frequentes & \\
Distância de visibilidade reduzida & 0,25 \\
\hline 3. Tipo de uso do solo & 0,25 \\
\hline Uso do solo predominantemente comercial & 0,25 \\
Uso do solo predominantemente industrial & \\
Uso do solo residencial com muitas entradas de garagem & \\
\hline
\end{tabular}

Fonte: EPPERSON (1994, p. 10).

A classificação dos segmentos viários segundo sua qualidade de serviço para o transporte cicloviário, de acordo com os valores do ICV de Epperson-Davis, é apresentada pela Tabela 3.12.

Tabela 3.12: Classificação dos segmentos viários de acordo com seu ICV - Epperson-Davis (1994).

\begin{tabular}{c|c}
\hline ICV & Classificação \\
\hline 0 a 3 & Excelente \\
3 a 4 & Bom \\
4 a 5 & Regular \\
$>5$ & Ruim \\
\hline
\end{tabular}

Fonte: EPPERSON (1994, p. 11). 
Dentre as vantagens de utilização do ICV de Epperson-Davis, destaca-se o fato deste modelo avaliar cada segmento viário separadamente, classificando-o de acordo com sua condição para acomodar o tráfego de bicicletas. Além disso, são consideradas nesta avaliação variáveis de diferentes naturezas, ou seja, relacionadas ao tráfego de veículos motorizados, às condições geométricas da via e ao ambiente onde a mesma está inserida.

Com relação às desvantagens de utilização do ICV de Epperson-Davis, destaca-se o fato deste modelo não avaliar as interseções e demais descontinuidades nas vias urbanas, mas apenas as condições dos segmentos viários. Além disso, alguns autores criticam a subjetividade de avaliação dos fatores relacionados ao pavimento e à localização no cálculo do ICV, isto é, um único segmento viário avaliado por planejadores diferentes pode apresentar também diferentes valores de ICV (LANDIS, 1996).

\subsubsection{Modelo de Dixon (1996)}

O procedimento proposto por Dixon (1996) foi desenvolvido com o objetivo de auxiliar na elaboração do plano de mobilidade da cidade de Gainesville (EUA). Trata-se de um modelo baseado em um sistema de pontuação criado pela própria autora.

O conjunto de variáveis considerado no sistema de pontuação foi subdividido em seis categorias: existência de facilidades para bicicletas, risco de conflitos envolvendo ciclistas, diferença de velocidades entre bicicletas e veículos motorizados, avaliação do nível de serviço para os veículos motorizados, manutenção das vias, e existência de iniciativas voltadas ao transporte cicloviário (DIXON, 1996).

A Tabela 3.13 apresenta os critérios para avaliação das variáveis selecionadas e os pontos atribuídos a cada uma elas. Para uma explicação mais detalhada dos itens considerados no sistema de pontuação o leitor deve consultar Monteiro e Campos (2011). 
Tabela 3.13: Sistema de pontuação para avaliação do nível de serviço - Dixon (1996).

\begin{tabular}{|c|c|c|}
\hline Categoria & Critérios & Pontos \\
\hline \multirow{4}{*}{$\begin{array}{l}\text { Facilidades para bicicletas } \\
\quad(\text { Valor máximo }=10)\end{array}$} & Ciclofaixa - faixa externa $\leq 3,66 \mathrm{~m}$ & 0 \\
\hline & Ciclofaixa - faixa externa $3,67 \mathrm{~m}-4,27 \mathrm{~m}$ & 5 \\
\hline & Ciclofaixa - faixa externa $\geq 4,27 \mathrm{~m}$ & 6 \\
\hline & Ciclovia & 4 \\
\hline \multirow{6}{*}{$\begin{array}{c}\text { Conflitos } \\
(\text { Valor máximo }=4)\end{array}$} & Poucas entradas de garagem e cruzamentos & 1 \\
\hline & Ausência de barreiras & 0,5 \\
\hline & Ausência de estacionamento lateral & 1 \\
\hline & Presença de canteiros centrais & 0,5 \\
\hline & Distância de visibilidade não obstruída & 0,5 \\
\hline & Tratamento de interseções para o ciclismo & 0,5 \\
\hline \multirow{3}{*}{$\begin{array}{c}\text { Diferença de velocidades } \\
\text { entre bicicletas e veículos } \\
\text { motorizados } \\
(\text { Valor máximo }=2)\end{array}$} & $>48 \mathrm{~km} / \mathrm{h}$ & 0 \\
\hline & $33-48 \mathrm{~km} / \mathrm{h}$ & 1 \\
\hline & $24-32 \mathrm{~km} / \mathrm{h}$ & 2 \\
\hline \multirow{3}{*}{$\begin{array}{l}\text { Nível de serviço para } \\
\text { veículos motorizados } \\
(\text { Valor máximo }=2)\end{array}$} & $\mathrm{NS}=\mathrm{E}$ ou $\mathrm{F}$ (ou 6 ou mais faixas de tráfego) & 0 \\
\hline & NS $=$ D (e menos de 6 faixas de tráfego $)$ & 1 \\
\hline & $\mathrm{NS}=\mathrm{A}, \mathrm{B}$ ou $\mathrm{C}$ (e menos que 6 faixas de tráfego) & 2 \\
\hline \multirow{3}{*}{$\begin{array}{c}\text { Manutenção das vias } \\
(\text { Valor máximo = 2) }\end{array}$} & Problemas graves ou frequentes & -1 \\
\hline & Problemas pequenos e menos frequentes & 0 \\
\hline & Ausência de problemas & 2 \\
\hline \multirow{2}{*}{$\begin{array}{c}\text { Iniciativas voltadas ao } \\
\text { transporte cicloviário } \\
(\text { Valor máximo }=1) \\
\end{array}$} & Sem iniciativas & 0 \\
\hline & Iniciativas existentes & 1 \\
\hline
\end{tabular}

Fonte: DIXON (1996, p. 2).

O cálculo do índice de uma determinada via de tráfego é efetuado por meio da média ponderada entre os comprimentos de cada segmento viário que a compõem, cujos pesos são representados pelos próprios índices (somatórias finais) destes segmentos, como apresenta a Equação 3.3. 
Em que:

$$
I_{\text {via }}=\frac{\sum_{i=1}^{n}\left(I_{i} * L_{i}\right)}{\sum_{i=1}^{n} L_{i}}
$$

Ivia: índice da via;

Ii índice (somatória) do segmento i;

$\mathrm{L}_{\mathrm{i}}$ : comprimento do segmento $\mathrm{i}$;

A classificação da via avaliada quanto ao seu nível de serviço para bicicletas é dada de acordo com o valor calculado para o índice desta via, ao qual é atribuída uma condição que varia de $\mathrm{A}$ até $\mathrm{F}$, sendo $\mathrm{A}$ a melhor condição e $\mathrm{F}$ a pior, de acordo com os intervalos apresentados pela Tabela 3.14.

Dentre as vantagens de utilização do modelo proposto por Dixon (1996) para avaliação do nível de serviço para bicicletas, destacam-se: simplicidade no levantamento dos dados de entrada e inclusão de variáveis raramente empregadas na avaliação da qualidade de serviço das vias para o transporte cicloviário, como tratamento de interseções, manutenção das vias e existência de programas e iniciativas voltadas ao ciclismo.

Com relação às desvantagens, os resultados da utilização do modelo de Dixon em alguns estudos de caso apontam que o mesmo não é indicado para a avaliação do nível de serviço das vias, em relação ao transporte cicloviário, para cidades brasileiras de porte médio. Isto se deve ao fato de que o sistema de pontuação proposto por Dixon dá especial atenção à existência de facilidades para ciclistas, raramente empregadas no Brasil, onde a maior parte do tráfego de bicicletas ocorre de maneira compartilhada com outros modos de transporte (KIRNER, 2006; MAGALHÃES; CAMPOS; BANDEIRA, 2015). 
Tabela 3.14: Interpretação para as faixas de nível de serviço - Dixon (1996).

\begin{tabular}{|c|c|c|}
\hline $\mathrm{I}_{\mathrm{via}}$ & $\begin{array}{l}\text { Nível de } \\
\text { Serviço }\end{array}$ & Descrição das vias \\
\hline 17 a 21 & A & $\begin{array}{l}\text { Vias seguras e atrativas, onde crianças podem usufruir sem a necessidade de } \\
\text { supervisão de um adulto. Baixo índice de interação com veículos motorizados em } \\
\text { facilidades para ciclistas contíguas à via ou segregadas. Bom nível de estrutura } \\
\text { funcional e ótimas condições de pavimento. }\end{array}$ \\
\hline 14 a 17 & B & $\begin{array}{l}\text { Vias adequadas para qualquer grupo de ciclista, onde crianças podem usufruir } \\
\text { sem a necessidade de supervisão de um adulto. Baixo índice de interação com } \\
\text { veículos motorizados em facilidades para ciclistas contíguas à via ou segregadas. } \\
\text { Bom nível de estrutura funcional e boas condições de conservação. }\end{array}$ \\
\hline 11 a 14 & $\mathrm{C}$ & $\begin{array}{l}\text { Vias adequadas à maioria dos ciclistas. Nível intermediário de interação com } \\
\text { veículos motorizados. Existência de facilidades para ciclistas, na maioria das } \\
\text { vezes, contíguas à via, sendo que em locais menos adequados à circulação de } \\
\text { bicicletas podem existir facilidades segregadas. A via é normalmente } \\
\text { caracterizada por combinações entre baixas velocidades e baixo volume de } \\
\text { tráfego motorizado, raras ocorrências de conflitos e boas condições de superfície. }\end{array}$ \\
\hline 7 a 11 & $\mathrm{D}$ & $\begin{array}{l}\text { Vias adequadas à circulação de ciclistas experientes. Estas vias podem não dispor } \\
\text { de estruturas funcionais voltadas ao transporte cicloviário. A interação com } \\
\text { veículos motorizados varia entre moderada e alta. Podem ou não apresentar } \\
\text { facilidades para ciclistas. No caso da ausência destas facilidades, a via deve } \\
\text { apresentar cinco ou mais características que permitam que os ciclistas } \\
\text { compartilhem a via com veículos motorizados (baixas velocidades e volumes de } \\
\text { veículos motorizados, poucos conflitos ou boas condições de pavimento). No } \\
\text { caso de existir uma facilidade para ciclistas contígua à via, espera-se que esta via } \\
\text { apresente características que a tornem inadequada para alguns grupos de ciclistas, } \\
\text { como altas velocidades e volumes de veículos motorizados, assim como conflitos } \\
\text { frequentes. }\end{array}$ \\
\hline 3 a 7 & $\mathrm{E}$ & $\begin{array}{l}\text { Via requer cuidado redobrado a todos os grupos de ciclistas. Alto índice de } \\
\text { interação com veículos motorizados. Podem ou não apresentar facilidades para } \\
\text { ciclistas. No caso da ausência destas facilidades, a via deve apresentar duas ou } \\
\text { mais características que permitam que os ciclistas compartilhem as vias com os } \\
\text { veículos motorizados (baixas velocidades e volumes de veículos motorizados, } \\
\text { poucos conflitos ou boas condições de pavimento). Conservação regular. } \\
\text { Inadequadas para ciclistas menos experientes. }\end{array}$ \\
\hline$<3$ & $\mathrm{~F}$ & $\begin{array}{l}\text { Via inadequada ao ciclismo. Altos volumes de tráfego de veículos motorizados. } \\
\text { Oferece risco iminente a todos os grupos de ciclistas. }\end{array}$ \\
\hline
\end{tabular}

Fonte: Adaptado de DIXON (1996, p 5-6). 


\subsubsection{Nível de Serviço para Bicicletas (NSB) de Landis et al. (1997)}

O modelo desenvolvido por Landis et al. (1997) para avaliação do nível de serviço para bicicletas baseia-se em um estudo elaborado pelos próprios autores na cidade de Tampa, Flórida (EUA). Neste estudo, aproximadamente 150 ciclistas avaliaram, de acordo com suas percepções de segurança e conforto, a qualidade de um percurso fechado com cerca de $27 \mathrm{~km}$ de extensão subdividido em 30 segmentos viários com condições de tráfego e características geométricas diferentes entre si.

Os resultados da pesquisa permitiram a calibração de um modelo matemático, por meio de técnicas estatísticas, utilizado para o cálculo do Nível de Serviço para Bicicletas (NSB), como apresentado pela Equação 3.4.

$$
\mathrm{NSB}=0,607 \ln \left(\frac{\mathrm{Vol}_{15}}{\mathrm{f}}\right)+0,901 \ln [\mathrm{V} *(1+\% \mathrm{P})]+6,51\left(\mathrm{PC}_{5}\right)-0,005(\mathrm{~L})^{2}-1,833
$$

Em que:

Vol 15 : volume de tráfego direcional em um intervalo de 15 minutos;

f: número de faixas de tráfego;

$\mathrm{V}$ : velocidade de tráfego permitida $(\mathrm{km} / \mathrm{h})$;

\%: porcentagem de veículos pesados;

$\mathrm{PC}_{5}$ : condição da superfície do pavimento, avaliada sob uma escala de 1 a 5, de acordo com o Sistema de Monitoramento de Desempenho de Rodovia (HPMS) da FHWA;

L: largura da faixa externa $(\mathrm{m})$.

O nível de serviço para bicicletas, segundo o modelo proposto por Landis et al. (1997), é determinado pelo valor do NSB calculado, de acordo com os intervalos apresentados na Tabela 3.15.

A principal vantagem de utilização do NSB proposto por Landis et al. (1997) é o fato deste modelo ser calibrado de acordo com respostas dadas pelos ciclistas com relação às condições reais de circulação. Desta maneira, é possível uma representação mais fiel das percepções de segurança e conforto dos próprios ciclistas, contrapondo-se à premissa de outros modelos que têm por base estimativas e aproximações (KIRNER, 2006). 
Com relação às desvantagens de utilização do modelo proposto por Landis et al. (1997), destaca-se a dificuldade da coleta das variáveis de entrada, principalmente aquelas relacionadas ao pavimento e à composição do tráfego. Além disso, este modelo não inclui a avaliação de interseções, limitando a análise da qualidade de serviço aos segmentos viários.

Tabela 3.15: Nível de serviço para bicicletas de Landis et al. (1997).

\begin{tabular}{c|c}
\hline Nível de serviço & Valor NSB \\
\hline A & $<1,50$ \\
B & $1,50-2,49$ \\
C & $2,50-3,49$ \\
D & $3,50-4,49$ \\
E & $4,40-5,49$ \\
F & $\geq 5,50$ \\
\hline
\end{tabular}

Fonte: LANDIS et al. (1997, p. 127).

\subsubsection{Bicycle Compatibility Index (BCI) de Harkey et al. (1998)}

O modelo proposto por Harkey et al. (1998), intitulado Bicycle Compatibility Index (BCI), tem como objetivo avaliar a qualidade das vias para comportar o tráfego compartilhado entre bicicletas e veículos motorizados. As variáveis consideradas neste modelo são: volume, velocidade e composição do tráfego de veículos motorizados, existência de ciclofaixa adjacente à via de tráfego, largura da via, tipo de uso de solo, presença de estacionamentos e densidade de entradas de garagem ao longo da via.

A coleta de informações para a elaboração do BCI, realizada nas cidades norteamericanas de Olympia, Austin e Chapel Hill, contou com mais de 200 participantes entre pedestres e ciclistas, os quais opinaram de acordo com suas percepções de conforto frente a cenários com diferentes condições geométricas e operacionais mostrados pelos pesquisadores com o auxílio de gravações em vídeo. Os resultados da pesquisa permitiram a calibração de um modelo matemático, por meio de regressão linear, utilizado para o cálculo do BCI, conforme apresentado pelas Equações 3.5 e 3.6.

$$
\begin{aligned}
\mathrm{BCI}= & 3,670-0,966 * \mathrm{BL}-0,410 * \mathrm{BLW}-0,498 * \mathrm{CLW}+0,002 * \mathrm{CLV}+ \\
& 0,0004 * \mathrm{OLV}+0,022 * \mathrm{SPD}+0,506 * \mathrm{PKG}-0,264 * \mathrm{AR}+\mathrm{AF}
\end{aligned}
$$




$$
\mathrm{AF}=\mathrm{f}_{\mathrm{t}}+\mathrm{f}_{\mathrm{p}}+\mathrm{f}_{\mathrm{rt}}
$$

Em que:

BL: existência de ciclofaixa $\{$ não $=0 ; \operatorname{sim}=1\}$;

BLW: largura da ciclofaixa (m);

CLW: largura da faixa de tráfego adjacente à ciclofaixa (m);

CLV: volume de veículos na faixa de tráfego adjacente à ciclofaixa (veíc./h/faixa);

OLV: volume de veículos nas demais faixas de tráfego com mesmo sentido de circulação da ciclofaixa (veíc./h/faixa);

SPD: $85 \%$ da velocidade de tráfego $(\mathrm{km} / \mathrm{h})$;

PKG: existência de estacionamento lateral paralelo \{ocupação longitudinal da via menor que $30 \%=0$; ocupação longitudinal da via maior que $30 \%=1\}$;

AR: tipo de uso do solo $\{$ residencial $=1 ;$ outro $=0\}$;

AF: somatória dos fatores de ajustamento;

$\mathrm{f}_{\mathrm{t}}$ : fator de ajustamento para veículos pesados;

$\mathrm{f}_{\mathrm{p}}$ : fator de ajustamento para estacionamentos; e

$\mathrm{f}_{\mathrm{rt}}$ : fator de ajustamento para conversões à direita.

Os fatores de ajustamento são apresentados pelas Tabela 3.16, 3.17 e 3.18.

Tabela 3.16: Fator de ajustamento para veículos pesados - BCI.

\begin{tabular}{c|c}
\hline Volume de veículos pesados (veíc./h/faixa) & $\mathrm{f}_{\mathrm{t}}$ \\
\hline$<10$ & 0,00 \\
$10-19$ & 0,10 \\
$20-29$ & 0,20 \\
$30-59$ & 0,30 \\
$60-119$ & 0,40 \\
$\geq 120$ & 0,50 \\
\hline
\end{tabular}

Fonte: HARKLEY et al. (1998, p. 54). 
Tabela 3.17: Fator de ajustamento para estacionamentos - BCI.

\begin{tabular}{c|c}
\hline Limite de tempo de estacionamento & $\mathrm{f}_{\mathrm{p}}$ \\
\hline$\leq 15 \mathrm{~min}$ & 0,60 \\
$16-30 \mathrm{~min}$ & 0,50 \\
$31-60 \mathrm{~min}$ & 0,40 \\
$1-2$ horas & 0,30 \\
$2-4$ horas & 0,20 \\
$4-8$ horas & 0,10 \\
$>8$ horas & 0,00 \\
\hline
\end{tabular}

Fonte: Adaptado de HARKLEY et al. (1998, p. 54).

Tabela 3.18: Fator de ajustamento para conversões à direita - BCI.

\begin{tabular}{c|c}
\hline Volume de conversões à direita (conversões/h) & $\mathrm{f}_{\mathrm{rt}}$ \\
\hline$<270$ & 0,00 \\
$\geq 270$ & 0,10 \\
\hline
\end{tabular}

Fonte: HARKLEY et al. (1998, p. 54).

O nível de compatibilidade da via para acomodar o tráfego compartilhado entre bicicletas e veículos motorizados, segundo o modelo proposto por Harkey et al. (1998), é determinado pelo valor do BCI calculado de acordo com os intervalos apresentados na Tabela 3.19 .

Tabela 3.19: Compatibilidade das vias com o transporte cicloviário - BCI.

\begin{tabular}{c|c}
\hline BCI & Nível de compatibilidade \\
$\leq 1,50$ & Extremamente alto \\
$1,51-2,30$ & Muito alto \\
$2,31-3,40$ & Moderadamente alto \\
$3,41-4,40$ & Moderadamente baixo \\
$4,41-5,30$ & Muito baixo \\
$>5,30$ & Extremamente baixo \\
\hline
\end{tabular}

Fonte: HARKLEY et al. (1998, p. 56). 
Dentre as vantagens de utilização do BCI proposto por Harkey et al. (1998), destaca-se o fato deste modelo incluir uma grande diversidade de variáveis, as quais envolvem características geométricas da via, condições de tráfego e fatores relacionados ao ambiente onde a mesma está inserida. Além disso, o BCI, apesar de não excluir a influência que as facilidades para ciclistas exercem sobre a via, procura avaliar a compatibilidade da mesma com o tráfego compartilhado entre ciclistas e usuários dos modos de transporte motorizados, apresentando-se como uma importante ferramenta para projetos voltados ao transporte cicloviário em locais onde a expansão do sistema viário deu-se de forma desordenada, sem planejamento prévio.

Com relação às desvantagens de utilização do BCI proposto por Harkey et al. (1998), alguns autores alertam para o fato de que este modelo não considera percepções de conforto reais de ciclistas, mas sim a opinião de usuários de diversos modos de transporte com relação a cenários hipotéticos caso trafegassem por bicicleta ao longo dos mesmos (PROVIDELO, 2011). Além disso, a calibração do modelo matemático do BCI, por ser feita por meio de regressão linear, não permite interações entre os diferentes fatores avaliados.

\subsubsection{Shared-Use Path Level of Service (SUPLOS) da FHWA (2006b)}

O modelo proposto pela FHWA (2006b), intitulado Shared-Use Path Level of Service (SUPLOS), tem como objetivo avaliar a qualidade de serviço das vias para o uso compartilhado entre usuários de diferentes modos de transporte não motorizados, com especial atenção para ciclistas e pedestres. As variáveis consideradas neste modelo são: número de encontros entre usuários que trafegam em direções opostas, largura da via, disposição de faixa separadora no centro da via e frequência de interrupções do fluxo de ciclistas.

A coleta de informações para a elaboração do SUPLOS, realizada em 15 cidades norteamericanas, contou com mais de 100 participantes entre ciclistas, pedestres e skatistas, os quais opinaram de acordo com suas percepções relativas a quatro aspectos operacionais das vias de uso compartilhado: disponibilidade de espaço lateral e longitudinal, facilidade para ultrapassagens e liberdade para efetuação de manobras.

Os resultados da pesquisa permitiram a calibração de um modelo matemático, por meio de regressão linear, utilizado para o cálculo do SUPLOS, como apresenta a Equação 3.7. 


$$
\text { SUPLOS }=5,446-0,00809 * \mathrm{E}-15,86 * \mathrm{RW}-0,287 * \mathrm{CL}-\mathrm{DPF}
$$

Em que:

E: número de encontros entre usuários trafegando em direções opostas por minuto +10 (encontros/min);

RW: inverso da largura da via (1/ft);

CL: faixa separadora no centro da via $\{$ não $=0 ; \operatorname{sim}=1\}$;

DPF: fator de fluxo interrompido.

Os valores para o fator de fluxo interrompido são mostrados pela Tabela 3.20.

Tabela 3.20: Fator de fluxo interrompido - DPF.

\begin{tabular}{c|c}
\hline Número de interrupções* (interrupções/h) & DPF \\
\hline$\leq 180$ & 0,00 \\
$>180$ & 1,50 \\
\hline
\end{tabular}

*Número de vezes em que os ciclistas são interrompidos por outros usuários trafegando na mesma direção.

Fonte: Adaptado de FHWA (2006b).

De acordo com as informações apresentadas para o cálculo do SUPLOS, a seguinte observação deve ser feita: a disposição da faixa separadora no centro da via possui um impacto negativo com relação ao nível de serviço. Isto é justificado pelo fato deste elemento reforçar a ideia de que para realizar uma ultrapassagem o ciclista deve utilizar a faixa de tráfego adjacente àquela onde trafega, criando-se uma relação de dependência entre a liberdade de manobra deste ciclista e as condições de circulação do sentido de tráfego oposto (FHWA, 2006b).

O nível de serviço das vias de uso compartilhado entre usuários de modos transporte não motorizados, segundo o método proposto pela FHWA (2006b), é determinado pelo valor do SUPLOS calculado, ao qual é atribuída uma condição que varia de A até F, sendo A a melhor condição e F a pior, de acordo com os intervalos apresentados na Tabela 3.21. A interpretação para cada uma das faixas de nível de serviço é apresentada Tabela 3.22. 
Tabela 3.21: Nível de serviço para vias de uso compartilhado - FHWA (2006b).

\begin{tabular}{c|c}
\hline Nível de serviço & SUPLOS \\
\hline A & $\geq 4,00$ \\
B & $3,50-3,99$ \\
C & $3,00-3,49$ \\
D & $2,50-2,99$ \\
E & $2,00-2,49$ \\
F & $<2,00$ \\
\hline
\end{tabular}

Fonte: FHWA (2006b, p. 14).

Tabela 3.22: Interpretação para as faixas de nível de serviço - FHWA (2006).

\begin{tabular}{c|l}
\hline $\begin{array}{c}\text { Nível de } \\
\text { Serviço }\end{array}$ & \multicolumn{1}{c}{ Interpretação } \\
\hline A & $\begin{array}{l}\text { Excelente: a via oferece ótimas condições de circulação aos ciclistas e possui } \\
\text { amplo espaço para acomodar usuários de diferentes modos de transporte não } \\
\text { motorizados com qualidade. }\end{array}$ \\
\hline B & $\begin{array}{l}\text { Bom: a via oferece boas condiçóes de circulação aos ciclistas e possui espaço } \\
\text { suficiente para acomodar usuários de diferentes modos de transporte não } \\
\text { motorizados com qualidade. }\end{array}$ \\
\hline C & $\begin{array}{l}\text { Regular: a via possui largura necessária para atender a demanda existente e } \\
\text { garantir qualidade de serviço básica aos ciclistas. Um pequeno adicional à } \\
\text { capacidade funcional da via é aceitável para ciclistas. No entanto, o aumento no } \\
\text { número de pedestres que trafega pela mesma pode provocar uma diminuição do } \\
\text { nível de serviço para bicicletas. }\end{array}$ \\
\hline D & $\begin{array}{l}\text { Ruim: a via está na iminência de atingir sua capacidade funcional. As velocidades } \\
\text { de circulação em horários de pico podem sofrer reduções devido aos grandes } \\
\text { volumes de tráfego. A adição de mais usuários à via, de qualquer modo de } \\
\text { transporte não motorizado, resultará em significante degradação das condições de } \\
\text { serviço da mesma. Alguns ciclistas podem passar a evitar horários de pico. }\end{array}$ \\
\hline E & $\begin{array}{l}\text { Muito ruim: a via já atingiu sua capacidade funcional. As velocidades de } \\
\text { circulação em horários de pico podem sofrer reduções devido aos grandes } \\
\text { volumes de tráfego. Alguns ciclistas podem passar a evitar horários de pico. } \\
\text { Péssimo: via inadequada para o uso da bicicleta por quase todos os grupos de } \\
\text { não motorizados devem ser esperados. }\end{array}$ \\
\hline
\end{tabular}


Dentre as vantagens de utilização do SUPLOS proposto pela FHWA (2006b), destacase a facilidade de coleta das variáveis de entrada. Além disso, apesar de considerar diferentes usuários de modos de transporte não motorizados, este modelo procura avaliar o nível de serviço das vias de acordo com as condições de mobilidade dos ciclistas.

Com relação às desvantagens, o SUPLOS proposto pela FHWA (2006b) possui uma série de limitações:

1) Quanto à qualidade da superfície, o modelo só é aplicável às vias com condições específicas de pavimentação, isto é, revestidas de asfalto ou concreto;

2) Quanto às condições de circulação, recomenda-se que o modelo seja aplicado às vias de duplo sentido; e

3) Quanto às interrupções de tráfego, o modelo não é aplicável às vias com paradas obrigatórias ou cruzamentos dispostos com frequência maior do que a cada $400 \mathrm{~m}$.

\subsubsection{Modelo do HCM (2010)}

O modelo proposto pelo HCM tem como objetivo avaliar a capacidade operacional e o nível de serviço de facilidades exclusivas para o tráfego de bicicletas e de espaços compartilhados entre ciclistas e pedestres. As variáveis consideradas neste modelo são, basicamente, frequências de eventos, como encontros e ultrapassagens que ocorrem nos locais avaliados. No entanto, por se tratar de um processo extenso e subdividido em diversas etapas, esta metodologia não é descrita neste trabalho. Para maiores detalhes sobre esta avaliação da qualidade de serviço das facilidades para bicicletas, o leitor deve consultar o capítulo 23 do HCM (TRB, 2010). 


\section{MÉTODO PARA DEFINIÇÃO DE REDE DE ROTAS CICLÁVEIS EM ÁREAS URBANAS DE CIDADES DE PEQUENO PORTE}

O método para definição de rede de rotas cicláveis em áreas urbanas de cidades de pequeno porte desenvolvido, proposto e aplicado neste trabalho, tem como ideia central avaliar segmentos viários com relação a fatores que influenciam no uso da bicicleta como modo de transporte urbano, tais como declividade, disponibilidade de espaço para comportar o transporte cicloviário, influência exercida pelos veículos motorizados sobre o tráfego de bicicletas, existência ou possibilidade de inserção de infraestrutura cicloviária e distância de viagem. A seleção dos modelos para avaliação da compatibilidade das vias com o transporte cicloviário a serem utilizados neste trabalho baseou-se na facilidade do levantamento dos dados de entrada e na aplicabilidade dos mesmos às cidades brasileiras de pequeno porte.

As cidades brasileiras de pequeno porte possuem algumas características vantajosas referentes ao transporte quando comparadas àquelas encontradas em grandes e médios centros urbanos: de uma maneira geral, os municípios menores apresentam também menor complexidade em seus problemas viários, ou seja, pouco número de interseções semaforizadas e menores volumes e velocidades dos veículos motorizados que trafegam pelas vias. Entretanto, algumas desvantagens também se fazem presentes: a maioria dos municípios de pequeno porte não dispõe de informações normalmente empregadas no planejamento de sistemas de transporte, como contagens volumétricas de automóveis, estimativas das velocidades médias dos automóveis ao trafegarem por uma determinada via (feita, por exemplo, com o auxílio de radares), pesquisas domiciliares para estimação de demanda e divisão modal etc.

Neste contexto, com relação à avaliação da qualidade de serviço das vias para o transporte cicloviário, optou-se pela utilização do modelo de avaliação do nível de estresse proposto por Sorton e Walsh (1994). Esta escolha é justificada, principalmente, pela facilidade de coleta dos dados de entrada, isto é, por existirem diversas metodologias para o levantamento do volume e da velocidade dos veículos motorizados aplicáveis às cidades de pequeno porte, como por exemplo: contagens manuais de veículos durante curtos intervalos nos horários de pico e estimativas das velocidades médias de tráfego por meio da cronometragem dos tempos que uma determinada amostra de veículos demora a transpor trechos de extensão conhecida das vias de interesse. 
Com relação à verificação do perfil topográfico das vias para o transporte cicloviário, optou-se pela utilização do critério proposto pela AASHTO (1999). Esta escolha é justificada pelo fato deste critério sugerir limites para os comprimentos em aclive, para graus de inclinação variando entre $6 \%$ e $10 \%$, menos rigorosos que os demais critérios, como apresentado pela Tabela 4.1. O critério proposto pelo GEIPOT (2001a) não foi incluso na análise comparativa por apresentar diretrizes para a verificação do perfil longitudinal voltadas apenas às ciclovias. Além disso, o grau de inclinação máximo analisado foi de $11 \%$, uma vez que o critério proposto pela FHWA (1977) não considera valores superiores a este.

Tabela 4.1: Máximos comprimentos em aclive para a verificação do perfil topográfico das vias com relação ao transporte cicloviário.

\begin{tabular}{c|c|c|c|c}
\hline \multirow{2}{*}[\%]{} & \multicolumn{4}{|c}{ Máximo comprimento em aclive (m) } \\
\cline { 2 - 5 } & FHWA (1977) & AASHTO (1999) & Toole (2010) & Austroads (2014) \\
\hline 5 & 300 & 240 & 60 & 110 \\
6 & 160 & 240 & 60 & 80 \\
7 & 110 & 120 & 60 & 60 \\
8 & 75 & 90 & 60 & 45 \\
9 & 50 & 60 & 9 & 35 \\
10 & 25 & 30 & 9 & 25 \\
11 & 0 & 15 & 3 & 20 \\
\hline
\end{tabular}

Fonte: Elaborado pelo autor.

As etapas do método proposto, apresentadas pelos fluxogramas das Figuras 4.1 e 4.2, são as seguintes:

1) Caracterização da área de estudo;

2) Análise dos polos geradores de tráfego por bicicleta;

3) Avaliação da compatibilidade das vias com o transporte cicloviário;

4) Identificação das rotas cicláveis; e

5) Definição da rede.

Os detalhes de cada uma destas etapas são apresentados ao longo deste capítulo. 
Figura 4.1: Fluxograma geral do método proposto: Etapas 1 a 3.

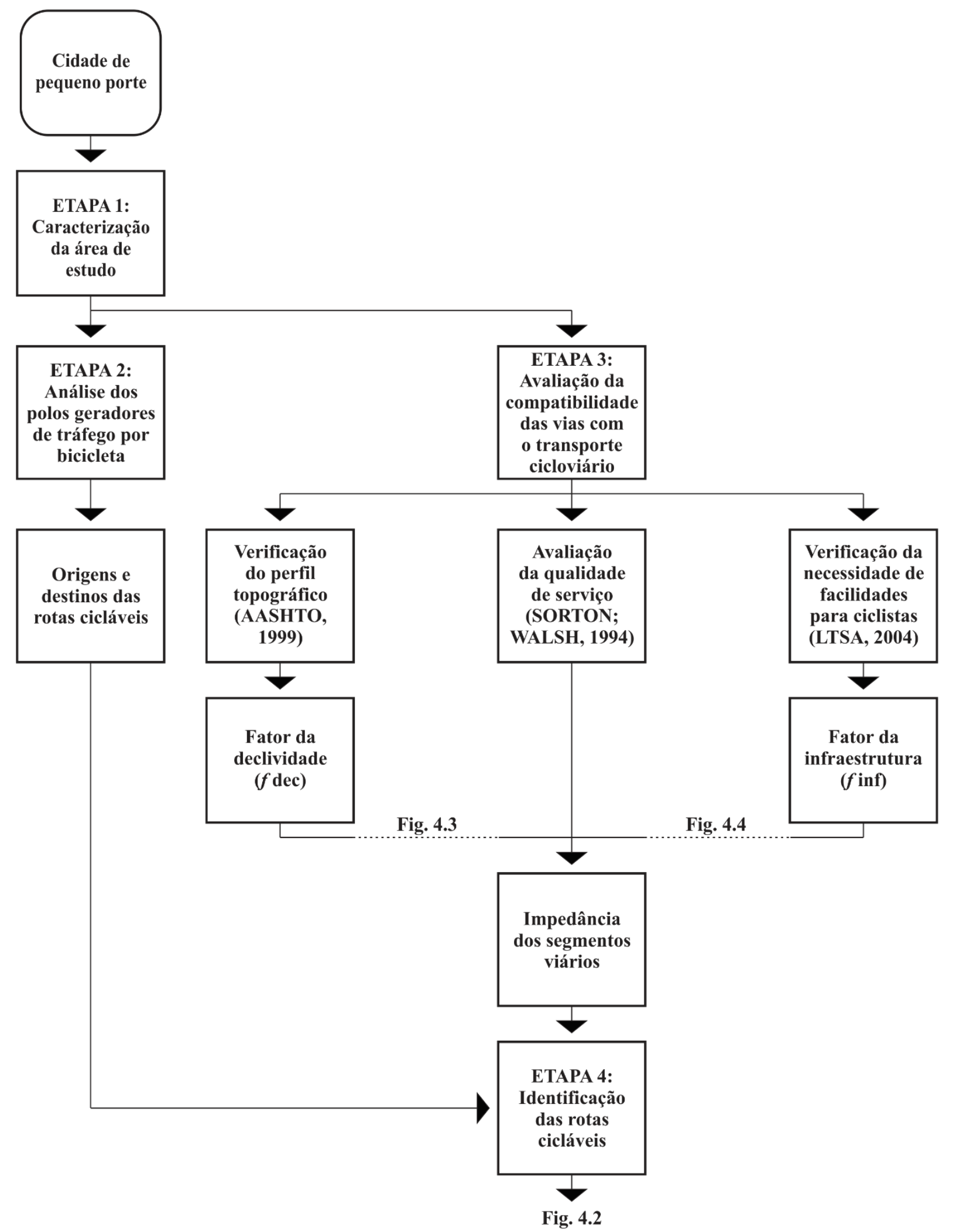

Fonte: Elaborado pelo autor. 
Figura 4.2: Fluxograma geral do método proposto: Etapas 4 e 5.

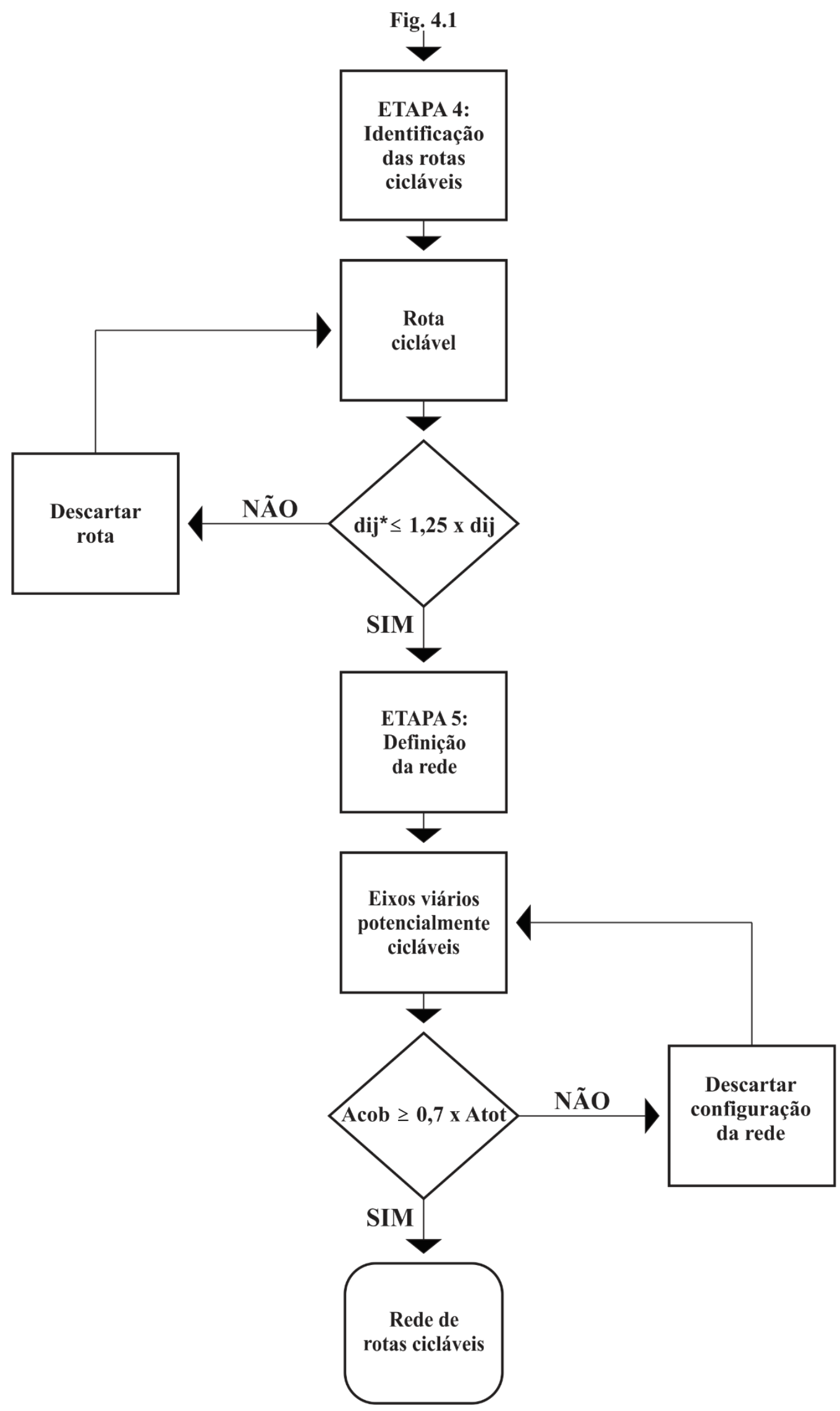

Fonte: Elaborado pelo autor. 


\subsection{Etapa 1: Caracterização da área de estudo}

A caracterização da área de estudo consiste no levantamento de informações preliminares necessárias ao planejamento de sistemas de transporte. Desta forma, o Ministério das Cidades (2007) sugere que, inicialmente, deve-se definir se o plano cicloviário a ser elaborado necessita incluir todo o município ou apenas uma determinada porção de seu território. No caso das cidades brasileiras de pequeno porte, devido às suas configurações compactas, deve ser definida como área de estudo toda a porção do território eminentemente urbana.

Hook (2003) sugere que uma das etapas preliminares do planejamento cicloviário é a divisão da área de estudo em zonas de tráfego. Esta divisão pode ser feita simultaneamente por meio de vários critérios: tipo de uso do solo (residencial, industrial, comercial etc.), redistribuição de setores censitários com características econômicas e populacionais homogêneas e agrupamento de bairros e loteamentos de maneira a promover facilidades político-administrativas.

Outra informação indispensável de ser levantada nesta etapa inicial são as características do sistema viário da área de estudo. O processo de escolha das rotas a comporem uma rede cicloviária depende diretamente do arranjo e da hierarquização das vias de tráfego ao longo da malha urbana, dos sentidos de circulação, da velocidade de tráfego permitida e de eventuais obstáculos ao fluxo contínuo de automóveis e bicicletas. Neste sentido, a Base de Faces de Logradouros, que consiste em um plano de informações disponível no repositório oficial do IBGE desde julho de 2016, apresenta as extensões compreendidas entre quarteirões das ruas para todos os 5.570 municípios brasileiros, com base no censo demográfico de 2010. Trata-se de um conjunto de dados vetoriais de grande importância na descrição do espaço urbano de locais que ainda não dispõem de bases cartográficas digitais, como ocorre na grande maioria das cidades brasileiras de pequeno porte.

Nas cidades de pequeno porte, as menores distâncias de viagem fazem com que os indivíduos não necessitem de diferentes modos de transporte para se locomoverem em um mesmo deslocamento, inviabilizando a integração entre o transporte público e o transporte cicloviário. No entanto, faz-se necessário ao planejamento cicloviário, mesmo nestas cidades, o mapeamento dos pontos de parada dos veículos de transporte público, permitindo a 
verificação da disponibilidade de espaço para garantir o tráfego de bicicletas ao longo dos segmentos viários que os sobrepõem.

O mapeamento de facilidades, rotas e informações sobre acidentes envolvendo ciclistas também são ferramentas extremamente importantes na elaboração de planos voltados ao transporte cicloviário. Em cidades ou regiões que já dispõem de algum tipo de infraestrutura cicloviária, particularmente, este processo pode indicar os locais de maior demanda existente pelo uso da bicicleta. Além disso, neste contexto, é interessante também que seja realizado o mapeamento de barreiras à inserção destas facilidades, evitando-se a definição de redes cicloviárias sem conectividade entre os trajetos (PETTINGA et al., 2009).

\subsection{Etapa 2: Análise dos polos geradores de tráfego por bicicleta}

A segunda etapa do método proposto é a análise dos polos geradores de tráfego por bicicleta existentes na área de estudo. Neste sentido, a FHWA (2006a) apresenta as seguintes diretrizes para identificação destes polos: admite-se que, com algumas restrições, os ciclistas desejam ter acesso aos mesmos destinos que os usuários dos modos de transporte motorizados. Assim, a identificação dos PGTs por bicicleta deve basear-se no uso do solo existente, enfatizando empreendimentos de grande porte, isto é, aqueles que, mesmo isoladamente, podem condicionar impactos significativos na paisagem urbana.

O fluxo de viagens por bicicleta, portanto, assemelha-se ao fluxo de veículos motorizados ao longo do sistema viário existente, o que possibilita a identificação dos segmentos com maior potencial de atração pelo transporte cicloviário. De acordo com Pezzuto (2002), é extremamente importante atender à demanda destas linhas de desejo potencial, incentivando o uso da bicicleta em viagens utilitárias.

Neste sentido, uma vez identificados os PGTs por bicicleta, é necessário também identificar as origens das viagens realizadas pelos ciclistas até estes polos, de maneira a apontar quais as zonas de tráfego da área de estudo com maior reincidência destas origens e, assim, auxiliar os planejadores em transportes no processo de identificação das rotas cicláveis. A definição destas origens pode ser realizada por meio de informações adquiridas junto às autoridades responsáveis pelos PGTs, ou ainda por meio de informações coletadas diretamente com os ciclistas que os frequentam. 


\subsection{Etapa 3: Avaliação da compatibilidade das vias com o transporte cicloviário}

A terceira etapa do método proposto consiste na avaliação da compatibilidade das vias de tráfego com o uso da bicicleta, isto é, na verificação do perfil topográfico destas vias, da sua qualidade de serviço com relação ao transporte cicloviário e da necessidade de inserção de facilidades para ciclistas ao longo das mesmas. O objetivo principal desta etapa é atribuir a cada segmento viário da área de estudo fatores relacionados à declividade $\left(f_{\mathrm{dec}}\right)$ e à infraestrutura cicloviária $\left(f_{\text {inf }}\right)$, assim como suas correspondentes avaliações globais do nível de estresse relacionado aos ciclistas, possibilitando o cálculo das impedâncias, isto é, dos custos generalizados de cada um destes segmentos, conforme apresentado pela Equação 4.1 a seguir:

$$
\mathrm{C}(\mathrm{e})=\frac{\mathrm{L}(\mathrm{e}) * \mathrm{NE}(\mathrm{e}) * f_{\mathrm{dec}}(\mathrm{e})}{f_{\mathrm{inf}}(\mathrm{e})}
$$

Em que:

$\mathrm{C}(\mathrm{e})$ : impedância (custo generalizado) do segmento $e$;

L(e): comprimento de segmento $e$;

$\mathrm{NE}(\mathrm{e})$ : avaliação do nível de estresse do segmento $e$;

$f_{\text {dec }}(\mathrm{e})$ : fator relacionado à declividade atribuído ao segmento $e$;

$f_{\text {inf }}(\mathrm{e})$ : fator relacionado à infraestrutura atribuído ao segmento $e$.

\subsubsection{Verificação do perfil topográfico (AASHTO, 1999)}

Para a verificação do perfil topográfico das vias com relação ao transporte cicloviário, neste trabalho propõe-se que a cada segmento viário seja atribuído um fator relacionado à declividade $\left(f_{\text {dec }}\right)$ de acordo com seu respectivo grau de inclinação e comprimento em aclive, respeitando-se os limites sugeridos pela AASHTO (1999), como apresenta a Figura 4.3. Para as vias cujo grau de inclinação é superior a 5\% e o comprimento em aclive excede o limite proposto pela AASHTO (1999), o fator da declividade deve ser calculado pela razão entre estes comprimentos. 
Figura 4.3: Verificação do perfil topográfico (AASHTO, 1999).

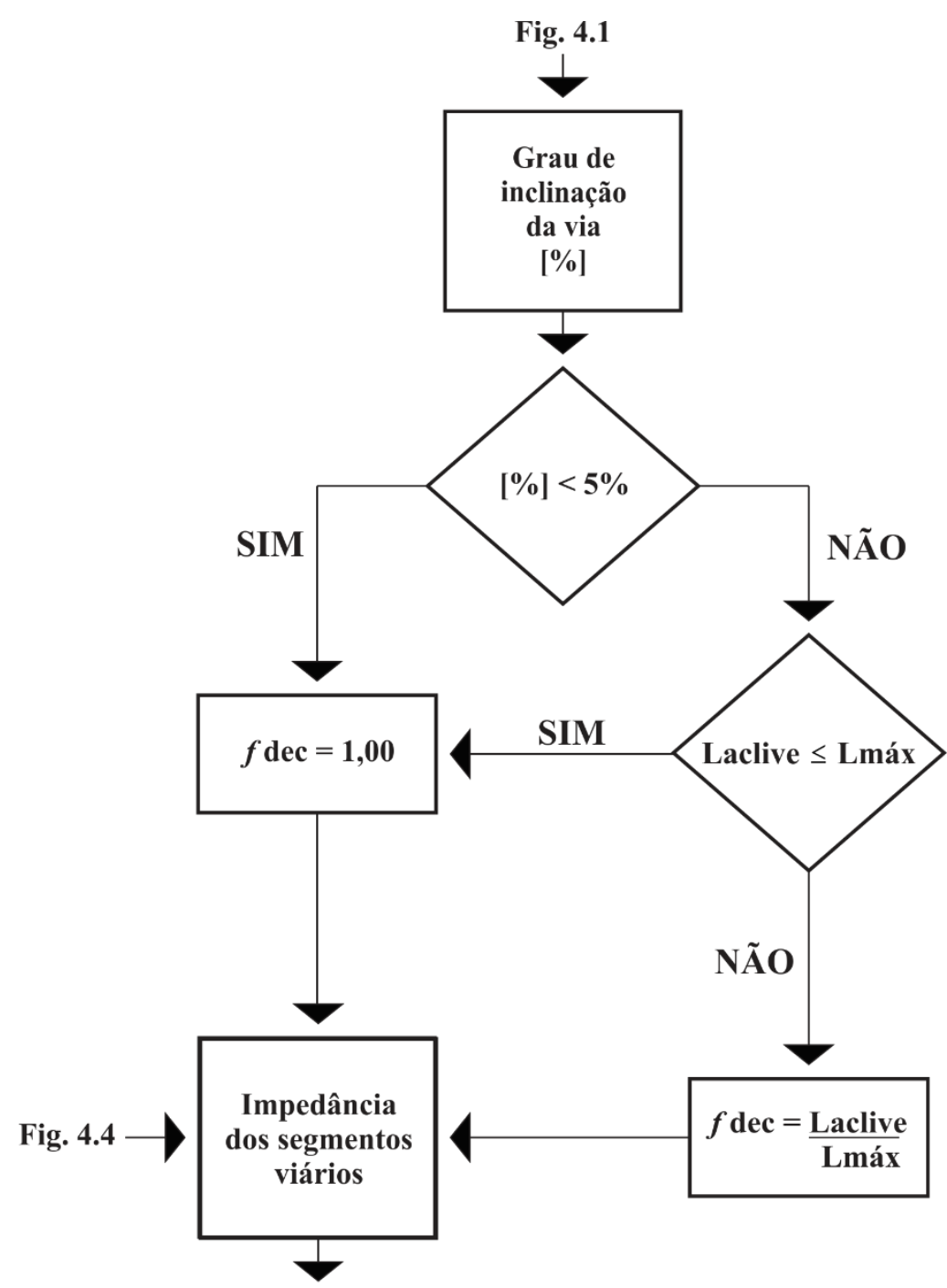

Fig. 4.2

Fonte: Elaborado pelo autor.

\subsubsection{Avaliação da qualidade de serviço das vias (SORTON; WALSH, 1994)}

Para a avaliação da qualidade de serviço das vias com relação ao transporte cicloviário, neste trabalho propõe-se que a cada segmento viário da área de estudo seja atribuída uma avaliação global do nível de estresse, variando entre 1 e 5, de acordo com a média aritmética das avaliações individuais das três variáveis de entrada do modelo proposto por Sorton e Walsh (1994). Desta forma, estas avaliações globais podem ser utilizadas para ponderar os comprimentos de seus respectivos segmentos viários no cálculo da impedância. Isto equivale a dizer que, por exemplo, um segmento viário com extensão de 100 m e avaliação global do nível 
de estresse igual a 3 oferece as mesmas condições de segurança e conforto aos ciclistas que um segmento com extensão de $300 \mathrm{~m}$ sob condições ideais de circulação.

\subsubsection{Verificação da necessidade de facilidades para ciclistas (LTSA, 2004)}

A verificação da necessidade de inserção de facilidades para ciclistas consiste em identificar os segmentos viários que requerem separação entre o tráfego de bicicletas e o de veículos motorizados, de acordo com o critério proposto pela LTSA (2004), apresentado na seção 2.4.3 deste trabalho, assim como verificar a disponibilidade de espaço ao longo dos mesmos para esta inserção, de acordo com as dimensões apresentadas na seção 2.4.5.

É importante destacar que o processo de verificação da disponibilidade de espaço para a inserção de facilidades para ciclistas proposto por este trabalho não considera os passeios e trilhas independentes do sistema viário. Isto é justificado pelo fato de que a inclusão destes equipamentos em projetos cicloviários pode torná-los muito onerosos se não fizerem parte de um programa a médio ou longo prazo. Além disso, a prática tem mostrado que a inserção de ciclovias junto aos passeios de várias cidades brasileiras tem consolidado a formação de micro redes descontínuas, formadas por infraestruturas isoladas e que não estimulam a utilização da bicicleta (MINISTÉRIO DAS CIDADES, 2007).

Com o intuito de padronizar os segmentos viários que dispõem de diferentes facilidades para ciclistas, neste trabalho propõe-se que a cada um deles seja atribuído um fator relacionado à infraestrutura cicloviária $\left(f_{\text {inf }}\right)$, de acordo com a relação de equivalência sugerida por Larsen e El-Geneidy (2011), como mostra a Tabela 4.2.

Tabela 4.2: Fator relacionado à infraestrutura cicloviária.

\begin{tabular}{l|l}
\hline \multicolumn{1}{c|}{ Alternativa viária para bicicletas } & $f_{\text {inf }}$ \\
\hline Via de tráfego compartilhado & 1,00 \\
Ciclofaixa* & 1,31 \\
Ciclovia* & 1,71 \\
\hline
\end{tabular}

*No caso das facilidades para ciclistas, deve ser avaliada a pré-existência destas infraestruturas ou a disponibilidade de espaço para construção das mesmas em locais onde são necessárias.

Fonte: Adaptado de LARSEN e EL-GENEIDY (2011).

A Figura 4.4 mostra um fluxograma de procedimentos para a atribuição destes fatores. 
Figura 4.4: Verificação da necessidade de facilidades para ciclistas (LTSA, 2004).

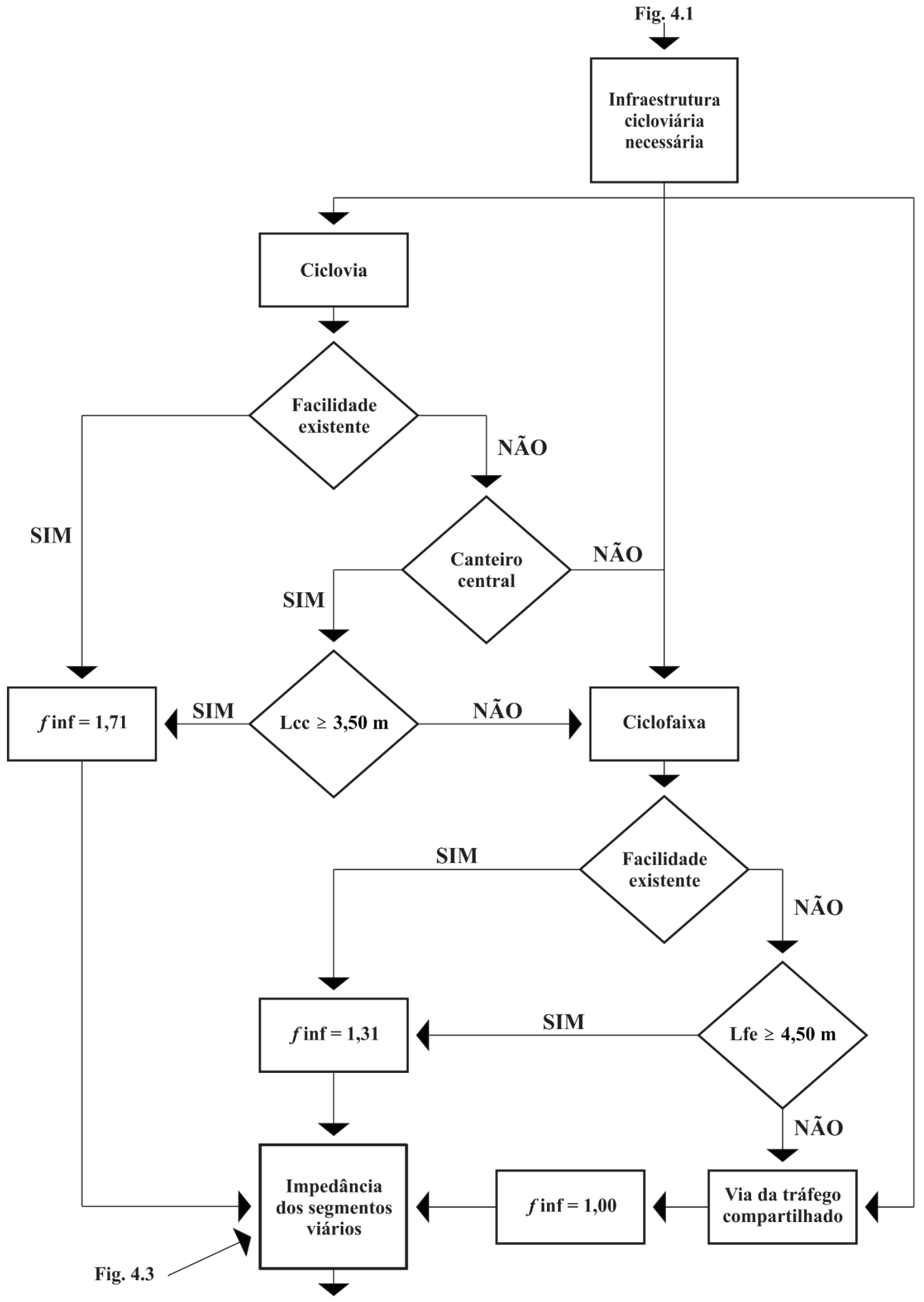

Fig. 4.2

Fonte: Elaborado pelo autor. 


\subsection{Etapa 4: Identificação das rotas cicláveis}

A identificação da rota mais adequada entre um par origem-destino pode ser realizada por diversos critérios, tais como o menor número de segmentos viários que promove a ligação entre estes dois pontos de interesse, a menor distância total ou o menor tempo de viagem. Abordagens alternativas, no entanto, têm sido utilizadas frequentemente entre os pesquisadores em transportes para a realização deste processo, com destaque para aquelas que avaliam os segmentos viários de acordo com sua impedância, isto é, baseando-se no custo generalizado destes segmentos relacionado a diversos fatores que influenciam nas condições de circulação ao longo dos mesmos. Assim, o "menor caminho" entre o par origem-destino de interesse pode ser definido como a rota que minimiza estes custos (MCDANIEL; LOWRY; DIXON, 2014)

Neste contexto, a quarta etapa do método proposto consiste na identificação das rotas cicláveis que promovem a ligação entre os pares origem-destino previamente selecionados na Etapa 2, de maneira a minimizar a somatória das impedâncias dos segmentos viários calculadas por meio dos fatores e avaliações do nível de estresse atribuídos na Etapa 3. Após identificadas, as rotas cicláveis devem ser verificadas com relação à distância de viagem. Desta forma, propõe-se neste trabalho a utilização do critério sugerido por Tucker e Manaugh (2016), isto é, a extensão total de uma determinada rota ciclável que liga um par origem-destino não deve exceder $25 \%$ da distância referente à menor rota entre este par. A Equação 4.2 apresenta, em termos matemáticos, esta verificação.

$$
d_{i j}^{*}=\sum_{i \in I, j \in J} \sigma_{i j}^{*}(e) \leq 1,25 x d_{i j}=1,25 x\left(\sum_{i \in I, j \in J} \sigma_{i j}(e)\right)
$$

Em que:

I: subconjunto das origens i da rede;

$\mathrm{J}$ : subconjunto dos destinos $\mathrm{j}$ da rede;

$\sigma_{\mathrm{ij}}$ : caminho de menor distância entre os nós i e j;

$\sigma_{\mathrm{ij}}{ }^{*}$ : caminho de menor impedância entre os nós i e j;

$\sigma_{\mathrm{ij}}(\mathrm{e}):\left\{\mathrm{L}(\mathrm{e})\right.$, se o segmento é usado em $\sigma_{\mathrm{ij}} ; 0$, caso contrário $\}$;

$\sigma_{\mathrm{ij}}{ }^{*}(\mathrm{e}):\left\{\mathrm{L}(\mathrm{e})\right.$, se o segmento é usado em $\sigma_{\mathrm{ij}}{ }^{*} ; 0$, caso contrário $\}$; 
$\mathrm{d}_{\mathrm{ij}}$ : menor distância entre os nós i e j;

$\mathrm{d}_{\mathrm{ij}}{ }^{*}$ : distância do caminho de menor impedância entre os nós i e j.

\subsection{Etapa 5: Definição da rede}

A última etapa do método proposto consiste na definição da rede, isto é, na priorização dos segmentos viários com maior reincidência das rotas cicláveis identificadas na Etapa 4, com o intuito de identificar eixos viários potencialmente cicláveis dispostos de maneira contínua, conexa e acessível. A infraestrutura cicloviária existente no local de estudo deve ser incorporada à rede cicloviária em formação, pois, de maneira geral, estes espaços próprios à circulação de bicicletas já estão inseridos em locais que atendem uma demanda existente de ciclistas, independentemente de sua qualidade de execução. Além disso, é necessário também definir os segmentos viários da área de estudo para inserção de novas facilidades para ciclistas, isto é, aqueles que, simultaneamente, compõem eixos viários potencialmente cicláveis, necessitam de infraestrutura cicloviária e dispõem de espaço para sua inserção.

A disposição de trajetos contínuos é extremamente importante para a manutenção de um nível homogêneo de atratividade e segurança de tráfego em toda a rede. Assim, a rede de rotas cicláveis deve ser definida, portanto, como uma unidade, evitando-se a disposição de infraestruturas pontuais ou isoladas. Além disso, estes trajetos devem possuir um número mínimo de interrupções, promover a interligação entre os principais polos geradores de tráfego por bicicletas e, caso necessário, permitir a integração com outros modos de transporte.

Em termos de acessibilidade da rede proposta, segundo Vale, Saraiva e Pereira (2016), os trabalhos encontrados na literatura sugerem que a área de influência exercida por eixos cicloviários seja limitada por raios de ação que variam de $400 \mathrm{~m}$ a 2,4km (distância euclidiana). Com relação à maioria das cidades brasileiras de pequeno porte, no entanto, as configurações compactas da área urbana e as menores distâncias de viagem permitem adotar limites menores para esta avaliação. Desta forma, neste trabalho propõe-se que a área de influência exercida pelos eixos viários a comporem a rede seja limitada por um raio de ação, também em distância euclidiana, de 200 m. Para que a configuração proposta para a rede seja aceita, portanto, sugerese que a área de cobertura da mesma, isto é, a somatória das áreas de influência dos eixos cicloviários, deve ser superior a 70\% da área de estudo. 


\section{ESTUDO DE CASO: BARIRI-SP}

Com o objetivo de aplicar o método proposto por este trabalho, foi realizado um estudo de caso para a cidade de Bariri-SP. Grande parte das informações levantadas junto à prefeitura municipal ou disponíveis no repositório oficial do IBGE encontram-se em formato digital de maneira georreferenciada, o que possibilitou com que fossem trabalhadas com o auxílio de SIGs. Os softwares utilizados neste trabalho, portanto, foram o QuantumGIS (QGIS) e o TransCAD.

O QGIS é um SIG de código aberto, isto é, um software disponível gratuitamente para download que permite um número cada vez mais crescente de utilidades. Além das funções básicas desempenhadas por um SIG (visualização, gerenciamento, edição e análise de dados espaciais, elaboração de mapas etc.), o QGIS também permite, por meio de uma plataforma Python, a codificação de novos complementos e aplicativos de acordo com o interesse do próprio usuário. Depois de validadas, estas novas ferramentas podem ser utilizadas pelos demais usuários das versões subsequentes do programa. Praticamente todo este trabalho foi realizado com o auxílio do QGIS. A versão utilizada foi a QGIS 2.18.12.

O TransCAD é um software comercial que, além de desempenhar as funções básicas de um SIG, possui ferramentas voltadas especificamente ao planejamento de redes de transporte, dentre elas, o cálculo de rotas entre pares origem-destino ao longo de um sistema viário prédefinido, de maneira a minimizar atributos dos segmentos deste sistema especificados pelo usuário. Neste trabalho, o TransCAD foi utilizado na Etapa 4 do método proposto, isto é, no processo de identificação de rotas cicláveis. A versão deste software disponível no Programa de Pós-graduação em Engenharia de Transportes da Escola de Engenharia de São Carlos (EESC/USP) é a TransCAD 5.0.

\subsection{Caracterização da área de estudo}

De acordo com o plano diretor de drenagem urbana do município de Bariri, a cidade está localizada no Comitê da Bacia Hidrográfica do Tietê/Jacaré, região central do Estado de São Paulo (PREFEITURA MUNICIPAL DE BARIRI, 2012), como ilustra a Figura 5.1. 
Figura 5.1: Localização do município de Bariri-SP (SIRGAS2000).

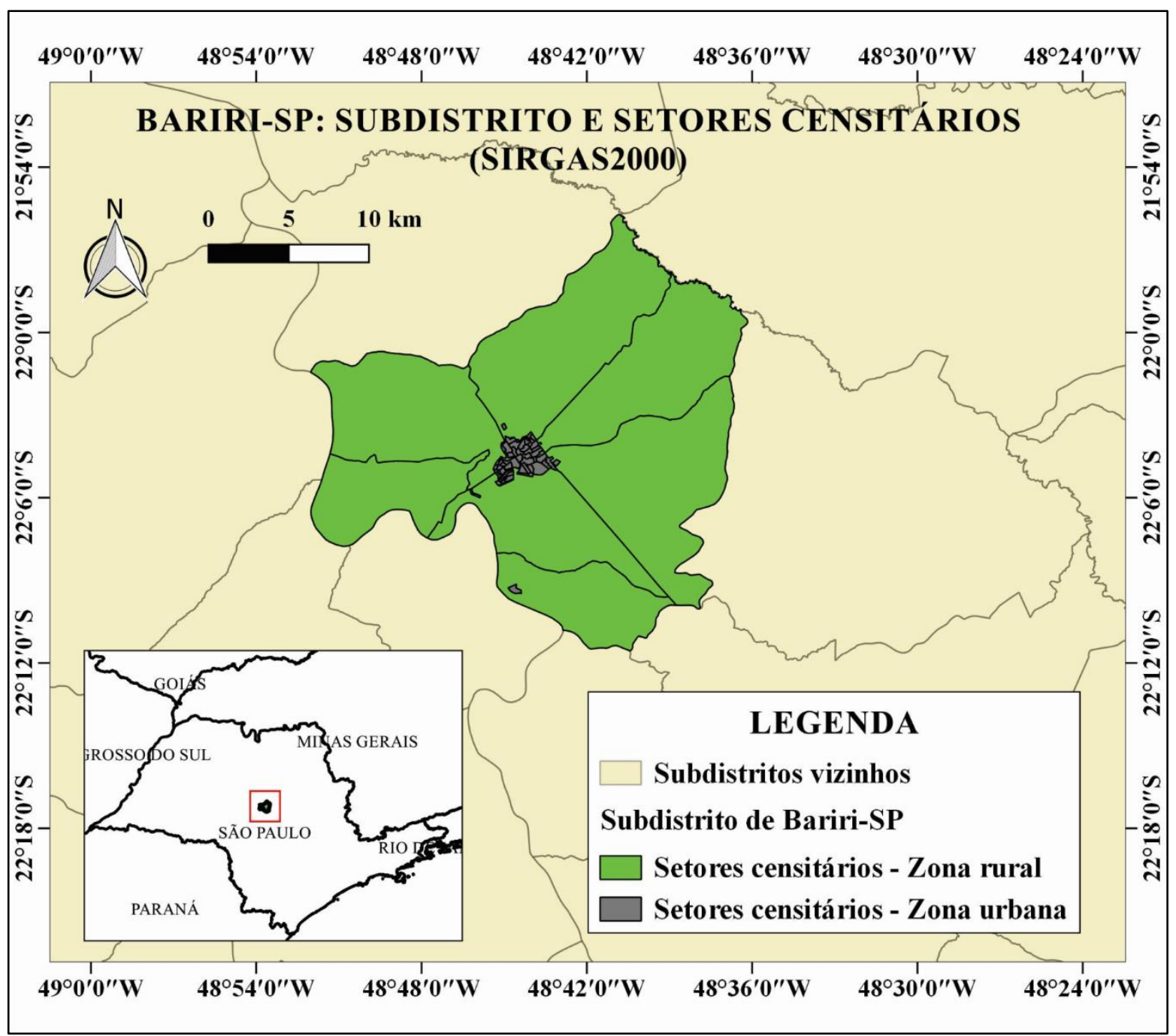

Fonte: Elaborado pelo autor.

De acordo com o último censo demográfico, realizado em 2010, a população de BaririSP, na época, era de 31.593 habitantes, sendo que 29.981 destes residiam na área urbana e 1.612 na área rural. Desde então, a cidade tem crescido consideravelmente por meio da criação de novos bairros e loteamentos, e, consequentemente, tornando-se cada vez mais populosa. Desta forma, estimativas realizadas pelo IBGE (2018) apontam que a população atual do município de Bariri-SP é da ordem de 34.600 habitantes, sendo que a grande maioria continua residindo na área urbana.

A área da unidade territorial estimada para Bariri-SP é de aproximadamente $444,5 \mathrm{~km}^{2}$, sendo a área delimitada para estudo, compreendida entre os limites urbanos do município, de aproximadamente $6,9 \mathrm{~km}^{2}$. Esta porção eminentemente urbana, por sua vez, pôde ser reorganizada em 36 zonas de tráfego de acordo com os critérios descritos na seção 4.1. 
As camadas vetoriais disponíveis no repositório oficial do IBGE, apesar de suas limitações técnicas, apresentam-se como ponto de partida para a representação dos sistemas viários dos municípios brasileiros. Desta forma, a compatibilização destas camadas, por meio de um processo de vetorização, com outras fontes de informação (mapas disponibilizados pela prefeitura local e bases de dados geográficos, como o Open Street Map - OSM), permitiram uma representação extremamente fiel e atual do sistema viário de Bariri-SP.

A Figura 5.2, a seguir, apresenta as zonas de tráfego definidas e a representação atualizada do sistema viário para a cidade de Bariri-SP. Vale destacar que, com relação ao sistema viário, as vias que compõem as redes primária e secundária são aquelas que, respectivamente, promovem as articulações estrada-centro e centro-bairros.

Figura 5.2: Bariri-SP: Zonas de tráfego e sistema viário.

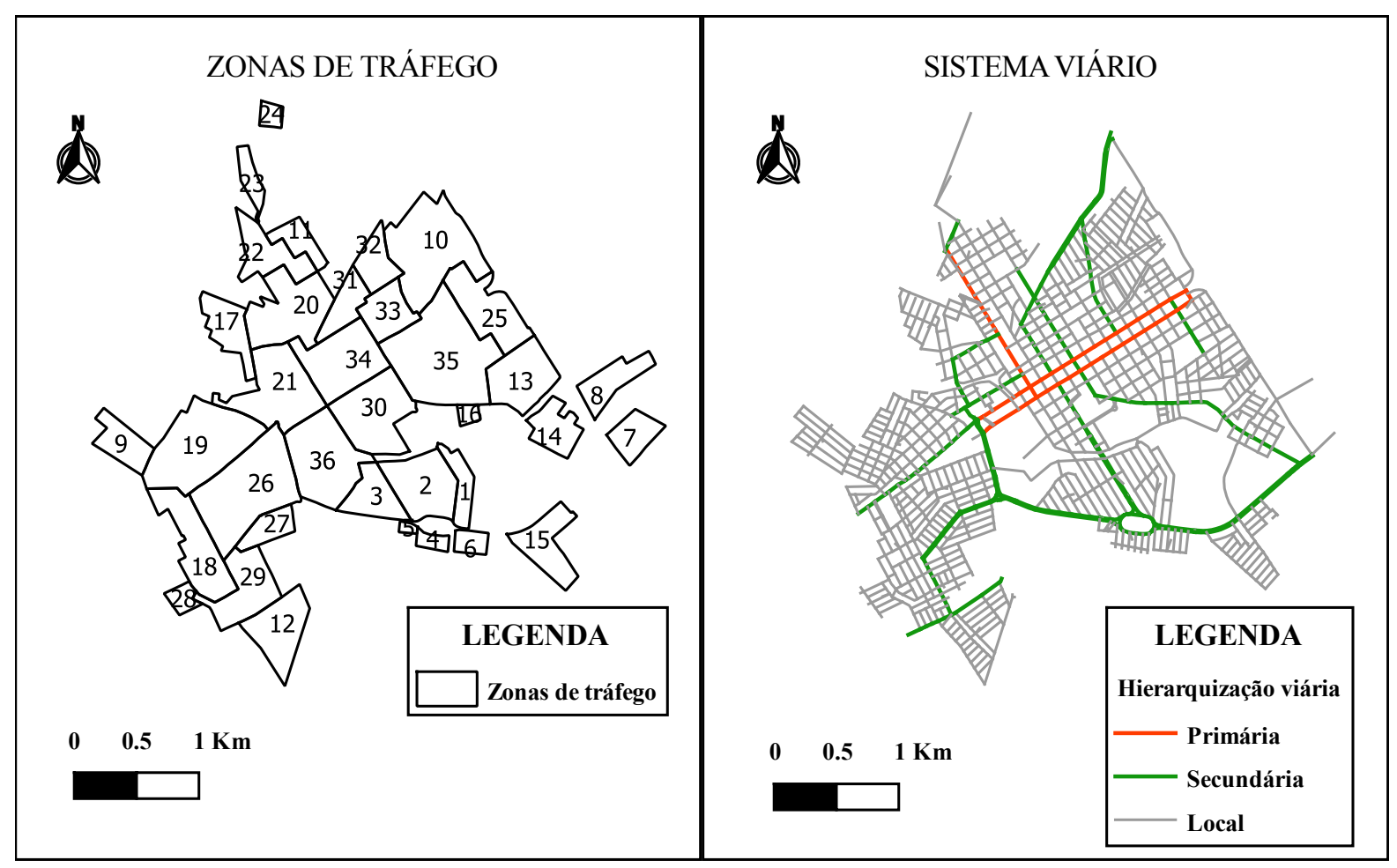

Fonte: Elaborado pelo autor.

A Figura 5.3 apresenta algumas características importantes do sistema viário do município de Bariri-SP com relação ao planejamento cicloviário: as linhas de transporte público oferecidas à população, organizadas em apenas dois trajetos, abrangem quase todas as regiões da cidade, com exceção dos bairros e loteamentos em expansão. Já com relação à infraestrutura cicloviária existente no município, esta pode ser resumida em três facilidades para ciclistas: 
uma via ciclável, um trecho com ciclofaixas unidirecionais e um trecho com ciclovia bidirecional.

Figura 5.3: Bariri-SP: Pontos de parada dos ônibus urbanos e infraestrutura cicloviária existente.

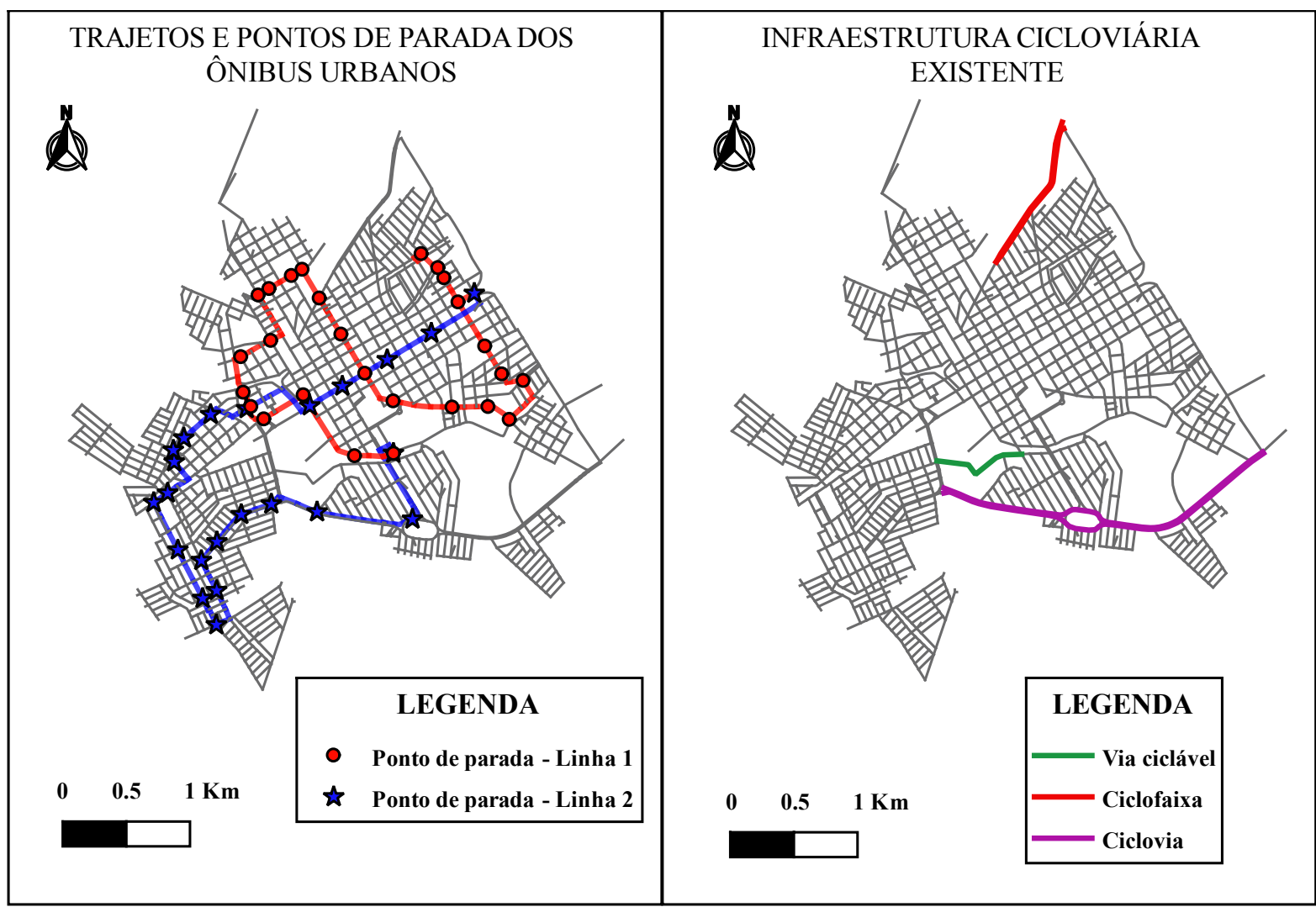

Fonte: Elaborado pelo autor.

A via ciclável existente em Bariri-SP possui extensão aproximada de 760 m e localizase à Av. das Indústrias e a um pequeno trecho da Av. Vicente Donda. Trata-se de um espaço compartilhado entre bicicletas e veículos motorizados que recebe o tratamento necessário para garantir a segurança dos ciclistas, como sinalização vertical adequada, controle da velocidade de tráfego de automóveis e proibição de estacionamento lateral paralelo à via por parte dos veículos motorizados.

As ciclofaixas localizam-se à Av. José Jorge Resegue. Tratam-se de espaços unidirecionais, cada um deles com extensão de aproximadamente $1,2 \mathrm{~km}$, dispostos junto às margens do canteiro central que divide a avenida, com mesmo sentido de fluxo dos veículos motorizados. As ciclofaixas não dispõem de sinalização horizontal adequada, isto é, pintura do pavimento, mas contam com dispositivos separadores e com equipamentos de sinalização vertical. 
A ciclovia localiza-se no canteiro central da Av. Perimetral Pref. Domingos Antônio Fortunato, popularmente conhecida como Av. Expresso Sul. Trata-se de uma infraestrutura bidirecional com extensão aproximada de $2,8 \mathrm{~km}$. A ciclovia não dispõe de sinalização horizontal ou vertical adequadas.

\subsection{Análise dos polos geradores de tráfego por bicicleta}

De acordo com o plano diretor de mobilidade do município de Bariri-SP, entende-se por unidades urbanísticas mínimas (UUMs) como estruturas responsáveis por articular equipamentos essenciais existentes, como escolas, creches, postos de saúde, praças, clubes etc. Esta articulação deve ocorrer dentro de uma trama contínua, acessível e, se possível, arborizada, privilegiando os modos de transporte não motorizados (PREFEITURA MUNICIPAL DE BARIRI, 2016).

A prefeitura municipal de Bariri-SP prevê ainda neste plano de mobilidade a inserção de nove UUMs nos próximos anos. Por meio desta informação foi possível identificar os principais polos geradores de tráfego da cidade e selecionar alguns destes polos para que os mesmos fossem inclusos na pesquisa. Assim, os PGTs por bicicleta selecionados foram: E. E. Prof. $^{a}$ Idalina Vianna Ferro, E. E. Prof. ${ }^{a}$ Ephigênia Cardoso Machado Fortunato, Centro Educacional SESI 143, Cooperativa Educacional de Bariri - COEBA, Indústria Plásticos Bariri e Umuarama Clube de Bariri.

A Escola Estadual Prof. ${ }^{a}$ Idalina Vianna Ferro de Bariri localiza-se à Avenida João Lemos, 31. De acordo com a coordenação da escola, o grupo de funcionários e professores é composto por cerca de 70 pessoas, e o número de alunos matriculados é da ordem de 950, sendo cerca de 450 destes pertencentes ao ensino fundamental ( $6^{\circ}$ a $9^{\circ}$ ano), e aproximadamente 500 ao ensino médio, com aulas ministradas nos períodos da manhã, tarde e noite.

A Escola Estadual Prof. ${ }^{a}$ Ephigênia Cardoso Machado Fortunato de Bariri localiza-se à Avenida Antônio José da Silva, 603. Segundo a coordenação da escola, o corpo docente e de funcionários é de aproximadamente 80 pessoas, e o número de alunos matriculados é da ordem de 730, sendo cerca de 150 destes pertencentes ao ensino fundamental ( $6^{\circ}$ a $9^{\circ}$ ano), aproximadamente 480 ao ensino médio, e 100 ao programa de educação à jovens e adultos, com aulas ministradas nos períodos da manhã, tarde e noite. 
O Centro Educacional SESI 143 de Bariri localiza-se à Estrada Perimetral Prefeito Domingos Antônio Fortunato, 450. Trata-se de uma instituição de dependência privada que conta com um corpo docente e de funcionários de aproximadamente 50 pessoas. De acordo com a coordenação do centro educacional, estima-se que o número de alunos matriculados é da ordem de 370, sendo 285 destes pertencentes ao ensino fundamental ( $1^{\circ}$ a $9^{\circ}$ ano), aproximadamente 70 ao ensino médio, e 15 ao programa de educação a jovens e adultos, com aulas ministradas nos períodos da manhã e da tarde.

A Cooperativa Educacional de Bariri localiza-se à Avenida Centenário, 257. Trata-se de uma instituição de dependência privada que conta com um corpo docente e de funcionários de aproximadamente 60 pessoas. De acordo com a coordenação da cooperativa, estima-se que o número de alunos matriculados é da ordem de 230, sendo 180 destes pertencentes ao ensino fundamental ( $1^{\circ}$ a $9^{\circ}$ ano), e aproximadamente 50 ao ensino médio. A instituição possui ainda infraestrutura para promoção de educação infantil, com creche e pré-escola, atendendo cerca de 90 crianças, com aulas ministradas nos períodos da manhã e da tarde.

A indústria Plásticos Bariri localiza-se à Avenida Sérgio Furcin, 243. Trata-se de uma empresa que atua no segmento de produção de laminados sintéticos desde o ano de 1993. Estima-se que a instituição emprega cerca de 300 funcionários, os quais se revezam em turnos, garantindo o funcionamento 24 horas por dia.

O Umuarama Clube de Bariri localiza-se à Rua Marechal Floriano Peixoto, 1.080. Tratase de uma associação de caráter privado que oferece extensa infraestrutura para lazer, prática de esportes e eventos em geral. De acordo com a diretoria do clube, estima-se que o mesmo possui cerca de 30 funcionários e 1.200 associados.

A Figura 5.4 apresenta os PGTs por bicicleta identificados para a cidade de Bariri e, dentre estes polos, aqueles que foram inclusos na pesquisa. Em síntese, com o intuito de apontar as zonas de tráfego que mais geram viagens até os polos selecionados, foi pedido a uma parcela dos ciclistas que os frequentam que indicassem, voluntariamente, as origens de seus deslocamentos (endereço domiciliar e/ou bairro). Este processo foi realizado junto aos bicicletários existentes nestes PGTs, de maneira a abordar os ciclistas à medida que fossem se apresentando. Vale destacar ainda que em todos os polos selecionados houve um consentimento para a coleta de informações por parte de suas respectivas autoridades responsáveis. 
Figura 5.4: PGTs por bicicleta em Bariri.

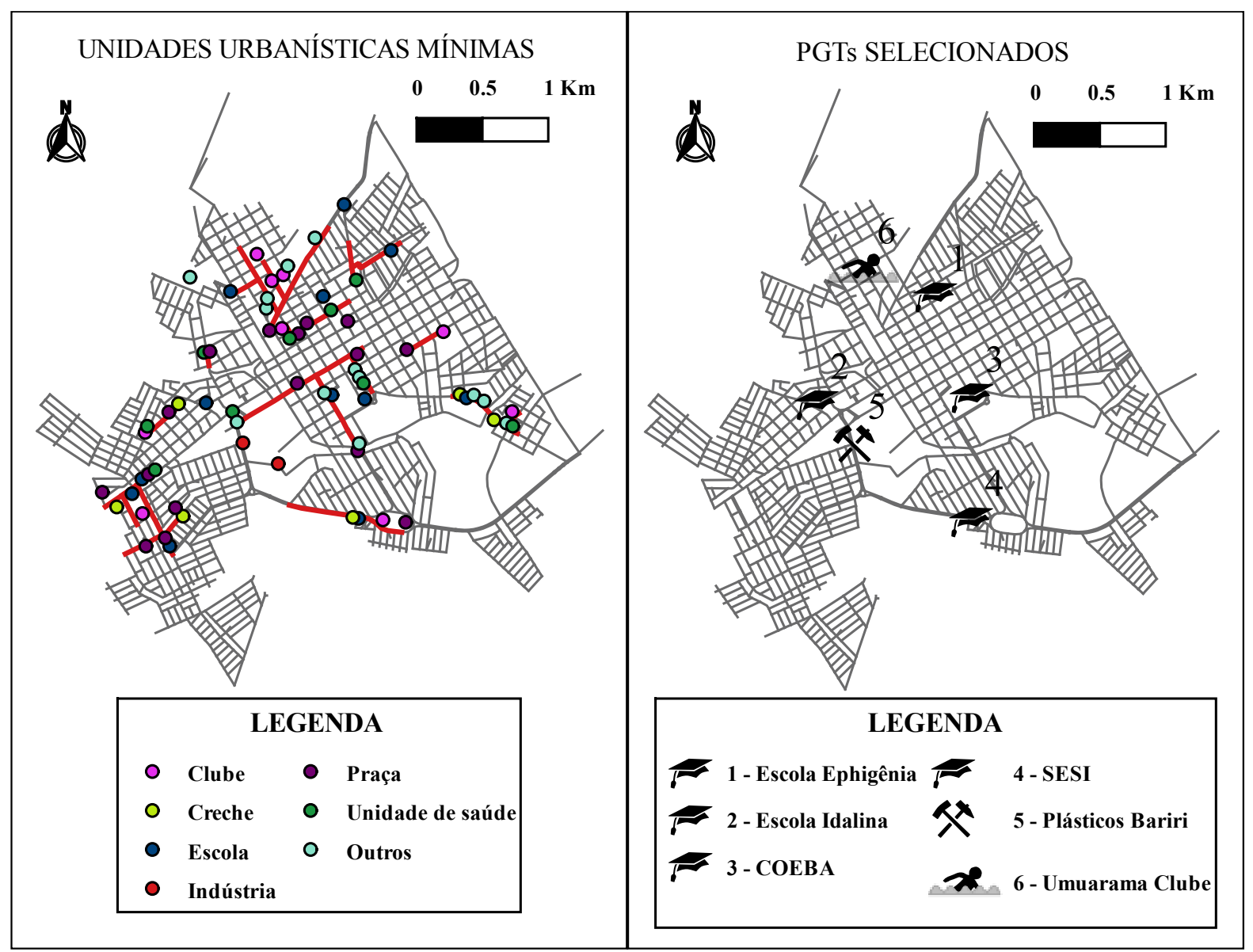

Fonte: Elaborado pelo autor.

\subsubsection{Tamanho da amostra}

Para a coleta de informações, fez-se necessária a definição do tamanho amostra de ciclistas a serem abordados. Segundo Richardson (1999), o tamanho da amostra é função de alguns fatores como: amplitude do universo de pesquisa, proporção da característica pesquisada, nível de confiança estabelecido, e erro de estimação permitido. $\mathrm{O}$ autor sugere ainda que, em pesquisas sociais, geralmente não se admite um erro de estimação superior a $6 \%$, adotando-se comumente $4 \%$.

De acordo com Barbetta (2002), as fórmulas utilizadas para o cálculo do tamanho da amostra são obtidas das expressões dos intervalos de confiança, fixando-se, a priori, o nível de confiança e o erro de estimação tolerado. Desta forma, faz-se com que o tamanho da amostra dependa basicamente da variabilidade da variável em estudo, representada pela sua variância $\left(\sigma^{2}\right)$, isto é, pelo quadrado de seu desvio-padrão. 
No caso da estimação de uma proporção, ainda segundo Barbetta (2002), a variância $(\sigma 2)$ pode ser substituída por uma estimativa, obtida por meio de algum estudo anterior. Desta forma, o tamanho da amostra pode ser calculado pela Equação 5.1 a seguir:

$$
\mathrm{n}_{0}=\frac{\mathrm{z}^{2} * \beta *(1-\beta)}{\mathrm{E}_{0}^{2}}
$$

Em que:

$\mathrm{n}_{0}$ : tamanho da amostra;

z: valor crítico correspondente ao nível de confiança;

$\beta$ : proporção populacional de indivíduos que pertence à categoria de interesse do estudo;

$\mathrm{E}_{0}$ : erro amostral admissível;

Pela teoria da distribuição normal, ao fixar-se um nível de confiança de 95\%, existe uma probabilidade de $95 \%$ de um valor a ser observado estar a menos de 1,96 desvios-padrão da média. Desta forma, o valor de z é igual a 1,96. Além disso, neste caso, com 95\% de confiança, pode-se considerar um erro amostral admissível de até 4\% (BARBETTA, 2002).

A ANTP, desde 2006, tem desenvolvido relatórios gerais de mobilidade urbana por meio da análise de dados sobre transporte e trânsito coletados anualmente em municípios brasileiros. Além disso, são desenvolvidos também relatórios comparativos, cujo objetivo é apresentar a evolução destes dados brasileiros sobre mobilidade urbana entre períodos distintos. O documento mais recente, intitulado "Relatório Geral (2014)", foi publicado em junho de 2016, e baseia-se em dados de 438 municípios integrantes do sistema de informações de mobilidade da ANTP (2016).

Dentre as informações presentes neste último relatório, encontram-se as divisões modais, em porcentagem, por porte dos municípios, como mostrado na Tabela 5.1. É válido observar que, apesar de os dados desta tabela só se referirem a municípios cuja população é superior a 60 mil habitantes, a porcentagem dos deslocamentos por modos de transporte não motorizados aumenta à medida que a população dos municípios diminui. Desta forma, para os municípios com população inferior a 60 mil habitantes, como é o caso de Bariri-SP, neste trabalho propõe-se a seguinte simplificação: considera-se, para estes municípios, que a divisão dos modos de transporte é semelhante à da primeira faixa de população considerada pela ANTP, isto é, entre 60 e 100 mil habitantes. 
Tabela 5.1: Divisões modais por porte dos municípios.

\begin{tabular}{l|c|c|c|c|c}
\hline \multirow{2}{*}{\multicolumn{1}{c|}{ Modo }} & \multicolumn{5}{c}{ Faixa de população } \\
\cline { 2 - 6 } & $>1$ milhão & $\begin{array}{c}500 \text { mil - } \\
1 \text { milhão }\end{array}$ & $\begin{array}{c}250-500 \\
\text { mil }\end{array}$ & $\begin{array}{c}100-250 \\
\text { mil }\end{array}$ & $\begin{array}{c}60-100 \\
\text { mil }\end{array}$ \\
\hline Transporte coletivo & 31 & 26 & 27 & 25 & 23 \\
\hline Ônibus municipal & 22 & 20 & 18 & 16 & 17 \\
Ônibus metropolitano & 2 & 6 & 9 & 9 & 6 \\
Trilhos & 8 & 0 & 0 & 0 & 0 \\
\hline Transporte individual & 33 & 34 & 30 & 27 & 24 \\
\hline Automóvel & 30 & 30 & 25 & 21 & 16 \\
Motocicleta & 3 & 4 & 5 & 6 & 8 \\
\hline Transporte não motorizado & 36 & 40 & 43 & 48 & 53 \\
\hline Bicicleta & 1 & 3 & 5 & 9 & 14 \\
A pé & 35 & 37 & 38 & 39 & 39 \\
\hline Total & 100 & 100 & 100 & 100 & 100 \\
\hline
\end{tabular}

Fonte: ANTP (2016, p. 30).

O modo de transporte cicloviário é responsável por $14 \%$ das viagens nos municípios com população entre 60 e 100 mil habitantes. Por meio das simplificações já apresentadas, temse então, para o município de Bariri-SP, $\beta=0,14$. Assim, o cálculo do tamanho da amostra é apresentado pela Equação 5.2.

$$
\mathrm{n}_{0}=\frac{(1,96)^{2} * 0,14 *(1-0,14)}{(0,04)^{2}}=289,08 \cong 290
$$

A pesquisa deve incluir, portanto, um mínimo de 290 ciclistas do município de BaririSP que se deslocam com destino aos polos geradores de tráfego por bicicleta selecionados. Neste sentido, foram cadastradas as respostas dadas por 293 ciclistas com relação às origens de suas viagens até os respectivos PGTs, obedecendo-se ao tamanho mínimo da amostra. Estas informações, georreferenciadas com o auxílio do QGIS, permitiram traçar as linhas de desejo dos ciclistas até os PGTs selecionados, as quais são apresentadas no capítulo 6 deste trabalho. 


\subsection{Avaliação da compatibilidade das vias com o transporte cicloviário}

A seguir é apresentada a metodologia utilizada para o levantamento de informações que possibilitaram a avaliação da compatibilidade das vias de tráfego de Bariri-SP com o transporte cicloviário.

\subsubsection{Nivelamento com auxílio da tecnologia GNSS}

A expressiva maioria dos trabalhos acadêmicos e dos estudos de viabilidade técnica voltados ao transporte cicloviário utiliza-se de modelos digitais de elevação (MDEs) para a análise do relevo da área de estudo, como, por exemplo, o SRTM (Shuttle Radar Topographic Mission), um trabalho realizado em fevereiro do ano 2000 em parceria entre a National Geospatial-Intelligence Agency (NGA) e a National Aeronautics and Space Administration (NASA) que teve como objetivo a produção de um modelo topográfico digital de alta resolução para a Terra. O referencial altimétrico utilizado pelo SRTM é o elipsoide WGS84, em que o modelo terrestre é representado pelo Earth Geopotential Model 1996 - EGM96 (LEMOS; SOUZA; ROCHA, 2009).

Segundo Landau e Guimarães (2011), os modelos SRTM são gerados a partir de um método de aquisição de dados altimétricos conhecido por interferometria, que consiste na comparação de duas imagens de radar tomadas de pontos ligeiramente diferentes para a obtenção da elevação ou informações sobre mudanças na superfície. A missão cobriu cerca de $80 \%$ da superfície terrestre (compreendida entre as latitudes $56^{\circ} \mathrm{S}$ e $60^{\circ} \mathrm{N}$ ), e os dados disponibilizados possuíam, inicialmente, resolução espacial de $30 \mathrm{~m}$ para os EUA, e 90 m para os demais locais da Terra.

Apesar do extenso uso entre os planejadores em transportes, os modelos SRTM apresentam algumas limitações: a aquisição dos dados pelo método da interferometria é constantemente prejudicada pelo efeito de ruídos provocados pela presença de corpos d'água e por problemas relacionados à perda do retorno do sinal (LEMOS; SOUZA; ROCHA, 2009). Além disso, a tolerância aos erros verticais absolutos para validação dos produtos gerados pelo SRTM, segundo os próprios idealizadores, é da ordem de 16 m (SLATER et al., 2006), inviabilizando a utilização destes MDEs em aplicações que exigem considerável acuracidade 
vertical, como a verificação de perfis longitudinais das vias de tráfego de uma determinada área de estudo. Ainda com relação às limitações dos modelos SRTM, Landau e Guimarães (2011) alertam para o fato de que, em função de sua resolução espacial, estes modelos apresentam restrições de uso para áreas pequenas, sendo relativamente mais adequados para áreas extensas.

Desta forma, neste trabalho propõe-se que o levantamento de informações referentes ao relevo da cidade de Bariri-SP seja realizado por meio do nivelamento das vias de tráfego com o auxílio da tecnologia GNSS, ou seja, por meio do trabalho de nivelamento realizado com o uso de antenas receptoras que captam sinais emitidos por satélites artificiais. Trata-se de um processo extremamente rápido quando comparado com os demais métodos de nivelamento, porém sua precisão pode degradar-se consideravelmente se o operador desconsiderar alguns aspectos importantes relacionados à tecnologia GNSS, como a geometria dos satélites e os efeitos da troposfera e da ionosfera (SILVA; SEGANTINE, 2015).

De acordo com Segantine (2005), diversas técnicas têm sido desenvolvidas nos últimos anos, explorando a capacidade da tecnologia GNSS, com o intuito de fornecer as coordenadas de pontos de interesse após um pequeno período de observação. Nos casos em que o rastreamento destas coordenadas é realizado com a antena em movimento, dá-se o nome de método cinemático.

O método cinemático é aquele em que uma antena receptora é fixada sobre um ponto de coordenadas conhecidas enquanto uma ou mais antenas são deslocadas sobre outros pontos durante a coleta de dados. Neste método, a antena remota (móvel) pode afastar-se da antena receptora o quanto for necessário, desde que ambas as antenas estejam coletando dados do mesmo conjunto de satélites. Os dados coletados em campo podem ser processados após o fim do levantamento (pós-processamento), ou em tempo real (RTK) (SEGANTINE, 2005).

O método cinemático pode ser usado para posicionar antenas remotas transportadas por veículos que trafegam por uma determinada área delimitada para estudo. Desta forma, é possível deslocar-se pelo terreno, obedecendo aos acidentes geográficos do mesmo, com o objetivo de rastrear as coordenadas tridimensionais dos pontos de interesse do nivelamento. Estas coordenadas podem ser determinadas com precisão da ordem de centímetros, possibilitando a representação do relevo por meio de mapas topográficos (pontos cotados) da área percorrida, curvas de nível ou mapas de declividades (SEGANTINE, 2005; SILVA; SEGANTINE, 2015). 
O levantamento das coordenadas dos pontos ao longo das vias de tráfego da cidade de Bariri-SP, com auxílio de receptores GNSS, foi realizado entre os dias 7 e 22 de setembro de 2017. Para isso, foram utilizadas duas antenas receptoras, uma fixa e uma móvel, sendo esta última transportada com o auxílio de um automóvel. Os detalhes destes equipamentos, pertencentes ao Laboratório de Mensuração do Departamento de Engenharia de Transportes da EESC/USP, são apresentados no Apêndice A.

A Figura 5.5 apresenta os pontos levantados com o auxílio da tecnologia GNSS na cidade de Bariri-SP.

Figura 5.5: Pontos levantados com o auxílio da tecnologia GNSS.

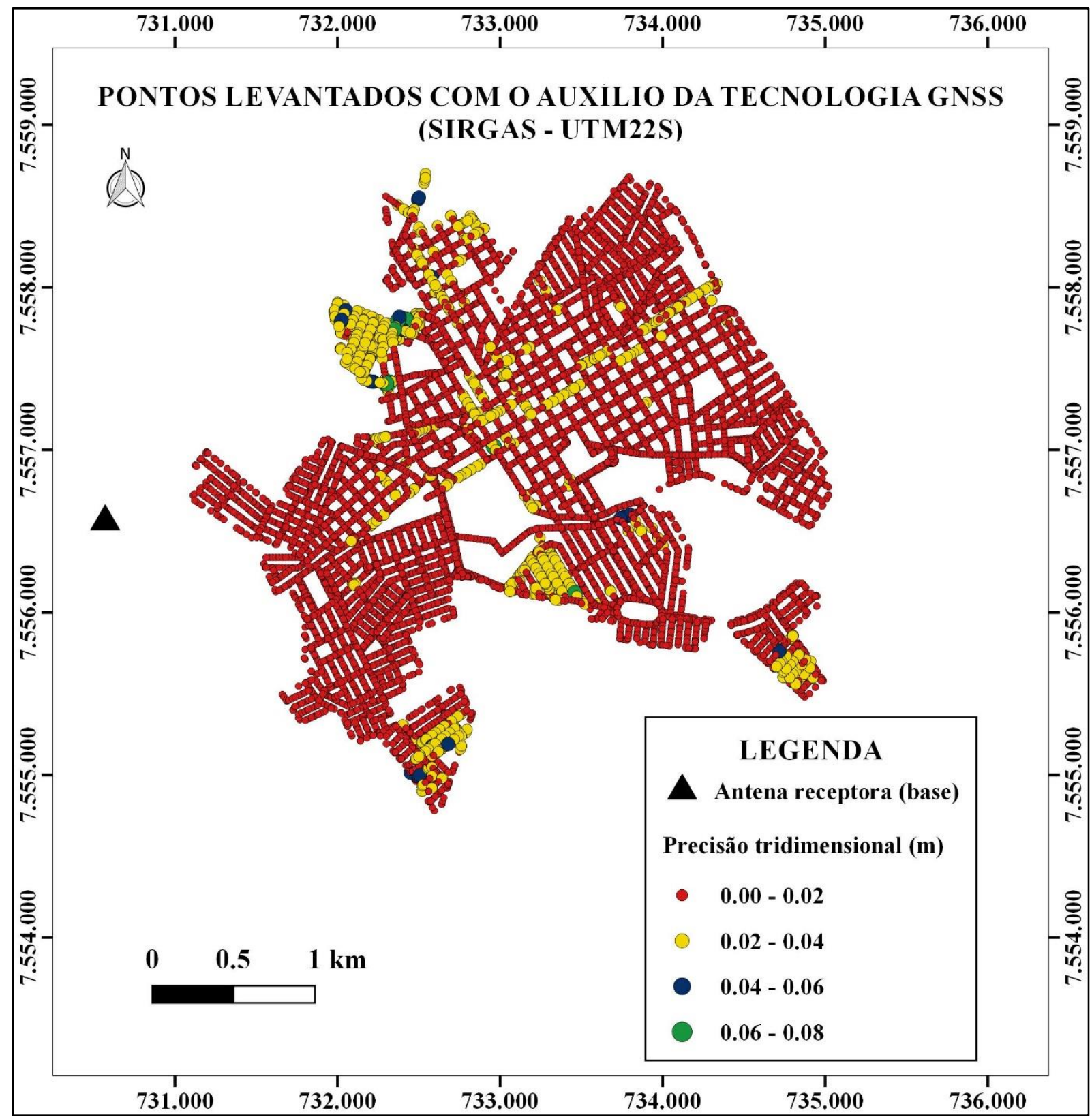

Fonte: Elaborado pelo autor. 
Com relação à antena receptora, ao invés de fixá-la sobre um ponto de coordenadas conhecidas, optou-se, neste trabalho, pela instalação da mesma sobre um ponto qualquer fora dos limites urbanos, com o intuito de evitar interferências nos sinais dos satélites por parte edificações, árvores e demais obstáculos. Assim, as coordenadas do ponto escolhido foram rastreadas por esta antena, numa primeira avaliação, por um intervalo de aproximadamente $9 \mathrm{~h}$, pós-processadas com o auxílio de dados RINEX (Receiver Independent Exchange), disponibilizados diariamente pelo IBGE, das três estações da Rede Brasileira de Monitoramento Contínuo (RBMC) mais próximas da área de estudo, isto é, EESC (São Carlos), SPBO (Botucatu) e SPPI (Piracicaba), e então ajustadas. Com estas coordenadas ajustadas, foi possível realizar o processamento das linhas de base para os demais pontos levantados ao longo da área de estudo pela antena remota.

O rastreamento das coordenadas pelas duas antenas ocorreu de maneira simultânea, com taxa de rastreamento de 1 segundo, e o processamento dos dados, realizado após o fim do levantamento (pós-processamento) com o auxílio do software LEICA Geo Office Combined (versão 7.0), permitiu que fossem alcançadas precisões tridimensionais centimétricas. Para isto foram utilizados os parâmetros de processamento padrão do próprio software, ou seja, para o ângulo vertical de altura para captação das efemérides transmitidas pelos satélites (ângulo de corte) foi admitido um valor de $\alpha=15^{\circ}$, e o modelo troposférico utilizado foi o de Hopfield. Não foi considerada a aplicação de modelos ionosféricos no processamento dos dados.

\subsubsection{Altitudes ortométricas}

As alturas obtidas para os pontos de interesse, por meio do levantamento com auxílio da tecnologia GNSS, são denominadas alturas geométricas ou elipsoidais (h), ou seja, as elevações destes pontos em relação à superfície de um determinado elipsoide de referência. Trata-se de um conceito puramente geométrico, sem significado físico, e, portanto, pouco útil aos trabalhos comuns da engenharia. Assim, para a correção dos valores das alturas elipsoidais, medidas com as antenas receptoras GNSS, deve ser considerada a ondulação geoidal (N), que é baseada nas irregularidades da superfície física da Terra (SILVA; SEGANTINE, 2015).

Para a obtenção da ondulação geoidal é necessário a utilização de softwares que contenham modelos geoidais precisos. O modelo utilizado neste trabalho foi o MAPGEO2015, disponibilizado gratuitamente pelo IBGE. Com relação à qualidade dos dados fornecidos, o 
próprio IBGE (2015) declara que o erro médio padrão associado ao modelo é da ordem de 0,5 m.

A diferença entre a altura elipsoidal e a ondulação geoidal recebe o nome de altitude ortométrica $(\mathrm{H})$, ou seja, a elevação de um ponto em relação ao geoide que, por sua vez, possui significado físico (potencial gravimétrico do ponto). Esta relação entre as alturas elipsoidal, ortométrica e ondulação geoidal é ilustrada pela Figura 5.6.

Figura 5.6: Relação entre alturas geométrica, altitude ortométrica e ondulação geoidal.

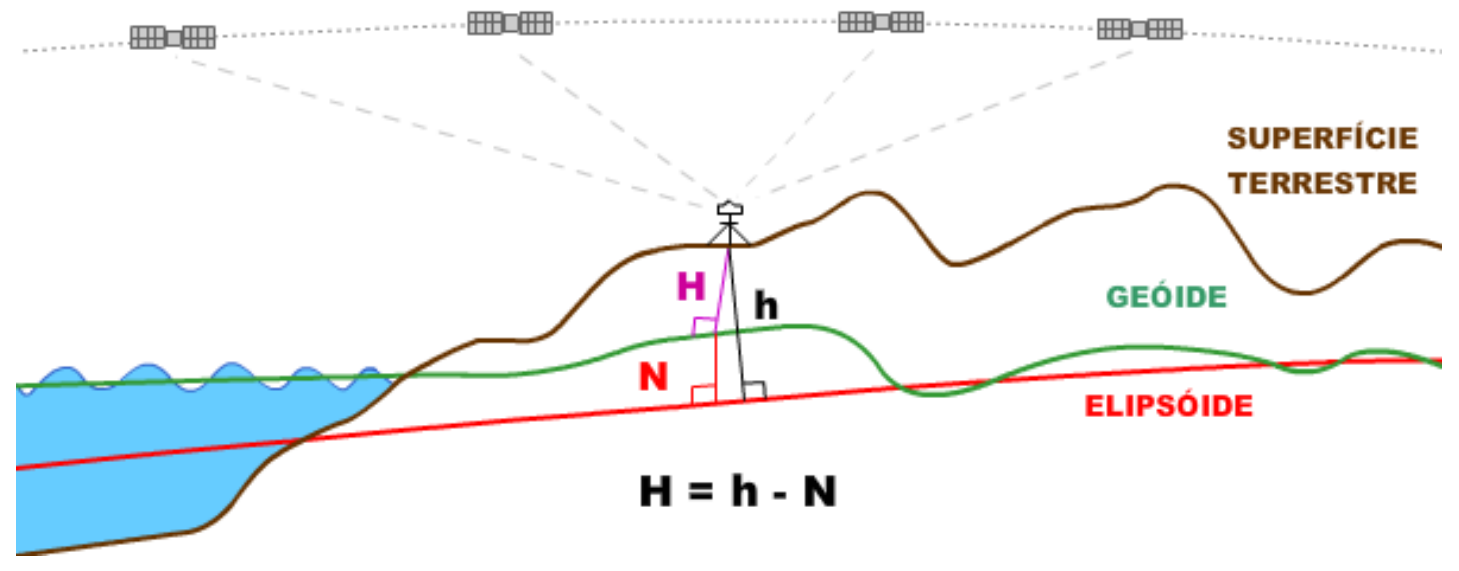

Fonte: IBGE (2015).

As altitudes ortométricas dos pontos levantados possibilitaram o traçado das curvas de nível e do mapa de elevações para a área delimitada para estudo. Para se estimar as elevações dos locais com ausência de informações, foi realizado um processo de interpolação destas altitudes, cujo método utilizado foi a ponderação pelo inverso da distância. A partir do mapa de elevações, foi possível a produção de um mapa de declividades contendo as classes de declividade de interesse ao transporte cicloviário. Todos estes resultados são apresentados no capítulo 6 deste trabalho.

\subsubsection{Volumes e velocidades dos veículos motorizados}

A avaliação do nível de estresse pelo modelo de Sorton e Walsh (1994) e a verificação da necessidade de inserção de facilidades para ciclistas pelo critério da LTSA (2004) possuem as seguintes variáveis de entrada em comum: volume e velocidade de tráfego dos veículos motorizados. A seguir são apresentados os procedimentos para o levantamento de cada uma 
destas variáveis ao longo dos segmentos viários da cidade de Bariri-SP. Os resultados das avaliações individuais do nível de estresse para estas variáveis são apresentados no capítulo 6.

\subsubsection{Volumes dos veículos motorizados}

Os volumes de veículos motorizados das vias de tráfego da área de estudo foram estimados por meio de contagens volumétricas manuais em 26 interseções entre vias que compõem as redes primária e secundária da cidade de Bariri-SP, as quais são apresentadas pela Figura 5.7. Estas contagens foram realizadas em intervalos de 15 minutos, compreendidos em horários de pico previamente estabelecidos $(7 \mathrm{~h}-8 \mathrm{~h}, 12 \mathrm{~h}-13 \mathrm{~h}$ e $18 \mathrm{~h}-19 \mathrm{~h})$, considerando-se os diferentes tipos de veículos a seguir: automóveis, motocicletas, veículos pesados (ônibus e caminhões) e bicicletas. O volume VHP foi então calculado projetando-se os valores levantados durante os períodos de 15 minutos para 1 hora, isto é, multiplicando-os por 4.

Figura 5.7: Interseções selecionadas para contagens volumétricas.

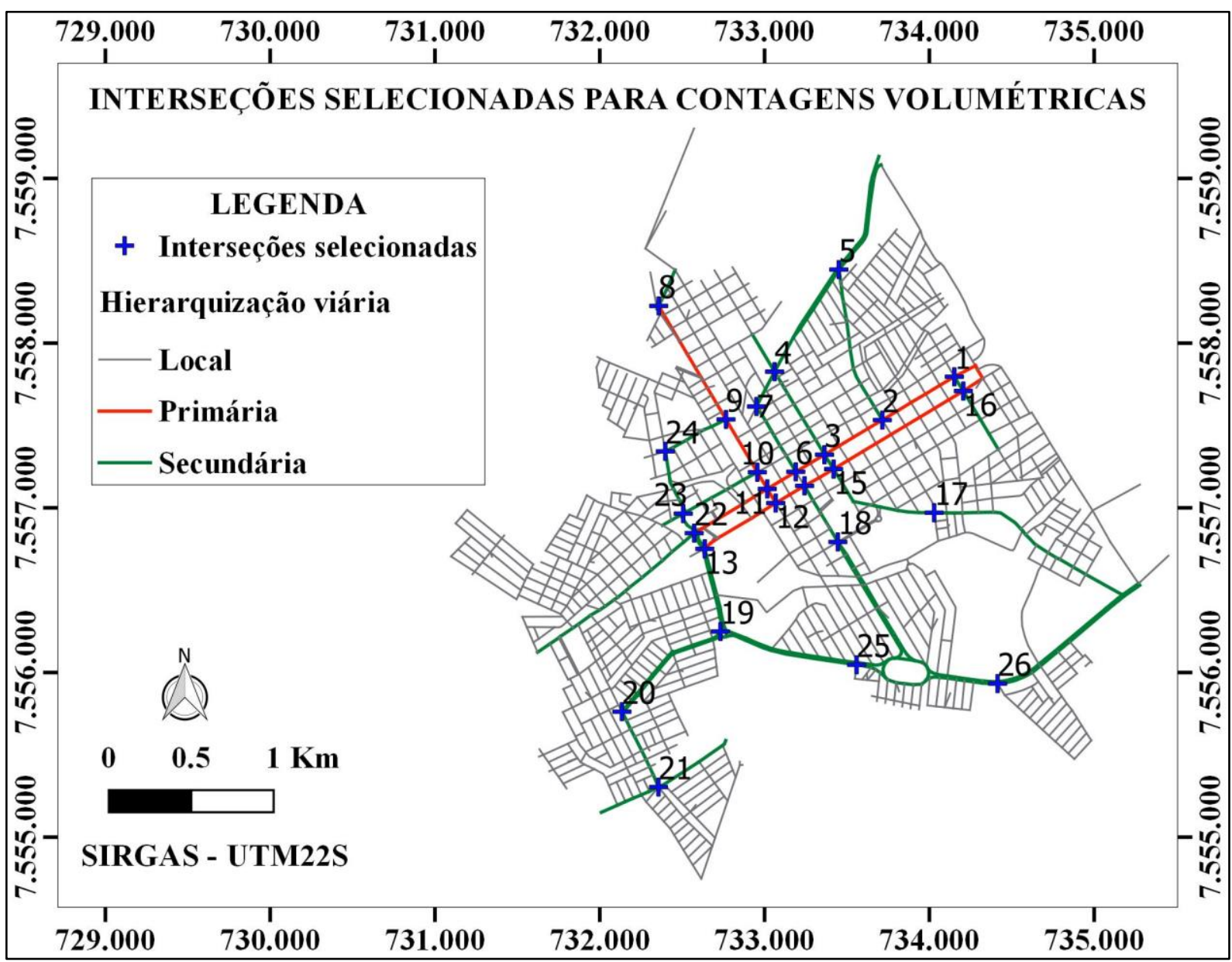

Fonte: Elaborado pelo autor. 
A coleta de informações foi realizada entre os dias 09 e 27 de outubro de 2017. Com o intuito de se evitar situações atípicas de volumes de tráfego, optou-se pela não realização do levantamento das informações no período da manhã das segundas-feiras e no período da tarde das sextas-feiras. Além disso, as contagens foram planejadas de maneira a não incluir vésperas de feriados, feriados e períodos de férias ou recessos escolares.

Para a conversão dos diferentes tipos de veículos analisados nas contagens em unidades de carro de passeio, o DNIT (2006) sugere que sejam utilizados fatores de equivalência propostos pelo manual alemão Handbuch für die Bemessung von Strassenverkehrsanlagen (FGSV, 2001), os quais são apresentados pela Tabela 5.2.

Tabela 5.2: Fator de equivalência em veículos de passeio - HBS.

\begin{tabular}{c|c|c|c|c}
\hline Tipo de Veículo & $\mathrm{A}$ & $\mathrm{M}$ & $\mathrm{O} / \mathrm{C}$ & $\mathrm{B}$ \\
\hline $\mathrm{F}_{\mathrm{eq}}$ & 1,0 & 1,0 & 1,5 & 0,5 \\
\hline
\end{tabular}

A=Automóveis; M=Motocicletas; $\mathrm{O} / \mathrm{C}=$ Ônibus e Caminhões; $\mathrm{B}=$ Bicicletas;

Fonte: Adaptado de DNIT (2006, p. 56).

Desta forma, o cálculo do volume de veículos motorizados em unidades de carro de passeio é dado pela Equação 5.3:

$$
\mathrm{V}_{\mathrm{p}}=1 *(\mathrm{~A})+1 *(\mathrm{M})+1,5 *(\mathrm{O} / \mathrm{C})
$$

Em que:

$\mathrm{V}_{\mathrm{p}}$ : volume de veículos motorizados em unidades de carro de passeio;

A: volume de automóveis;

M: volume de motocicletas;

O/C: volume de ônibus e caminhões.

Os resultados das contagens volumétricas expressas em veículos de passeio para cada interseção avaliada são apresentados no Apêndice B.

As limitações de tempo e de recursos deste trabalho implicam em algumas considerações para o volume de veículos motorizados nas vias locais e residenciais. Neste sentido, Sorton e Walsh (1994) indicam que para vias residenciais de duplo sentido de circulação pode ser considerado um VMD de 1000 veíc./dia. 
Como já descrito na seção 3.2.1.1 deste trabalho, o VHP por faixa pode ser calculado de acordo com uma porcentagem representativa deste VMD (aproximadamente 10\%). Desta forma, dividindo-se este valor igualmente entre os dois sentidos de circulação, estima-se que o VHP para as vias residenciais seja da ordem de 50 veíc./h/faixa. Com base neste baixo valor de VHP calculado para vias residenciais, neste trabalho propõe-se que a avaliação individual do nível de estresse relacionada a esta variável, nestes locais, seja igual a 1. Isto significa que, com relação exclusivamente ao volume de automóveis que trafegam por estas vias, a mesma é indicada à utilização de todos os grupos de ciclistas, com exceção de crianças com idade inferior a 10 anos.

\subsubsection{Velocidades dos veículos motorizados}

A velocidade média dos veículos motorizados que trafegam por um determinado ponto ou seção da via pode ser estimada por meio da média aritmética simples das velocidades pontuais de cada veículo observado. Desta forma, com o objetivo de se conhecer a velocidade instantânea de cada veículo, os radares se apresentam como os dispositivos mais adequados para estes levantamentos (DNIT, 2006).

$\mathrm{O}$ alto custo dos radares, no entanto, restringe a utilização destes equipamentos em estudos de tráfego, principalmente em locais que dispõem de recursos limitados e corpo técnico não especializado, como é o caso da maioria das cidades brasileiras de pequeno porte. Desta forma, outros métodos mais simples e baratos podem ser encontrados na literatura para a estimativa da velocidade média dos veículos motorizados.

A estimativa da velocidade por meio da utilização de cronômetros consiste em medir o tempo que um determinado veículo demora para transpor um trecho de extensão conhecida ("base"). O equipamento deve ser acionado nos momentos em que o veículo entra e sai da base. O comprimento deste trecho, dividido pelo tempo registrado, fornece a velocidade média deste veículo. Para bases variando entre 30 e $100 \mathrm{~m}$, esta velocidade pode ser considerada a velocidade pontual (DNIT, 2006).

A principal desvantagem de utilização deste método consiste no erro derivado da decisão do operador em acionar o cronômetro nos momentos em que o veículo entra e sai da base. Entretanto, a facilidade de aplicação e o requerimento mínimo de recursos justificam a 
escolha do mesmo na estimação da velocidade dos veículos para o estudo de caso realizado na cidade de Bariri-SP.

A coleta de informações foi realizada entre os dias 23 e 27 de outubro de 2017. Assim, como indicado por Providelo (2011), foram utilizadas amostras aleatórias de 30 automóveis em cada um dos trechos analisados. A velocidade média do tráfego em cada um destes trechos pode então ser estimada pela média aritmética das 30 velocidades pontuais calculadas.

A seleção dos trechos para o processo de cronometragem, assim como para as contagens volumétricas, foi baseada na hierarquização viária da cidade de Bariri-SP, como mostra a Figura 5.8 .

Figura 5.8: Trechos selecionados para estimativas das velocidades.

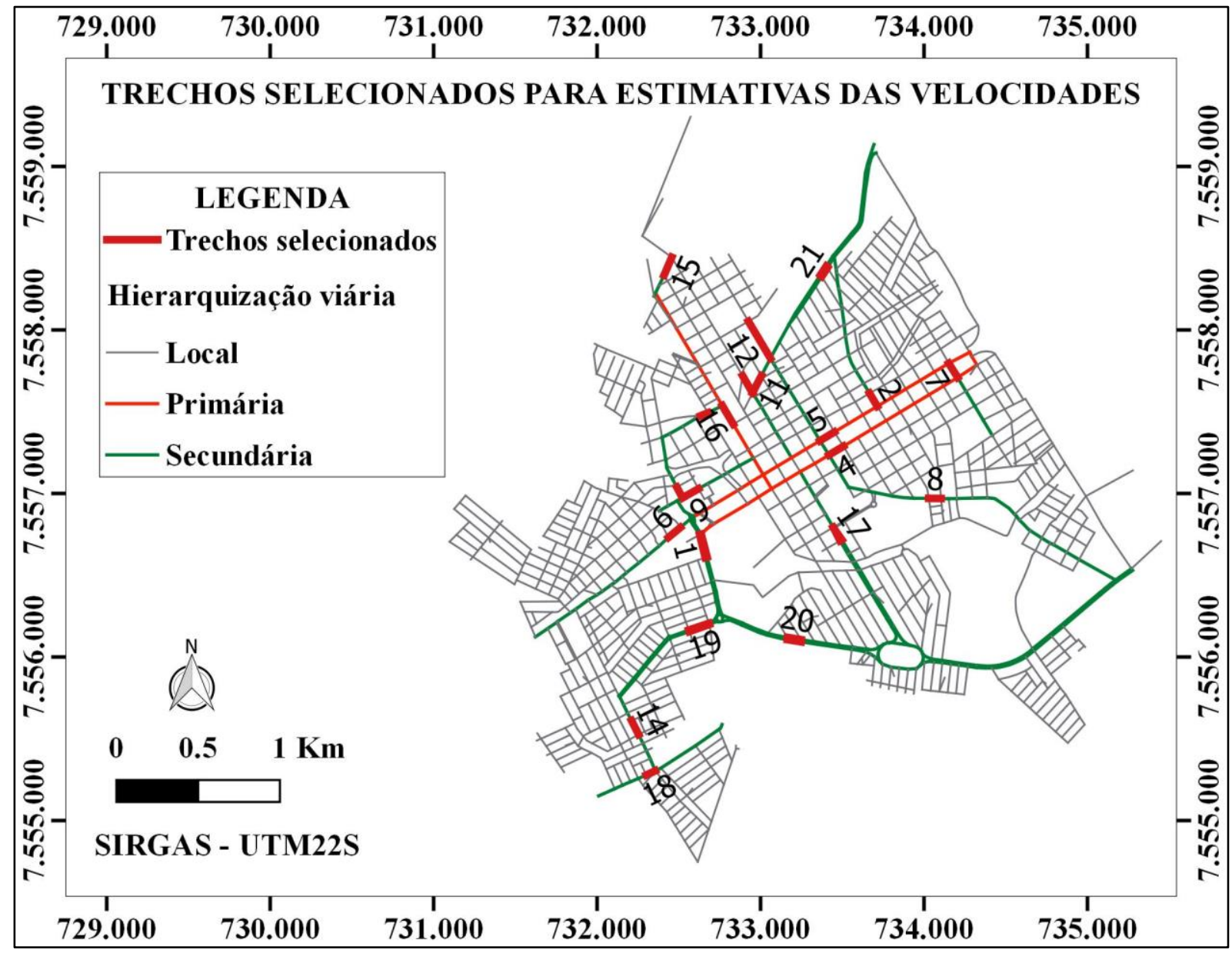

Fonte: Elaborado pelo autor.

Com relação às vias residenciais e locais, assim como na avaliação do volume de veículos motorizados, algumas considerações foram feitas: para a velocidade dos veículos motorizados que trafegam nestas vias foi adotado o valor de $30 \mathrm{~km} / \mathrm{h}$, baseando-se nos limites 
de velocidade de circulação de automóveis em vias urbanas previstos no Código de Trânsito Brasileiro (CTB, 2010). Desta forma, neste trabalho propõe-se que, para estas vias, a avaliação individual do nível de estresse relacionada à variável velocidade, assim como para a avaliação do volume, seja igual a 1 .

As extensões de cada trecho selecionado e as velocidades médias estimadas para cada um deles são apresentadas pelas Tabelas 5.3 e 5.4. Os tempos cronometrados para as amostras de veículos de cada trecho são apresentados no Apêndice C.

Tabela 5.3: Estimativas das velocidades médias dos veículos (ID: 1-10).

\begin{tabular}{c|c|c|c|c|c|c|c|c|c|c}
\hline \multicolumn{1}{c}{} & \multicolumn{10}{c}{ ID } \\
\cline { 2 - 11 } & 1 & 2 & 3 & 4 & 5 & 6 & 7 & 8 & 9 & 10 \\
\hline $\mathrm{L}(\mathrm{m})$ & 65 & 71 & 81 & 94 & 95 & 75 & 100 & 83 & 63 & 55 \\
$\mathrm{~V}(\mathrm{~km} / \mathrm{h})$ & 46 & 39 & 44 & 35 & 37 & 33 & 38 & 39 & 36 & 29 \\
\hline
\end{tabular}

Fonte: Elaborado pelo autor.

Tabela 5.4: Estimativas das velocidades médias dos veículos (ID: 11-20).

\begin{tabular}{c|c|c|c|c|c|c|c|c|c|c}
\hline \multicolumn{1}{c}{} & \multicolumn{10}{c}{ ID } \\
\cline { 2 - 11 } & 11 & 12 & 13 & 14 & 15 & 16 & 17 & 18 & 19 & 20 \\
\hline $\mathrm{L}(\mathrm{m})$ & 68 & 75 & 79 & 100 & 72 & 61 & 99 & 76 & 99 & 92 \\
$\mathrm{~V}(\mathrm{~km} / \mathrm{h})$ & 45 & 50 & 38 & 34 & 41 & 40 & 52 & 34 & 36 & 54 \\
\hline
\end{tabular}

Fonte: Elaborado pelo autor.

\subsubsection{Larguras das faixas externas das vias de tráfego}

As larguras das faixas externas das vias de tráfego da cidade de Bariri-SP foram estimadas com o auxílio das dimensões das faixas de domínio, isto é, das distâncias compreendidas entre as edificações de cada quarteirão, por meio de um mapa com diversas camadas vetoriais disponibilizado pela prefeitura municipal. Desta forma, para cada um dos segmentos viários da área de estudo pôde ser atribuído um valor que corresponde à disponibilidade de espaço do mesmo para comportar o transporte cicloviário. 
A partir destas distâncias compreendidas entre edificações, a largura da faixa externa pôde ser calculada por meio da subtração das larguras dos passeios, estacionamentos e eventuais pontos de parada de coletivos, como apresenta a Equação 5.4.

$$
\mathrm{L}_{\mathrm{fe}}=\frac{\mathrm{L}_{\mathrm{fd}}-\left(\mathrm{A} * \mathrm{~L}_{\text {passeio }}\right)-\left(\mathrm{B} * \mathrm{~L}_{\mathrm{dir}}\right)-\left(\mathrm{C} * \mathrm{~L}_{\mathrm{esq}}\right)}{\mathrm{D}}
$$

Em que:

$\mathrm{L}_{\mathrm{fe}}$ : largura da faixa externa;

Lfd: largura da faixa de domínio;

$\mathrm{L}_{\text {passeio: }}$ redução da largura pelos passeios $=2,0 \mathrm{~m}$;

$\mathrm{L}_{\text {dir }}=\mathrm{L}_{\mathrm{esq}}$ : redução da largura, respectivamente, pelos lados direito e esquerdo $\{2,30 \mathrm{~m}$, se permitido estacionamento lateral paralelo à pista de rolamento; $2,70 \mathrm{~m}$ se permitida parada de coletivos\};

A: $\{1$, se existir canteiro central; 2 , caso contrário $\}$;

B: $\{1$, se permitido estacionamento lateral paralelo ou parada de coletivos do lado direito da pista de rolamento; 0 , caso contrário\};

C: $\{1$, se permitido estacionamento lateral paralelo ou parada de coletivos do lado esquerdo da pista de rolamento; 0 , caso contrário $\}$;

D: sentidos de circulação $\{1$, se mão única; 2 , se mão dupla $\}$.

Os passeios são definidos como parte da calçada destinada à circulação de pedestres e, eventualmente, ao tráfego de bicicletas. A largura dos passeios em áreas residenciais pode variar entre 1,20 m e 2,40 m (DNIT, 2010). Assim, para a redução das faixas de domínio ocasionada pelos passeios foi considerado, neste trabalho, que estas estruturas possuem larguras da ordem de $2,0 \mathrm{~m}$.

Com relação às faixas de estacionamento, o DNIT (2010) recomenda, para locais com predominância de veículos leves, que as larguras destas estruturas estejam compreendidas entre 2,20 m e 2,50 m. Assim, para este trabalho, foram consideradas larguras para faixas de estacionamento da ordem de $2,30 \mathrm{~m}$. A verificação dos locais onde é permitido o estacionamento contíguo às vias de tráfego foi realizada utilizando-se o Google Street View, 
uma ferramenta do Google Earth que permite aos usuários navegarem por algumas regiões da superfície terrestre ao nível do solo por meio de vistas panorâmicas com alcances de $360^{\circ}$ na horizontal, e $290^{\circ}$ na vertical.

Com relação aos pontos de para de coletivos, apresentados na seção 5.1, recomenda-se que a largura da faixa necessária a estes espaços seja da ordem de 2,70 m (CET, 2001). Desta forma, para segmentos viários que dispõem tanto de estacionamentos laterais paralelos quanto de pontos de parada de coletivos, a redução da faixa de domínio, imaginando-se o cenário crítico, foi feita considerando-se a maior largura entre estas estruturas, ou seja, 2,70 m.

Os resultados da avaliação individual do nível de estresse com relação à largura da faixa externa das vias de tráfego são apresentados no capítulo 6. 
120|P á g i n a 


\section{RESULTADOS E DISCUSSÕES}

A seguir são apresentados os resultados e as discussões referentes à aplicação do método proposto por este trabalho na cidade de Bariri-SP

\subsection{Origens das viagens}

A Figura 6.1 apresenta as linhas de desejo, elaboradas com o auxílio do QGIS, para cada PGT incluso na pesquisa, as quais ilustram graficamente os fluxos de ciclistas ao longo da área delimitada para estudo, permitindo a identificação das origens das viagens realizadas por estes ciclistas. Neste sentido, pode-se afirmar que:

1) Com relação a Escola Estadual Prof. ${ }^{a}$ Idalina Vianna Ferro, as rotas cicláveis a serem identificadas para este PGT devem partir das zonas de tráfego 9, 12, 18, 19, 26 e 29;

2) Com relação a Escola Estadual Prof. ${ }^{a}$ Ephigênia Cardoso Machado Fortunato, as rotas cicláveis a serem identificadas para este PGT devem partir das zonas de tráfego 10, 12, $13,14,26$ e 29 ;

3) Com relação ao Centro Educacional SESI 143, as rotas cicláveis a serem identificadas para este PGT devem partir das zonas de tráfego 2, 12, 13, 14, 26 e 29;

4) Com relação à Cooperativa Educacional de Bariri - COEBA, a zona de tráfego 2 é a única realmente expressiva na geração de viagens até este PGT por bicicleta. Todas as demais zonas identificadas como origem dos deslocamentos são representadas por linhas de fluxo correspondentes a poucas viagens. Desta forma, pela não diferenciação entre estas demais zonas de tráfego, é proposto que, no caso deste PGT, sejam identificadas rotas cicláveis partindo-se de cada uma elas, ou seja, das zonas de tráfego 2, 10, 11, 22, 31, 34 e 35;

5) Com relação a indústria Plásticos Bariri, as rotas cicláveis a serem identificadas para este PGT devem partir das zonas de tráfego 19, 26, 29 e 35; e

6) Com relação ao Umuarama Clube de Bariri, as rotas cicláveis a serem identificadas para este PGT devem partir das zonas de tráfego 2, 10, 22, 25, 34 e 35. 
Figura 6.1: Linhas de desejo até os PGTs por bicicleta.

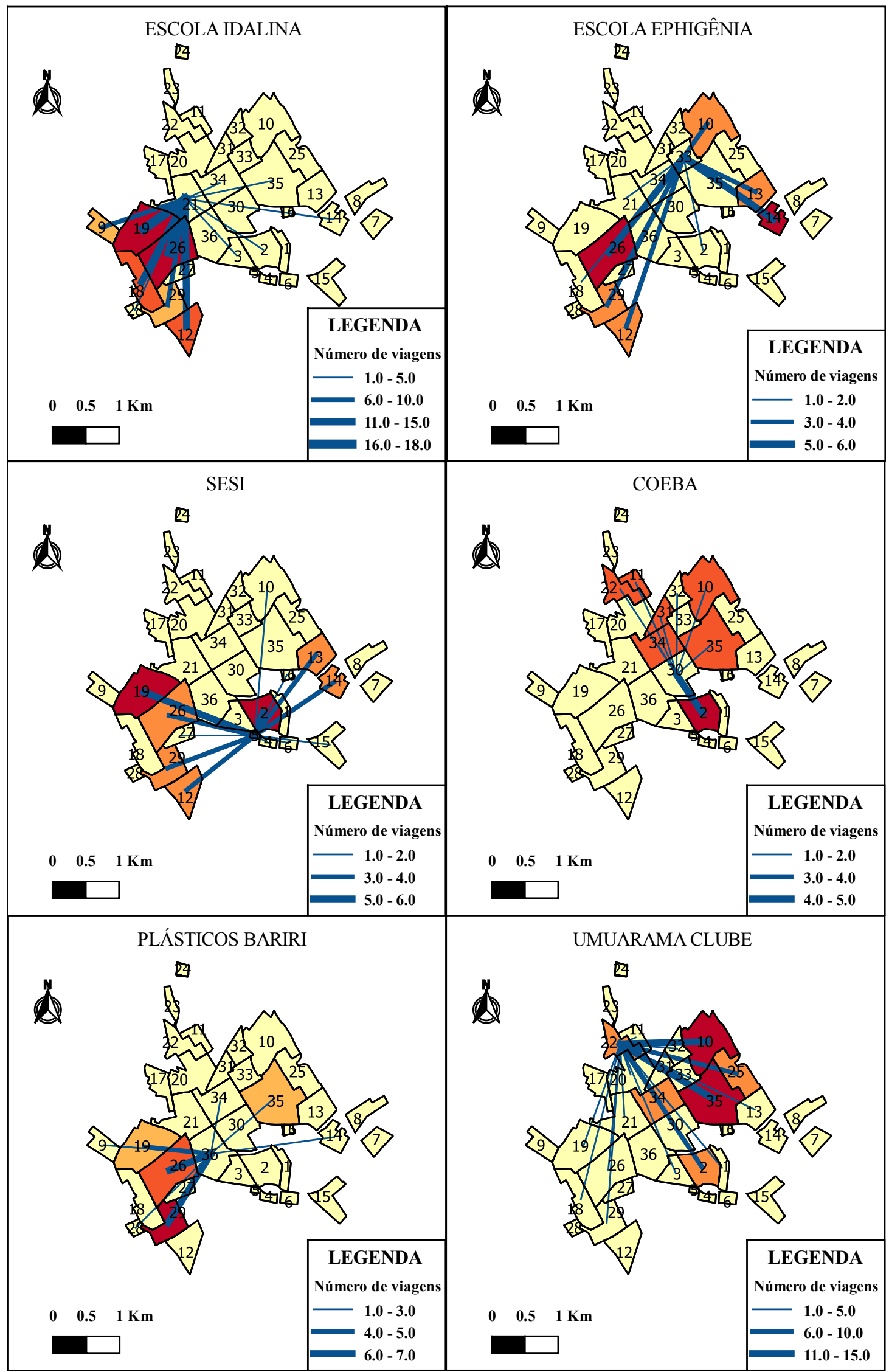

Fonte: Elaborado pelo autor. 


\subsection{Verificação do perfil topográfico (AASHTO, 1999)}

Os resultados do nivelamento das vias de tráfego da cidade de Bariri-SP com o auxílio da tecnologia GNSS permitiram a verificação do perfil topográfico destas vias, com relação ao transporte cicloviário, de acordo com o critério sugerido pela AASHTO (1999).

A Figura 6.2, a seguir, apresenta as curvas de nível e o mapa de elevações referentes à área de estudo.

Figura 6.2: Elevações dentro dos limites urbanos de Bariri-SP.

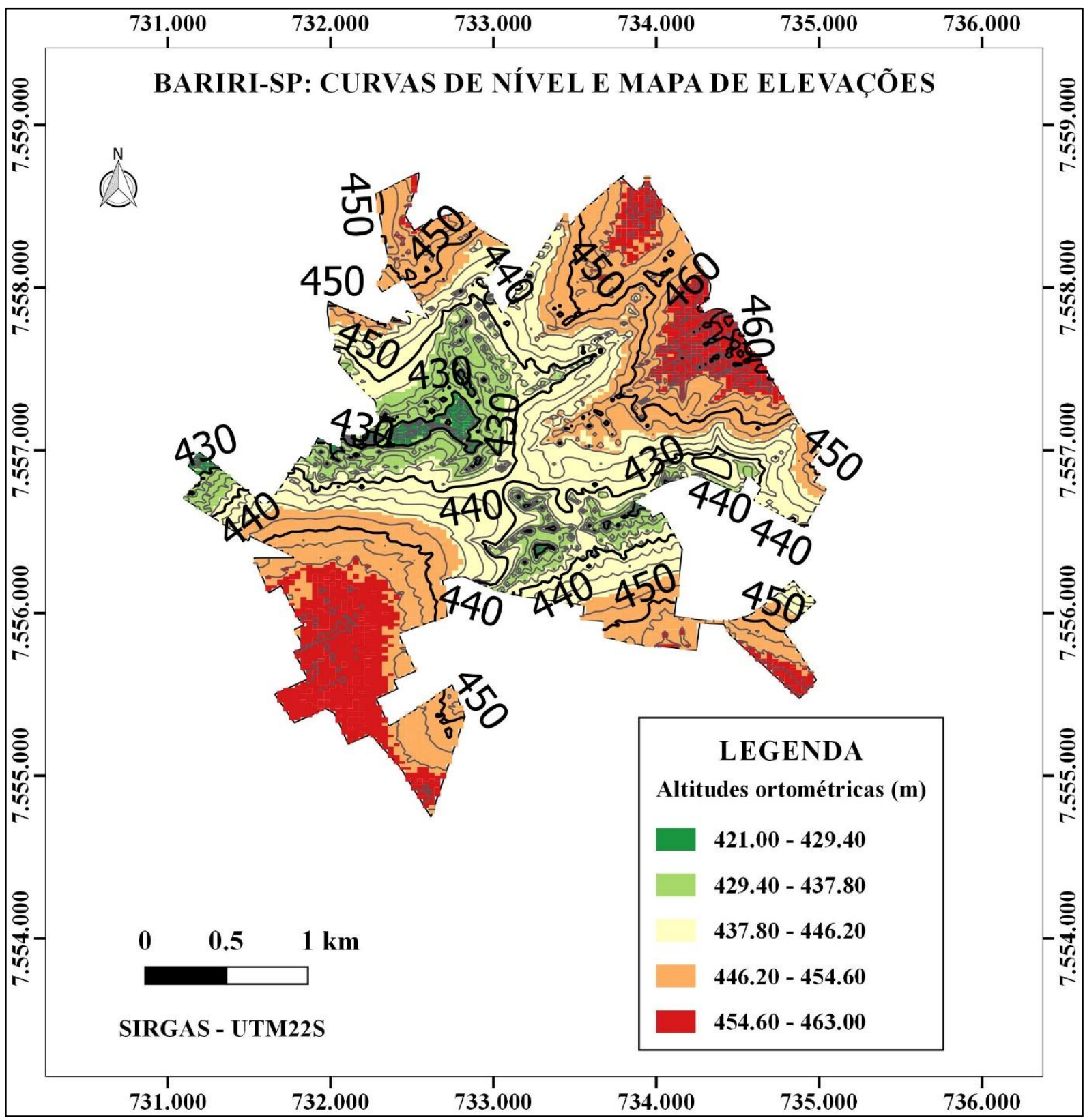

Fonte: Elaborado pelo autor. 
As altitudes ortométricas da área de estudo variam entre $421 \mathrm{~m}$ e $463 \mathrm{~m}$, com predominância de elevações menores na região central e maiores nas regiões periféricas. Estas informações, por sua vez, foram utilizadas para a produção de um mapa contendo as classes de declividade de interesse ao transporte cicloviário, apresentado pela Figura 6.3.

Figura 6.3: Classes de declividade para verificação do perfil topográfico das vias.

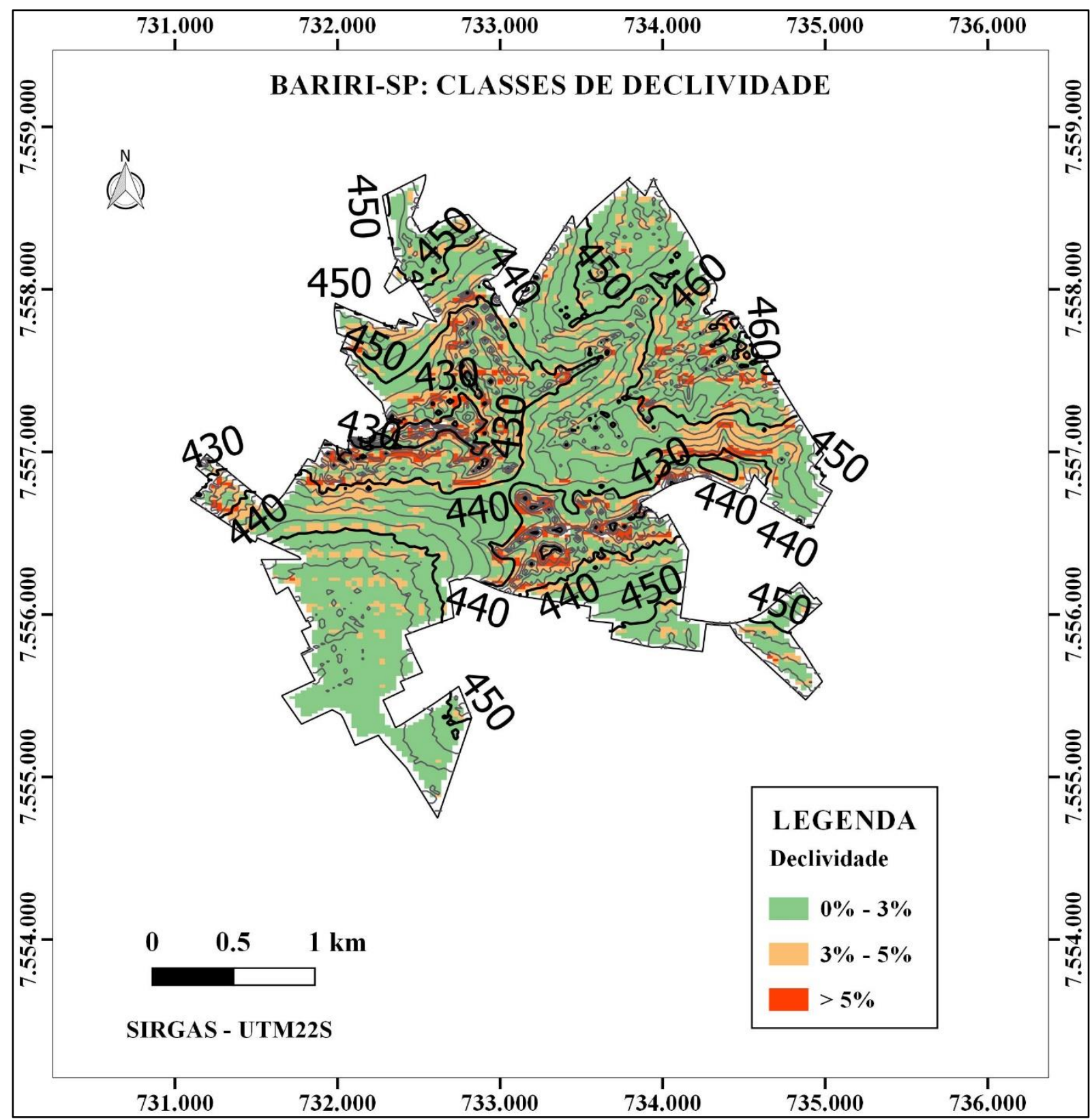

Fonte: Elaborado pelo autor.

De acordo com a Figura 6.3, pode-se afirmar que a área urbana do município de BaririSP possui, com relação ao relevo, um alto potencial ciclável, tendo em vista que aproximadamente $83 \%$ da mesma possui declividades inferiores a 5\%. A cada segmento viário 
da área de estudo foi atribuído, baseando-se nas informações apresentadas pelo mapa de declividades, um fator relacionado à declividade $\left(f_{\mathrm{dec}}\right)$ de acordo com seu grau de inclinação e respectivo comprimento em aclive, permitindo a verificação do perfil topográfico com relação ao transporte cicloviário.

\subsection{Avaliação da qualidade de serviço das vias (SORTON; WALSH, 1994)}

A seguir são apresentados os resultados da avaliação da compatibilidade das vias com o transporte cicloviário de acordo com as informações levantadas na cidade de Bariri-SP.

\subsubsection{Avaliações individuais do nível de estresse}

A Figura 6.4 apresenta, para cada segmento viário da cidade de Bariri-SP, suas respectivas avaliações individuais das variáveis utilizadas pelo modelo de Sorton e Walsh (1994). Para facilitar a visualização de como cada uma destas variáveis influencia isoladamente na qualidade de serviço das vias para o transporte cicloviário, a representação gráfica das avaliações individuais foi realizada aproximando-se o valor real destas avaliações ao número inteiro mais próximo. Os resultados são os seguintes:

1) Com relação ao volume de veículos motorizados, são observados, nas vias que compõem a rede primária, resultados ruins para a avaliação do nível de estresse (4 e 5). Com relação às vias que compõem a rede secundária, estes volumes são menores, resultando em uma predominância de avaliações intermediárias (3);

2) Com relação à velocidade de tráfego dos veículos motorizados, são observadas boas avaliações do nível de estresse (1 e 2), com exceção de algumas vias de tráfego pertencentes à rede secundária, cujas avaliações assumem valores intermediários (3); e

3) Com relação a largura da faixa externa, observa-se que, em vias locais, a disponibilidade de espaço para comportar o transporte cicloviário é um fator crítico, resultando em avaliações ruins do nível de estresse. Isto pode ser justificado pelo fato de a maioria destas vias possuir duplo sentido de circulação e, também, por ser permitido o estacionamento lateral de veículos paralelo a estes dois sentidos. Já com relação às vias 
que compõem as redes primária e secundária, são observadas avaliações do nível de estresse para a largura da faixa externa variando entre boas e intermediárias (1, 2 e 3).

Figura 6.4: Avaliações individuais das variáveis do nível de estresse.

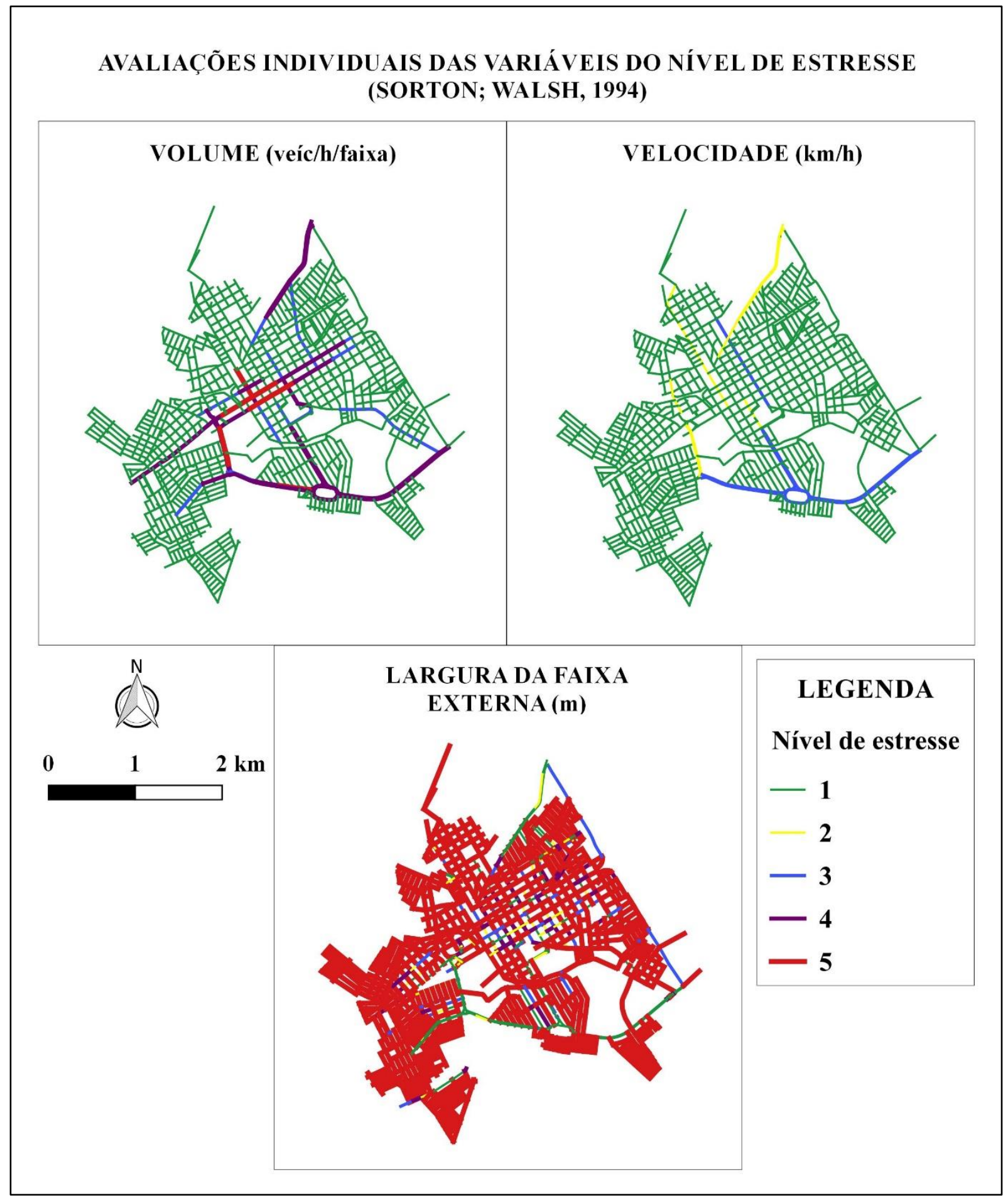

Fonte: Elaborado pelo autor. 


\subsubsection{Avaliação global do nível de estresse}

A Figura 6.5 apresenta, para cada segmento viário da área de estudo, suas respectivas avaliações globais com relação ao modelo de nível de estresse proposto por Sorton e Walsh (1994), calculada por meio da média aritmética entre as avaliações individuais apresentadas anteriormente. O valor final calculado, para termos de simplificação, foi aproximado do valor inteiro mais próximo.

Figura 6.5: Avaliação global do nível de estresse.

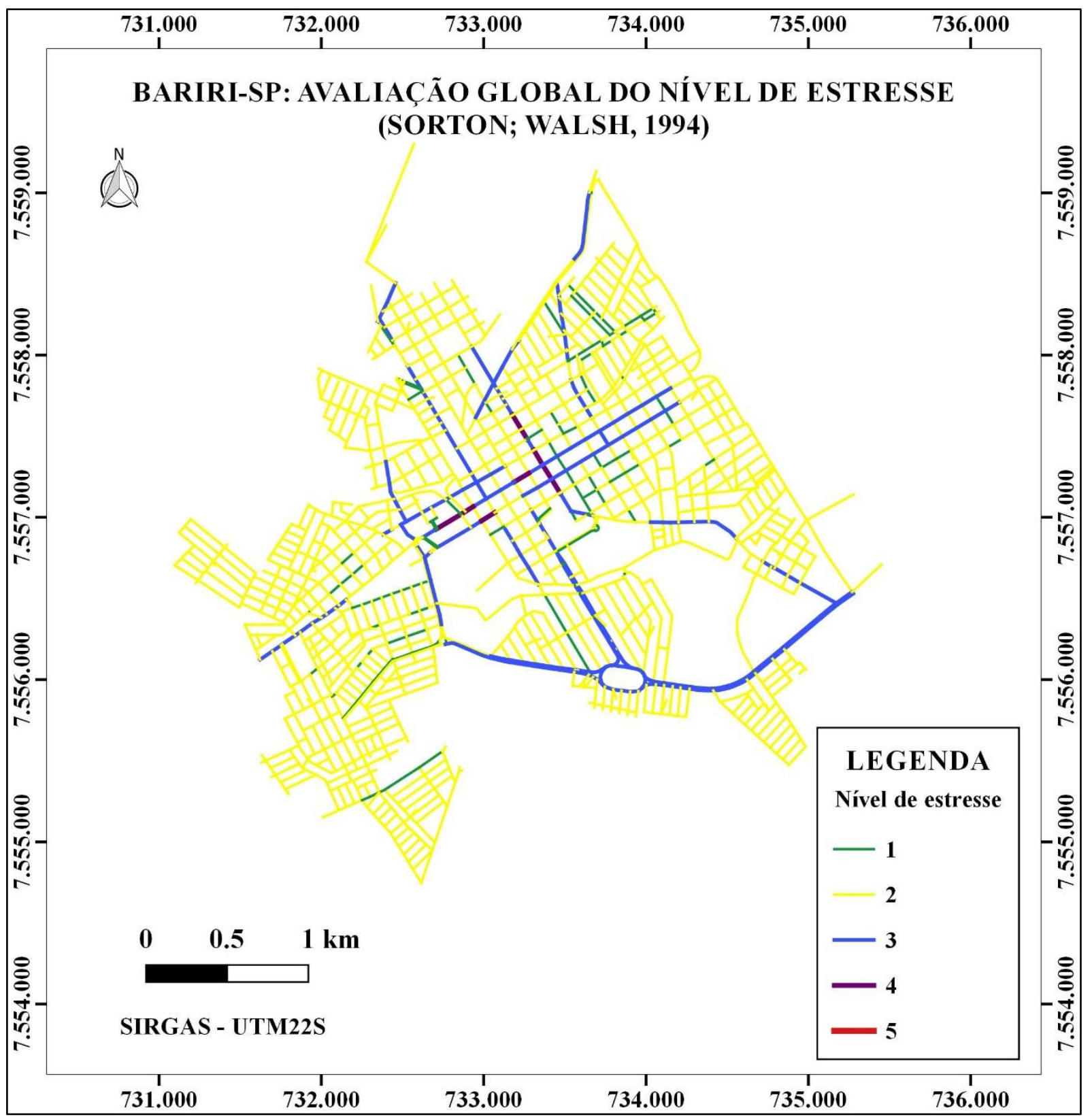

Fonte: Elaborado pelo autor. 
Os resultados desta avaliação são os seguintes:

1) Nas vias locais, observa-se a predominância de boas avaliações globais do nível de estresse ( 1 e 2). Desta forma, pode-se afirmar que a baixa disponibilidade de espaço para comportar o transporte cicloviário nestas vias é compensada pelos pequenos volumes e velocidades dos veículos motorizados que nelas trafegam, tornando-as indicadas para a utilização da bicicleta a quase todos os grupos de ciclistas; e

2) Nas vias que compõem as redes primária e secundária, observa-se a predominância de avaliações globais intermediárias para o nível de estresse (3). Em alguns trechos, no entanto, são identificadas avaliações globais ruins (4);

É válido destacar que não foram observados segmentos viários com avaliações globais do nível de estresse iguais a 5, o que significa que, necessitando-se ou não de alterações ou condições compensatórias, todos os segmentos viários avaliados são potencialmente adequados para acomodar o tráfego de bicicletas.

\subsection{Verificação da necessidade de facilidades para ciclistas}

A Figura 6.6 apresenta os segmentos viários da área de estudo que, de acordo com os critérios sugeridos pela LTSA (2004), necessitam de separação entre o tráfego de bicicletas e o de veículos motorizados, assim como as respectivas facilidades para ciclistas necessárias a esta separação. Além disso, são apresentados também os resultados para a verificação da disponibilidade de espaço, dentre os locais identificados, para a inserção destas facilidades.

De acordo com as informações apresentadas, observa-se a necessidade de inserção de ciclofaixas em segmentos viários que compõem cinco vias de tráfego da área de estudo. Além disso, foram identificados também alguns locais onde é sugerida a separação do tráfego de bicicletas devido às combinações entre baixas velocidades e aos altos volumes de tráfego de veículos motorizados. Não foram verificados locais com a necessidade de inserção de ciclovias.

A verificação da disponibilidade de espaço para inserção destas facilidades, dentre os locais identificados, permitiu a atribuição de fatores relacionados à infraestrutura cicloviária $\left(f_{\text {inf }}\right)$. Os demais locais, apesar de necessitarem destas infraestruturas, devem ser avaliados no processo de identificação das rotas cicláveis como vias de tráfego compartilhado entre veículos motorizados e bicicletas. 
Figura 6.6: Facilidades necessárias à circulação de ciclistas.

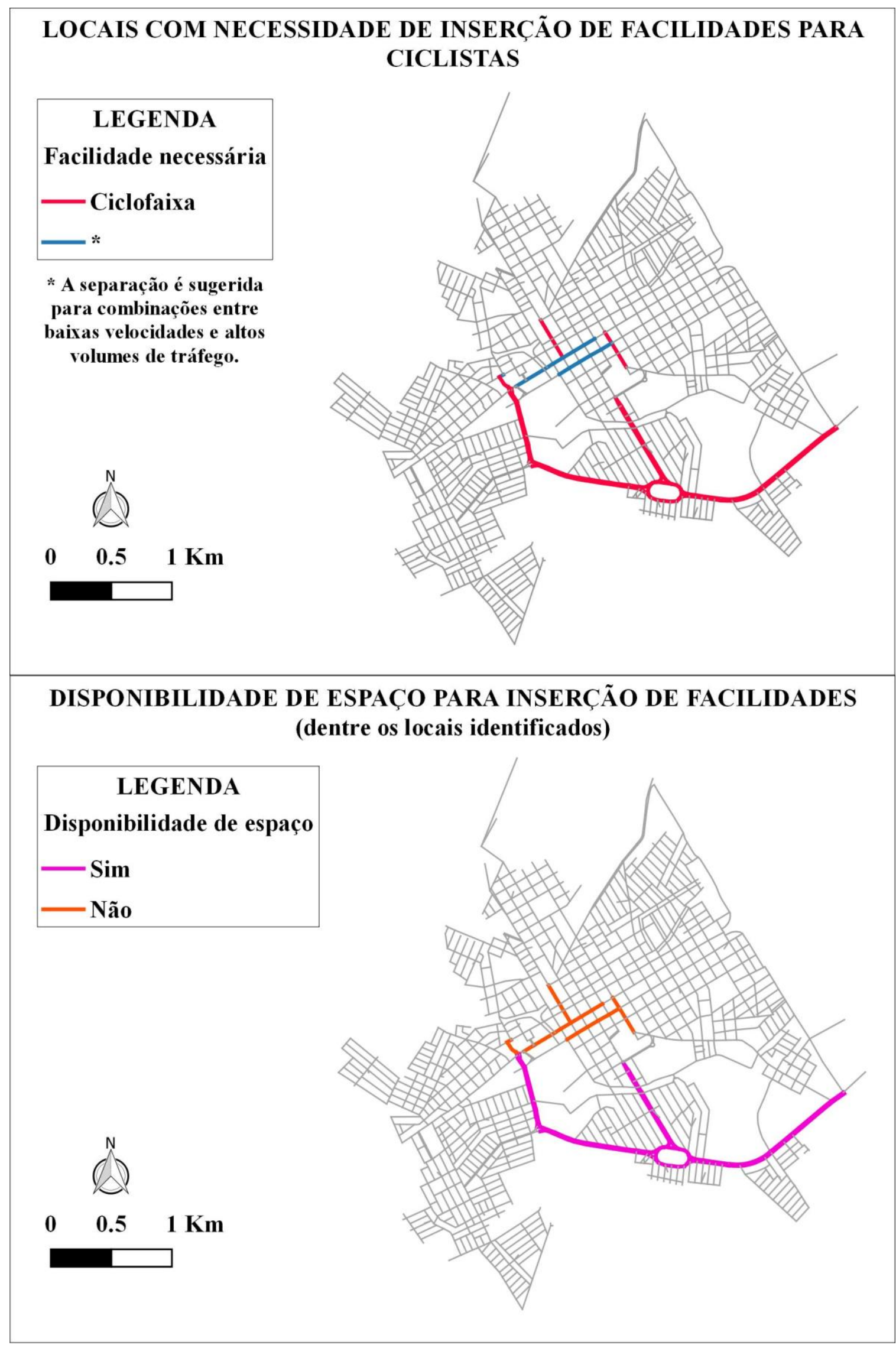

Fonte: Elaborado pelo autor. 


\subsection{Identificação das rotas cicláveis}

As Figuras 6.7 a 6.12 apresentam as 35 rotas cicláveis identificadas pelo método proposto, as quais promovem as ligações entre os pares origem-destino pré-estabelecidos.

Figura 6.7: Rotas cicláveis - Umuarama Clube.

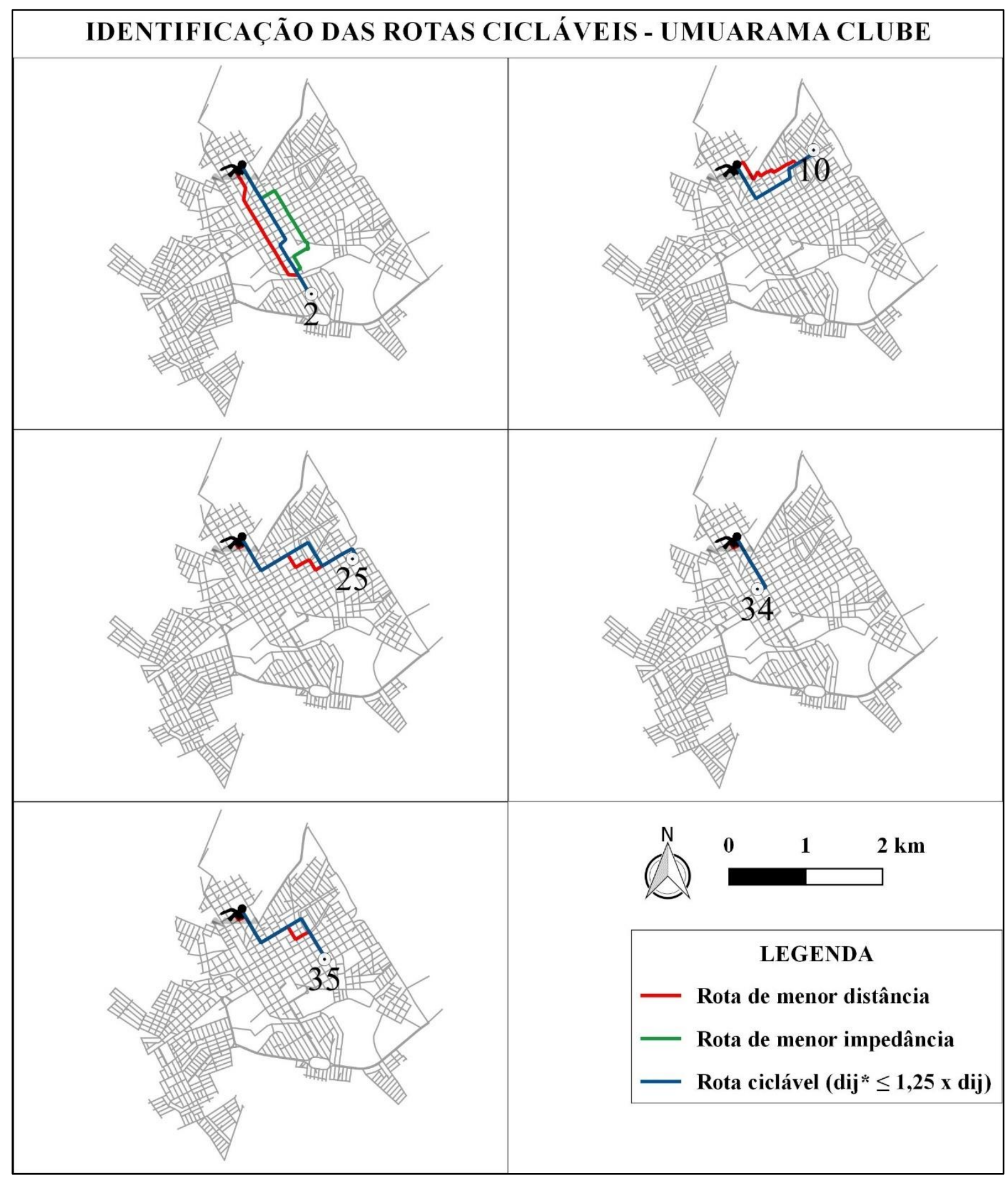

Fonte: Elaborado pelo autor. 
Figura 6.8: Rotas cicláveis - Idalina.

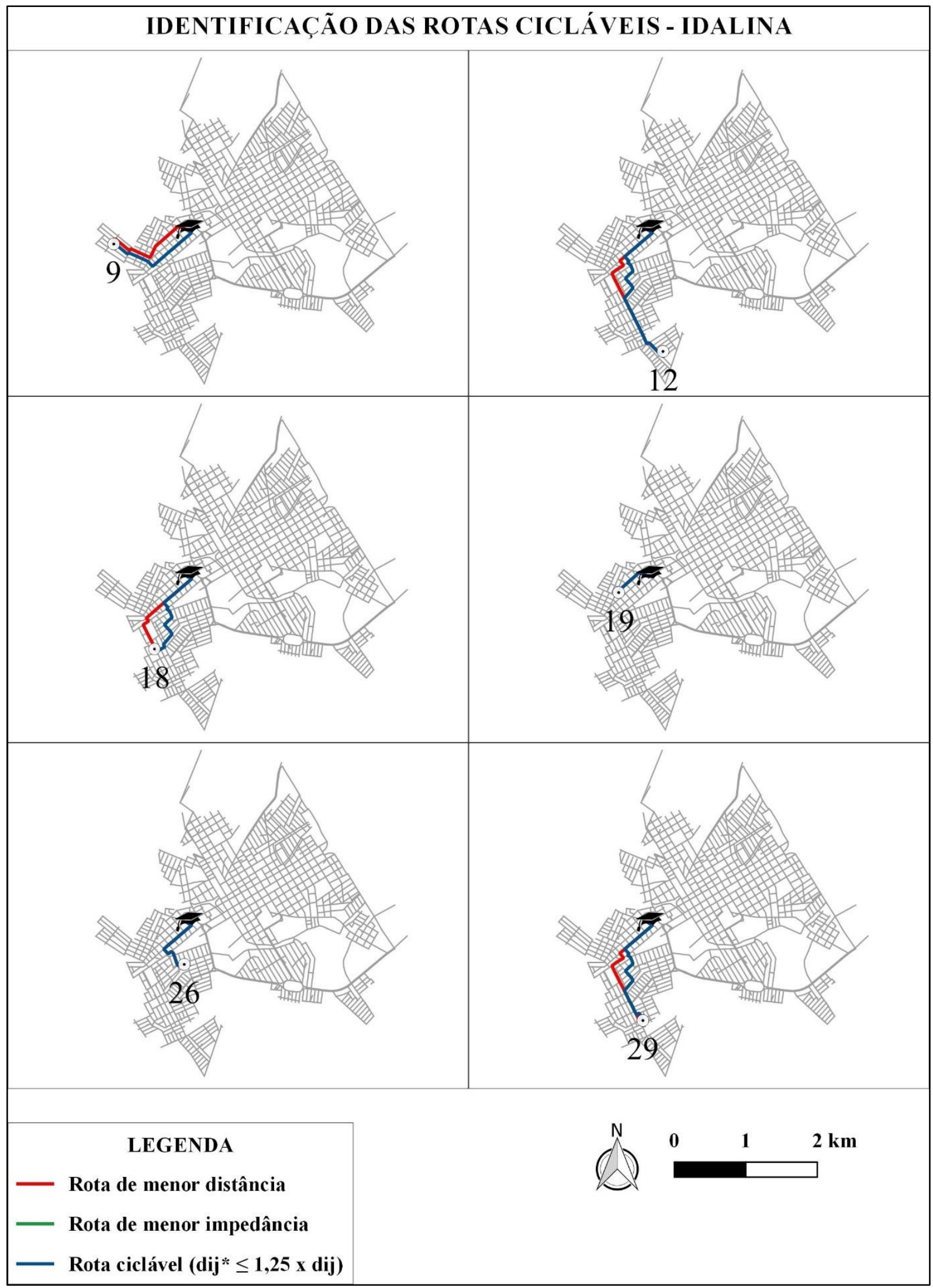

Fonte: Elaborado pelo autor. 
Figura 6.9: Rotas cicláveis - Ephigênia.

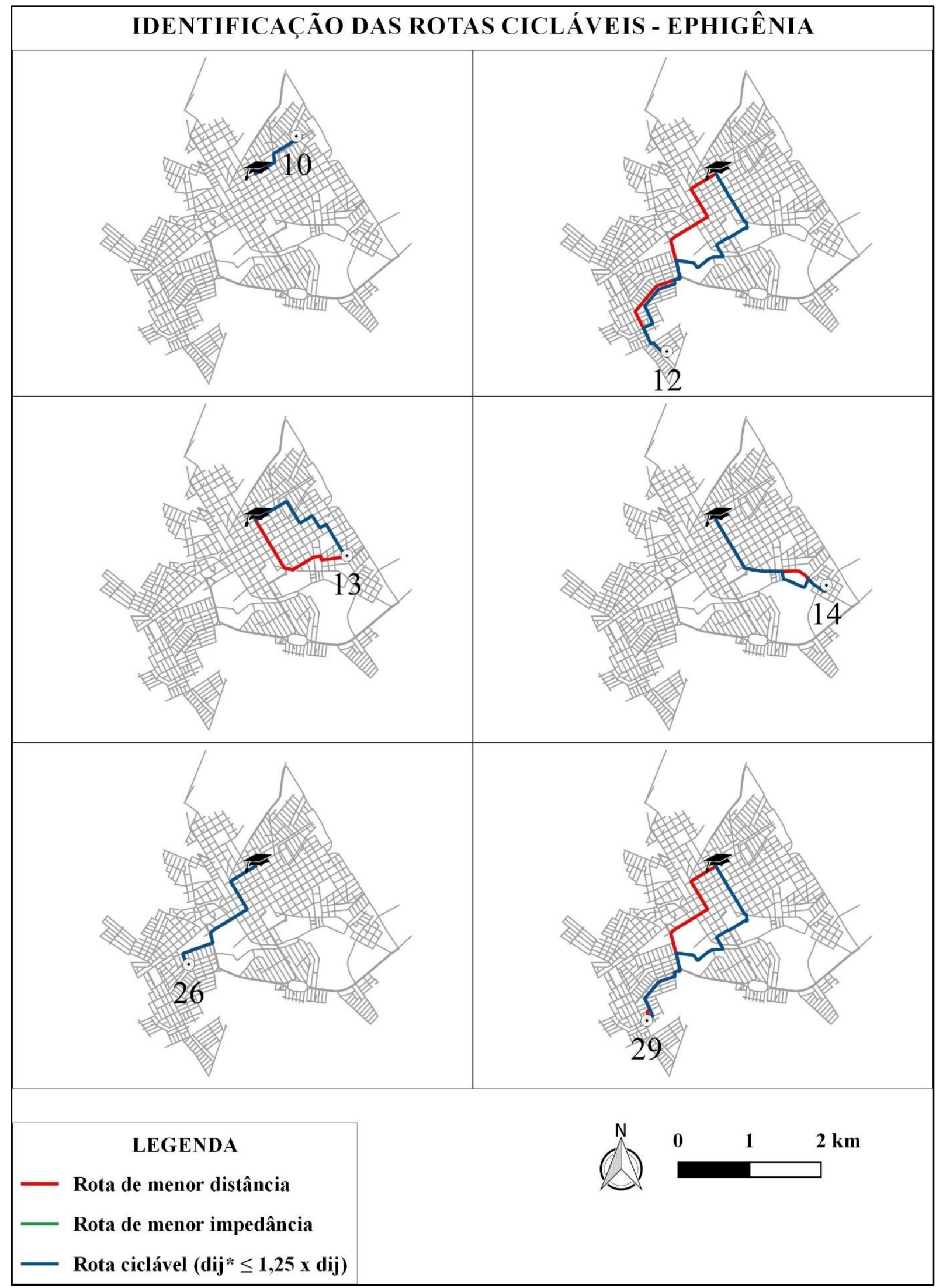

Fonte: Elaborado pelo autor. 
Figura 6.10: Rotas cicláveis - SESI.

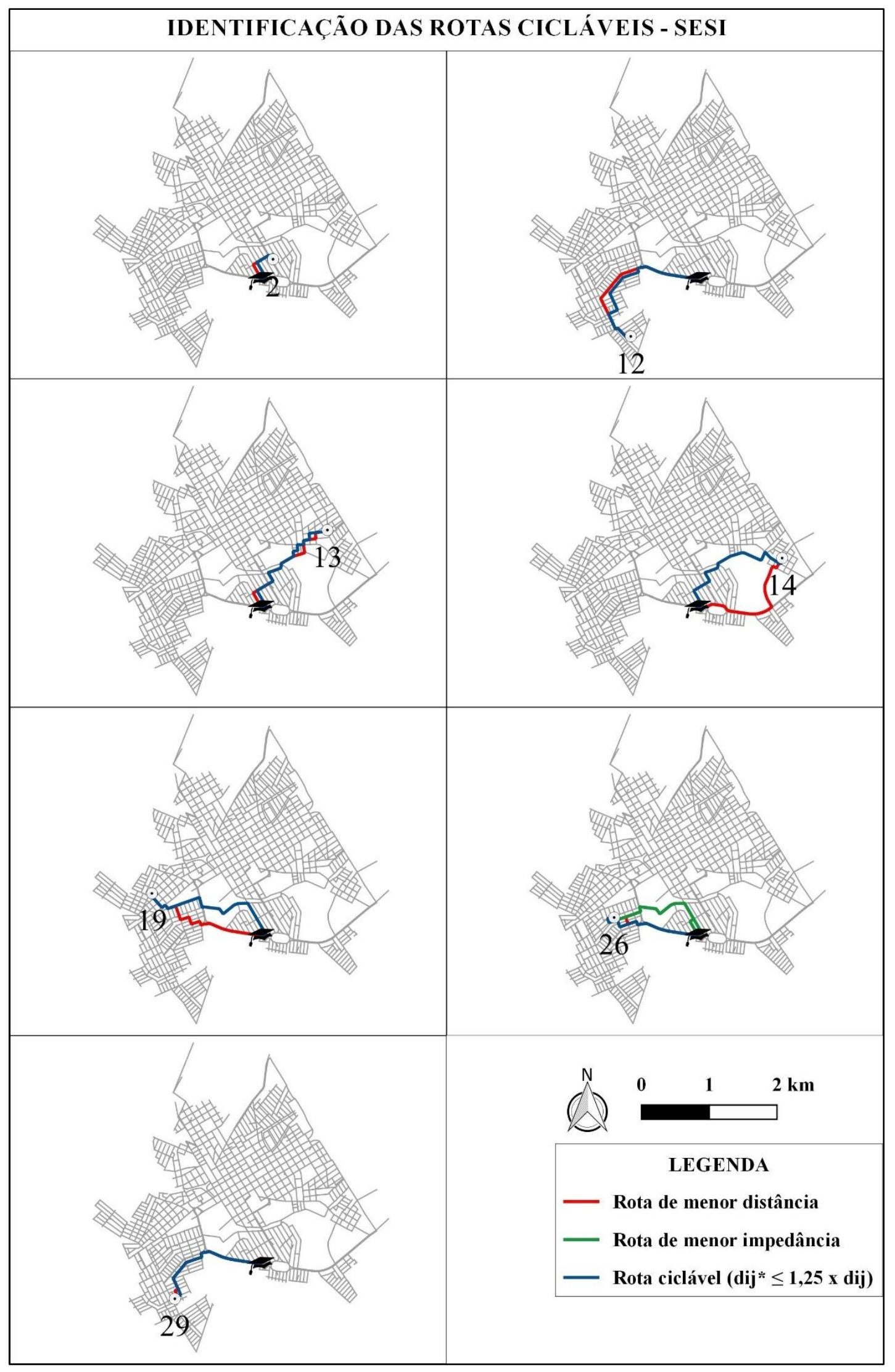

Fonte: Elaborado pelo autor. 
Figura 6.11: Rotas cicláveis - COEBA.

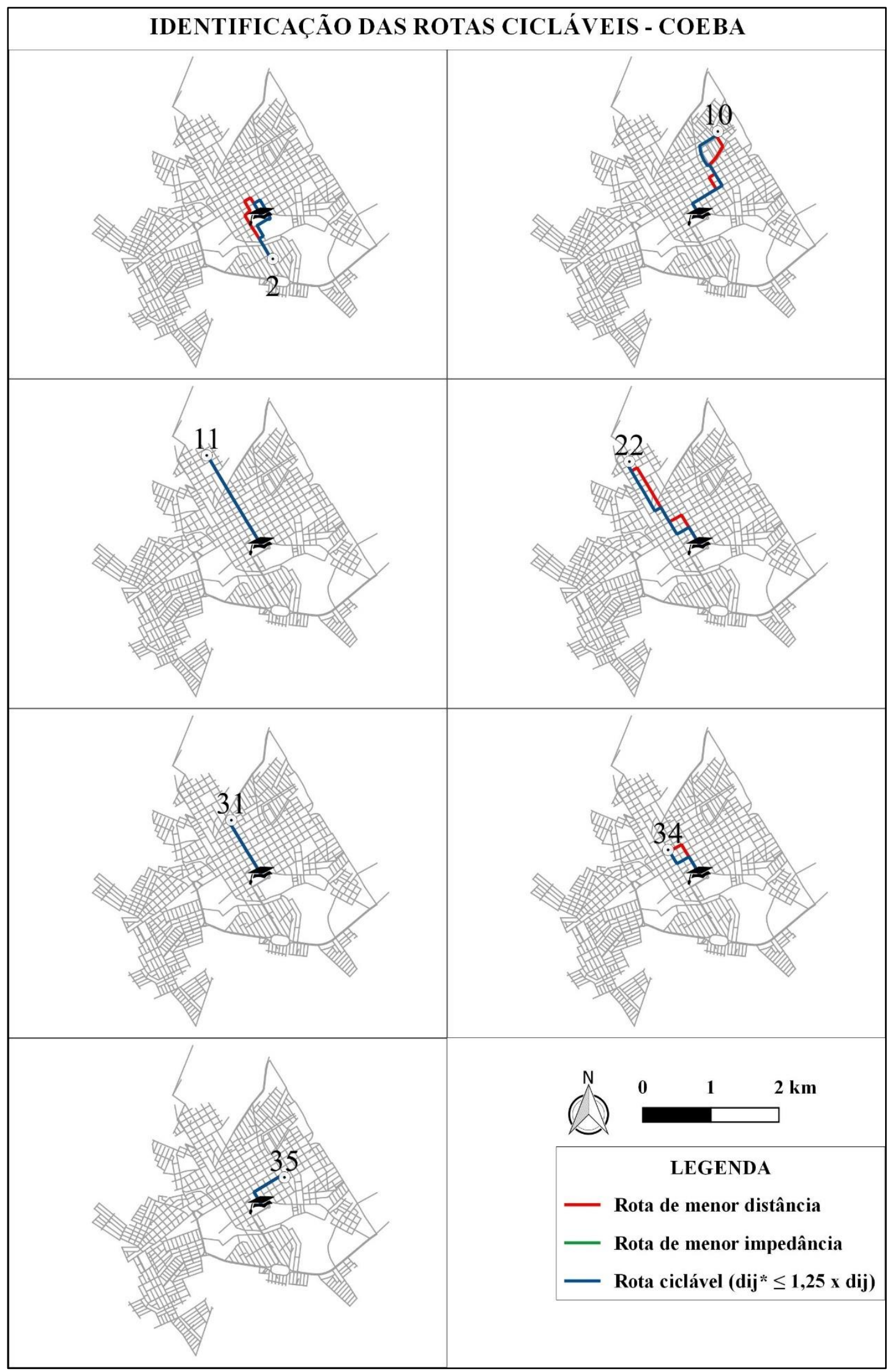

Fonte: Elaborado pelo autor. 
Figura 6.12: Rotas cicláveis - Plásticos Bariri.

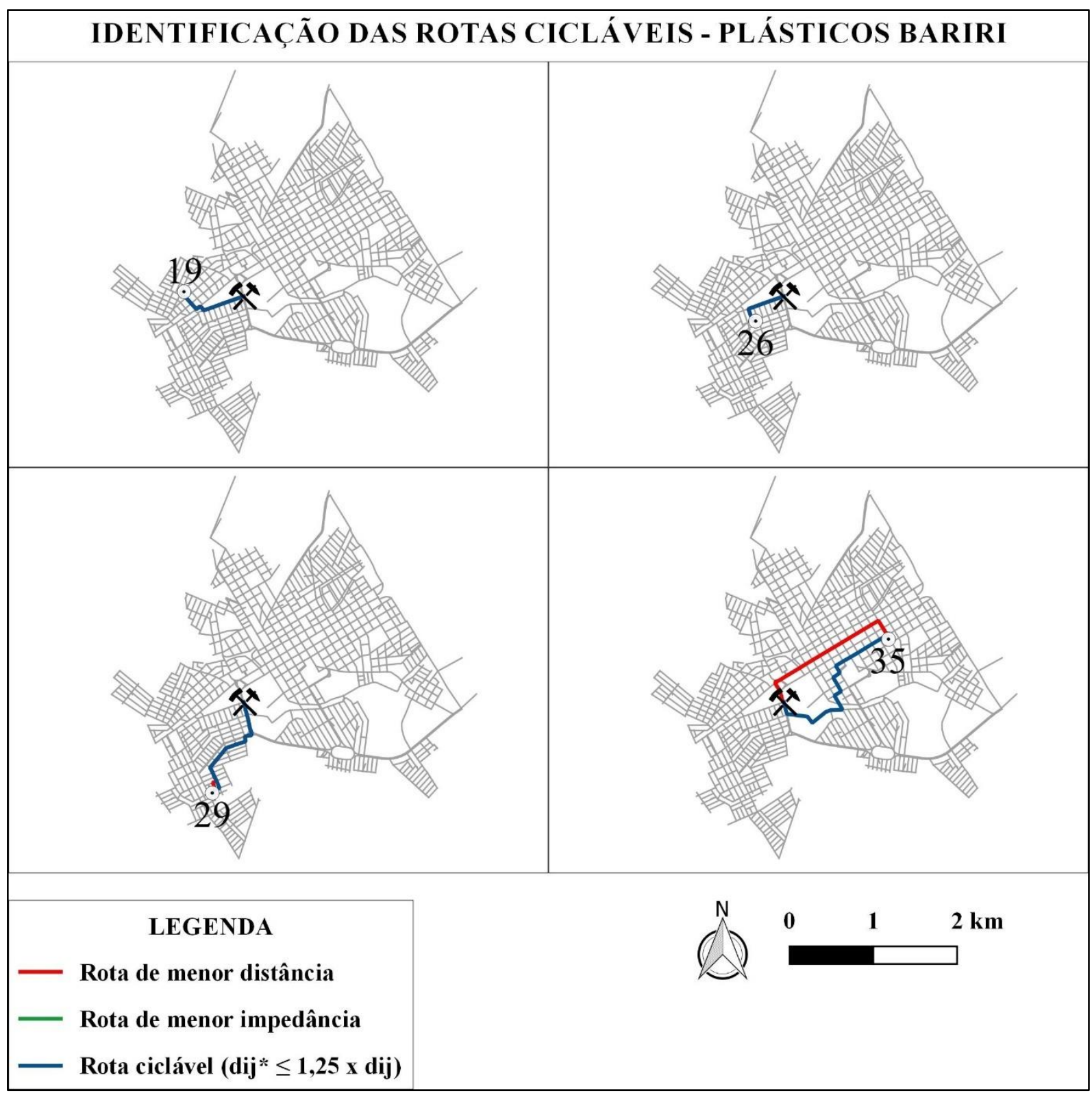

Fonte: Elaborado pelo autor.

De acordo com as informações apresentadas pelas Figuras 6.7 a 6.12, pode-se afirmar que 9 das 35 rotas cicláveis identificadas são coincidentes as rotas que minimizam a distância de viagem entre os respectivos pares origem-destino. Além disso, apenas os seguintes dois pares origem-destino não tiveram suas rotas cicláveis identificadas em uma primeira iteração:

1) A rota ciclável que promove a ligação entre o centroide da zona de tráfego 26 e o Centro Educacional SESI 143 necessitou de 3 iterações para que fosse verificado o critério da distância. Desta forma, com relação à primeira iteração, observa-se, simultaneamente, 
uma diminuição de $23,72 \%$ na distância de viagem e um aumento de $13,06 \%$ no custo generalizado total;

2) A rota ciclável que promove a ligação entre o centroide da zona de tráfego 2 e o Umuarama Clube de Bariri necessitou de 2 iterações para que fosse verificado o critério da distância. Desta forma, com relação à primeira iteração, observa-se, simultaneamente, uma diminuição de $17,71 \%$ na distância de viagem e um aumento de $4,80 \%$ no custo generalizado total.

Com relação à verificação do perfil topográfico, observa-se que pouco mais de $65 \%$ de toda a extensão dos segmentos viários que compõem as rotas cicláveis é caracterizada por declividades inferiores a 3\%, e aproximadamente 30\% da mesma é caracterizada por declividades entre 3\% e 5\%. Em síntese, cerca de $95 \%$ de toda a malha formada pelas rotas cicláveis possui graus de inclinação aceitáveis de acordo com o critério proposto pela AASHTO (1999).

Com relação às facilidades para ciclistas, 7 das rotas identificadas fazem uso da infraestrutura cicloviária existente na cidade de Bariri-SP e 9 são compostas por alguns trechos das vias que necessitam destas infraestruturas e dispõem de espaço para sua inserção. Já com relação ao nível de estresse, nota-se uma expressiva tendência de que as rotas cicláveis sejam compostas por segmentos viários com boas avaliações globais (1 e 2).

\subsection{Definição da rede}

A Figura 6.13 ilustra a reincidência das rotas cicláveis identificadas ao longo dos segmentos viários da área de estudo. Esta informação é o principal ponto de partida para a proposta de trajetos contínuos a comporem a rede, tendo em vista que os segmentos pertencentes a um maior número de rotas cicláveis são justamente aqueles que possuem maior potencial para a promoção do transporte cicloviário de maneira confortável e segura. Assim, estes segmentos devem ser priorizados e adequados à infraestrutura cicloviária existente, com o intuito de formar uma unidade que atenda a todas as regiões da área delimitada para estudo. 
Figura 6.13: Reincidência dos segmentos viários.

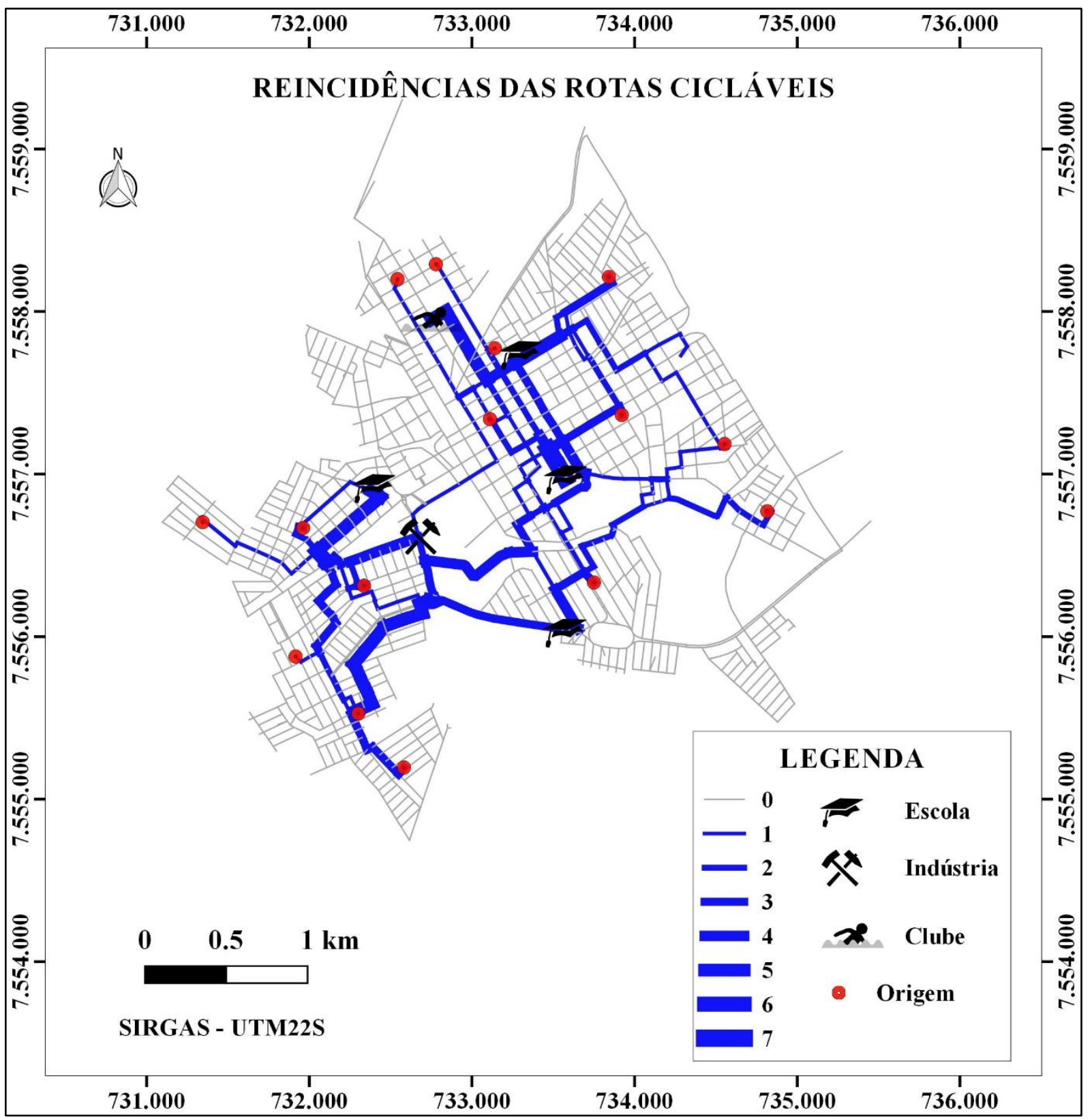

Fonte: Elaborado pelo autor.

A partir da priorização dos segmentos viários com maior reincidência nas rotas cicláveis identificadas, puderam ser propostos 19 eixos viários potencialmente cicláveis, adequados à infraestruestrutura cicloviária e aos planos municipais existentes na cidade de Bariri-SP, os quais são apresentados pela Figura 6.14.

Por meio da definição dos eixos viários potencialmente cicláveis, puderam ser identificados também os segmentos viários que, simultaneamente, pertencem a estes eixos, necessitam de facilidades exclusivas à circulação de ciclistas e dispõem de espaço para sua 
inserção. Desta forma, propõe-se a inserção de ciclofaixas unidirecionais, contíguas às faixas de tráfego dos veículos motorizados, ao longo de toda a extensão da Av. Sérgio Furcin. Estas facilidades devem ser dispostas às margens do canteiro central que divide a avenida e com mesmo sentido de fluxo que o permitido aos veículos motorizados.

Figura 6.14: Eixos viários potencialmente cicláveis em Bariri-SP.

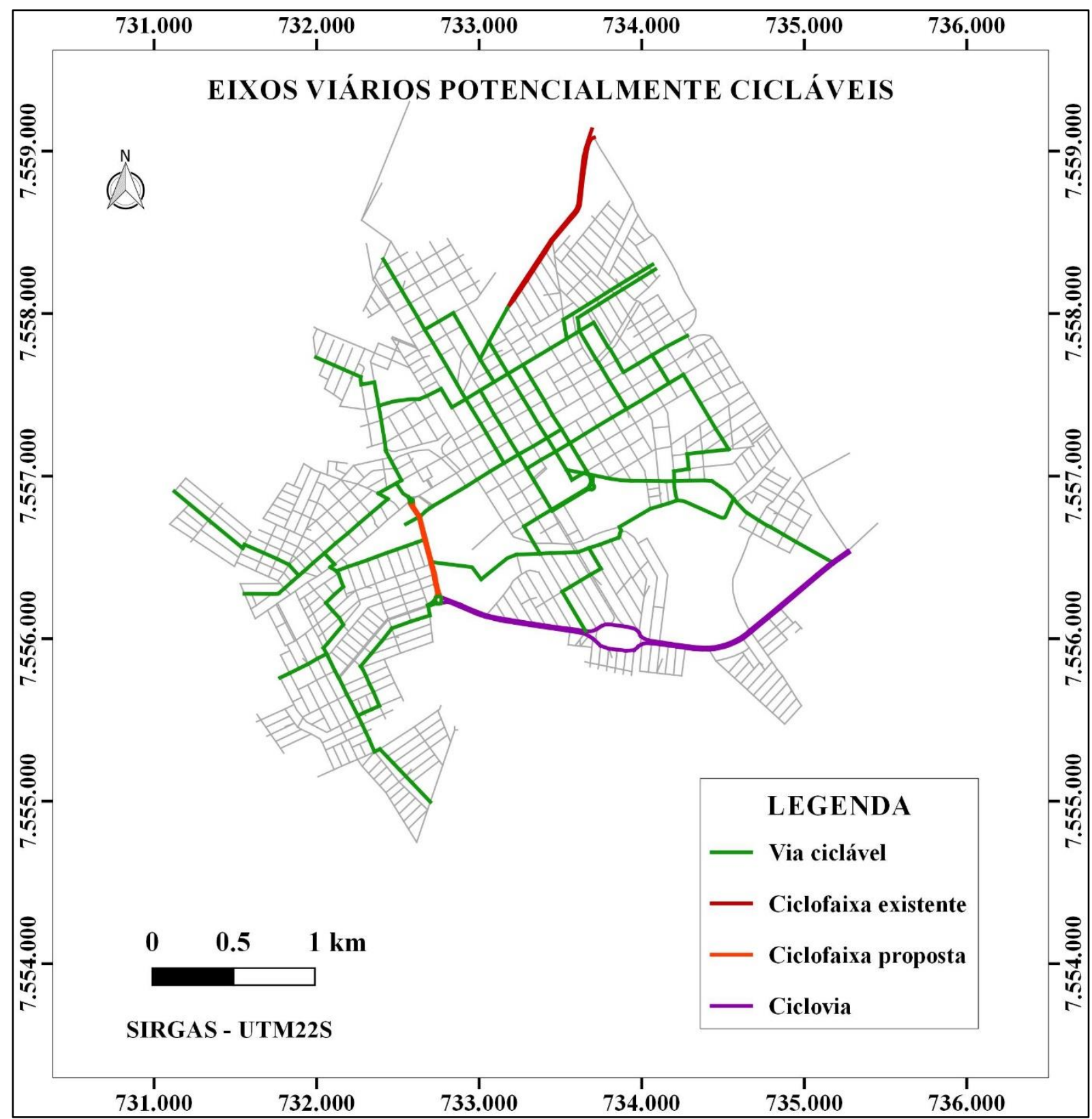

Fonte: Elaborado pelo autor.

Após proposta a configuração da rede de rotas cicláveis para a cidade de Bariri-SP, foi necessário avaliá-la com relação à sua facilidade de acesso por parte da população residente. Desta maneira, a cada um dos eixos viários potencialmente cicláveis foi definida uma área de 
influência, correspondente a um raio de ação de 200 m (distância euclidiana), por meio da ferramenta buffer do QGIS, como apresentam as Figuras 6.15 a 6.18 a seguir.

Figura 6.15: Cobertura dos eixos viários potencialmente cicláveis (1).

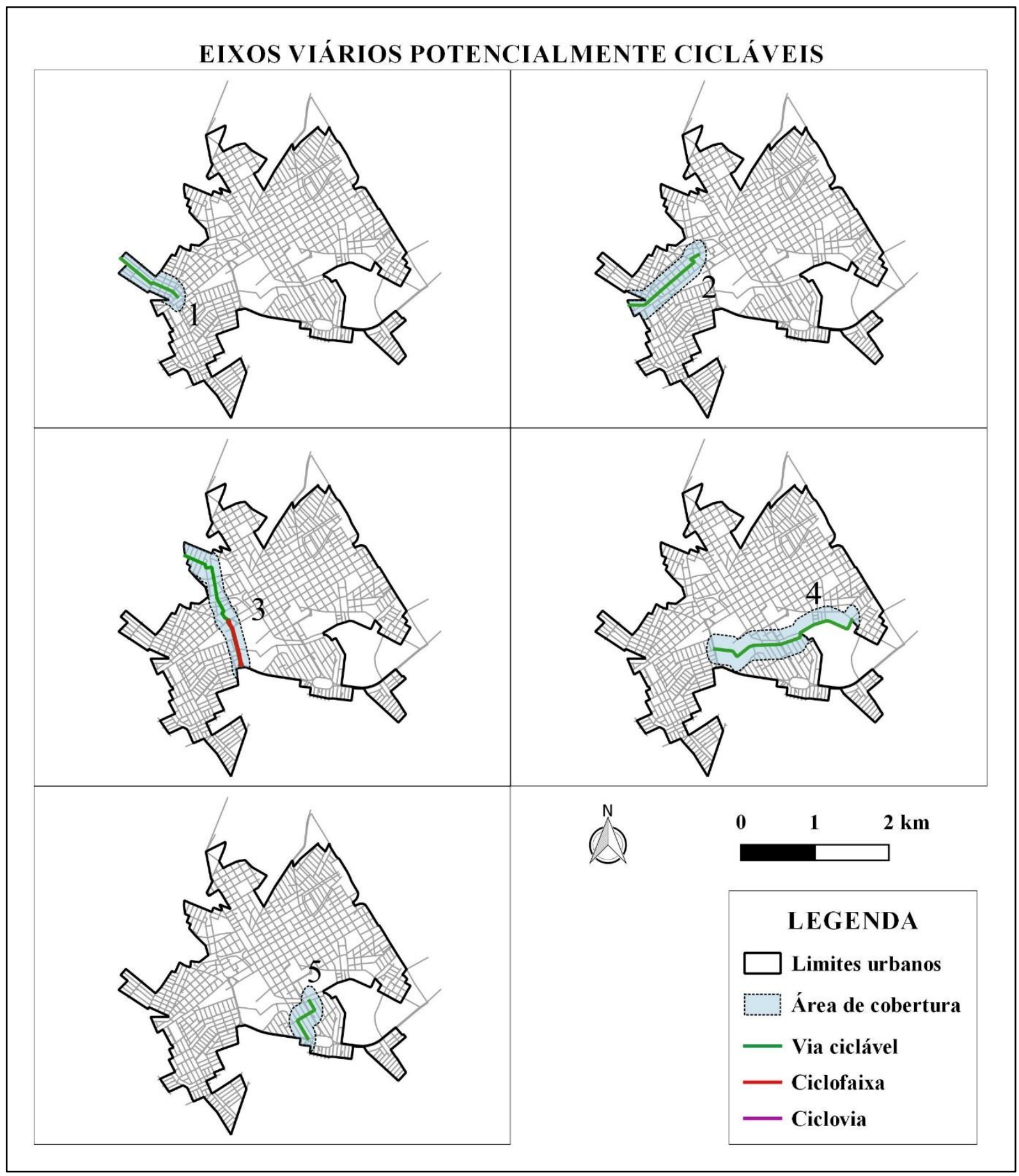

Fonte: Elaborado pelo autor. 
Figura 6.16: Cobertura dos eixos viários potencialmente cicláveis (2).

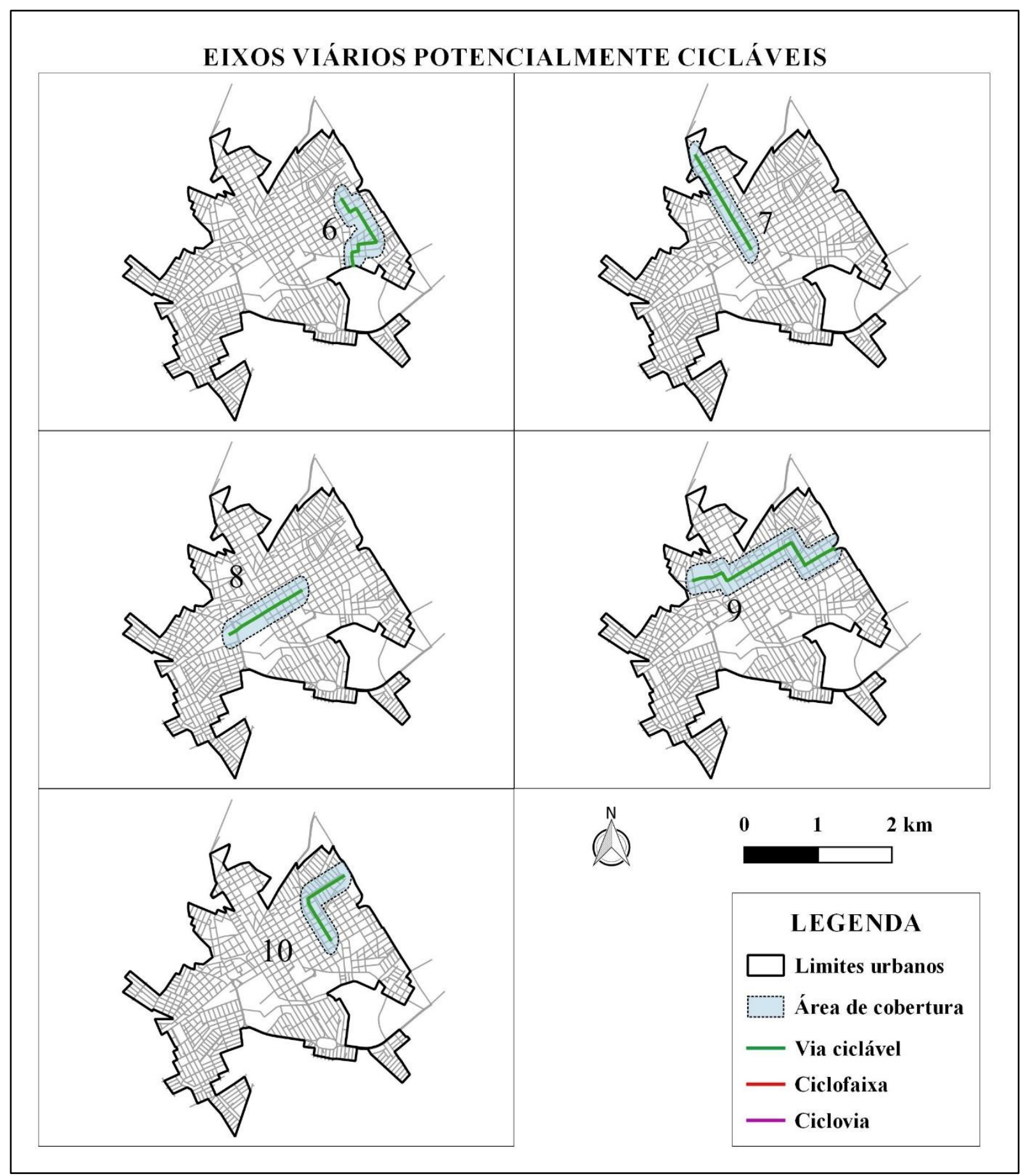

Fonte: Elaborado pelo autor. 
Figura 6.17: Cobertura dos eixos viários potencialmente cicláveis (3).

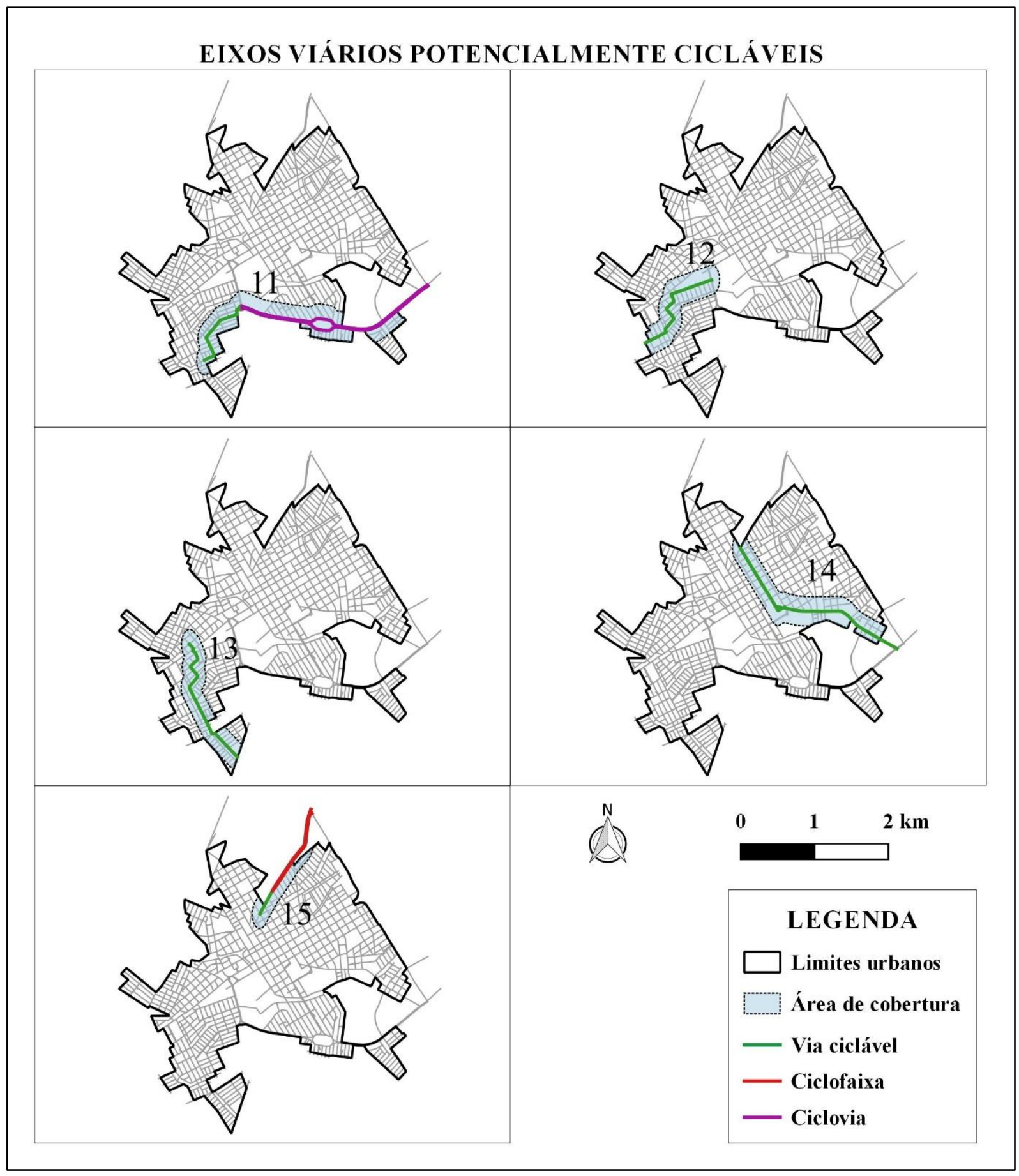

Fonte: Elaborado pelo autor. 
Figura 6.18: Cobertura dos eixos viários potencialmente cicláveis (4).

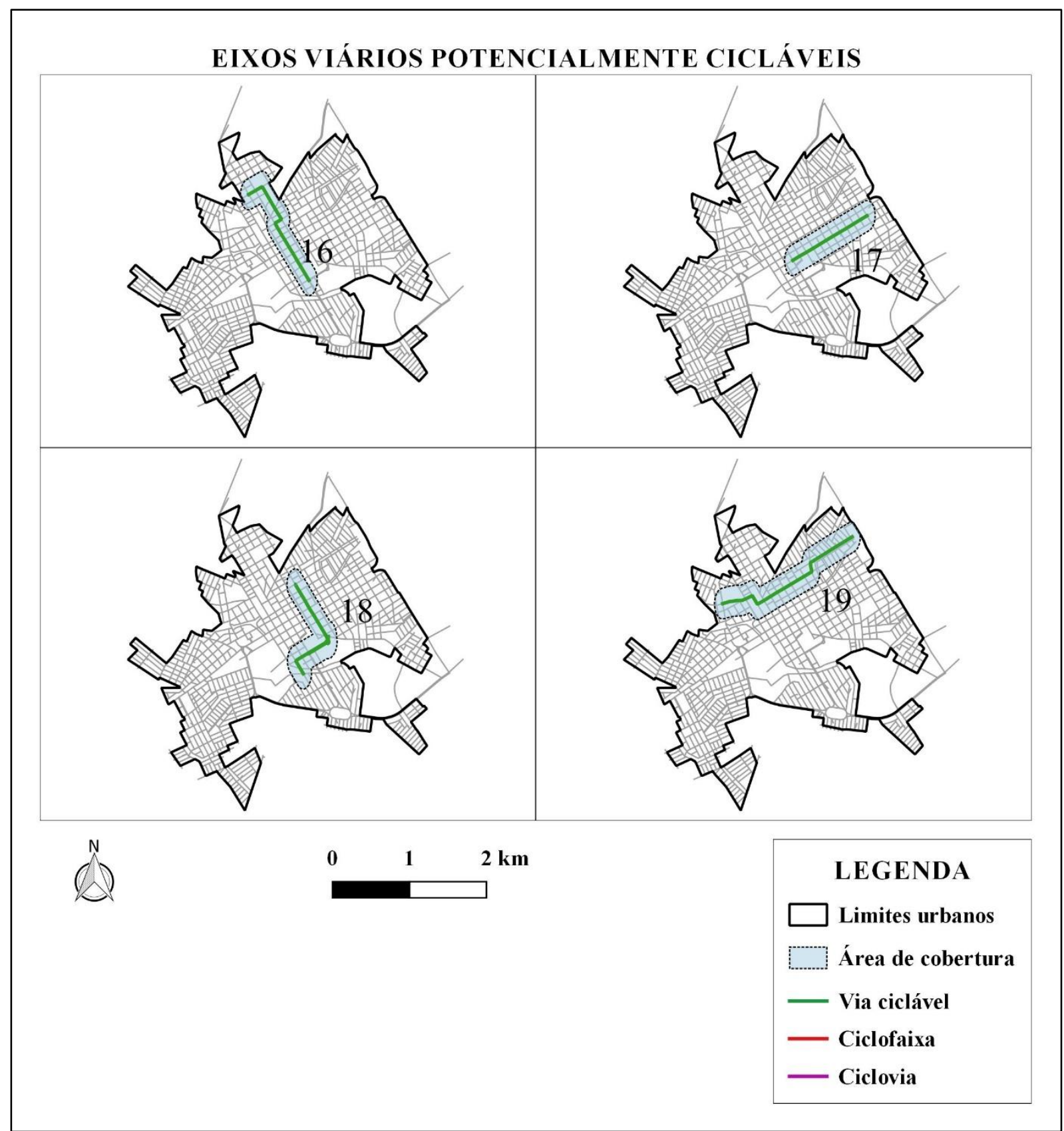

Fonte: Elaborado pelo autor.

A área urbana total coberta pela rede proposta, apresentada pela Figura 6.19, é da ordem de $5,6 \mathrm{~km}^{2}$, correspondente a pouco mais de $81 \%$ de toda a área delimitada para estudo e, assim, superando os $70 \%$ propostos por este trabalho para que este parâmetro fosse verificado. Além disso, é possível observar que 55 dos 67 (82\%) polos previstos nas UUMs do município são atendidos pela configuração da rede de rotas cicláveis proposta. 
Figura 6.19: Cobertura total da rede proposta.

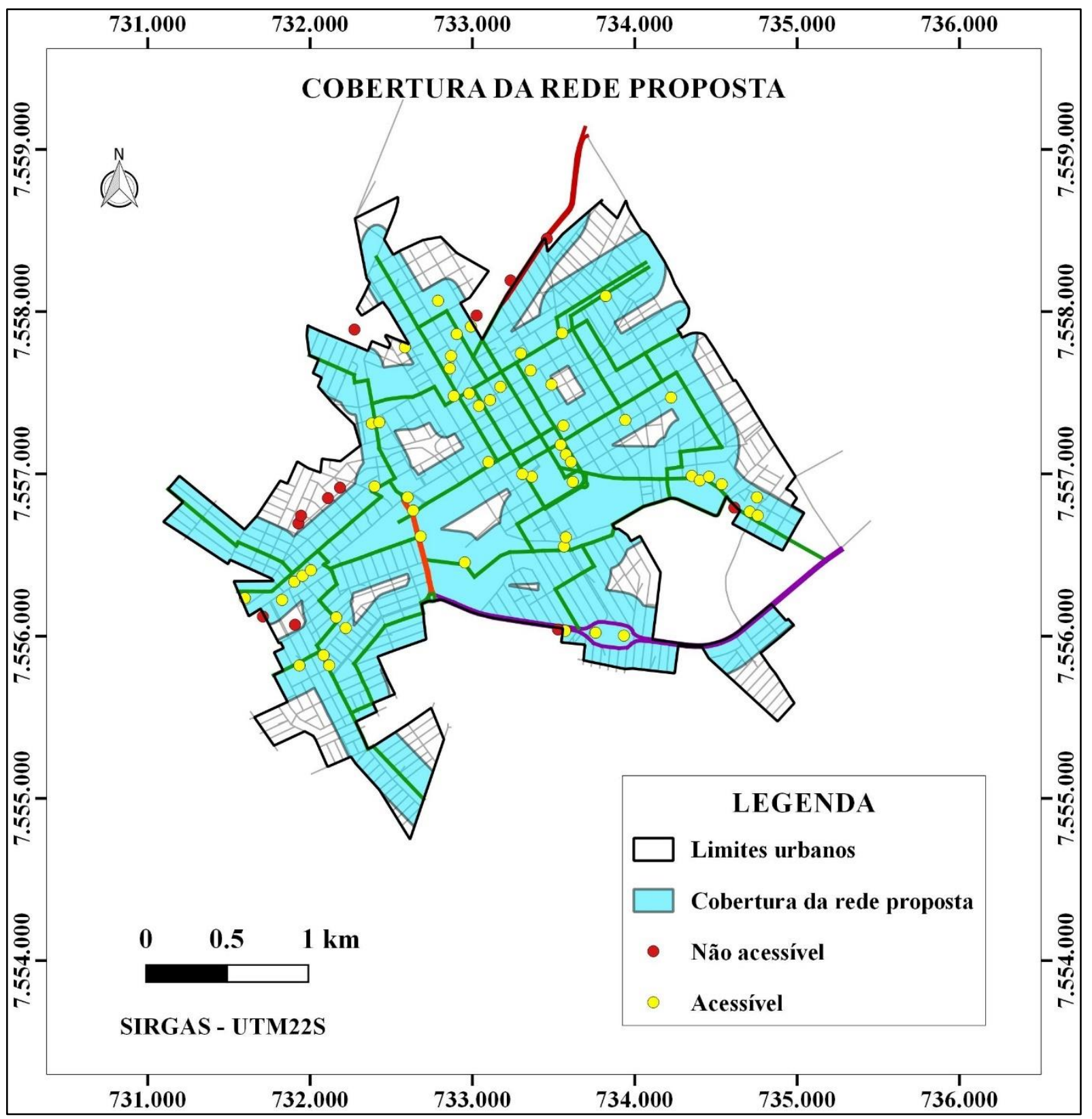

Fonte: Elaborado pelo autor.

Com relação às alternativas viárias para ciclistas, a rede proposta é composta por 26,8 km de vias compartilhadas entre ciclistas e usuários dos modos de transporte motorizados, 3,7 $\mathrm{km}$ de ciclofaixas, sendo 2,4 km já existentes e 1,3 km propostos, e 5,6 km de ciclovias. 
144 | P á g i n a 


\section{CONSIDERAÇÕES FINAIS}

Com o objetivo de elaborar e aplicar um método para definição de rede de rotas cicláveis em áreas urbanas de cidades de pequeno porte, neste trabalho é apresentada uma sequência de procedimentos que podem ser reproduzidos por autoridades em transportes com o intuito de priorizar o transporte cicloviário nos planos diretores dos municípios brasileiros. Este conjunto de procedimentos é baseado em trabalhos realizados por outros autores na tentativa de avaliar fatores que influenciam no uso da bicicleta como modo de transporte urbano, tais como declividade e qualidade de serviço das vias para o transporte cicloviário, existência de infraestrutura cicloviária e distância de viagem.

De acordo com a revisão bibliográfica, constata-se o importante papel desempenhado pela bicicleta na promoção da mobilidade urbana sustentável. Desta forma, é de extrema importância que sejam desenvolvidas diretrizes passíveis de serem aplicadas aos municípios brasileiros e que sirvam de suporte técnico à elaboração de sistemas cicloviários que funcionem de maneira eficiente, ou seja, garantindo o acesso aos principais polos geradores de tráfego por bicicleta de maneira segura aos ciclistas.

É neste contexto que é enfatizado o conceito de rotas cicláveis, isto é, trajetos que promovem a ligação entre pares origem-destino de interesse proporcionando segurança e conforto às viagens por bicicleta. Estas rotas podem ser compostas por diversas alternativas viárias para ciclistas, como ciclovias, ciclofaixas e vias de tráfego compartilhado, e sua configuração ao longo da malha urbana de um determinado município deve ser prevista de maneira contínua, conexa e acessível.

O método para definição de rede de rotas cicláveis em áreas urbanas de cidades de pequeno porte, proposto neste trabalho, é subdividido em cinco etapas: (1) caracterização da área de estudo; (2) análise dos polos geradores de tráfego por bicicletas; (3) avaliação da compatibilidade das vias com o transporte cicloviário; (4) identificação das rotas cicláveis e (5) definição da rede.

A caracterização da área de estudo consiste em definir os limites da região eminentemente urbana do município em que se pretende aplicar o método, e levantar informações relevantes à elaboração de sistemas de transporte ao longo do mesmo, como 
organização territorial em zonas de tráfego, representação do sistema viário, trajetos das linhas de transporte público e infraestrutura cicloviária pré-existente.

A análise dos polos geradores de tráfego consiste na identificação das instalações que mais atraem viagens por bicicleta ao longo da área delimitada para estudo, enfatizando instituições de ensino, grandes indústrias e locais de lazer. Os principais polos identificados devem ser inclusos na pesquisa, com o intuito de definir as origens das viagens realizadas pelos ciclistas até estes polos, apontando assim as zonas de tráfego de maior geração de viagens até os mesmos.

A avaliação da compatibilidade das vias com o transporte cicloviário consiste em atribuir a cada segmento viário da área delimitada para estudo fatores relacionados à declividade $\left(f_{\text {dec }}\right)$ e à infraestrutura cicloviária $\left(f_{\text {inf }}\right)$, assim como avaliações correspondentes a seus respectivos níveis de estresse, possibilitando o cálculo da impedância, isto é, do custo generalizado de cada um destes segmentos.

Para a verificação do perfil topográfico das vias com relação ao transporte cicloviário, optou-se pela utilização do critério da AASHTO (1999). Esta escolha é justificada pelo fato do mesmo possuir limites para os comprimentos em aclive, para declividades variando entre $6 \%$ e $10 \%$, menos rigorosos que os demais critérios encontrados na literatura.

Com relação à avaliação da qualidade de serviço das vias para o transporte cicloviário, optou-se pela utilização do modelo de avaliação do nível de estresse proposto por Sorton e Walsh (1994). Esta escolha é justificada, principalmente, pela facilidade de coleta dos dados de entrada e da própria aplicação do método.

Para a verificação da necessidade de facilidades para ciclistas, optou-se pela utilização do diagrama de infraestrutura cicloviária para vias urbanas proposto pela LTSA (2004). Após esta verificação, é necessário avaliar a disponibilidade de espaço dos canteiros centrais e das seções transversais das vias para comportar eventuais facilidades. As relações de equivalência para a atribuição do fator relacionado à infraestrutura cicloviária $\left(f_{\text {inf }}\right)$ são baseadas no trabalho de Larsen e El-Geneidy (2011).

O processo de identificação das rotas cicláveis deve ser realizado de maneira a promover a ligação entre os pares origem-destino previamente selecionados, minimizando a somatória das impedâncias dos segmentos viários da área delimitada para estudo. Em seguida, as mesmas devem ser verificadas quanto à distância de viagem em termos relativos às distâncias mínimas 
entre cada par origem-destino avaliado, de acordo com o critério proposto por Tucker e Manaugh (2016).

A definição da rede de rotas cicláveis ao longo da área delimitada para estudo deve ser realizada por meio da priorização dos segmentos viários com maior reincidência das rotas cicláveis identificadas, formando trajetos de maneira contínua, conexa, acessível e adequada à infraestrutura cicloviária e aos planos municipais pré-existentes. Além disso, devem ser definidos os locais para inserção de novas facilidades aos ciclistas, como ciclofaixas e ciclovias.

O estudo de caso foi realizado na cidade de Bariri-SP. A metodologia utilizada para o levantamento das informações necessárias e os resultados da aplicação do método na área urbana do município são apresentados, respectivamente, pelos capítulos 5 e 6 deste trabalho.

A rede de rotas cicláveis definida para a cidade de Bariri-SP é composta por 19 eixos viários potencialmente cicláveis, os quais estão distribuídos de maneira a atender toda a área delimitada para estudo. Trata-se de uma unidade coerente com o sistema viário municipal, formada por $26,8 \mathrm{~km}$ de vias compartilhadas entre ciclistas e usuários dos modos de transporte motorizados, $3,7 \mathrm{~km}$ de ciclofixas e 5,6 km de ciclovias.

De maneira geral, a aplicação do método proposto na cidade de Bariri-SP mostrou-se extremamente satisfatória aos objetivos deste trabalho. A simplicidade da coleta de informações e da própria aplicação do método podem servir de estímulo aos planejadores em transportes para a elaboração de redes cicloviárias em cidades de pequeno porte. Entretanto, é importante destacar que este método foi desenvolvido e aplicado considerando-se uma série de limitações.

O porte de uma cidade considerado neste trabalho é determinado de acordo com sua população residente na área urbana, e não de acordo com sua forma ou tamanho. A grande maioria dos municípios de pequeno porte, além de possuírem população urbana inferior a 100 mil habitantes, também possuem configurações compactas. No entanto, podem haver casos em que determinadas cidades são classificadas como de pequeno porte pelo critério da população e, mesmo assim, possuem áreas urbanas relativamente extensas.

Nestes casos, o limite proposto para a verificação da distância de viagem ao longo das rotas cicláveis (25\% superior à distância mínima) pode não ser o mais adequado, indicando-se a verificação por meio de valores absolutos. O mesmo ocorre com o limite proposto para a verificação da área coberta pela rede de rotas cicláveis (70\% da área total) que, nestes casos, 
torna-se extremamente difícil de ser alcançado, sendo necessárias abordagens alternativas para a avaliação da acessibilidade.

Os municípios menores apresentam também um menor número de interseções semaforizadas e menor complexidade de problemas viários, como acidentes de trânsito em cruzamentos. Desta forma, estas descontinuidades nas vias de tráfego não foram consideradas na elaboração do método para definição da rede de rotas cicláveis. Porém, podem haver situações, mesmo em cidades menores, em que as interseções e os cruzamentos atuam como fatores de grande influência na escolha das rotas por parte dos ciclistas. Logo, para estes casos, é interessante que a avaliação da qualidade de serviço das vias seja realizada por meio de um modelo que avalie a influência destas descontinuidades, o que não ocorre com a utilização do modelo de Sorton e Walsh (1994).

Quanto aos volumes e velocidades de tráfego dos veículos motorizados, a limitação de tempo e recursos deste trabalho não possibilitou o levantamento destas informações ao longo de todo o sistema viário da área de estudo. Desta forma, foram realizadas contagens volumétricas e estimativas de velocidades médias apenas para trechos das principais vias de tráfego do município, isto é, aquelas que promovem as ligações estrada-centro e centro-bairros. Para as vias locais, foram considerados valores para o volume e para velocidade de veículos motorizados, respectivamente, iguais a 1.000 veíc./dia e $30 \mathrm{~km} / \mathrm{h}$.

Quanto ao processo de verificação da disponibilidade de espaço para inserção de facilidades para ciclistas proposto por este trabalho, optou-se pela não inclusão de passeios ou trilhas independentes do sistema viário. No entanto, podem haver casos em que o planejamento prévio destes equipamentos e sua inclusão em políticas para a promoção da mobilidade os tornem soluções interessantes para integrarem rotas cicláveis em áreas urbanas.

Com relação às recomendações para trabalhos futuros, sugere-se que outros fatores sejam inclusos na avaliação da compatibilidade das vias com o transporte cicloviário, tais como densidade de entradas de garagens, composição do tráfego e condições do pavimento. Além disso, sugere-se também que outros modelos sejam utilizados para a verificação do perfil topográfico e para a avaliação da qualidade de serviço das vias para o transporte cicloviário, com o intuito de confrontar os resultados encontrados com os deste trabalho e, assim, definindose quais os modelos mais adequados para a identificação de rotas cicláveis em cidades de pequeno porte. 
Outra sugestão é aplicação de questionários, aprovados pelo Comitê de Ética em Pesquisa, aos ciclistas que frequentam os PGTs por bicicleta, possibilitando a caracterização desta demanda existente (perfil socieconômico e características das viagens realizadas). Além disso, estes questionários podem ser complementados por pesquisas de preferência declarada ou revelada, possibilitando estimar também a demanda potencial de ciclistas.

Finalmente, este trabalho procurou colaborar com o planejamento cicloviário por meio da elaboração de diretrizes para a definição de redes de rotas cicláveis em áreas urbanas de cidades de pequeno porte. Desta forma, o mesmo pode servir como ponto de partida para outros trabalhos com objetivos semelhantes e também para eventuais adequações no sentido de ser expandido às cidades brasileiras de médio e grande porte. 
150|P á g i n a 


\section{REFERÊNCIAS BIBLIOGRÁFICAS}

AASHTO. Guide for the Development of Bicycle Facilities. 3 ed. Washington D. C: Association of State Highway and Transportation Officials, 1999. 86 p.

ABNT. NBR 12255:1990 - Execução e utilização de passeios públicos. Associação Brasileira De Normas Técnicas. Rio de Janeiro, 1990. 6 p.

ACKER, V. V.; GOODWIN, P.; WITLOX, F. Key research themes on travel behavior, lifestyle, and sustainable urban mobility. International Journal of Sustainable Transportation, v. 10, n. 1, p. 25-32, 2016.

AFFONSO, N. S. Mobilidade e Qualidade de vida. Revista dos Transportes Públicos. Associação Nacional de Transportes Públicos, Ano 24, $3^{\circ}$ trimestre, p. 7-23, 2002.

AFFONSO, N. S.; BADINI, C.; GOUVÊA, F. Mobilidade e Cidadania. São Paulo: Associação Nacional de Transportes Públicos, 2003. 256 p.

ANTONAKOS, C. I. Environmental and travel preferences of cyclists. Transportation Research Record, n. 1438, p. 25-33, 1994.

ANTP. Relatório Geral 2014. Sistema de Informações da Mobilidade Urbana: Associação Nacional de Transportes Públicos, 2016. 96 p.

AULTMAN, L.; HALL, F. L.; BAETZ, B.B. Analysis of bicycle commuter routes using geographic Information systems: implications for bicycle planning. Transportation Research Record, n. 1578, p. 102-110, 1997.

AUSTROADS. Cycling Aspects of Austroads Guides. 2. ed. Sydney: Austroads Ltd., 2014. $177 \mathrm{p}$.

AXHAUSEN, K. W.; SMITH, R. L. Bicyclist Link Evaluation: A Stated-preference Approach. Transportation Research Record, n. 1085, p. 7-15, 1986.

BARBETTA, P. A. Estatística Aplicada às Ciências Sociais. 5. ed. Florianópolis: Ed. da UFSC, 2002. $340 \mathrm{p}$.

BICALHO, M. P. Gestão do Transporte Cicloviário. Transporte Cicloviário. Associação Nacional de Transportes Públicos. Série de cadernos técnicos, v. 7, p. 112-128, 2007.

BOARETO, R. A política de mobilidade urbana e a construção de cidades sustentáveis. Revista dos Transportes Públicos. Associação Nacional de Transportes Públicos, Ano 30, $3^{\circ}$ trimestre, p. 143-160, 2008.

BOVY, P. H. L.; BRADLEY, M. A. Route choice analyzed with stated-preference approaches. Transportation Research Record, n. 1037, p. 11-20, 1985. 
BRASIL. Lei $\mathrm{n}^{\circ}$ 12.587, de 3 de janeiro de 2012. Institui as diretrizes da Política Nacional de Mobilidade Urbana. Diário Oficial da União, Brasília, DF, 4 jan. 2012. Seção 1, p. 1.

BROACH, J.; GLIEBE, J. G.; DILL, J.L. Development of a Multi-class Bicyclist Route Choice Model Using Revealed Preference Data. Anais do $12^{\text {th }}$ International Conference on Travel Behavior Research. Jaipur, 2009.

BUEHLER, R.; DILL, J. Bikeway Networks: A Review of Effects on Cycling. Transport Reviews, v. 36, n. 1, p. 9-27, 2015.

CALGARY. Calgary commuter cyclist survey 1992/1993: Final results. City of Calgary Transportation Department. Calgary, 1993.

CARDOSO, P. B.; CAMPOS, V. B. G. Metodologia para o planejamento de um sistema cicloviário. Revista Transportes, v. 24, n. 4, p. 39-48, 2016.

CARVAlHO, C. H. R. Mobilidade Urbana Sustentável: Conceitos, Tendências e Reflexões. Instituto de Pesquisa Econômica Aplicada. Ministério do Planejamento, Orçamento e Gestão: Brasília, 2016. 38 p.

CAUFIELD, B.; BRICK, E.; MCCARTHY, O. T. Determining bicycle infrastructure preferences - A case study of Dublin. Transportation Research Part D. n. 17, p. 413-417, 2012.

CET. Regulamento de Estacionamento e Parada: Ponto de Ônibus - Critérios de Projeto. Companhia de Engenharia de Tráfego. Manual de Sinalização Urbana, v. 10, parte 1, p. 10, 2001.

COSTA, M. S. Mobilidade Urbana Sustentável: um estudo comparativo e as bases de um sistema de gestão para Brasil e Portugal. 2003. 184 p. Dissertação (Mestrado em Engenharia Civil). Universidade Federal de São Carlos, São Carlos, 2003.

CTB. Código de Trânsito Brasileiro. 4 ed. Brasília: Ed. Câmara, 2010. 296 p. Disponível em: <http://bd.camara.gov.br>. Acesso em: 15 nov. 2017.

DILL, J.; CARR, T. Bicycle Commuting and Facilities in Major U.S. Cities: if you build them, commuters will use them. Transportation Research Board 82 ${ }^{\text {th }}$ Annual Meeting Compendium of Papers. Washington D. C., 2003.

DIXON, L. B. Bicycle and Pedestrian Level of Service Performance Measures and Standards for Congestion Management Systems. Transportation Research Record, n. 1538, p. 1-9, 1996.

DNIT. Manual de Estudos de Tráfego. Departamento Nacional de Infraestrutura de Transportes, Instituto de Pesquisas Rodoviárias. Rio de Janeiro, 2006. 388 p. (Publicação IPR723). 
DNIT. Manual de Projeto Geométrico de Travessias Urbanas. Departamento Nacional de Infraestrutura de Transportes, Instituto de Pesquisas Rodoviárias. Rio de Janeiro, 2010. 392 p. (Publicação IPR-740).

DRUCKER, M. Using GIS to Manage the Redlands Bicycle Classic: master thesis as partial requirement for a Master of Science in GIS. 2003. 94 p. Dissertação (Mestrado em Sistemas de Informação Geográfica). University of Redlands, Redlands, 2003.

EPPERSON, B. Evaluating Suitability of Roadways for Bicycle Use: Toward a Cycling Level of Service Standard. Transportation Research Record, n. 1438, p. 9-16, 1994.

FGSV. Handbuch für die Bemessung von Strassenverkehrsanlagen. Forschungsgesellschaft für Straßen und Verkehrswesen. Colonia, 2001.

FHWA. Safety and Location Criteria for Bicycle Facilities. Offices of Research and Development: Federal Highway Administration - US Department of Transportation. Washington D. C., 1975. 242 p. (Publicação FHWA-RD-75-112).

FHWA. A bikeway criteria digest: The ABCD's of bikeways. Offices of Research and Development: Federal Highway Administration - US Department of Transportation. Washington D. C., 1977. 99 p. (Publicação FHWA-TS-77-201).

FHWA. Reasons why Bicycling and Walking are not being used more extensively as travel modes. National Bicycling \& Walking Study - Case Study $\mathrm{n}^{\circ}$ 1. Offices of Research and Development: Federal Highway Administration - US Department of Transportation, 1992. 95 p. (Publicação FHWA-PD-92-041).

FHWA. University Course on Bicycle \& Pedestrian Transportation. Offices of Research and Development: Federal Highway Administration - US Department of Transportation. Research, Development and Technology Turn-Fairbank Highway Research Center. McLean, 2006a. 282 p. (Publicação FHWA-HRT-05-133).

FHWA. Shared-Use Path Level of Service Calculator: a user's guide. Offices of Research and Development: Federal Highway Administration - US Department of Transportation. Research, Development and Technology Turn-Fairbank Highway Research Center. McLean, 2006b. 69 p. (Publicação FHWA-HRT-05-138).

FISHER, G. Bikeway Planning Criteria and Guidelines. Institute of Transportation and Traffic Engineering. University of California, Berkeley, 1972.

FURTH, P. G.; MEKURIA, M. C.; NIXON, H. Low-Stress Bicycling and Network Connectivity. Mineta Transportation Institute, Report 11-19. Mineta, 2012. 84 p.

FURTH, P. G.; MEKURIA, M. C. Network Connectivity and Low-Stress Bicycling. Transportation Research Board 92 ${ }^{\text {th }}$ Annual Meeting Compendium of Papers. Washington D. C., 2013. 
GEELONG PLANNING COMMITTEE. Geelong Bikeplan. Geelong, 1978.

GEIPOT. Manual de Planejamento Cicloviário. Grupo Executivo De Integração Da Política De Transportes. Ministério dos Transportes: Brasília, 2001a. 116 p.

GEIPOT. Planejamento Cicloviário: Diagnóstico Nacional. Grupo Executivo De Integração Da Política De Transportes. Ministério dos Transportes: Brasília, 2001b. 218 p.

GELLER, R. Four Types of Cyclists. City of Portland Office of Transportation. Portland, 2006. 9 p.

GONDIM, M. F. Cadernos de Desenhos - Ciclovias. COPPE - Universidade Federal do Rio de Janeiro, Rio de Janeiro, 2010. 110 p.

GROOT, R. Design manual for bicycle traffic. Utrecht: Ed. CROW., 2007. 388 p.

HARKEY, D. L.; REINFURT, D. W.; KNUIMAN, M.; STEWART, J. R.; SORTON, A. Development of a Bicycle Compatibility Index: A Level of Service Concept. Highway Safety Research Center. University of North Carolina. Chapel Hill, 1998. 116 p.

HEALY, J. Wearable and Automotive Systems for Affect Recognition from Physiology. 2000. 158 p. Tese (Doutorado em Filosofia). Massachusetts Institute of Technology, Cambridge, 2000.

HOOK, W. Preserving and Expanding the Role of Non-Motorized Transport. Sustainable Transport: A Sourcebook for Policy-makers in Developing Cities. Módulo 3d. Eschborn, 2003. 40 p.

HOPKINSON, P.; WARDMAN, M. Evaluating the demand for new cycle facilities. Transport Policy, v. 3, n. 4, p. 433-439, 1996.

HUNT, J. D.; ABRAHAM, J. E. Influences on bicycle use. Transportation, v. 34, n. 4, p. 453470, 2007.

HYODO, T.; SUZUKI, N.; TAKAHASHI, K. Modeling of Bicycle Route and Destination Choice Behavior for Bicycle Road Network Plan. Transportation Research Record, n. 1705, p. 70-76, 2000.

IBGE. Relatórios de desenvolvimento do MAPGEO2015. Instituto Brasileiro de Geografia e Estatística. Coordenação de Geodésia. Rio de Janeiro, 2015. 17 p. Disponível em:

<fttp://geoftp.ibge.gov.br/modelos_digitais_de_superficie/modelo_de_ondulacao_geoidal/cart ograma/rel_mapgeo2015.pdf>. Acesso em: 12 nov. 2017. 
IBGE. Arranjos Populacionais e Concentrações Urbanas do Brasil. 2 ed. Instituto Brasileiro de Geografia e Estatística. Coordenação de Geografia. Rio de Janeiro, 2016. 167 p. Disponível em: 〈https://www.ibge.gov.br/apps/arranjos_populacionais/2015/pdf/publicacao.pdf>. Acesso em: 14 abr. 2017.

IBGE. Estimativas de população. Instituto Brasileiro de Geografia e Estatística. Disponível em: <https://cidades.ibge.gov.br/brasil/sp/bariri/panorama>. Acesso em: 11 jan. 2018.

ISEKI, H.; TINGSTROM, M. A New Approach in the GIS Bikeshed Analysis with Consideration of Topography, Street Connectivity, and Energy Consumption. Transportation Research Board 92 ${ }^{\text {th }}$ Annual Meeting Compendium of Papers. Washington D. C., 2013.

JENSEN, S. U. et al. Collection of Cycle Concepts. Danish Cyclists Federation. Copenhagen: Road Directorate, 2000. 187 p.

KAMARGIANNI, M. Designing Sustainable Cities based on Next Generation's Cycling Ridership Demand. Transportation Research Board 94 ${ }^{\text {th }}$ Annual Meeting Compendium of Papers. Washington D. C., 2015.

KIRNER, J. Proposta de um Método para a Definição de Rotas Cicláveis em Áreas Urbanas. 2006. 229 p. Dissertação (Mestrado em Engenharia Urbana). Universidade Federal de São Carlos, São Carlos, 2006.

KLOBUCAR, M. S.; FRICKER, J. D. Network Evaluation Tool to Improve Real and Perceived Bicycle Safety. Transportation Research Record, n. 2031, p. 25-33, 2007.

KNEIB, E. C. Caracterização de empreendimentos geradores de viagens: contribuição conceitual à análise de seus impactos no uso, ocupação e valorização do solo urbano. 2004. 182 p. Dissertação (Mestrado em Transportes). Universidade de Brasília, Brasília, 2004.

KNEIB, E. C. Mobilidade urbana e qualidade de vida: do panorama geral ao caso de Goiânia. Revista UFG, Ano 13, n. 12, p. 71-78, 2012.

LAMONDIA, J. J.; MOORE, N. Comparing Bicycle Level of Service Measures, Roadway Characteristics, and Perceived Bike Route Suitability. Transportation Research Board 94 ${ }^{\text {th }}$ Annual Meeting Compendium of Papers. Washington D. C., 2015.

LANDAU, E. C.; GUIMARÃES, D. P. Análise Comparativa entre os modelos digitais de elevação ASTER, SRTM e TOPODATA. Anais do XV Simpósio Brasileiro de Sensoriamento Remoto - SBSR, p. 4003-4010. Curitiba, 2011.

LANDIS, B. W. Bicycle System Performance Measures. ITE Journal, v. 66, n. 2, p. 18-26, 1996.

LANDIS, B. W. et al. Real Time Human Perceptions: Toward a Bicycle Level of Service. Transportation Research Record, n. 1578, p. 119-126, 1997. 
LARSEN, J.; EL-GENEIDY, A. A travel behavior analysis of urban cycling facilities in Montreal, Canada. Transportation Research Part D, n. 16, p. 172-177, 2011.

LEE, R. J.; SENER, I. N.; JONES, S. N. A Review of Equity in Active Transportation. Transportation Research Board 94 ${ }^{\text {th }}$ Annual Meeting Compendium of Papers. Washington D. C., 2015.

LEMOS, M. C.; SOUZA, S. F.; ROCHA, R. S. Avaliação Da Qualidade Dos Dados Altimétricos Derivado Do Shuttle Radar Topographic Mission (SRTM): Resultados Preliminares. Anais do I Simpósio em Ciências Geodésicas e Tecnologias da Geoinformação. Recife, 2009.

LITMAN, T. et al. Pedestrian and Bicycle planning: a guide to best practices. Victoria Transport Policy Institute. Victoria, 2000. 37 p.

LITMAN, T. Evaluating Active Transport Benefits and Costs: Guide to Valuing Walking and Cycling Improvements and Encouragement Programs. Victoria Transport Policy Institute. Victoria, 2015. 89 p.

LOTT, D.Y.; TARDIFF, T.; LOTT, D. F. Evaluation by experienced riders of a new bicycle lane in an established bikeway system. Transportation Research Record, n. 683, p. 40-46, 1978.

LOWRY, M.; CALLISTER, D.; GRESHAM, M.; MOORE, B. Assessment of cummunitywide bikeability with bicycle level of service. Transportation Research Record, n. 2314, p. 41-48, 2012.

LTSA. Cycle Network and Route Planning Guide. New Zealand: Land Transport Safety Authority, 2004. 92 p.

MAGAlHÃES, J. R. L.; CAMPOS, V. B. G.; BANDEIRA, R. A. M. Metodologia para identificação de redes de rotas cicláveis em áreas urbanas. The Journal of Transport Literature, v. 9, n. 3, p. 35-39, 2015.

MARSHALL, S. Streets \& Patterns. 9. ed. New York: Taylor \& Francis Group, 2004. 333 p.

MCDANIEL, S.; LOWRY, M. B.; DIXON, M. Using Origin-Destination Centrality to Estimate Directional Bicycle Volumes. Transportation Research Board 93 ${ }^{\text {th }}$ Annual Meeting Compendium of Papers. Washington D. C., 2014.

MCNEIL, N. Bikeability and the Twenty-Minute Neighborhood: how infrastructure and destinations influence Bicycle Accessibility. Transportation Research Board 90 ${ }^{\text {th }}$ Annual Meeting Compendium of Papers. Washington D. C., 2011.

MENGHINI, G.; CARRASCO, N.; SCHÜSSLER, N.; AXHAUSEN, K. W. Route choice of cyclists in Zurich. Transportation Research Part A, n. 44, p. 754-765, 2010. 
MINISTÉRIO DAS CIDADES. Coleção Bicicleta Brasil: Programa Brasileiro de Mobilidade por Bicicleta. Ministério das Cidades: Brasília, 2007. 232 p.

MIRANDA, A. C. M. Se tivesse que ensinar a projetar ciclovias. Transporte Cicloviário. Associação Nacional de Transportes Públicos. Série de cadernos técnicos, v. 7, p. 66-112, 2007.

MONTEIRO, F. B.; CAMPOS, V. B. G. Métodos de avaliação da qualidade dos espaços para ciclistas. Anais do XXV Congresso da Associação Nacional de Pesquisa e Ensino em Transportes, v. 2, p. 1242-1253. Belo Horizonte, 2011.

NERI, T. B. Proposta Metodológica para definição de Rede Cicloviária: um estudo de caso de Maringá. 2012. 169 p. Dissertação (Mestrado em Engenharia Urbana). Universidade Estadual de Maringá, Maringá, 2012.

NYENHUIS, D. W. An Investigation of Factors Influencing Route Choice of Bicyclists. Tese (Mestrado em Engenharia Civil). University of California, Irvine, 2012.

ORTUZAR, J. D.; IACOBELLI, I.; VALEZE, C. Estimating demand for a cycle-way network. Transportation Research Part A, n. 34, p. 353-373, 2000.

PARKIN, J.; WARDMAN, M.; PAGE M. Models of Perceived Cycling Risk and Route Acceptability. Accident Analysis and Prevention, v. 39, n. 2. p. 364-371. Leeds, 2007.

PETTINGA, A. et al. Cycling-Inclusive Policy Development: A Handbook. Federal Ministry for Economic Cooperation and Development. Utrecht, 2009. 256 p.

PEZZUTO, C. C. Fatores que influenciam o uso da bicicleta. Dissertação (Mestrado em Engenharia Urbana). 2002, 146 p. Universidade Federal de São Carlos, São Carlos, 2002.

PORTUGAL, L. S.; GOLDNER, L. G. Estudo de Polos Geradores de Tráfego e de seus Impactos nos Sistemas Viários e de Transportes. 1 ed. São Paulo: Ed. Edgard Blucher, 2003. $322 \mathrm{p}$.

PREFEITURA MUNICIPAL DE BARIRI. Plano Diretor de Drenagem Urbana do Município de Bariri. Bariri, 2012. 26 p.

PREFEITURA MUNICIPAL DE BARIRI. Plano Diretor de Mobilidade. Bariri, 2016. 70 p.

PRESADA, B. Cicloativismo: a expansão da bicicleta. Transporte Cicloviário. Associação Nacional de Transportes Públicos. Série de cadernos técnicos, v. 7, p. 132-138, 2007.

PROVIDELO, J. K. Nível de Serviço para Bicicletas: um estudo de caso nas cidades de São Carlos e Rio Claro. 2011. 168 p. Tese (Doutorado em Engenharia Urbana). Universidade Federal de São Carlos, São Carlos, 2011. 
PUCHER, J.; BUEHLER, R. Cycling for Everyone: Lessons from Europe. Transportation Research Board 87 ${ }^{\text {th }}$ Annual Meeting Compendium of Papers. Washington D. C., 2008.

PUCHER, J.; DILL, J.; HANDY, S. Infrastructure, programs and policies to increase bicycling: An International review. Preventive Medicine, n. 50, p. 106-125, 2009.

RICHARDSON, R. J. Pesquisa Social - Métodos e Técnicas. 3. ed. São Paulo: Ed. Atlas, 1999. $168 \mathrm{p}$.

SEGADILHA, A. B. P. Identificação dos fatores que influenciam na escolha da rota pelos ciclistas: estudo de caso da cidade de São Carlos. 2014. 83 p. Dissertação (Mestrado em Engenharia Urbana). Universidade Federal de São Carlos, São Carlos, 2014.

SEGANTINE, P. C. L. Estudo do Sinergismo entre os Sistemas de informação Geográfica e o Posicionamento Global. 2001. 237 p. Tese (Livre Docência). Universidade de São Paulo, São Carlos, 2001.

SEGANTIINE, P. C. L. GPS - Sistema de Posicionamento Global. Escola de Engenharia de São Carlos - EESC/USP, São Carlos, 2005. 362 p.

SILVA, A. N. R. Sistemas de Informações Geográficas para Planejamento de Transportes. 1998. 124 p. Tese (Livre Docência). Universidade de São Paulo, São Carlos, 1998.

SILVA, I.; SEGAnTINE, P. C. L. Topografia para Engenharia - Teoria e Prática de Geomática. Rio de Janeiro: Elsevier Editora Ltda, 2015. 412 p.

SLATER, J. A. et al. The SRTM Data "Finishing" Process and Products. Photogrammetric Engineering \& Remote Sensing, v. 72, n. 3, p. 237-247, 2006.

SORTON, A.; WALSH, T. Bicycle Stress Level as a Tool to Evaluate Urban and Suburban Bicycle Compatibility. Transportation Research Record, n. 1438, p. 17-24, 1994.

SOUSA, P. B. Análise de Fatores que influenciam no uso da bicicleta para fins de Planejamento Cicloviário. 2012. 190 p. Tese (Doutorado em Engenharia de Transportes). Universidade de São Paulo, São Carlos, 2012.

STINSON, M. A.; BHAT C. R. Commuter Bicyclist Route Choice: Analysis Using a Stated Preference Survey. Transportation Research Record, n. 1828, p. 107-115, 2003.

STINSON, M. A.; BHAT, C. R. A Comparison of the Route Preferences of Experienced and Inexperienced Bicycle Commuters. Transportation Research Board 84 ${ }^{\text {th }}$ Annual Meeting Compendium of Papers. Washington D. C., 2005.

TILAHUN, N.; LEVINSON, D.; KRIZEK, K. Trails, lanes, or traffic: Valuing bicycle facilities with an adaptive stated preference survey. Transportation Research Part A, n. 41, p. 287301, 2007. 
TOOLE, J. Revising the AASHTO Guide for the Development of Bicycle Facilities. The National Cooperative Highway Research Program. Hyattsville, 2010. 248 p.

TRB. Highway Capacity Manual. Transportation Research Board. National Research Council, Washington D. C., 2010.

TUCKER, B.; MANAUGH, K. Whose bike lanes? Access to safe Cycling routes across neighborhoods in Rio de Janeiro and Curitiba. Transportation Research Board $95^{\text {th }}$ Annual Meeting Compendium of Papers. Washington D. C., 2016.

VALE, D. S.; SARAIVA, M.; PEREIRA, M. Active accessibility: A review of operational measures of walking and cycling accessibility. Journal of Transport and Land Use, v. 9, n. 1, p. 209-235, 2016.

WINTERS, M.; TESCHKE, K.; GRANT, M.; SETTON, E. M.; BRAUER, M. How far out the way will we travel? Built environmental influences on route selection for bicycle and car travel. Transportation Research Record, n. 2190, p. 1-10, 2010.

ZACHARIAS, J.; ZHANG, R. Revealed Bicyclist Route Choice Preferences and Street Conditions. Transportation Research Board $95^{\text {th }}$ Annual Meeting Compendium of Papers. Washington D. C., 2016. 
$160 \mid$ Pág i n a 


\section{APÊNDICE A}

Neste apêndice são detalhados os equipamentos utilizados para o trabalho de nivelamento das vias de tráfego da área de estudo com o auxílio da tecnologia GNSS. A Figura A1 apresenta estes equipamentos e a Tabela A1 apresenta suas respectivas características principais.

Figura A1: Equipamentos utilizados para o nivelamento com auxílio da tecnologia GNSS.

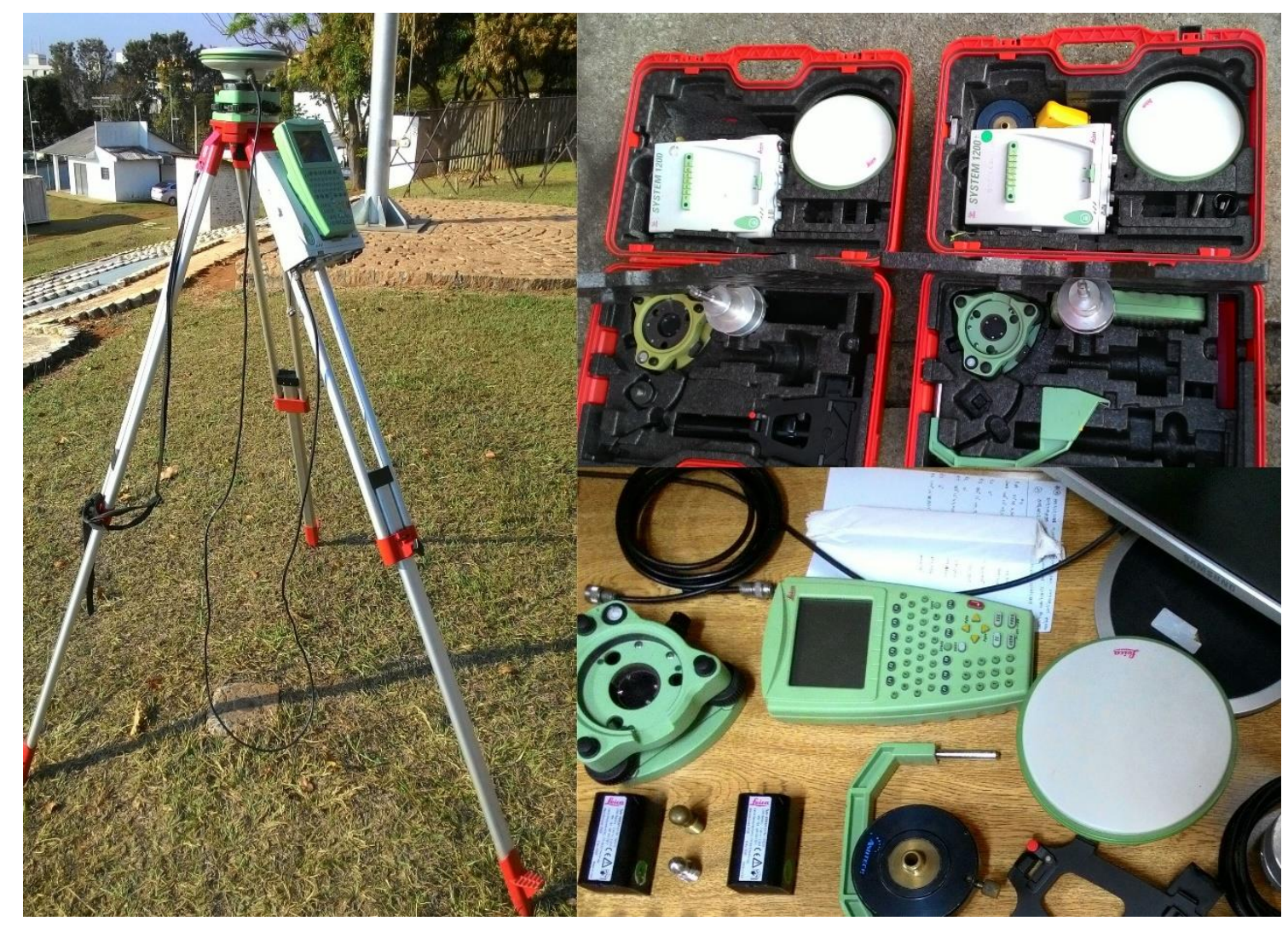

Fonte: Elaborado pelo autor.

Tabela A1: Receptores GNSS utilizados no levantamento.

\begin{tabular}{c|c|c|c}
\hline \multicolumn{4}{c}{ Receptores GNSS } \\
\hline Receptor 01: & GX1230GG & Receptor 02: & GX1230GG \\
Equip. N & 3418396 & Equip. N & 3418386 \\
S/N: & 472682 & S/N: & 472672 \\
Antena: & AX1202-GG & Antena: & AX1202-GG \\
S/N: & 8420002 & S/N: & 8430030 \\
\hline
\end{tabular}

Fonte: Elaborado pelo autor. 
$162 \mid$ P á g i n a 


\section{APÊNDICE B}

Neste apêndice são apresentados os resultados das contagens volumétricas em cada uma das interseções selecionadas da área de estudo. 
164 | P á g i n a 
ID: 1

LOCALIZAÇÃO: Av. XV de Novembro (I) x Rua Santa Cruz (II)

DATA: 09/10/2017 (segunda-feira)

HORÁRIO: Início: 18:12h - Final: 18:27h

\section{MOVIMENTOS PERMITIDOS:}

Figura B1: Av. XV de Novembro (I) x Rua Santa Cruz (II).
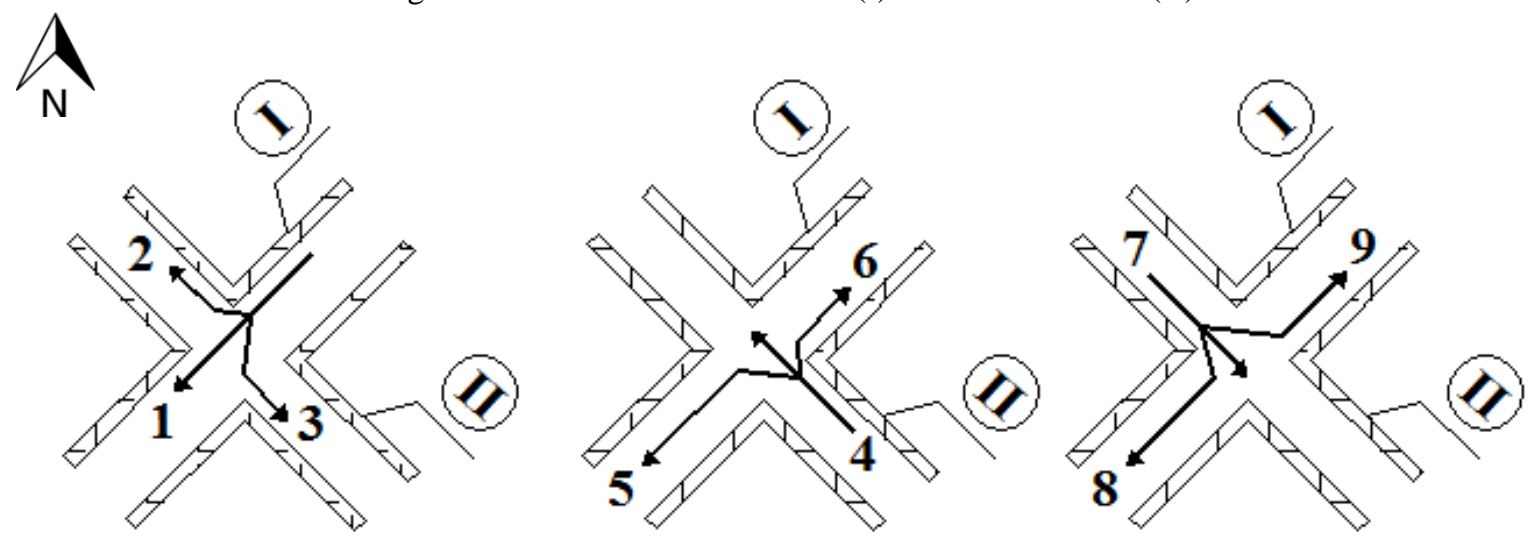

Fonte: Elaborado pelo autor.

Desenho sem escala.

\section{CONTAGENS:}

$$
\mathrm{V}_{\mathrm{p}}=1,0 *(\mathrm{~A})+1,0 *(\mathrm{M})+1,5 *(\mathrm{O} / \mathrm{C})
$$

Tabela B1: Av. XV de Novembro (I) x Rua Santa Cruz (II).

\begin{tabular}{c|c|c|c|c|c}
\hline \multirow{2}{*}{ Movimento } & \multicolumn{5}{|c}{ Tipo de veículo } \\
\cline { 2 - 6 } & A & M & O/C & B & Vp \\
\hline 1 & 19 & 5 & 6 & 1 & 33 \\
2 & 1 & 0 & 1 & 0 & 3 \\
3 & 2 & 2 & 1 & 0 & 6 \\
4 & 5 & 4 & 0 & 1 & 9 \\
5 & 5 & 0 & 0 & 0 & 5 \\
6 & 4 & 2 & 0 & 0 & 6 \\
7 & 6 & 3 & 0 & 0 & 9 \\
8 & 11 & 4 & 1 & 0 & 17 \\
9 & 3 & 3 & 2 & 0 & 9 \\
\hline
\end{tabular}

A=Automóveis; $\mathrm{M}=$ Motocicletas; $\mathrm{O} / \mathrm{C}=$ Ônibus e Caminhões; $\mathrm{B}=$ Bicicletas; $\mathrm{Vp}=\mathrm{Veículos} \mathrm{de} \mathrm{Passeio.}$

Fonte: Elaborado pelo autor. 
ID: 2

LOCALIZAÇÃO: Av. XV de Novembro (I) x Rua Prudente de Moraes (II)

DATA: 10/10/2017 (terça-feira)

HORÁRIO: Início: 18:10h - Final: 18:25h

MOVIMENTOS PERMITIDOS:

Figura B2: Av. XV de Novembro (I) x Rua Prudente de Moraes (II).
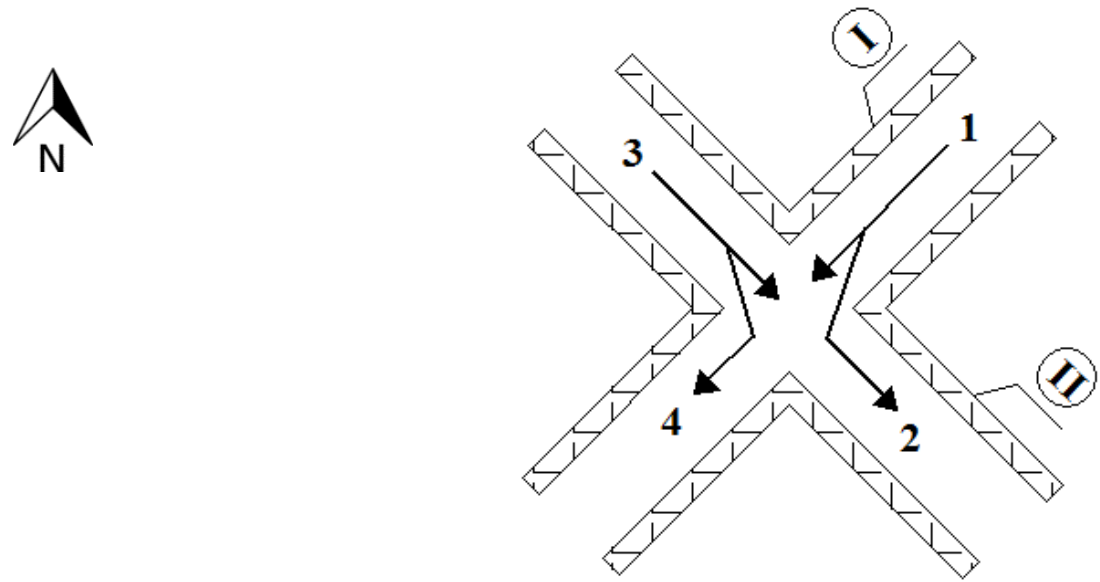

Fonte: Elaborado pelo autor.

Desenho sem escala.

CONTAGENS:

$$
\mathrm{V}_{\mathrm{p}}=1,0 *(\mathrm{~A})+1,0 *(\mathrm{M})+1,5 *(\mathrm{O} / \mathrm{C})
$$

Tabela B2: Av. XV de Novembro (I) x Rua Prudente de Moraes (II).

\begin{tabular}{c|c|c|c|c|c}
\hline \multirow{2}{*}{ Movimento } & \multicolumn{5}{|c}{ Tipo de veículo } \\
\cline { 2 - 6 } & $\mathrm{A}$ & $\mathrm{M}$ & $\mathrm{O} / \mathrm{C}$ & $\mathrm{B}$ & $\mathrm{Vp}$ \\
\hline 1 & 70 & 24 & 3 & 2 & 99 \\
2 & 6 & 2 & 0 & 0 & 8 \\
3 & 25 & 9 & 0 & 0 & 34 \\
4 & 9 & 3 & 0 & 0 & 12 \\
\hline
\end{tabular}

A=Automóveis; $\mathrm{M}=$ Motocicletas; $\mathrm{O} / \mathrm{C}=$ Ônibus e Caminhões; $\mathrm{B}=$ Bicicletas; $\mathrm{Vp}=$ Veículos de Passeio.

Fonte: Elaborado pelo autor. 
ID: 3

LOCALIZAÇÃO: Av. XV de Novembro (I) x Rua Rui Barbosa (II)

DATA: $11 / 10 / 2017$ (quarta-feira)

HORÁRIO: Início: 18:23h - Final: 18:38h

\section{MOVIMENTOS PERMITIDOS:}

Figura B3: Av. XV de Novembro (I) x Rua Rui Barbosa (II).
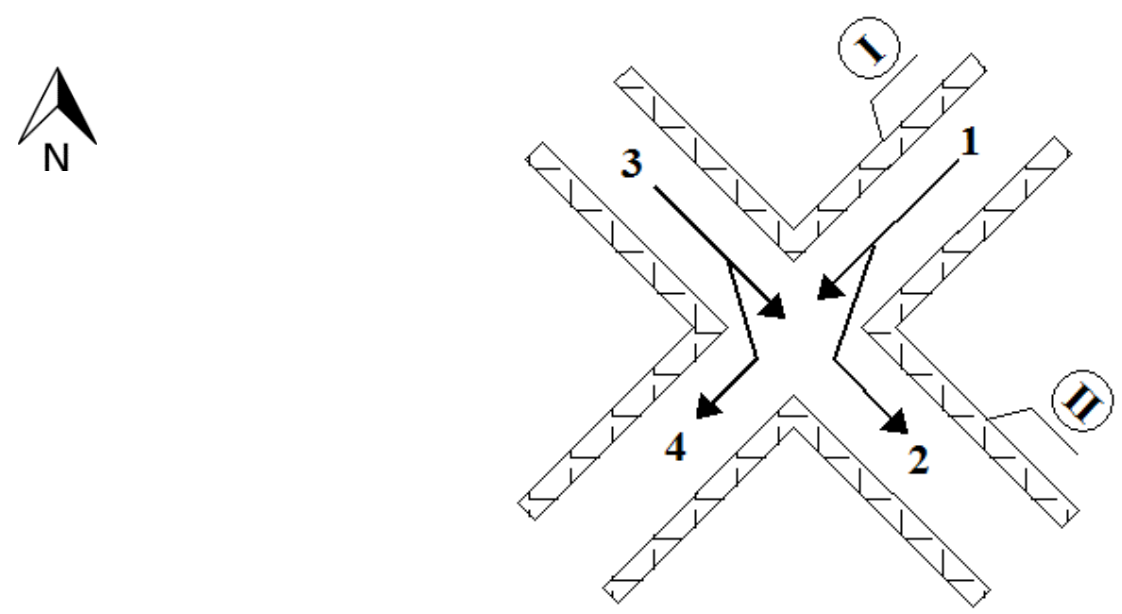

Fonte: Elaborado pelo autor.

Desenho sem escala.

\section{CONTAGENS:}

$$
\mathrm{V}_{\mathrm{p}}=1,0 *(\mathrm{~A})+1,0 *(\mathrm{M})+1,5 *(\mathrm{O} / \mathrm{C})
$$

Tabela B3: Av. XV de Novembro (I) x Rua Rui Barbosa (II).

\begin{tabular}{c|c|c|c|c|c}
\hline \multirow{2}{*}{ Movimento } & \multicolumn{5}{|c}{ Tipo de veículo } \\
\cline { 2 - 6 } & A & M & O/C & B & Vp \\
\hline 1 & 64 & 23 & 2 & 2 & 90 \\
2 & 15 & 5 & 1 & 0 & 22 \\
3 & 28 & 8 & 0 & 0 & 36 \\
4 & 10 & 3 & 0 & 0 & 13 \\
\hline
\end{tabular}

A=Automóveis; $\mathrm{M}=$ Motocicletas; $\mathrm{O} / \mathrm{C}=$ Ônibus e Caminhões; $\mathrm{B}=$ Bicicletas; $\mathrm{V} p=$ Veículos de Passeio.

Fonte: Elaborado pelo autor. 
ID: $4 \mathrm{a}$

LOCALIZAÇÃO: Av. José Jorge Resegue (I) x Rua Rui Barbosa (II)

DATA: 24/10/2017 (terça-feira)

HORÁRIO: Início: 07:33h - Final: 07:48h

\section{MOVIMENTOS PERMITIDOS:}

Figura B4: Av. José Jorge Resegue (I) x Rua Rui Barbosa (II) - (a).
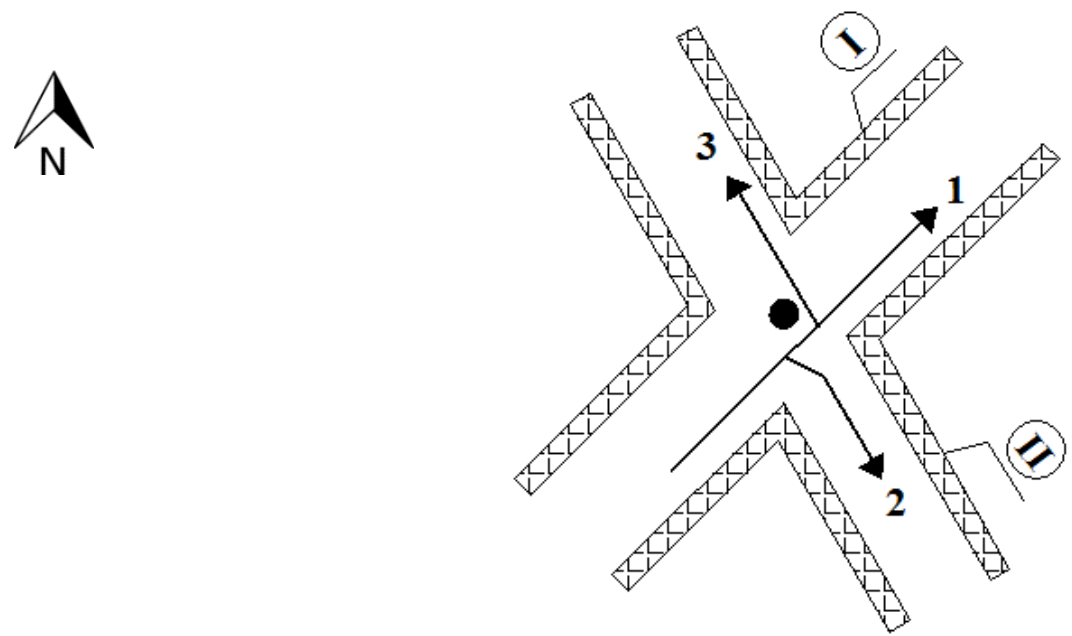

Fonte: Elaborado pelo autor.

Desenho sem escala.

Legenda:

- Rotatória

\section{CONTAGENS:}

$$
\mathrm{V}_{\mathrm{p}}=1,0 *(\mathrm{~A})+1,0 *(\mathrm{M})+1,5 *(\mathrm{O} / \mathrm{C})
$$

Tabela B4: Av. José Jorge Resegue (I) x Rua Rui Barbosa (II) - (a).

\begin{tabular}{c|c|c|c|c|c}
\hline \multirow{2}{*}{ Movimento } & \multicolumn{5}{|c}{ Tipo de veículo } \\
\cline { 2 - 6 } & $\mathrm{A}$ & $\mathrm{M}$ & $\mathrm{O} / \mathrm{C}$ & $\mathrm{B}$ & $\mathrm{Vp}$ \\
\hline 1 & 27 & 9 & 1 & 4 & 38 \\
2 & 5 & 3 & 0 & 1 & 8 \\
3 & 14 & 1 & 0 & 2 & 15 \\
\hline
\end{tabular}

A=Automóveis; $\mathrm{M}=$ Motocicletas; $\mathrm{O} / \mathrm{C}=$ Ônibus e Caminhões; $\mathrm{B}=$ Bicicletas; $\mathrm{Vp}=$ Veículos de Passeio.

Fonte: Elaborado pelo autor. 
ID: $4 \mathrm{~b}$

LOCALIZAÇÃO: Av. José Jorge Resegue (I) x Rua Rui Barbosa (II)

DATA: 24/10/2017 (terça-feira)

HORÁRIO: Início: 07:33h - Final: 07:48h

\section{MOVIMENTOS PERMITIDOS:}

Figura B5: Av. José Jorge Resegue (I) x Rua Rui Barbosa (II) - (b).
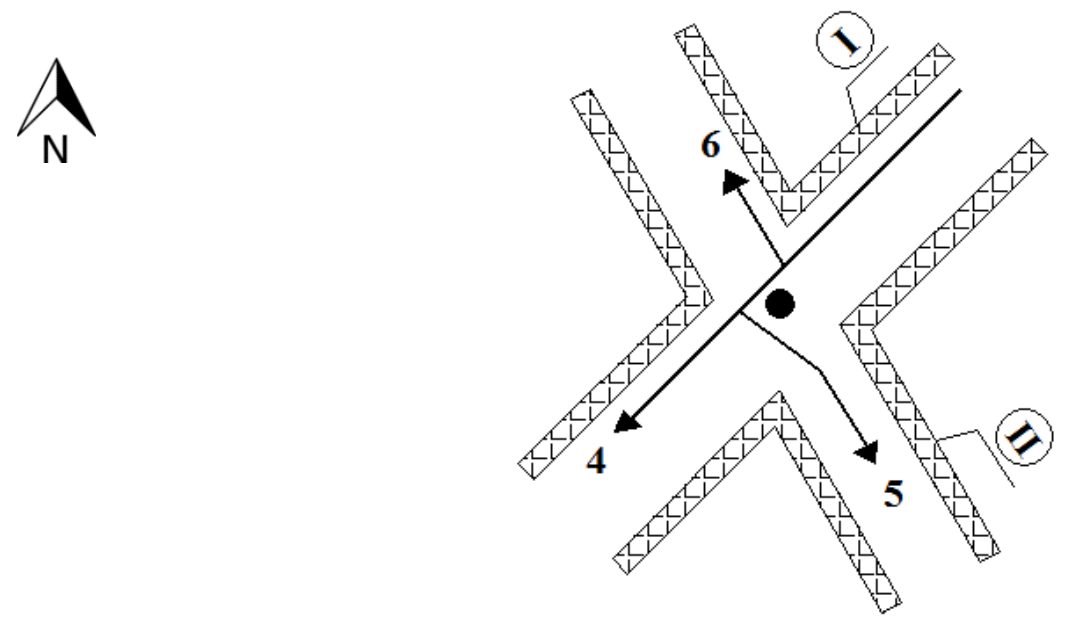

Fonte: Elaborado pelo autor.

Desenho sem escala.

Legenda:

- Rotatória

CONTAGENS:

$$
\mathrm{V}_{\mathrm{p}}=1,0 *(\mathrm{~A})+1,0 *(\mathrm{M})+1,5 *(\mathrm{O} / \mathrm{C})
$$

Tabela B5: Av. José Jorge Resegue (I) x Rua Rui Barbosa (II) - (b).

\begin{tabular}{c|c|c|c|c|c}
\hline \multirow{2}{*}{ Movimento } & \multicolumn{5}{|c}{ Tipo de veículo } \\
\cline { 2 - 6 } & $\mathrm{A}$ & $\mathrm{M}$ & $\mathrm{O} / \mathrm{C}$ & $\mathrm{B}$ & $\mathrm{Vp}$ \\
\hline 4 & 21 & 3 & 1 & 0 & 26 \\
5 & 5 & 0 & 0 & 1 & 5 \\
6 & 2 & 0 & 0 & 0 & 2 \\
\hline
\end{tabular}

A=Automóveis; $\mathrm{M}=$ Motocicletas; $\mathrm{O} / \mathrm{C}=$ Ônibus e Caminhões; $\mathrm{B}=$ Bicicletas; $\mathrm{V} p=$ Veículos de Passeio.

Fonte: Elaborado pelo autor. 
ID: $4 \mathrm{c}$

LOCALIZAÇÃO: Av. José Jorge Resegue (I) x Rua Rui Barbosa (II)

DATA: 24/10/2017 (terça-feira)

HORÁRIO: Início: 07:33h - Final: 07:48h

\section{MOVIMENTOS PERMITIDOS:}

Figura B6: Av. José Jorge Resegue (I) x Rua Rui Barbosa (II) - (c).

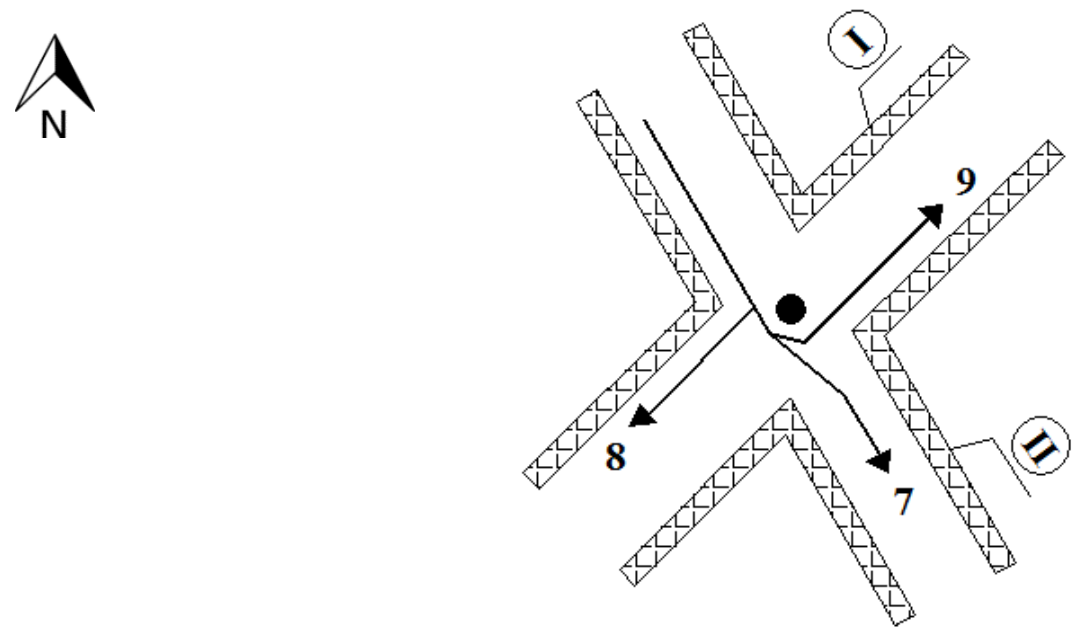

Fonte: Elaborado pelo autor.

Desenho sem escala.

Legenda:

- Rotatória

\section{CONTAGENS:}

$$
\mathrm{V}_{\mathrm{p}}=1,0 *(\mathrm{~A})+1,0 *(\mathrm{M})+1,5 *(\mathrm{O} / \mathrm{C})
$$

Tabela B6: Av. José Jorge Resegue (I) x Rua Rui Barbosa (II) - (c).

\begin{tabular}{c|c|c|c|c|c}
\hline \multirow{2}{*}{ Movimento } & \multicolumn{5}{|c}{ Tipo de veículo } \\
\cline { 2 - 6 } & $\mathrm{A}$ & $\mathrm{M}$ & O/C & $\mathrm{B}$ & $\mathrm{Vp}$ \\
\hline 7 & 13 & 2 & 0 & 1 & 15 \\
8 & 4 & 1 & 0 & 2 & 5 \\
9 & 9 & 4 & 2 & 2 & 16 \\
\hline
\end{tabular}

A=Automóveis; $\mathrm{M}=$ Motocicletas; $\mathrm{O} / \mathrm{C}=$ Ônibus e Caminhões; $\mathrm{B}=$ Bicicletas; $\mathrm{Vp}=$ Veículos de Passeio.

Fonte: Elaborado pelo autor. 
ID: 5

LOCALIZAÇÃO: Av. José Jorge Resegue (I) x Rua Prudente de Moraes (II)

DATA: 11/10/2017 (quarta-feira)

HORÁRIO: Início: 07:32h - Final: 07:47h

\section{MOVIMENTOS PERMITIDOS:}

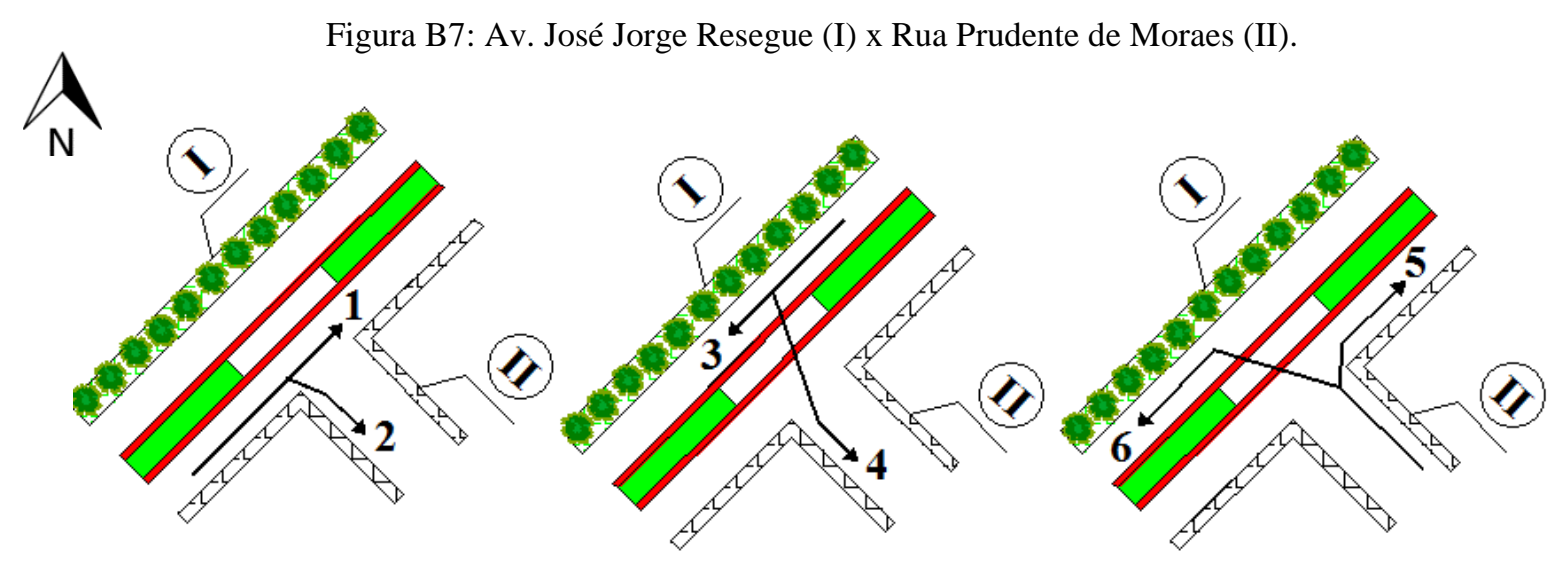

Fonte: Elaborado pelo autor.

Desenho sem escala.

Legenda:

Canteiro central

Infraestrutura cicloviária

\section{CONTAGENS:}

$$
\mathrm{V}_{\mathrm{p}}=1,0 *(\mathrm{~A})+1,0 *(\mathrm{M})+1,5 *(\mathrm{O} / \mathrm{C})
$$

Tabela B7: Av. José Jorge Resegue (I) x Rua Prudente de Moraes (II).

\begin{tabular}{c|c|c|c|c|c}
\hline \multirow{2}{*}{ Movimento } & \multicolumn{5}{|c}{ Tipo de veículo } \\
\cline { 2 - 6 } & $\mathrm{A}$ & $\mathrm{M}$ & O/C & $\mathrm{B}$ & Vp \\
\hline 1 & 53 & 3 & 0 & 3 & 56 \\
2 & 19 & 2 & 0 & 0 & 21 \\
3 & 56 & 3 & 3 & 6 & 64 \\
4 & 21 & 3 & 1 & 0 & 26 \\
5 & 22 & 1 & 0 & 1 & 23 \\
6 & 17 & 6 & 0 & 0 & 23 \\
\hline
\end{tabular}

A=Automóveis; $\mathrm{M}=$ Motocicletas; $\mathrm{O} / \mathrm{C}=$ Ônibus e Caminhões; $\mathrm{B}=$ Bicicletas; $\mathrm{Vp}=\mathrm{Veículos} \mathrm{de} \mathrm{Passeio.}$

Fonte: Elaborado pelo autor. 
ID: 6

LOCALIZAÇÃO: Av. XV de Novembro (I) x Rua Floriano Peixoto (II)

DATA: 16/10/2017 (segunda-feira)

HORÁRIO: Início: 18:25h - Final: 18:40h

\section{MOVIMENTOS PERMITIDOS:}

Figura B8: Av. XV de Novembro (I) x Rua Floriano Peixoto (II).
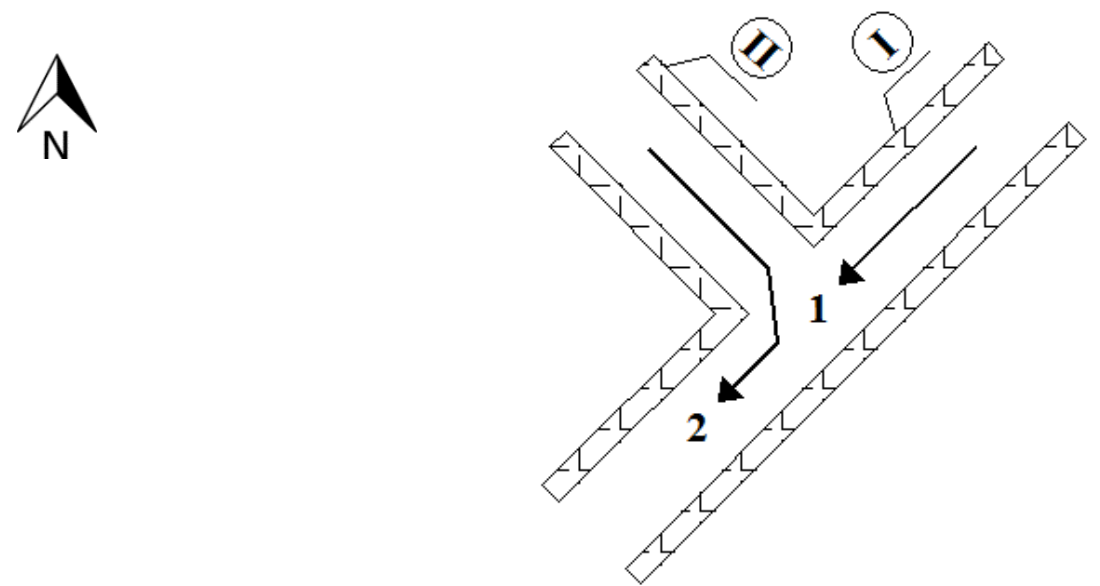

Fonte: Elaborado pelo autor.

Desenho sem escala.

CONTAGENS:

$$
\mathrm{V}_{\mathrm{p}}=1,0 *(\mathrm{~A})+1,0 *(\mathrm{M})+1,5 *(\mathrm{O} / \mathrm{C})
$$

Tabela B8: Av. XV de Novembro (I) x Rua Floriano Peixoto (II).

\begin{tabular}{c|c|c|c|c|c}
\hline \multirow{2}{*}{ Movimento } & \multicolumn{5}{|c}{ Tipo de veículo } \\
\cline { 2 - 6 } & $\mathrm{A}$ & $\mathrm{M}$ & $\mathrm{O} / \mathrm{C}$ & $\mathrm{B}$ & $\mathrm{Vp}$ \\
\hline 1 & 83 & 43 & 3 & 7 & 131 \\
2 & 13 & 4 & 1 & 1 & 19 \\
\hline
\end{tabular}

A=Automóveis; $\mathrm{M}=$ Motocicletas; $\mathrm{O} / \mathrm{C}=$ Ônibus e Caminhões; $\mathrm{B}=$ Bicicletas; $\mathrm{Vp}=$ Veículos de Passeio.

Fonte: Elaborado pelo autor. 
ID: 7

LOCALIZAÇÃO: Av. José Jorge Resegue (I) x Rua Floriano Peixoto (II)

DATA: 25/10/2017 (quarta-feira)

HORÁRIO: Início: 07:44h - Final: 07:59h

\section{MOVIMENTOS PERMITIDOS:}

Figura B9: Av. José Jorge Resegue (I) x Rua Floriano Peixoto (II).
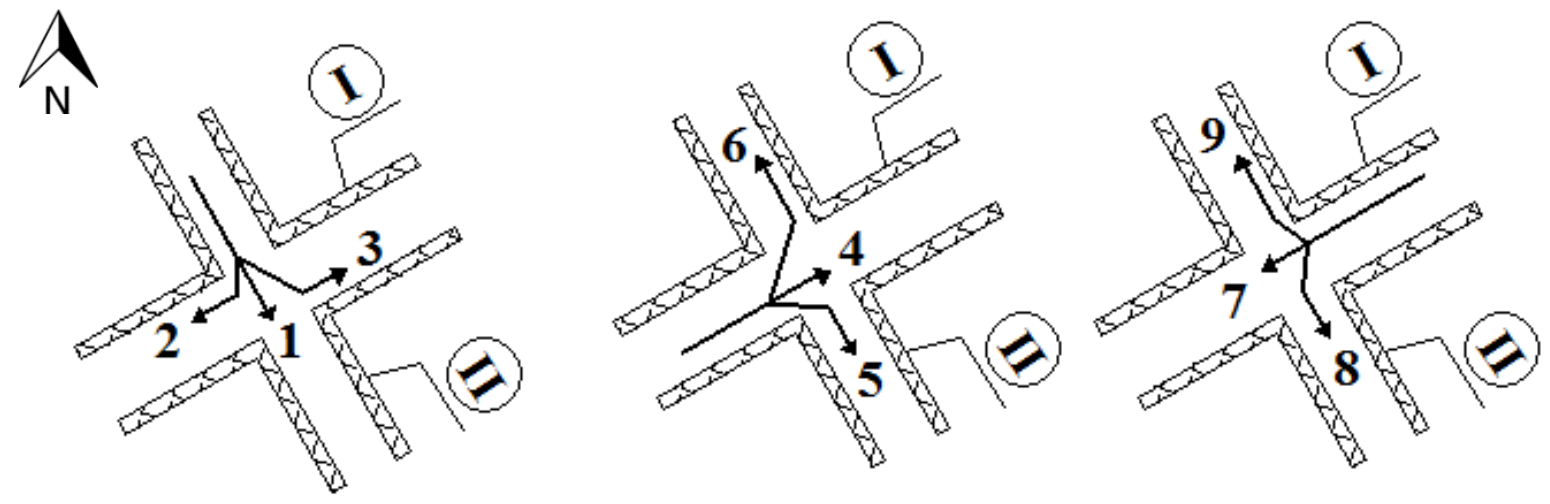

Fonte: Elaborado pelo autor.

Desenho sem escala.

\section{CONTAGENS:}

$$
\mathrm{V}_{\mathrm{p}}=1,0 *(\mathrm{~A})+1,0 *(\mathrm{M})+1,5 *(\mathrm{O} / \mathrm{C})
$$

Tabela B9: Av. José Jorge Resegue (I) x Rua Floriano Peixoto (II).

\begin{tabular}{c|c|c|c|c|c}
\hline \multirow{2}{*}{ Movimento } & \multicolumn{5}{|c}{ Tipo de veículo } \\
\cline { 2 - 6 } & $\mathrm{A}$ & $\mathrm{M}$ & $\mathrm{O} / \mathrm{C}$ & $\mathrm{B}$ & $\mathrm{Vp}$ \\
\hline 1 & 12 & 1 & 0 & 1 & 13 \\
2 & 0 & 1 & 1 & 0 & 3 \\
3 & 5 & 1 & 0 & 4 & 6 \\
4 & 20 & 8 & 2 & 2 & 31 \\
5 & 4 & 0 & 0 & 1 & 4 \\
6 & 4 & 0 & 0 & 2 & 4 \\
7 & 24 & 6 & 0 & 1 & 30 \\
8 & 4 & 0 & 0 & 1 & 4 \\
9 & 2 & 0 & 0 & 0 & 2 \\
\hline
\end{tabular}

A=Automóveis; $\mathrm{M}=$ Motocicletas; $\mathrm{O} / \mathrm{C}=$ Ônibus e Caminhões; $\mathrm{B}=$ Bicicletas; $\mathrm{Vp}=\mathrm{Veículos} \mathrm{de} \mathrm{Passeio.}$

Fonte: Elaborado pelo autor. 
ID: 8

LOCALIZAÇÃO: Rua 7 de Setembro (I) x Rua Antônio C. Baricelo (II)

DATA: 10/10/2017 (terça-feira)

HORÁRIO: Início: 12:13h - Final: 12:28h

\section{MOVIMENTOS PERMITIDOS:}

Figura B10: Rua 7 de Setembro (I) x Rua Antônio C. Baricelo (II).
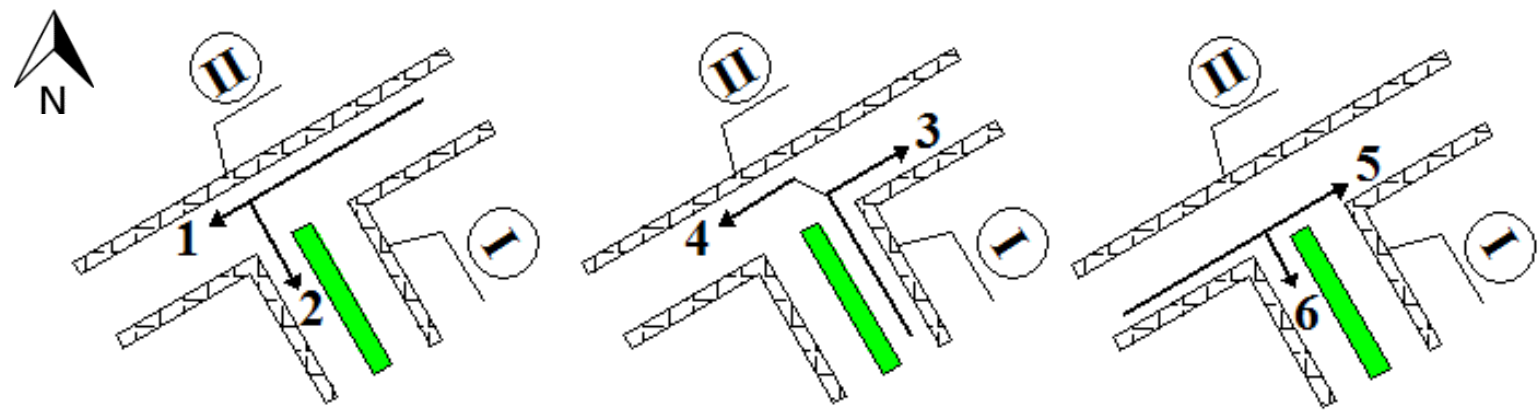

Fonte: Elaborado pelo autor.

Desenho sem escala.

Legenda:

Canteiro central

\section{CONTAGENS:}

$$
\mathrm{V}_{\mathrm{p}}=1,0 *(\mathrm{~A})+1,0 *(\mathrm{M})+1,5 *(\mathrm{O} / \mathrm{C})
$$

Tabela B10: Rua 7 de Setembro (I) x Rua Antônio C. Baricelo (II).

\begin{tabular}{c|c|c|c|c|c}
\hline \multirow{2}{*}{ Movimento } & \multicolumn{5}{|c}{ Tipo de veículo } \\
\cline { 2 - 6 } & $\mathrm{A}$ & $\mathrm{M}$ & $\mathrm{O} / \mathrm{C}$ & $\mathrm{B}$ & $\mathrm{Vp}$ \\
\hline 1 & 1 & 0 & 0 & 0 & 1 \\
2 & 3 & 1 & 1 & 2 & 6 \\
3 & 3 & 1 & 0 & 1 & 4 \\
4 & 3 & 1 & 0 & 0 & 4 \\
5 & 0 & 0 & 0 & 0 & 0 \\
6 & 0 & 0 & 0 & 0 & 0 \\
\hline
\end{tabular}

A=Automóveis; $\mathrm{M}=$ Motocicletas; $\mathrm{O} / \mathrm{C}=$ Ônibus e Caminhões; $\mathrm{B}=$ Bicicletas; $\mathrm{Vp}=$ Veículos de Passeio.

Fonte: Elaborado pelo autor. 
ID: 9

LOCALIZAÇÃO: Rua 7 de Setembro (I) x Rua Vitório E. Prearo (II)

DATA: 11/10/2017 (quarta-feira)

HORÁRIO: Início: 12:09h - Final: 12:24h

\section{MOVIMENTOS PERMITIDOS:}

Figura B11: Rua 7 de Setembro (I) x Rua Vitório E. Prearo (II).
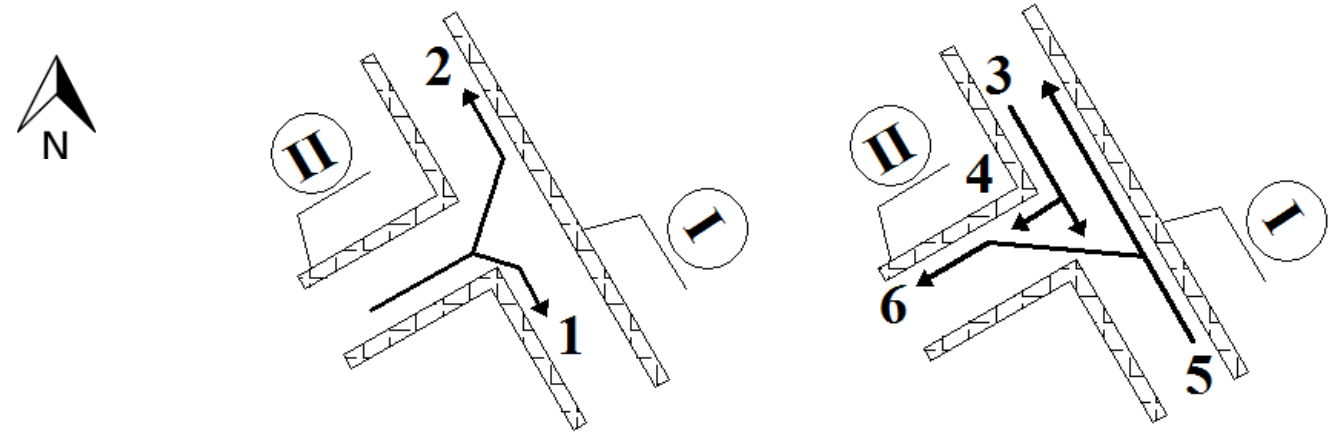

Fonte: Elaborado pelo autor.

Desenho sem escala.

CONTAGENS:

$$
\mathrm{V}_{\mathrm{p}}=1,0 *(\mathrm{~A})+1,0 *(\mathrm{M})+1,5 *(\mathrm{O} / \mathrm{C})
$$

Tabela B11: Rua 7 de Setembro (I) x Rua Vitório E. Prearo (II).

\begin{tabular}{c|c|c|c|c|c}
\hline \multirow{2}{*}{ Movimento } & \multicolumn{5}{|c}{ Tipo de veículo } \\
\cline { 2 - 6 } & A & M & O/C & B & Vp \\
\hline 1 & 15 & 4 & 0 & 0 & 19 \\
2 & 11 & 1 & 3 & 0 & 17 \\
3 & 9 & 3 & 3 & 0 & 17 \\
4 & 4 & 1 & 0 & 0 & 5 \\
5 & 4 & 3 & 0 & 0 & 7 \\
6 & 4 & 1 & 2 & 0 & 8 \\
\hline
\end{tabular}

A=Automóveis; $\mathrm{M}=$ Motocicletas; $\mathrm{O} / \mathrm{C}=$ Ônibus e Caminhões; $\mathrm{B}=$ Bicicletas; $\mathrm{V}$ =Véículos de Passeio.

Fonte: Elaborado pelo autor. 
ID: 10

LOCALIZAÇÃ̃: Rua 7 de Setembro (I) x Av. João Lemos (II)

DATA: 17/10/2017 (terça-feira)

HORÁRIO: Início: 12:10h - Final: 12:25h

MOVIMENTOS PERMITIDOS:

Figura B12: Rua 7 de Setembro (I) x Av. João Lemos (II).
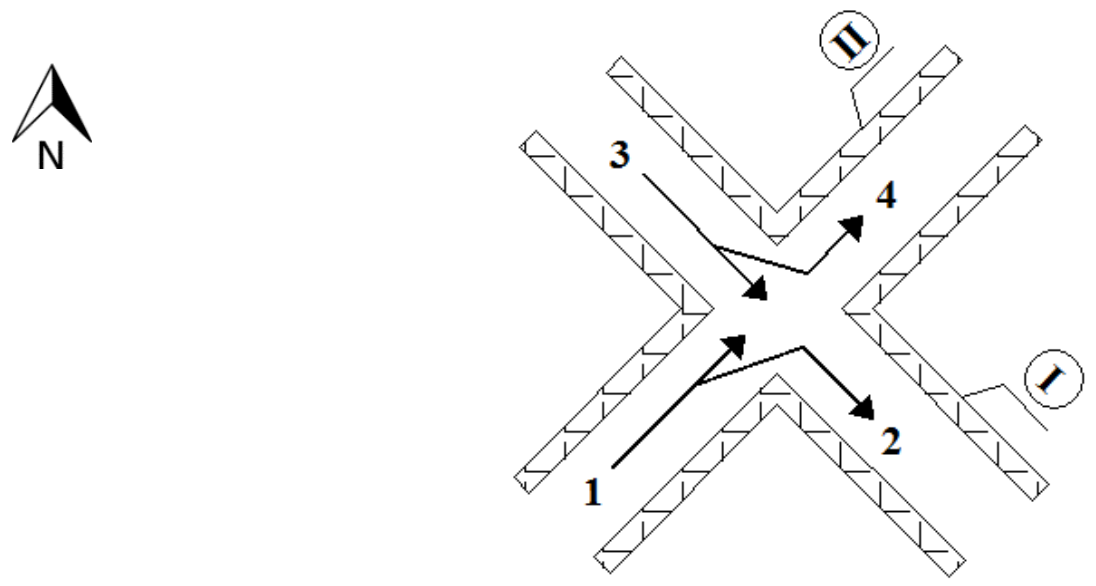

Fonte: Elaborado pelo autor.

Desenho sem escala.

CONTAGENS:

$$
\mathrm{V}_{\mathrm{p}}=1,0 *(\mathrm{~A})+1,0 *(\mathrm{M})+1,5 *(\mathrm{O} / \mathrm{C})
$$

Tabela B12: Rua 7 de Setembro (I) x Av. João Lemos (II).

\begin{tabular}{c|c|c|c|c|c}
\hline \multirow{2}{*}{ Movimento } & \multicolumn{5}{|c}{ Tipo de veículo } \\
\cline { 2 - 6 } & $\mathrm{A}$ & $\mathrm{M}$ & $\mathrm{O} / \mathrm{C}$ & $\mathrm{B}$ & $\mathrm{Vp}$ \\
\hline 1 & 46 & 20 & 0 & 2 & 66 \\
2 & 16 & 4 & 2 & 3 & 23 \\
3 & 80 & 29 & 7 & 5 & 120 \\
4 & 10 & 1 & 0 & 1 & 11 \\
\hline
\end{tabular}

A=Automóveis; M=Motocicletas; O/C=Ônibus e Caminhões; B=Bicicletas; Vp=Veículos de Passeio.

Fonte: Elaborado pelo autor. 
ID: 11

LOCALIZAÇÃO: Av. XV de Novembro (I) x Rua 7 de Setembro (II)

DATA: 17/10/2017 (terça-feira)

HORÁRIO: Início: 18:05h - Final: 18:20h

\section{MOVIMENTOS PERMITIDOS:}

Figura B13: Av. XV de Novembro (I) x Rua 7 de Setembro (II).
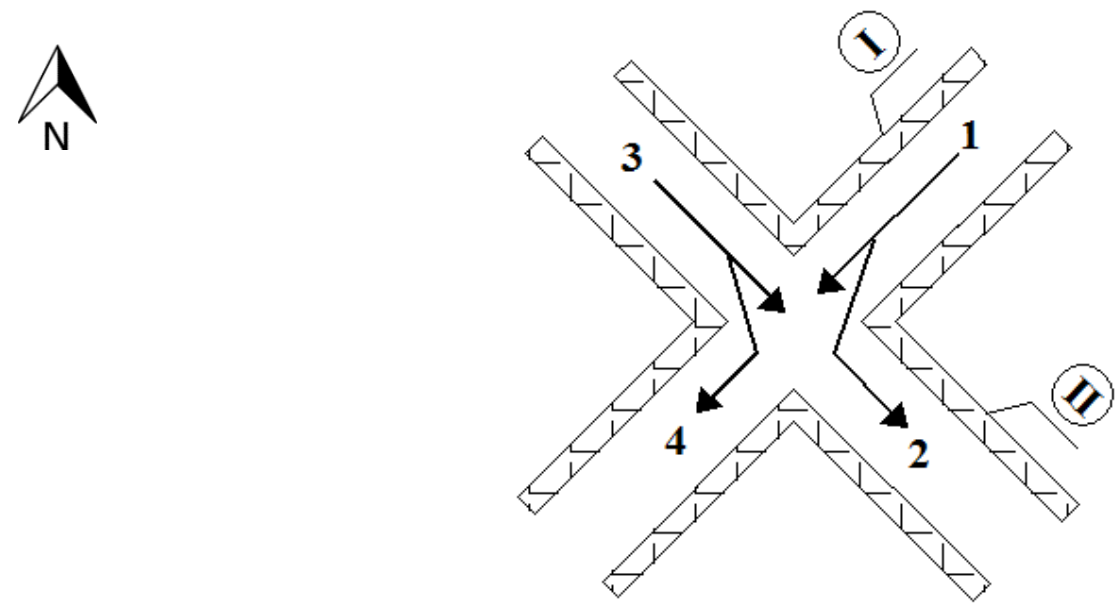

Fonte: Elaborado pelo autor.

Desenho sem escala.

CONTAGENS:

$$
\mathrm{V}_{\mathrm{p}}=1,0 *(\mathrm{~A})+1,0 *(\mathrm{M})+1,5 *(\mathrm{O} / \mathrm{C})
$$

Tabela B13: Av. XV de Novembro (I) x Rua 7 de Setembro (II).

\begin{tabular}{c|c|c|c|c|c}
\hline \multirow{2}{*}{ Movimento } & \multicolumn{5}{|c}{ Tipo de veículo } \\
\cline { 2 - 6 } & $\mathrm{A}$ & $\mathrm{M}$ & $\mathrm{O} / \mathrm{C}$ & $\mathrm{B}$ & Vp \\
\hline 1 & 71 & 35 & 1 & 9 & 108 \\
2 & 20 & 10 & 0 & 1 & 30 \\
3 & 65 & 13 & 1 & 2 & 80 \\
4 & 36 & 18 & 5 & 2 & 62 \\
\hline
\end{tabular}

A=Automóveis; M=Motocicletas; $\mathrm{O} / \mathrm{C}=$ Ônibus e Caminhões; $\mathrm{B}=$ Bicicletas; $\mathrm{V}$ =Veículos de Passeio.

Fonte: Elaborado pelo autor. 
ID: 12

LOCALIZAÇÃO: Av. Claudionor Barbieri (I) x Rua 7 de Setembro (II)

DATA: 19/10/2017 (quinta-feira)

HORÁRIO: Início: 07:39h - Final: 07:54h

\section{MOVIMENTOS PERMITIDOS:}

Figura B14: Av. Claudionor Barbieri (I) x Rua 7 de Setembro (II).
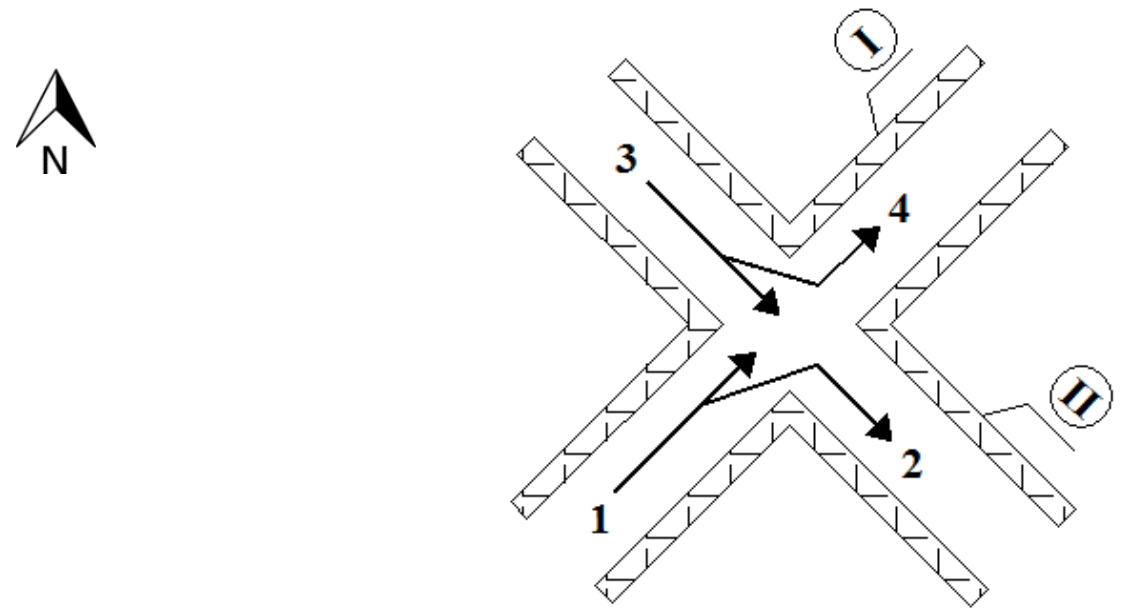

Fonte: Elaborado pelo autor.

Desenho sem escala.

CONTAGENS:

$$
\mathrm{V}_{\mathrm{p}}=1,0 *(\mathrm{~A})+1,0 *(\mathrm{M})+1,5 *(\mathrm{O} / \mathrm{C})
$$

Tabela B14: Av. Claudionor Barbieri (I) x Rua 7 de Setembro (II).

\begin{tabular}{c|c|c|c|c|c}
\hline \multirow{2}{*}{ Movimento } & \multicolumn{5}{|c}{ Tipo de veículo } \\
\cline { 2 - 6 } & $\mathrm{A}$ & $\mathrm{M}$ & O/C & $\mathrm{B}$ & $\mathrm{Vp}$ \\
\hline 1 & 74 & 36 & 1 & 4 & 112 \\
2 & 6 & 1 & 0 & 1 & 7 \\
3 & 36 & 6 & 0 & 1 & 42 \\
4 & 53 & 8 & 0 & 4 & 61 \\
\hline
\end{tabular}

A=Automóveis; $\mathrm{M}=$ Motocicletas; $\mathrm{O} / \mathrm{C}=$ Ônibus e Caminhões; $\mathrm{B}=$ Bicicletas; $\mathrm{Vp}=$ Veículos de Passeio.

Fonte: Elaborado pelo autor. 
ID: 13

LOCALIZAÇÃO: Av. Claudionor Barbieri (I) x Av. Sérgio Furcin (II)

DATA: 20/10/2017 (sexta-feira)

HORÁRIO: Início: 07:38h - Final: 07:53h

\section{MOVIMENTOS PERMITIDOS:}

Figura B15: Av. Claudionor Barbieri (I) x Av. Sérgio Furcin (II).
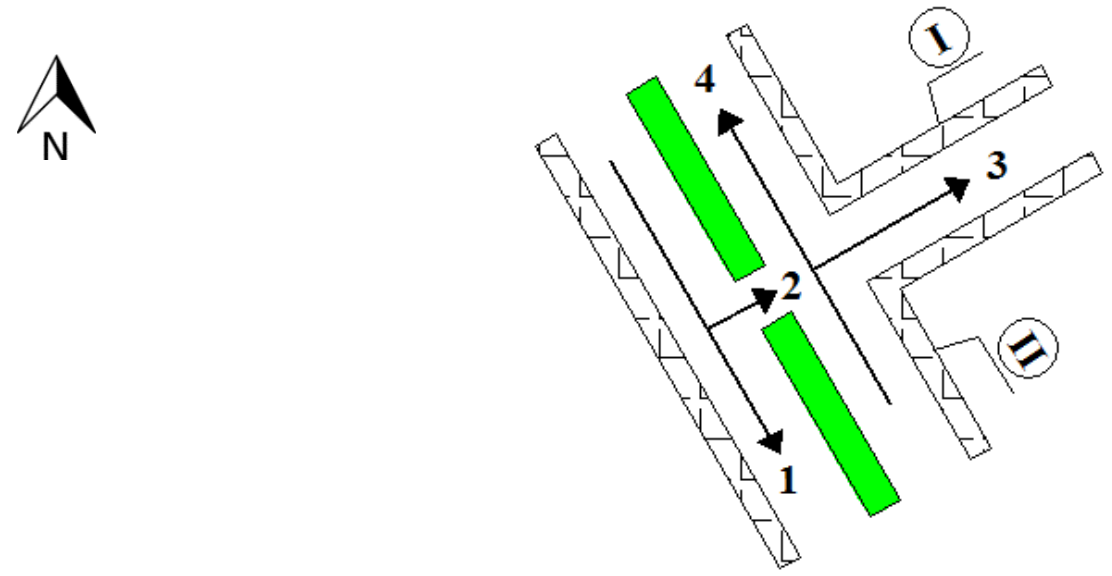

Fonte: Elaborado pelo autor.

Desenho sem escala.

Legenda:

Canteiro central

\section{CONTAGENS:}

$$
\mathrm{V}_{\mathrm{p}}=1,0 *(\mathrm{~A})+1,0 *(\mathrm{M})+1,5 *(\mathrm{O} / \mathrm{C})
$$

Tabela B15: Av. Claudionor Barbieri (I) x Av. Sérgio Furcin (II).

\begin{tabular}{c|c|c|c|c|c}
\hline \multirow{2}{*}{ Movimento } & \multicolumn{5}{|c}{ Tipo de veículo } \\
\cline { 2 - 6 } & $\mathrm{A}$ & $\mathrm{M}$ & O/C & $\mathrm{B}$ & Vp \\
\hline 1 & 59 & 19 & 2 & 6 & 81 \\
2 & 13 & 4 & 1 & 2 & 19 \\
3 & 64 & 23 & 4 & 10 & 93 \\
4 & 49 & 21 & 4 & 5 & 76 \\
\hline
\end{tabular}

A=Automóveis; $\mathrm{M}=$ Motocicletas; $\mathrm{O} / \mathrm{C}=$ Ônibus e Caminhões; $\mathrm{B}=$ Bicicletas; $\mathrm{Vp}=$ Veículos de Passeio.

Fonte: Elaborado pelo autor. 
ID: 14

LOCALIZAÇÃO: Av. Claudionor Barbieri (I) x Av. Francisco Munhoz Cegarra (II)

DATA: 18/10/2017 (quarta-feira)

HORÁRIO: Início: 07:40h - Final: 07:55h

\section{MOVIMENTOS PERMITIDOS:}

Figura B16: Av. Claudionor Barbieri (I) x Av. Francisco Munhoz Cegarra (II).
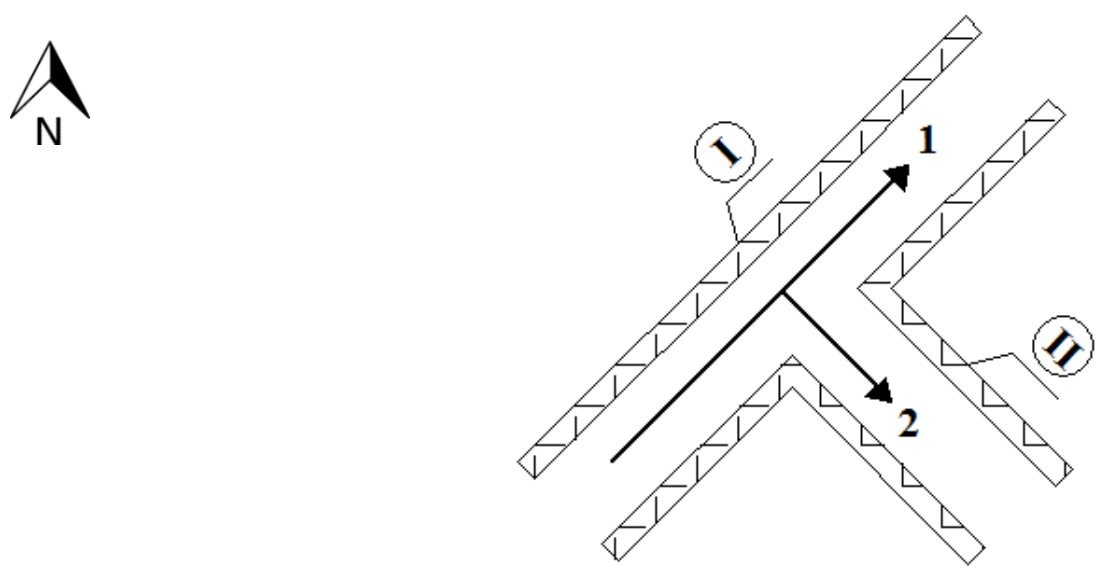

Fonte: Elaborado pelo autor.

Desenho sem escala.

CONTAGENS:

$$
\mathrm{V}_{\mathrm{p}}=1,0 *(\mathrm{~A})+1,0 *(\mathrm{M})+1,5 *(\mathrm{O} / \mathrm{C})
$$

Tabela B16: Av. Claudionor Barbieri (I) x Av. Francisco Munhoz Cegarra (II).

\begin{tabular}{c|c|c|c|c|c}
\hline \multirow{2}{*}{ Movimento } & \multicolumn{5}{|c}{ Tipo de veículo } \\
\cline { 2 - 6 } & $\mathrm{A}$ & $\mathrm{M}$ & $\mathrm{O} / \mathrm{C}$ & $\mathrm{B}$ & $\mathrm{Vp}$ \\
\hline 1 & 59 & 27 & 1 & 3 & 88 \\
2 & 14 & 2 & 0 & 5 & 16 \\
\hline
\end{tabular}

A=Automóveis; $\mathrm{M}=$ Motocicletas; $\mathrm{O} / \mathrm{C}=$ Ônibus e Caminhões; $\mathrm{B}=$ Bicicletas; $\mathrm{Vp}=$ Veículos de Passeio.

Fonte: Elaborado pelo autor. 
ID: 15

LOCALIZAÇÃO: Av. Claudionor Barbieri (I) x Rua Rui Barbosa (II)

DATA: 17/10/2017 (terça-feira)

HORÁRIO: Início: 07:45h - Final: 08:00h

\section{MOVIMENTOS PERMITIDOS:}

Figura B17: Av. Claudionor Barbieri (I) x Rua Rui Barbosa (II).
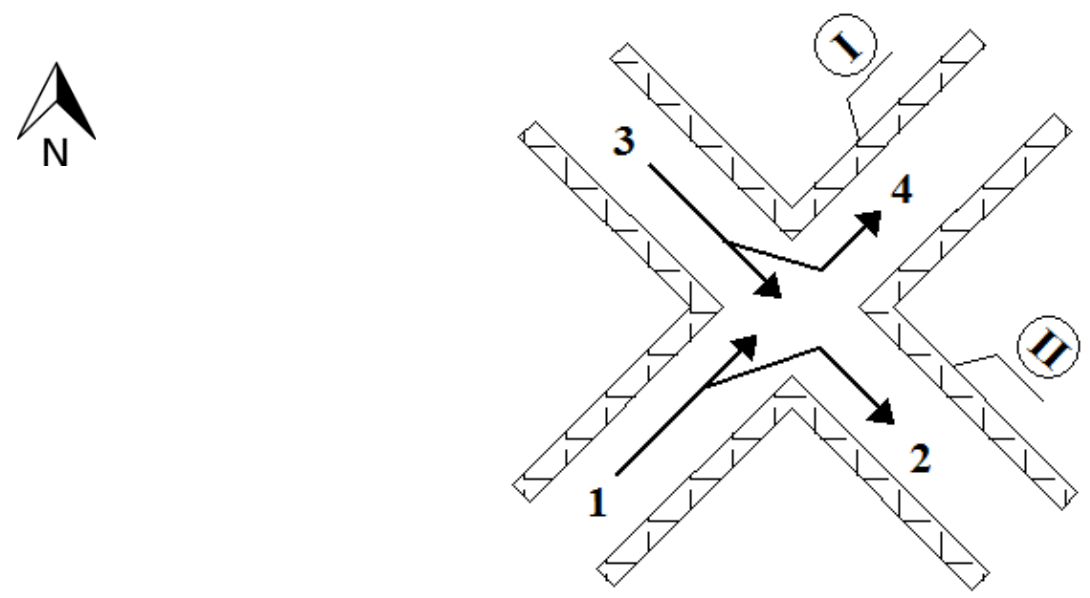

Fonte: Elaborado pelo autor.

Desenho sem escala.

\section{CONTAGENS:}

$$
\mathrm{V}_{\mathrm{p}}=1,0 *(\mathrm{~A})+1,0 *(\mathrm{M})+1,5 *(\mathrm{O} / \mathrm{C})
$$

Tabela B17: Av. Claudionor Barbieri (I) x Rua Rui Barbosa (II).

\begin{tabular}{c|c|c|c|c|c}
\hline \multirow{2}{*}{ Movimento } & \multicolumn{5}{|c}{ Tipo de veículo } \\
\cline { 2 - 6 } & $\mathrm{A}$ & $\mathrm{M}$ & $\mathrm{O} / \mathrm{C}$ & $\mathrm{B}$ & $\mathrm{Vp}$ \\
\hline 1 & 59 & 31 & 3 & 0 & 95 \\
2 & 17 & 8 & 0 & 0 & 25 \\
3 & 36 & 12 & 0 & 1 & 48 \\
4 & 16 & 2 & 1 & 0 & 20 \\
\hline
\end{tabular}

A=Automóveis; $\mathrm{M}=$ Motocicletas; $\mathrm{O} / \mathrm{C}=$ Ônibus e Caminhões; $\mathrm{B}=$ Bicicletas; $\mathrm{Vp}=\mathrm{Veículos} \mathrm{de} \mathrm{Passeio.}$

Fonte: Elaborado pelo autor. 
ID: 16

LOCALIZAÇÃO: Av. Claudionor Barbieri (I) x Rua Santa Cruz (II)

DATA: 10/10/2017 (terça-feira)

HORÁRIO: Início: 07:44h - Final: 07:59h

MOVIMENTOS PERMITIDOS:

Figura B18: Av. Claudionor Barbieri (I) x Rua Santa Cruz (II).
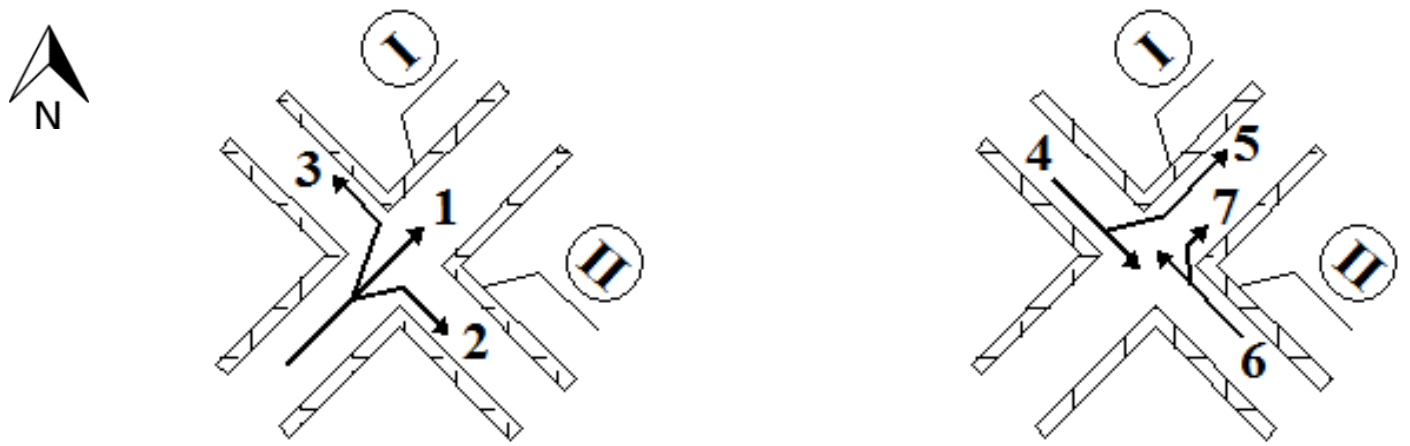

Fonte: Elaborado pelo autor.

Desenho sem escala.

CONTAGENS:

$$
\mathrm{V}_{\mathrm{p}}=1,0 *(\mathrm{~A})+1,0 *(\mathrm{M})+1,5 *(\mathrm{O} / \mathrm{C})
$$

Tabela B18: Av. Claudionor Barbieri (I) x Rua Santa Cruz (II).

\begin{tabular}{c|c|c|c|c|c}
\hline \multirow{2}{*}{ Movimento } & \multicolumn{5}{|c}{ Tipo de veículo } \\
\cline { 2 - 6 } & $\mathrm{A}$ & $\mathrm{M}$ & $\mathrm{O} / \mathrm{C}$ & $\mathrm{B}$ & $\mathrm{Vp}$ \\
\hline 1 & 20 & 2 & 6 & 0 & 31 \\
2 & 3 & 2 & 0 & 0 & 5 \\
3 & 2 & 1 & 0 & 0 & 3 \\
4 & 10 & 1 & 3 & 1 & 16 \\
5 & 1 & 0 & 0 & 0 & 1 \\
6 & 11 & 2 & 2 & 1 & 16 \\
7 & 0 & 2 & 0 & 1 & 2 \\
\hline
\end{tabular}

A=Automóveis; $\mathrm{M}=$ Motocicletas; $\mathrm{O} / \mathrm{C}=$ Ônibus e Caminhões; $\mathrm{B}=$ Bicicletas; $\mathrm{Vp}=$ Veículos de Passeio.

Fonte: Elaborado pelo autor. 
ID: 17

LOCALIZAÇÃO: Av. Dr. Antônio Galízia (I) x Rua Prudente de Moraes (II)

DATA: 26/10/2017 (quinta-feira)

HORÁRIO: Início: 07:43h - Final: 07:58h

\section{MOVIMENTOS PERMITIDOS:}

Figura B19: Av. Dr. Antônio Galízia (I) x Rua Prudente de Moraes (II).
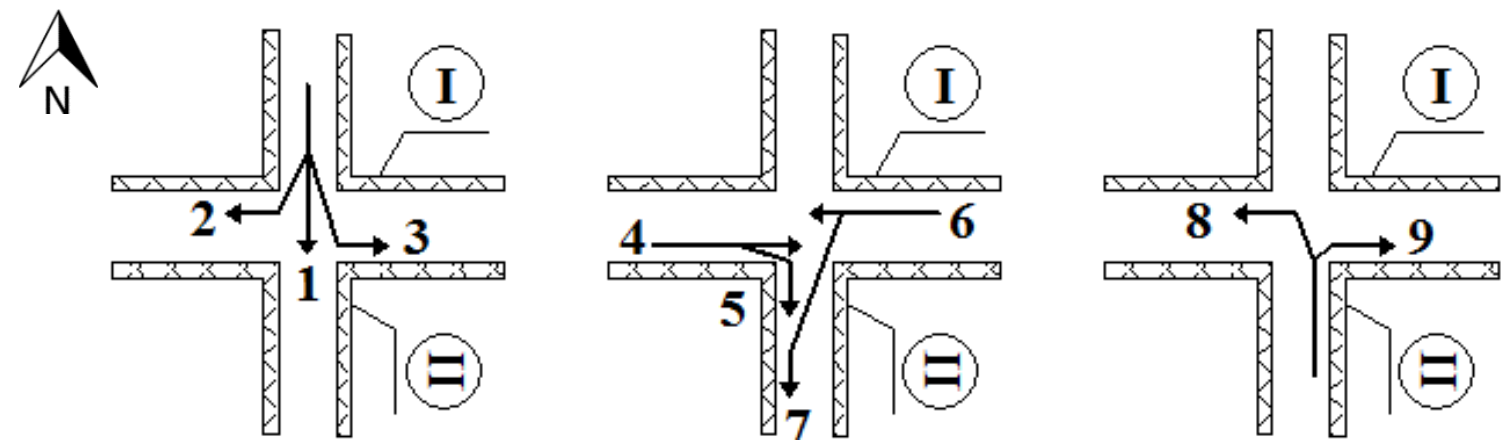

Fonte: Elaborado pelo autor.

Desenho sem escala.

CONTAGENS:

$$
\mathrm{V}_{\mathrm{p}}=1,0 *(\mathrm{~A})+1,0 *(\mathrm{M})+1,5 *(\mathrm{O} / \mathrm{C})
$$

Tabela B19: Av. Dr. Antônio Galízia (I) x Rua Prudente de Moraes (II).

\begin{tabular}{c|c|c|c|c|c}
\hline \multirow{2}{*}{ Movimento } & \multicolumn{5}{|c}{ Tipo de veículo } \\
\cline { 2 - 6 } & $\mathrm{A}$ & $\mathrm{M}$ & $\mathrm{O} / \mathrm{C}$ & $\mathrm{B}$ & $\mathrm{Vp}$ \\
\hline 1 & 5 & 7 & 0 & 0 & 12 \\
2 & 4 & 1 & 0 & 0 & 5 \\
3 & 6 & 2 & 1 & 0 & 10 \\
4 & 15 & 10 & 2 & 14 & 28 \\
5 & 0 & 0 & 0 & 2 & 0 \\
6 & 14 & 16 & 1 & 6 & 32 \\
7 & 9 & 1 & 2 & 5 & 13 \\
8 & 1 & 2 & 1 & 0 & 5 \\
9 & 3 & 6 & 0 & 1 & 9 \\
\hline
\end{tabular}

A=Automóveis; $\mathrm{M}=$ Motocicletas; $\mathrm{O} / \mathrm{C}=$ Ônibus e Caminhões; $\mathrm{B}=$ Bicicletas; $\mathrm{V} p=$ Veículos de Passeio.

Fonte: Elaborado pelo autor. 
ID: $18 \mathrm{a}$

LOCALIZAÇÃO: Av. Francisco Munhoz Cegarra (I) x Av. Centenário (II)

DATA: $27 / 10 / 2017$ (sexta-feira)

HORÁRIO: Início: 07:41h - Final: 07:56h

\section{MOVIMENTOS PERMITIDOS:}

Figura B20: Av. Francisco Munhoz Cegarra (I) x Av. Centenário (II) - (a).
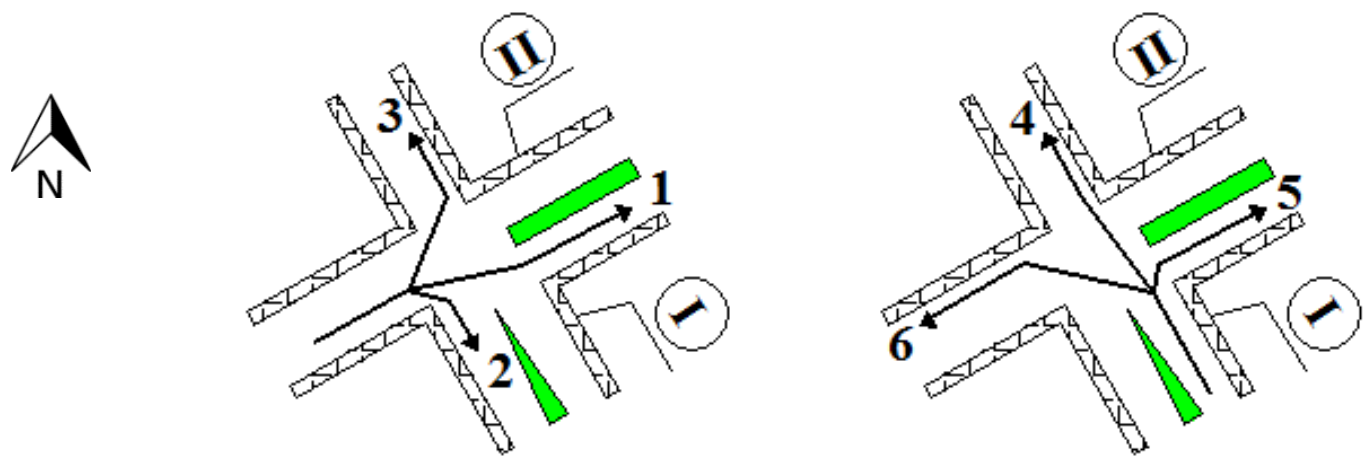

Fonte: Elaborado pelo autor.

Desenho sem escala.

Legenda:

Canteiro central

\section{CONTAGENS:}

$$
\mathrm{V}_{\mathrm{p}}=1,0 *(\mathrm{~A})+1,0 *(\mathrm{M})+1,5 *(\mathrm{O} / \mathrm{C})
$$

Tabela B20: Av. Francisco Munhoz Cegarra (I) x Av. Centenário (II) - (a).

\begin{tabular}{c|c|c|c|c|c}
\hline \multirow{2}{*}{ Movimento } & \multicolumn{5}{|c}{ Tipo de veículo } \\
\cline { 2 - 6 } & $\mathrm{A}$ & $\mathrm{M}$ & $\mathrm{O} / \mathrm{C}$ & $\mathrm{B}$ & $\mathrm{Vp}$ \\
\hline 1 & 0 & 0 & 0 & 0 & 0 \\
2 & 3 & 0 & 0 & 0 & 3 \\
3 & 2 & 0 & 0 & 0 & 2 \\
4 & 38 & 3 & 1 & 2 & 43 \\
5 & 15 & 12 & 0 & 0 & 27 \\
6 & 1 & 0 & 0 & 0 & 1 \\
\hline
\end{tabular}

A=Automóveis; $\mathrm{M}=$ Motocicletas; $\mathrm{O} / \mathrm{C}=$ Ônibus e Caminhões; $\mathrm{B}=$ Bicicletas; $\mathrm{Vp}=$ Veículos de Passeio.

Fonte: Elaborado pelo autor. 
ID: $18 b$

LOCALIZAÇÃO: Av. Francisco Munhoz Cegarra (I) x Av. Centenário (II)

DATA: $27 / 10 / 2017$ (sexta-feira)

HORÁRIO: Início: 07:41h - Final: 07:56h

\section{MOVIMENTOS PERMITIDOS:}

Figura B21: Av. Francisco Munhoz Cegarra (I) x Av. Centenário (II) - (b).
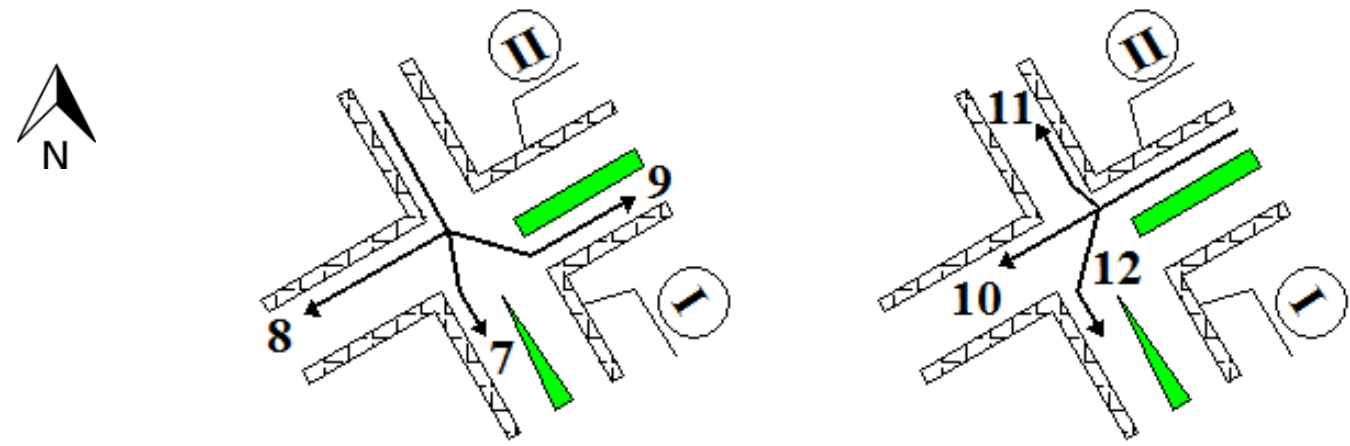

Fonte: Elaborado pelo autor.

Desenho sem escala.

Legenda:

Canteiro central

CONTAGENS:

$$
\mathrm{V}_{\mathrm{p}}=1,0 *(\mathrm{~A})+1,0 *(\mathrm{M})+1,5 *(\mathrm{O} / \mathrm{C})
$$

Tabela B21: Av. Francisco Munhoz Cegarra (I) x Av. Centenário (II) - (b).

\begin{tabular}{c|c|c|c|c|c}
\hline \multirow{2}{*}{ Movimento } & \multicolumn{5}{|c}{ Tipo de veículo } \\
\cline { 2 - 6 } & A & M & O/C & B & Vp \\
\hline 7 & 47 & 17 & 2 & 5 & 67 \\
8 & 0 & 0 & 0 & 0 & 0 \\
9 & 0 & 0 & 0 & 0 & 0 \\
10 & 3 & 0 & 0 & 0 & 3 \\
11 & 2 & 0 & 0 & 0 & 2 \\
12 & 28 & 5 & 0 & 1 & 33 \\
\hline
\end{tabular}

A=Automóveis; $\mathrm{M}=$ Motocicletas; $\mathrm{O} / \mathrm{C}=$ Ônibus e Caminhões; $\mathrm{B}=$ Bicicletas; $\mathrm{V} p=$ Veículos de Passeio.

Fonte: Elaborado pelo autor. 
ID: $19 \mathrm{a}$

LOCALIZAÇÃO: Av. Sérgio Furcin (I) x Av. Padre João Eid (II)

DATA: 20/10/2017 (sexta-feira)

HORÁRIO: Início: 12:12h - Final: 12:27h

MOVIMENTOS PERMITIDOS:

Figura B22: Av. Sérgio Furcin (I) x Av. Padre João Eid (II) - (a).
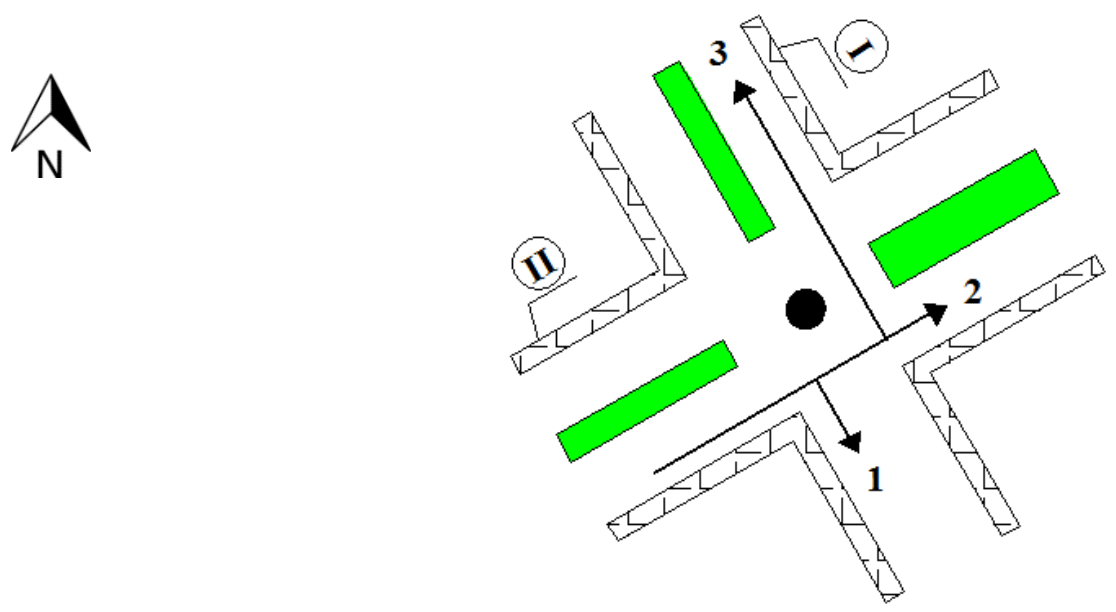

Fonte: Elaborado pelo autor.

Desenho sem escala.

Legenda:

Canteiro central

- Rotatória

CONTAGENS:

$$
\mathrm{V}_{\mathrm{p}}=1,0 *(\mathrm{~A})+1,0 *(\mathrm{M})+1,5 *(\mathrm{O} / \mathrm{C})
$$

Tabela B22: Av. Sérgio Furcin (I) x Av. Padre João Eid (II) - (a).

\begin{tabular}{c|c|c|c|c|c}
\hline \multirow{2}{*}{ Movimento } & \multicolumn{5}{|c}{ Tipo de veículo } \\
\cline { 2 - 6 } & $\mathrm{A}$ & $\mathrm{M}$ & $\mathrm{O} / \mathrm{C}$ & $\mathrm{B}$ & $\mathrm{Vp}$ \\
\hline 1 & 15 & 7 & 4 & 2 & 28 \\
2 & 13 & 12 & 3 & 4 & 30 \\
3 & 24 & 17 & 0 & 6 & 41 \\
\hline
\end{tabular}

A=Automóveis; $\mathrm{M}=$ Motocicletas; $\mathrm{O} / \mathrm{C}=$ Ônibus e Caminhões; $\mathrm{B}=$ Bicicletas; $\mathrm{Vp}=$ Veículos de Passeio.

Fonte: Elaborado pelo autor. 
ID: $19 b$

LOCALIZAÇÃO: Av. Sérgio Furcin (I) x Av. Padre João Eid (II)

DATA: 20/10/2017 (sexta-feira)

HORÁRIO: Início: 12:12h - Final: 12:27h

\section{MOVIMENTOS PERMITIDOS:}

Figura B23: Av. Sérgio Furcin (I) x Av. Padre João Eid (II) - (b).
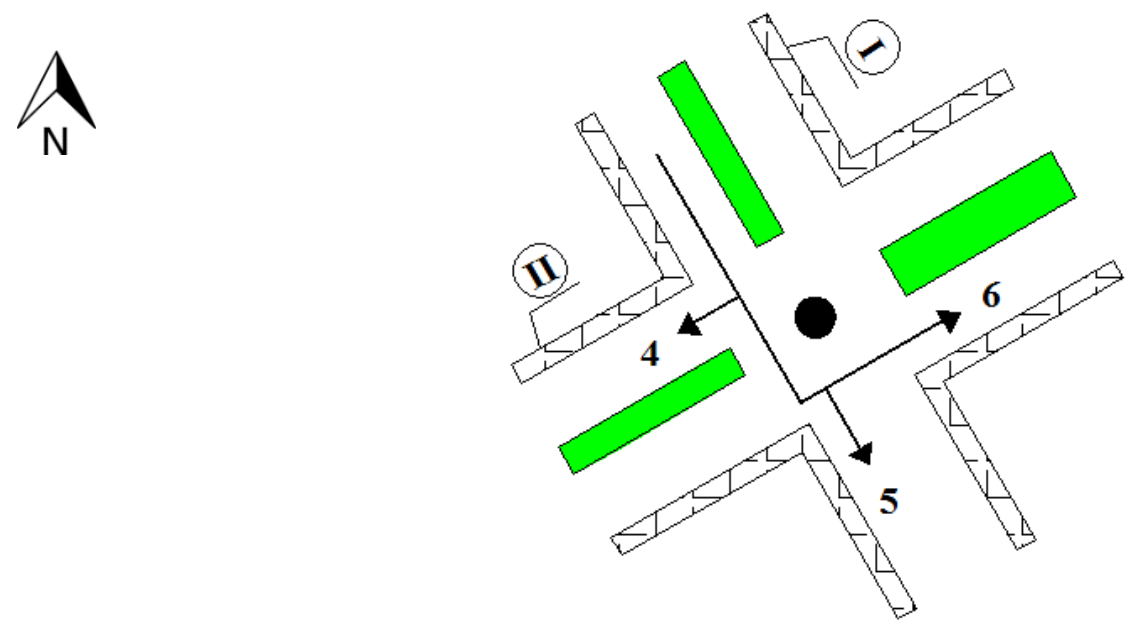

Fonte: Elaborado pelo autor.

Desenho sem escala.

Legenda:

Canteiro central

- Rotatória

\section{CONTAGENS:}

$$
\mathrm{V}_{\mathrm{p}}=1,0 *(\mathrm{~A})+1,0 *(\mathrm{M})+1,5 *(\mathrm{O} / \mathrm{C})
$$

Tabela B23: Av. Sérgio Furcin (I) x Av. Padre João Eid (II) - (b).

\begin{tabular}{c|c|c|c|c|c}
\hline \multirow{2}{*}{ Movimento } & \multicolumn{5}{|c}{ Tipo de veículo } \\
\cline { 2 - 6 } & $\mathrm{A}$ & $\mathrm{M}$ & $\mathrm{O} / \mathrm{C}$ & $\mathrm{B}$ & $\mathrm{Vp}$ \\
\hline 4 & 13 & 5 & 1 & 0 & 20 \\
5 & 20 & 2 & 5 & 0 & 30 \\
6 & 5 & 8 & 6 & 1 & 22 \\
\hline
\end{tabular}

A=Automóveis; $\mathrm{M}=$ Motocicletas; $\mathrm{O} / \mathrm{C}=$ Ônibus e Caminhões; $\mathrm{B}=$ Bicicletas; $\mathrm{Vp}=$ Veículos de Passeio.

Fonte: Elaborado pelo autor. 
ID: $19 \mathrm{c}$

LOCALIZAÇÃO: Av. Sérgio Furcin (I) x Av. Padre João Eid (II)

DATA: 20/10/2017 (sexta-feira)

HORÁRIO: Início: 12:12h - Final: 12:27h

\section{MOVIMENTOS PERMITIDOS:}

Figura B24: Av. Sérgio Furcin (I) x Av. Padre João Eid (II) - (c).
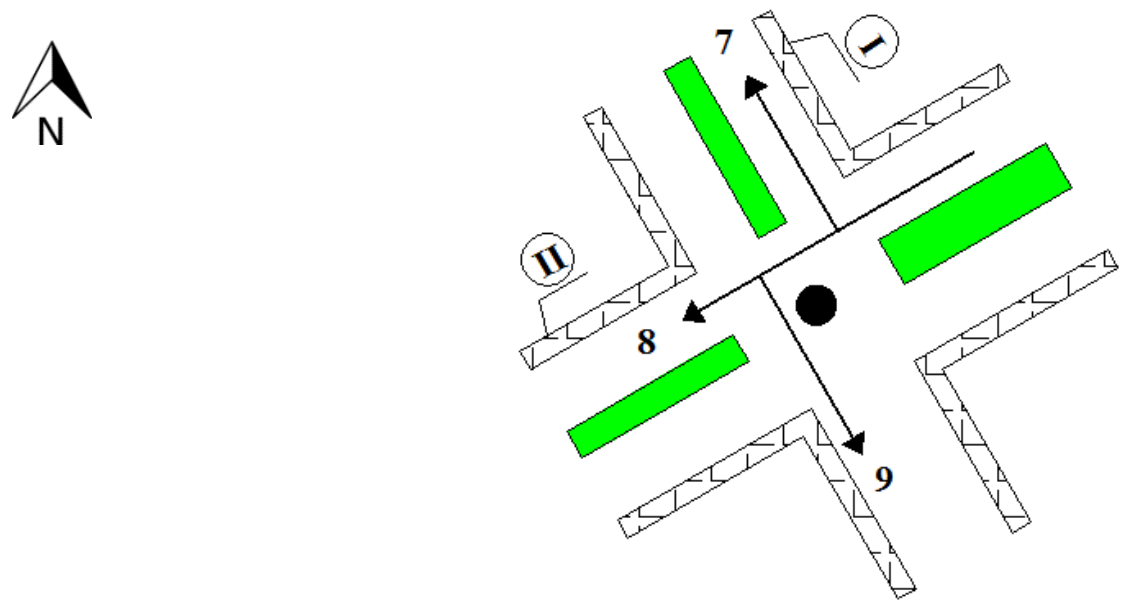

Fonte: Elaborado pelo autor.

Desenho sem escala.

Legenda:

Canteiro central

- Rotatória

\section{CONTAGENS:}

$$
\mathrm{V}_{\mathrm{p}}=1,0 *(\mathrm{~A})+1,0 *(\mathrm{M})+1,5 *(\mathrm{O} / \mathrm{C})
$$

Tabela B24: Av. Sérgio Furcin (I) x Av. Padre João Eid (II) - (c).

\begin{tabular}{c|c|c|c|c|c}
\hline \multirow{2}{*}{ Movimento } & \multicolumn{5}{|c}{ Tipo de veículo } \\
\cline { 2 - 6 } & $\mathrm{A}$ & $\mathrm{M}$ & $\mathrm{O} / \mathrm{C}$ & $\mathrm{B}$ & $\mathrm{Vp}$ \\
\hline 7 & 19 & 4 & 1 & 0 & 25 \\
8 & 4 & 0 & 3 & 0 & 9 \\
9 & 17 & 7 & 3 & 0 & 29 \\
\hline
\end{tabular}

A=Automóveis; $\mathrm{M}=$ Motocicletas; $\mathrm{O} / \mathrm{C}=$ Ônibus e Caminhões; $\mathrm{B}=$ Bicicletas; $\mathrm{Vp}=$ Veículos de Passeio.

Fonte: Elaborado pelo autor. 
ID: $19 \mathrm{~d}$

LOCALIZAÇÃO: Av. Sérgio Furcin (I) x Av. Padre João Eid (II)

DATA: 20/10/2017 (sexta-feira)

HORÁRIO: Início: 12:12h - Final: 12:27h

\section{MOVIMENTOS PERMITIDOS:}

Figura B25: Av. Sérgio Furcin (I) x Av. Padre João Eid (II) - (d).

$\widehat{N}_{\mathrm{N}}$

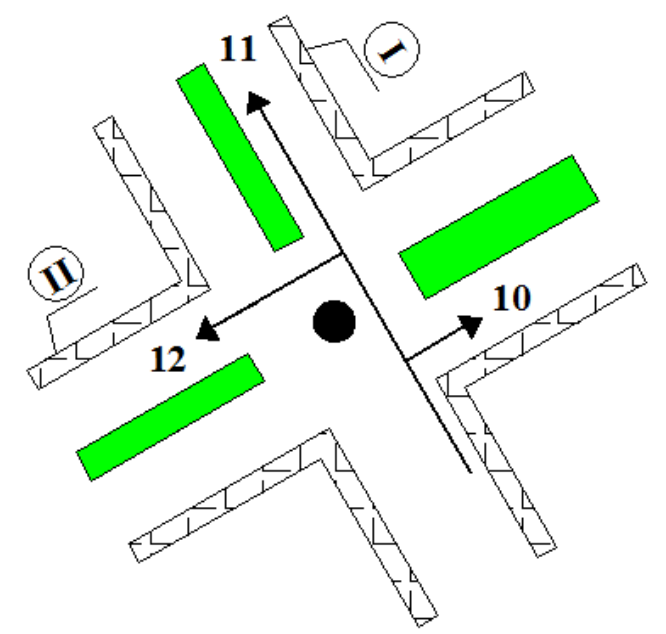

Fonte: Elaborado pelo autor.

Desenho sem escala.

Legenda:

Canteiro central

- Rotatória

\section{CONTAGENS:}

$$
\mathrm{V}_{\mathrm{p}}=1,0 *(\mathrm{~A})+1,0 *(\mathrm{M})+1,5 *(\mathrm{O} / \mathrm{C})
$$

Tabela B25: Av. Sérgio Furcin (I) x Av. Padre João Eid (II) - (d).

\begin{tabular}{c|c|c|c|c|c}
\hline \multirow{2}{*}{ Movimento } & \multicolumn{5}{|c}{ Tipo de veículo } \\
\cline { 2 - 6 } & $\mathrm{A}$ & $\mathrm{M}$ & $\mathrm{O} / \mathrm{C}$ & $\mathrm{B}$ & $\mathrm{Vp}$ \\
\hline 10 & 21 & 3 & 5 & 2 & 32 \\
11 & 25 & 15 & 3 & 3 & 45 \\
12 & 4 & 2 & 0 & 0 & 6 \\
\hline
\end{tabular}

A=Automóveis; $\mathrm{M}=$ Motocicletas; $\mathrm{O} / \mathrm{C}=$ Ônibus e Caminhões; $\mathrm{B}=$ Bicicletas; $\mathrm{V} p=$ Veículos de Passeio.

Fonte: Elaborado pelo autor. 
ID: 20

LOCALIZAÇÃO: Av. Padre João Eid (I) x Rua Luís Furlaneto (II)

DATA: 24/10/2017 (terça-feira)

HORÁRIO: Início: 12:14h - Final: 12:29h

\section{MOVIMENTOS PERMITIDOS:}

Figura B26: Av. Padre João Eid (I) x Rua Luís Furlaneto (II).
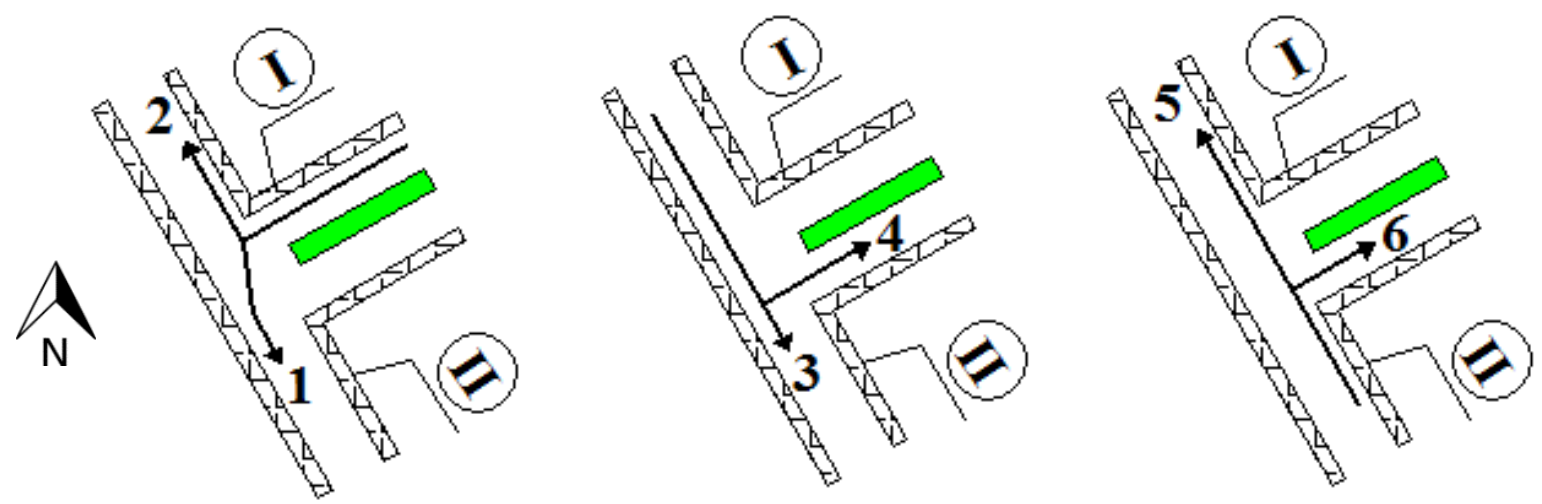

Fonte: Elaborado pelo autor.

Desenho sem escala.

Legenda:

Canteiro central

CONTAGENS:

$$
\mathrm{V}_{\mathrm{p}}=1,0 *(\mathrm{~A})+1,0 *(\mathrm{M})+1,5 *(\mathrm{O} / \mathrm{C})
$$

Tabela B26: Av. Padre João Eid (I) x Rua Luís Furlaneto (II).

\begin{tabular}{c|c|c|c|c|c}
\hline \multirow{2}{*}{ Movimento } & \multicolumn{5}{|c}{ Tipo de veículo } \\
\cline { 2 - 6 } & $\mathrm{A}$ & $\mathrm{M}$ & $\mathrm{O} / \mathrm{C}$ & $\mathrm{B}$ & $\mathrm{Vp}$ \\
\hline 1 & 7 & 2 & 0 & 3 & 9 \\
2 & 6 & 9 & 3 & 4 & 20 \\
3 & 8 & 6 & 0 & 3 & 14 \\
4 & 14 & 5 & 2 & 8 & 22 \\
5 & 9 & 5 & 0 & 7 & 14 \\
6 & 13 & 11 & 0 & 5 & 24 \\
\hline
\end{tabular}

A=Automóveis; $\mathrm{M}=$ Motocicletas; $\mathrm{O} / \mathrm{C}=$ Ônibus e Caminhões; $\mathrm{B}=$ Bicicletas; $\mathrm{Vp}=$ Veículos de Passeio.

Fonte: Elaborado pelo autor. 
ID: $21 \mathrm{a}$

LOCALIZAÇÃO: Rua Luís Furlaneto (I) x Estrada Municipal Fernando Romero (II)

DATA: 25/10/2017 (quarta-feira)

HORÁRIO: Início: 12:09h - Final: 12:24h

MOVIMENTOS PERMITIDOS:

Figura B27: Rua Luís Furlaneto (I) x Estrada Municipal Fernando Romero (II) - (a).
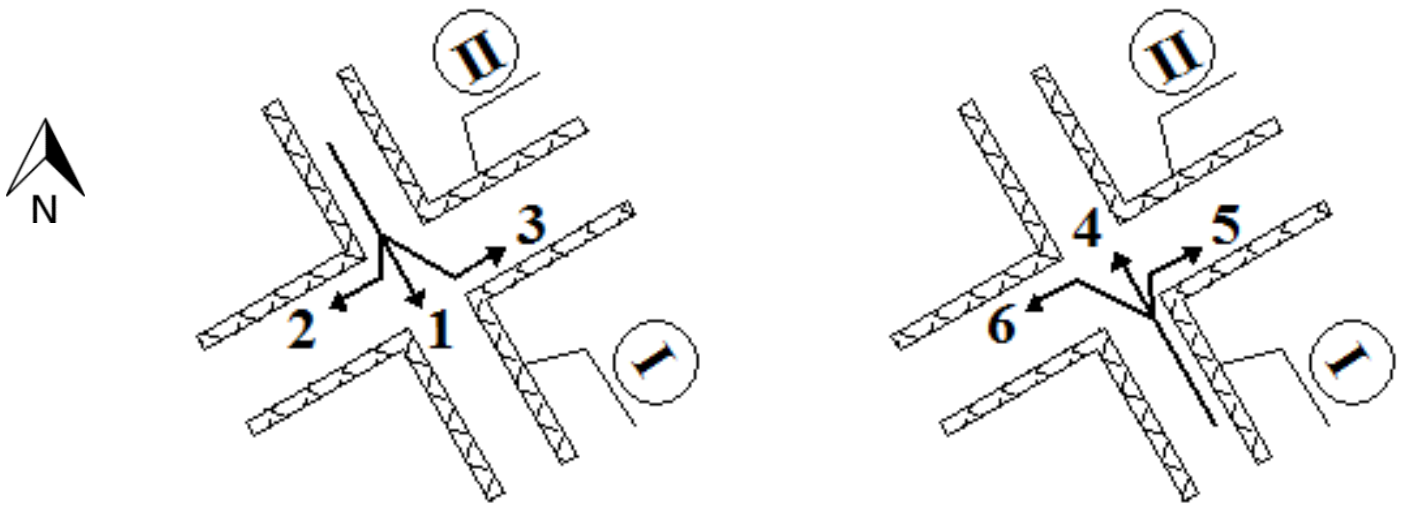

Fonte: Elaborado pelo autor.

Desenho sem escala.

\section{CONTAGENS:}

$$
\mathrm{V}_{\mathrm{p}}=1,0 *(\mathrm{~A})+1,0 *(\mathrm{M})+1,5 *(\mathrm{O} / \mathrm{C})
$$

Tabela B27: Rua Luís Furlaneto (I) x Estrada Municipal Fernando Romero (II) - (a).

\begin{tabular}{c|c|c|c|c|c}
\hline \multirow{2}{*}{ Movimento } & \multicolumn{5}{|c}{ Tipo de veículo } \\
\cline { 2 - 6 } & $\mathrm{A}$ & $\mathrm{M}$ & $\mathrm{O} / \mathrm{C}$ & $\mathrm{B}$ & $\mathrm{Vp}$ \\
\hline 1 & 0 & 0 & 0 & 1 & 0 \\
2 & 0 & 0 & 0 & 0 & 0 \\
3 & 3 & 1 & 0 & 2 & 4 \\
4 & 1 & 2 & 0 & 1 & 3 \\
5 & 1 & 1 & 0 & 0 & 2 \\
6 & 0 & 0 & 0 & 0 & 0 \\
\hline
\end{tabular}

A=Automóveis; $\mathrm{M}=$ Motocicletas; $\mathrm{O} / \mathrm{C}=$ Ônibus e Caminhões; $\mathrm{B}=$ Bicicletas; $\mathrm{V}$ p=Veículos de Passeio.

Fonte: Elaborado pelo autor. 
ID: $21 \mathrm{~b}$

LOCALIZAÇÃO: Rua Luís Furlaneto (I) x Estrada Municipal Fernando Romero (II)

DATA: 25/10/2017 (quarta-feira)

HORÁRIO: Início: 12:09h - Final: 12:24h

\section{MOVIMENTOS PERMITIDOS:}

Figura B28: Rua Luís Furlaneto (I) x Estrada Municipal Fernando Romero (II) - (b).
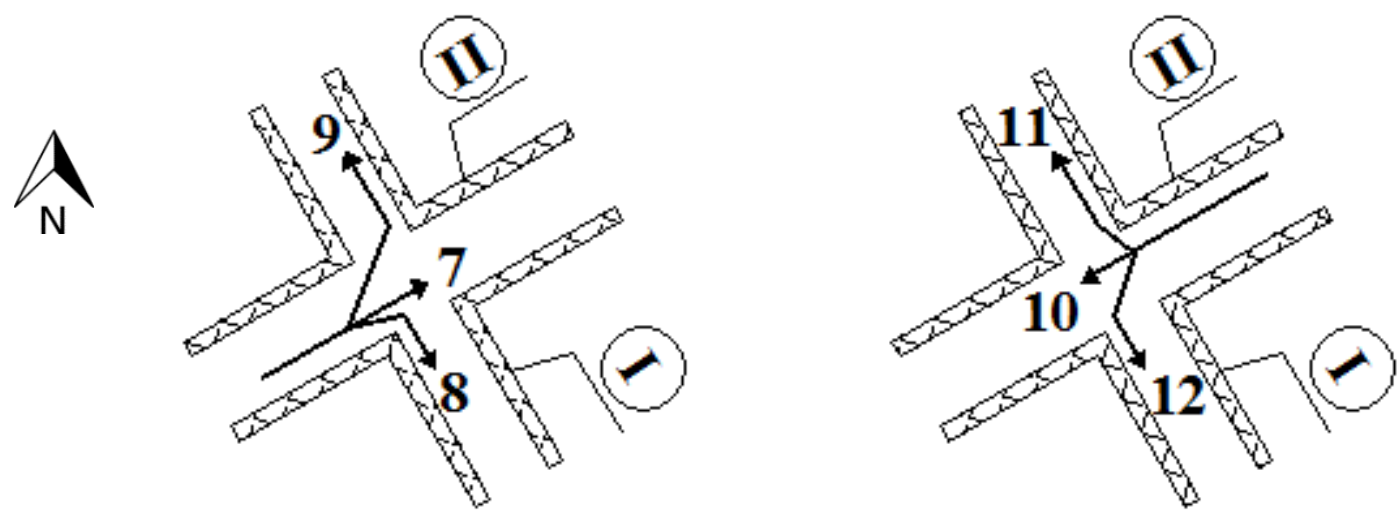

Fonte: Elaborado pelo autor.

Desenho sem escala.

CONTAGENS:

$$
\mathrm{V}_{\mathrm{p}}=1,0 *(\mathrm{~A})+1,0 *(\mathrm{M})+1,5 *(\mathrm{O} / \mathrm{C})
$$

Tabela B28: Rua Luís Furlaneto (I) x Estrada Municipal Fernando Romero (II) - (b).

\begin{tabular}{c|c|c|c|c|c}
\hline \multirow{2}{*}{ Movimento } & \multicolumn{5}{|c}{ Tipo de veículo } \\
\cline { 2 - 6 } & $\mathrm{A}$ & $\mathrm{M}$ & $\mathrm{O} / \mathrm{C}$ & $\mathrm{B}$ & $\mathrm{Vp}$ \\
\hline 7 & 0 & 1 & 0 & 3 & 1 \\
8 & 3 & 2 & 0 & 1 & 5 \\
9 & 2 & 0 & 0 & 0 & 2 \\
10 & 2 & 3 & 1 & 4 & 7 \\
11 & 0 & 0 & 0 & 0 & 0 \\
12 & 1 & 0 & 0 & 0 & 1 \\
\hline
\end{tabular}

A=Automóveis; $\mathrm{M}=$ Motocicletas; $\mathrm{O} / \mathrm{C}=$ Ônibus e Caminhões; $\mathrm{B}=$ Bicicletas; $\mathrm{Vp}=$ Veículos de Passeio.

Fonte: Elaborado pelo autor. 
ID: $22 \mathrm{a}$

LOCALIZAÇÃO: Av. XV de Novembro (I) x Av. Sérgio Furcin (II)

DATA: 18/10/2017 (quarta-feira)

HORÁRIO: Início: 18:18h - Final: 18:33h

MOVIMENTOS PERMITIDOS:

Figura B29: Av. XV de Novembro (I) x Av. Sérgio Furcin (II) - (a).

$\widehat{N}_{\mathrm{N}}$

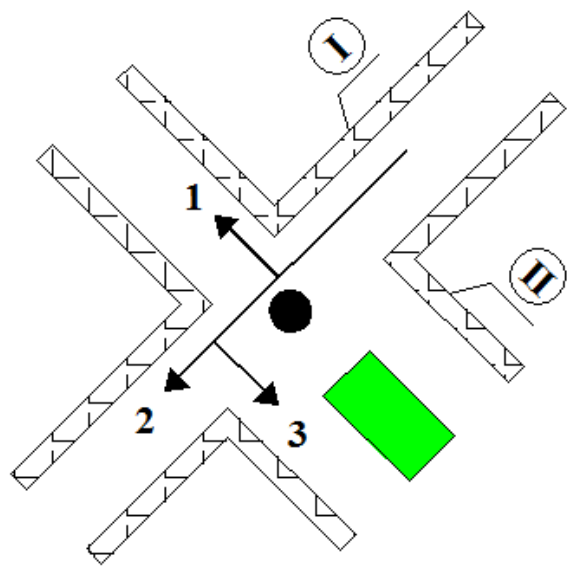

Fonte: Elaborado pelo autor.

Desenho sem escala.

Legenda:

Canteiro central

- Rotatória

CONTAGENS:

$$
\mathrm{V}_{\mathrm{p}}=1,0 *(\mathrm{~A})+1,0 *(\mathrm{M})+1,5 *(\mathrm{O} / \mathrm{C})
$$

Tabela B29: Av. XV de Novembro (I) x Av. Sérgio Furcin (II) - (a).

\begin{tabular}{c|c|c|c|c|c}
\hline \multirow{2}{*}{ Movimento } & \multicolumn{5}{|c}{ Tipo de veículo } \\
\cline { 2 - 6 } & $\mathrm{A}$ & $\mathrm{M}$ & O/C & $\mathrm{B}$ & Vp \\
\hline 1 & 13 & 11 & 0 & 1 & 24 \\
2 & 27 & 9 & 3 & 2 & 41 \\
3 & 32 & 5 & 2 & 0 & 40 \\
\hline
\end{tabular}

A=Automóveis; $\mathrm{M}=$ Motocicletas; $\mathrm{O} / \mathrm{C}=$ Ônibus e Caminhões; $\mathrm{B}=$ Bicicletas; $\mathrm{Vp}=$ Veículos de Passeio.

Fonte: Elaborado pelo autor. 
ID: $22 b$

LOCALIZAÇÃO: Av. XV de Novembro (I) x Av. Sérgio Furcin (II)

DATA: $18 / 10 / 2017$ (quarta-feira)

HORÁRIO: Início: 18:18h - Final: 18:33h

MOVIMENTOS PERMITIDOS:

Figura B30: Av. XV de Novembro (I) x Av. Sérgio Furcin (II) - (b).
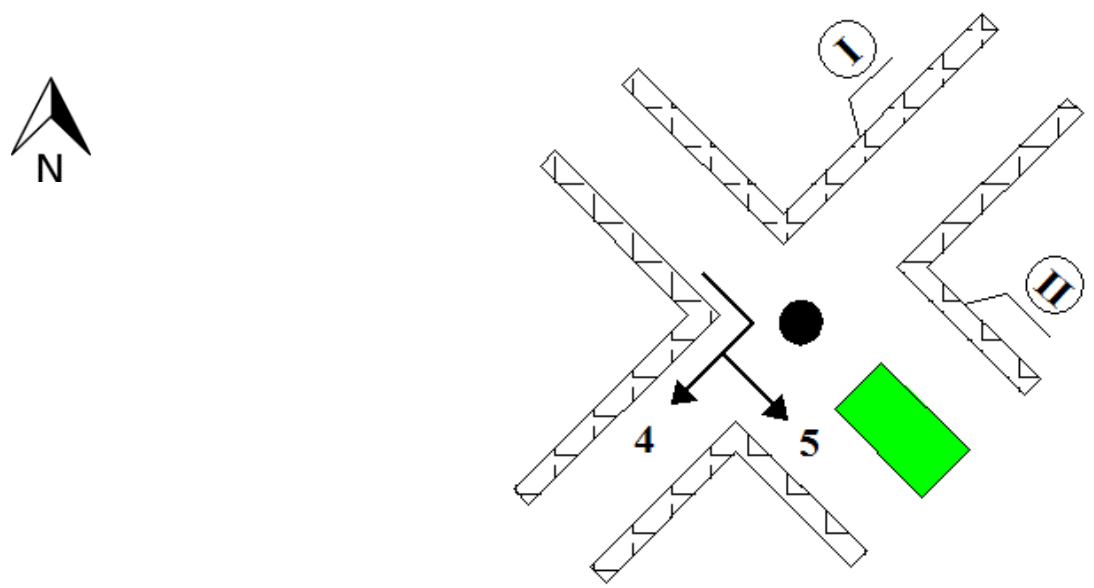

Fonte: Elaborado pelo autor.

Desenho sem escala.

Legenda:

Canteiro central

- Rotatória

CONTAGENS:

$$
\mathrm{V}_{\mathrm{p}}=1,0 *(\mathrm{~A})+1,0 *(\mathrm{M})+1,5 *(\mathrm{O} / \mathrm{C})
$$

Tabela B30: Av. XV de Novembro (I) x Av. Sérgio Furcin (II) - (b).

\begin{tabular}{c|c|c|c|c|c}
\hline \multirow{2}{*}{ Movimento } & \multicolumn{5}{|c}{ Tipo de veículo } \\
\cline { 2 - 6 } & $\mathrm{A}$ & $\mathrm{M}$ & $\mathrm{O} / \mathrm{C}$ & $\mathrm{B}$ & $\mathrm{Vp}$ \\
\hline 4 & 13 & 10 & 0 & 5 & 23 \\
5 & 24 & 7 & 0 & 3 & 31 \\
\hline
\end{tabular}

A=Automóveis; $\mathrm{M}=$ Motocicletas; $\mathrm{O} / \mathrm{C}=$ Ônibus e Caminhões; $\mathrm{B}=$ Bicicletas; $\mathrm{Vp}=$ Veículos de Passeio.

Fonte: Elaborado pelo autor. 
ID: $22 \mathrm{c}$

LOCALIZAÇÃO: Av. XV de Novembro (I) x Av. Sérgio Furcin (II)

DATA: 18/10/2017 (quarta-feira)

HORÁRIO: Início: 18:18h - Final: 18:33h

MOVIMENTOS PERMITIDOS:

Figura B31: Av. XV de Novembro (I) x Av. Sérgio Furcin (II) - (c).

$\widehat{N}_{\mathrm{N}}$

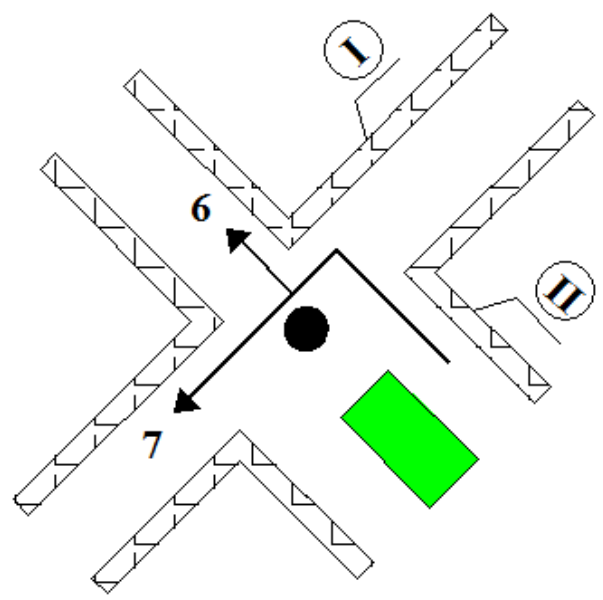

Fonte: Elaborado pelo autor.

Desenho sem escala.

Legenda:

Canteiro central

- Rotatória

CONTAGENS:

$$
\mathrm{V}_{\mathrm{p}}=1,0 *(\mathrm{~A})+1,0 *(\mathrm{M})+1,5 *(\mathrm{O} / \mathrm{C})
$$

Tabela B31: Av. XV de Novembro (I) x Av. Sérgio Furcin (II) - (c).

\begin{tabular}{c|c|c|c|c|c}
\hline \multirow{2}{*}{ Movimento } & \multicolumn{5}{|c}{ Tipo de veículo } \\
\cline { 2 - 6 } & $\mathrm{A}$ & $\mathrm{M}$ & $\mathrm{O} / \mathrm{C}$ & $\mathrm{B}$ & $\mathrm{Vp}$ \\
\hline 6 & 38 & 14 & 3 & 10 & 57 \\
7 & 26 & 9 & 1 & 0 & 37 \\
\hline
\end{tabular}

A=Automóveis; $\mathrm{M}=$ Motocicletas; $\mathrm{O} / \mathrm{C}=$ Ônibus e Caminhões; $\mathrm{B}=$ Bicicletas; $\mathrm{V}$ =Véículos de Passeio.

Fonte: Elaborado pelo autor. 
ID: $23 \mathrm{a}$

LOCALIZAÇÃO: Av. João Lemos (I) x Rua Euclides G. Corrêa (II)

DATA: 19/10/2017 (quinta-feira)

HORÁRIO: Início: 12:11h - Final: 12:26h

\section{MOVIMENTOS PERMITIDOS:}

Figura B32: Av. João Lemos (I) x Rua Euclides G. Corrêa (II) - (a).
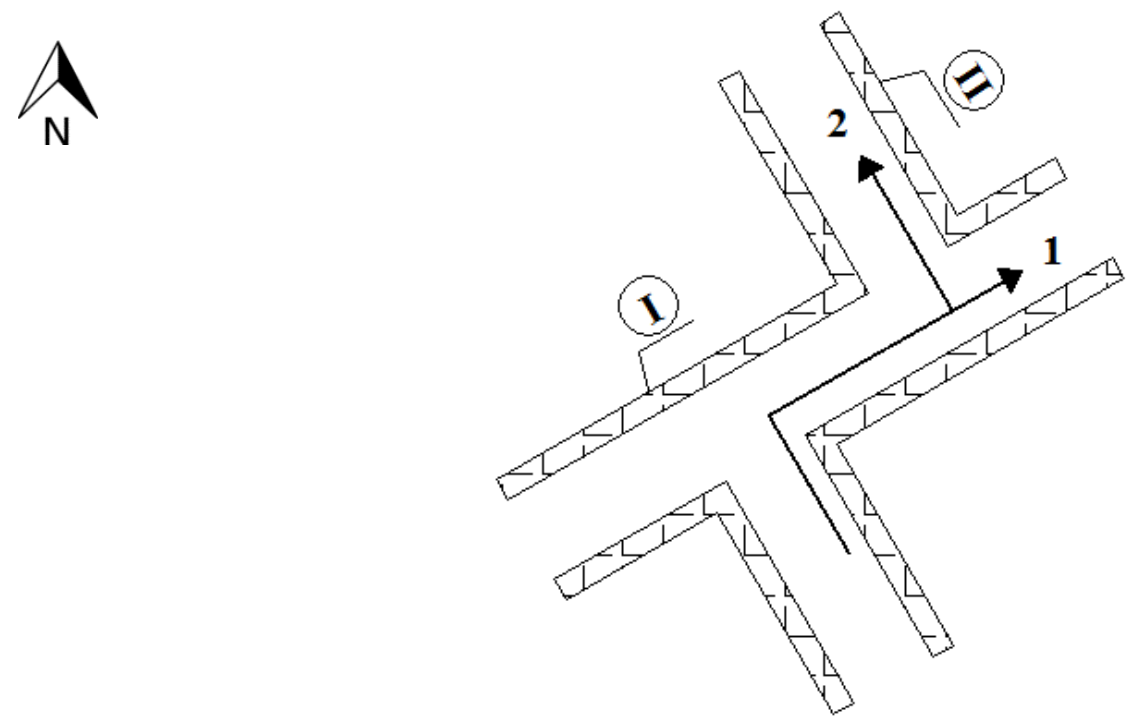

Fonte: Elaborado pelo autor.

Desenho sem escala.

CONTAGENS:

$$
\mathrm{V}_{\mathrm{p}}=1,0 *(\mathrm{~A})+1,0 *(\mathrm{M})+1,5 *(\mathrm{O} / \mathrm{C})
$$

Tabela B32: Av. João Lemos (I) x Rua Euclides G. Corrêa (II) - (a).

\begin{tabular}{c|c|c|c|c|c}
\hline \multirow{2}{*}{ Movimento } & \multicolumn{5}{|c}{ Tipo de veículo } \\
\cline { 2 - 6 } & $\mathrm{A}$ & $\mathrm{M}$ & $\mathrm{O} / \mathrm{C}$ & $\mathrm{B}$ & $\mathrm{Vp}$ \\
\hline 1 & 24 & 4 & 1 & 5 & 30 \\
2 & 14 & 4 & 0 & 3 & 18 \\
\hline
\end{tabular}

A=Automóveis; $\mathrm{M}=$ Motocicletas; $\mathrm{O} / \mathrm{C}=$ Ônibus e Caminhões; $\mathrm{B}=$ Bicicletas; $\mathrm{Vp}=$ Veículos de Passeio.

Fonte: Elaborado pelo autor. 
ID: $23 b$

LOCALIZAÇÃO: Av. João Lemos (I) x Rua Euclides G. Corrêa (II)

DATA: 19/10/2017 (quinta-feira)

HORÁRIO: Início: 12:11h - Final: 12:26h

\section{MOVIMENTOS PERMITIDOS:}

Figura B33: Av. João Lemos (I) x Rua Euclides G. Corrêa (II) - (b).
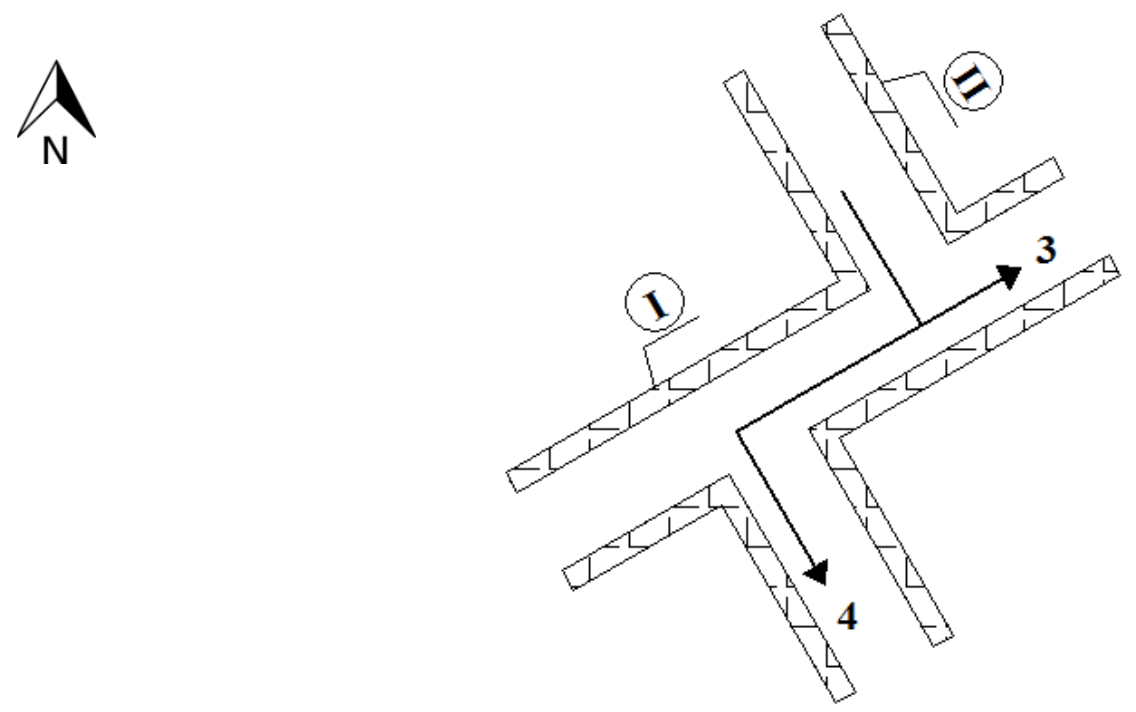

Fonte: Elaborado pelo autor.

Desenho sem escala.

\section{CONTAGENS:}

$$
\mathrm{V}_{\mathrm{p}}=1,0 *(\mathrm{~A})+1,0 *(\mathrm{M})+1,5 *(\mathrm{O} / \mathrm{C})
$$

Tabela B33: Av. João Lemos (I) x Rua Euclides G. Corrêa (II) - (b).

\begin{tabular}{c|c|c|c|c|c}
\hline \multirow{2}{*}{ Movimento } & \multicolumn{5}{|c}{ Tipo de veículo } \\
\cline { 2 - 6 } & $\mathrm{A}$ & $\mathrm{M}$ & $\mathrm{O} / \mathrm{C}$ & $\mathrm{B}$ & $\mathrm{Vp}$ \\
\hline 3 & 1 & 0 & 0 & 0 & 1 \\
4 & 16 & 13 & 2 & 1 & 32 \\
\hline
\end{tabular}

A=Automóveis; $\mathrm{M}=$ Motocicletas; $\mathrm{O} / \mathrm{C}=$ Ônibus e Caminhões; $\mathrm{B}=$ Bicicletas; $\mathrm{Vp}=\mathrm{Veículos} \mathrm{de} \mathrm{Passeio.}$

Fonte: Elaborado pelo autor. 
ID: $23 \mathrm{c}$

LOCALIZAÇÃ̃: Av. João Lemos (I) x Rua Euclides G. Corrêa (II)

DATA: 19/10/2017 (quinta-feira)

HORÁRIO: Início: 12:11h - Final: 12:26h

\section{MOVIMENTOS PERMITIDOS:}

Figura B34: Av. João Lemos (I) x Rua Euclides G. Corrêa (II) - (c).
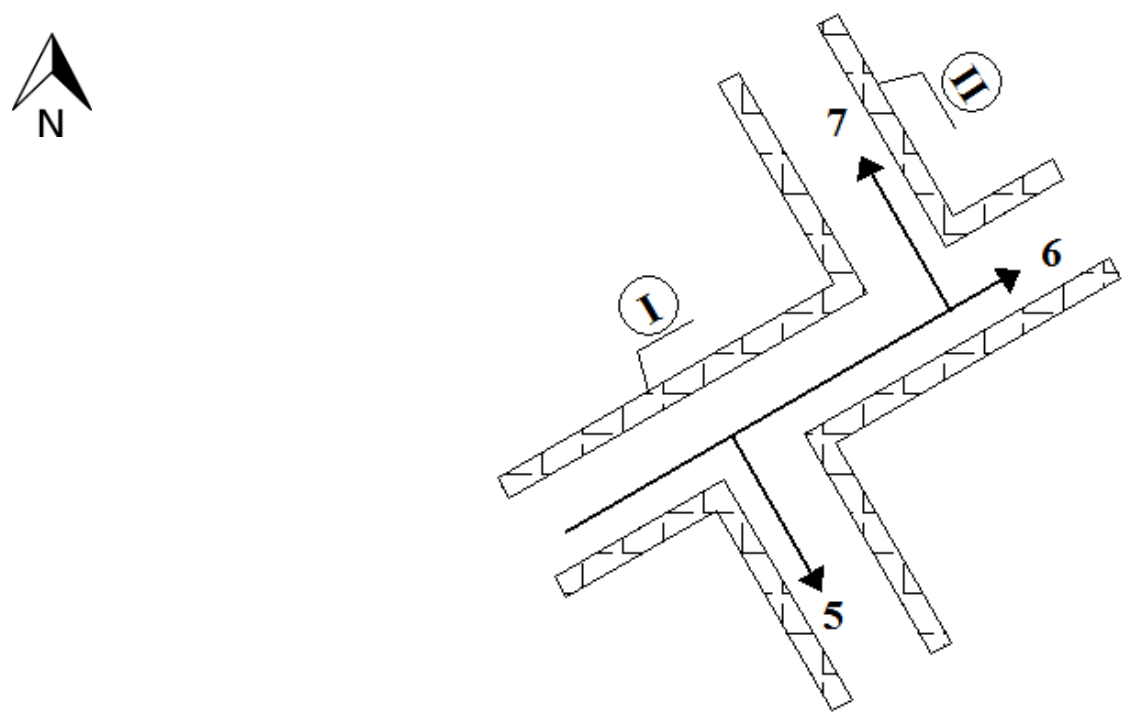

Fonte: Elaborado pelo autor.

Desenho sem escala.

\section{CONTAGENS:}

$$
\mathrm{V}_{\mathrm{p}}=1,0 *(\mathrm{~A})+1,0 *(\mathrm{M})+1,5 *(\mathrm{O} / \mathrm{C})
$$

Tabela B34: Av. João Lemos (I) x Rua Euclides G. Corrêa (II) - (c).

\begin{tabular}{c|c|c|c|c|c}
\hline \multirow{2}{*}{ Movimento } & \multicolumn{5}{|c}{ Tipo de veículo } \\
\cline { 2 - 6 } & $\mathrm{A}$ & $\mathrm{M}$ & $\mathrm{O} / \mathrm{C}$ & $\mathrm{B}$ & $\mathrm{Vp}$ \\
\hline 5 & 22 & 9 & 0 & 6 & 31 \\
6 & 16 & 6 & 1 & 1 & 24 \\
7 & 4 & 1 & 0 & 1 & 5 \\
\hline
\end{tabular}

A=Automóveis; $\mathrm{M}=$ Motocicletas; $\mathrm{O} / \mathrm{C}=$ Ônibus e Caminhões; $\mathrm{B}=$ Bicicletas; $\mathrm{Vp}=$ Veículos de Passeio.

Fonte: Elaborado pelo autor. 
ID: $23 d$

LOCALIZAÇÃO: Av. João Lemos (I) x Rua Euclides G. Corrêa (II)

DATA: 19/10/2017 (quinta-feira)

HORÁRIO: Início: 12:11h - Final: 12:26h

\section{MOVIMENTOS PERMITIDOS:}

Figura B35: Av. João Lemos (I) x Rua Euclides G. Corrêa (II) - (d).
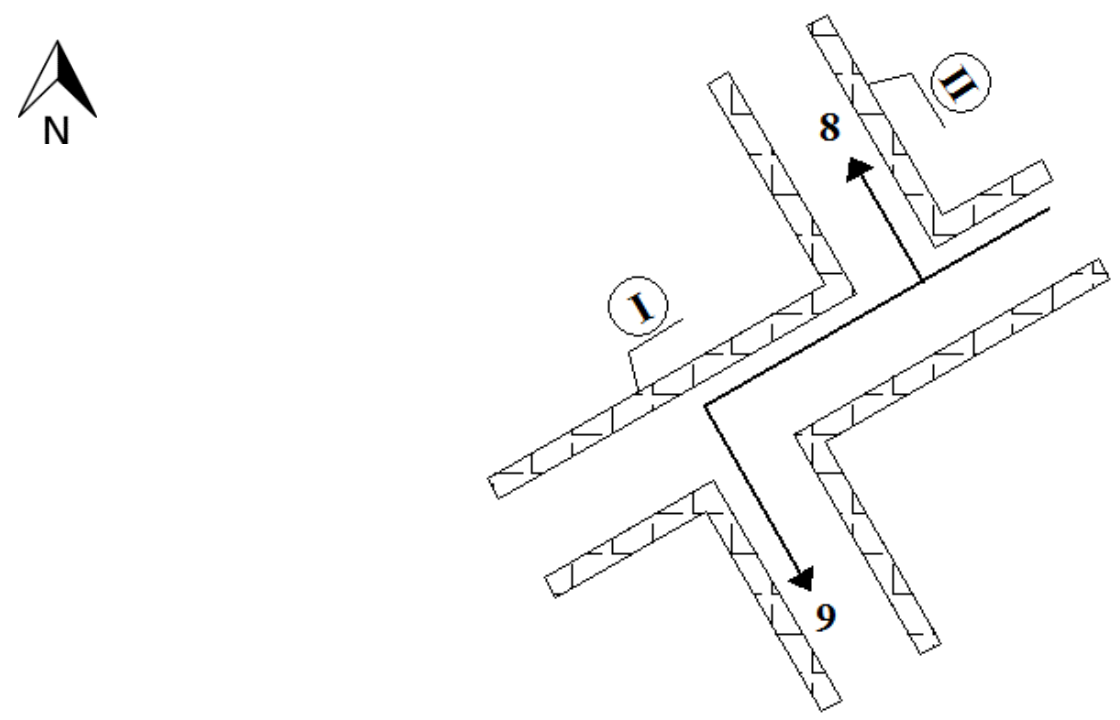

Fonte: Elaborado pelo autor.

Desenho sem escala.

CONTAGENS:

$$
\mathrm{V}_{\mathrm{p}}=1,0 *(\mathrm{~A})+1,0 *(\mathrm{M})+1,5 *(\mathrm{O} / \mathrm{C})
$$

Tabela B35: Av. João Lemos (I) x Rua Euclides G. Corrêa (II) - (d).

\begin{tabular}{c|c|c|c|c|c}
\hline \multirow{2}{*}{ Movimento } & \multicolumn{5}{|c}{ Tipo de veículo } \\
\cline { 2 - 6 } & $\mathrm{A}$ & $\mathrm{M}$ & $\mathrm{O} / \mathrm{C}$ & $\mathrm{B}$ & $\mathrm{Vp}$ \\
\hline 8 & 2 & 0 & 0 & 0 & 2 \\
9 & 12 & 12 & 0 & 4 & 24 \\
\hline
\end{tabular}

A=Automóveis; $\mathrm{M}=$ Motocicletas; $\mathrm{O} / \mathrm{C}=$ Ônibus e Caminhões; $\mathrm{B}=$ Bicicletas; $\mathrm{Vp}=$ Veículos de Passeio.

Fonte: Elaborado pelo autor. 
ID: $24 \mathrm{a}$

LOCALIZAÇÃO: Rua Vitório E. Prearo (I) x Rua Euclides G. Corrêa (II)

DATA: 18/10/2017 (quarta-feira)

HORÁRIO: Início: 12:08h - Final: 12:23h

MOVIMENTOS PERMITIDOS:

Figura B36: Rua Vitório E. Prearo (I) x Rua Euclides G. Corrêa (II) - (a).
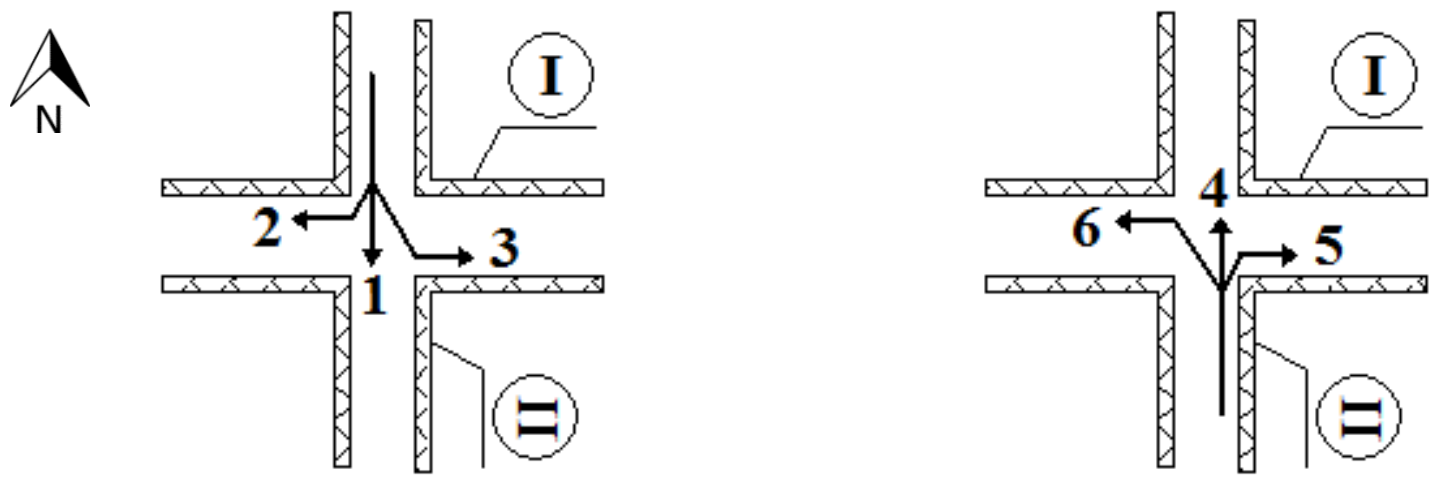

Fonte: Elaborado pelo autor.

Desenho sem escala.

CONTAGENS:

$$
\mathrm{V}_{\mathrm{p}}=1,0 *(\mathrm{~A})+1,0 *(\mathrm{M})+1,5 *(\mathrm{O} / \mathrm{C})
$$

Tabela B36: Rua Vitório E. Prearo (I) x Rua Euclides G. Corrêa (II) - (a).

\begin{tabular}{c|c|c|c|c|c}
\hline \multirow{2}{*}{ Movimento } & \multicolumn{5}{|c}{ Tipo de veículo } \\
\cline { 2 - 6 } & $\mathrm{A}$ & $\mathrm{M}$ & O/C & $\mathrm{B}$ & $\mathrm{Vp}$ \\
\hline 1 & 12 & 5 & 0 & 1 & 17 \\
2 & 8 & 2 & 0 & 1 & 10 \\
3 & 0 & 0 & 0 & 0 & 0 \\
4 & 10 & 4 & 0 & 2 & 14 \\
5 & 1 & 0 & 0 & 0 & 1 \\
6 & 1 & 0 & 0 & 0 & 1 \\
\hline
\end{tabular}

A=Automóveis; $\mathrm{M}=$ Motocicletas; $\mathrm{O} / \mathrm{C}=$ Ônibus e Caminhões; $\mathrm{B}=$ Bicicletas; $\mathrm{Vp}=$ Veículos de Passeio.

Fonte: Elaborado pelo autor. 
ID: $24 b$

LOCALIZAÇÃO: Rua Vitório E. Prearo (I) x Rua Euclides G. Corrêa (II)

DATA: 18/10/2017 (quarta-feira)

HORÁRIO: Início: 12:08h - Final: 12:23h

\section{MOVIMENTOS PERMITIDOS:}

Figura B37: Rua Vitório E. Prearo (I) x Rua Euclides G. Corrêa (II) - (b).
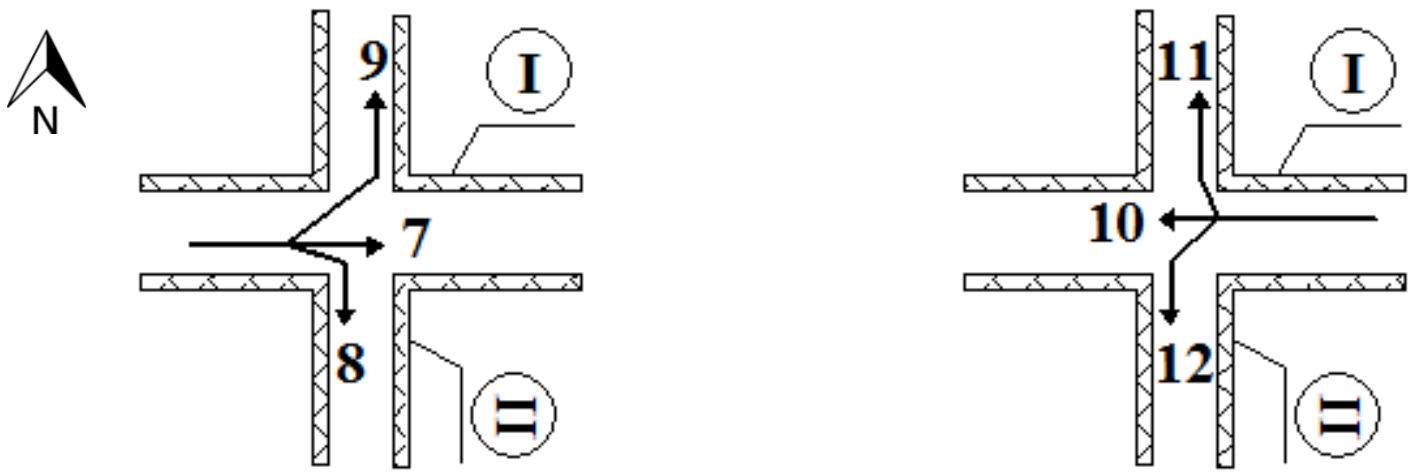

Fonte: Elaborado pelo autor.

Desenho sem escala.

CONTAGENS:

$$
\mathrm{V}_{\mathrm{p}}=1,0 *(\mathrm{~A})+1,0 *(\mathrm{M})+1,5 *(\mathrm{O} / \mathrm{C})
$$

Tabela B37: Rua Vitório E. Prearo (I) x Rua Euclides G. Corrêa (II) - (b).

\begin{tabular}{c|c|c|c|c|c}
\hline \multirow{2}{*}{ Movimento } & \multicolumn{5}{|c}{ Tipo de veículo } \\
\cline { 2 - 6 } & A & M & O/C & B & Vp \\
\hline 7 & 0 & 0 & 1 & 0 & 2 \\
8 & 1 & 1 & 0 & 0 & 2 \\
9 & 6 & 0 & 0 & 1 & 6 \\
10 & 0 & 1 & 0 & 0 & 1 \\
11 & 0 & 0 & 0 & 0 & 0 \\
12 & 1 & 0 & 0 & 0 & 1 \\
\hline
\end{tabular}

A=Automóveis; $\mathrm{M}=$ Motocicletas; $\mathrm{O} / \mathrm{C}=$ Ônibus e Caminhões; $\mathrm{B}=$ Bicicletas; $\mathrm{V}$ =Veículos de Passeio.

Fonte: Elaborado pelo autor. 
ID: 25

LOCALIZAÇÃO: Estrada Perimetral Pref. Domingos Antônio Fortunato (I)

DATA: 26/10/2017 (quinta-feira)

HORÁRIO: Início: 12:04h - Final: 12:19h

\section{MOVIMENTOS PERMITIDOS:}

Figura B38: Estrada Perimetral Pref. Domingos Antônio Fortunato (I).
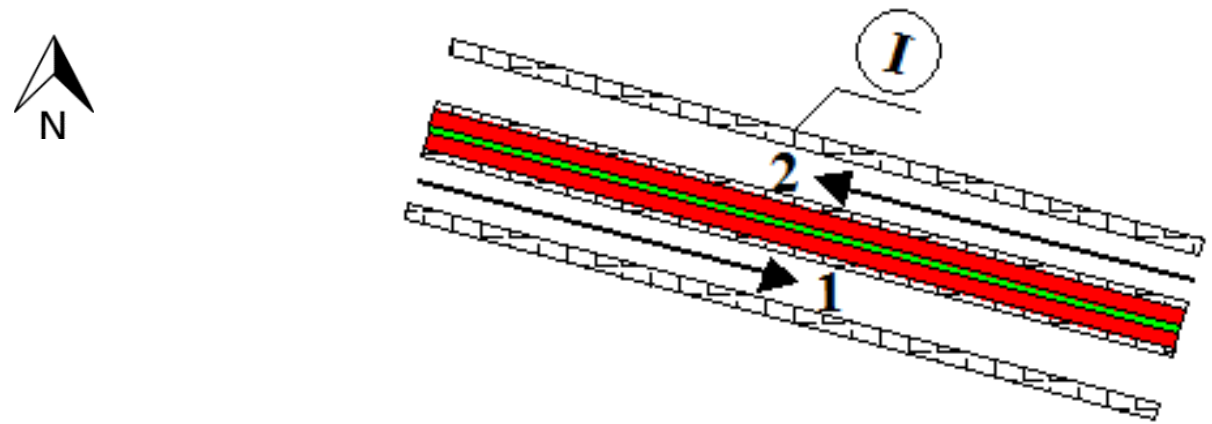

Fonte: Elaborado pelo autor.

Desenho sem escala.

Legenda:

Canteiro central

Infraestrutura cicloviária

CONTAGENS:

$$
\mathrm{V}_{\mathrm{p}}=1,0 *(\mathrm{~A})+1,0 *(\mathrm{M})+1,5 *(\mathrm{O} / \mathrm{C})
$$

Tabela B38: Estrada Perimetral Pref. Domingos Antônio Fortunato (I).

\begin{tabular}{c|c|c|c|c|c}
\hline \multirow{2}{*}{ Movimento } & \multicolumn{5}{|c}{ Tipo de veículo } \\
\cline { 2 - 6 } & $\mathrm{A}$ & $\mathrm{M}$ & $\mathrm{O} / \mathrm{C}$ & $\mathrm{B}$ & $\mathrm{Vp}$ \\
\hline 1 & 60 & 18 & 8 & 5 & 90 \\
2 & 91 & 44 & 10 & 10 & 150 \\
\hline
\end{tabular}

A=Automóveis; $\mathrm{M}=$ Motocicletas; $\mathrm{O} / \mathrm{C}=$ Ônibus e Caminhões; $\mathrm{B}=$ Bicicletas; $\mathrm{Vp}=$ Veículos de Passeio.

Fonte: Elaborado pelo autor. 
ID: 26

LOCALIZAÇÃO: Estrada Perimetral Pref. Domingos Antônio Fortunato (I)

DATA: 27/10/2017 (sexta-feira)

HORÁRIO: Início: 12:05h - Final: 12:20h

\section{MOVIMENTOS PERMITIDOS:}

Figura B39: Estrada Perimetral Pref. Domingos Antônio Fortunato (I).
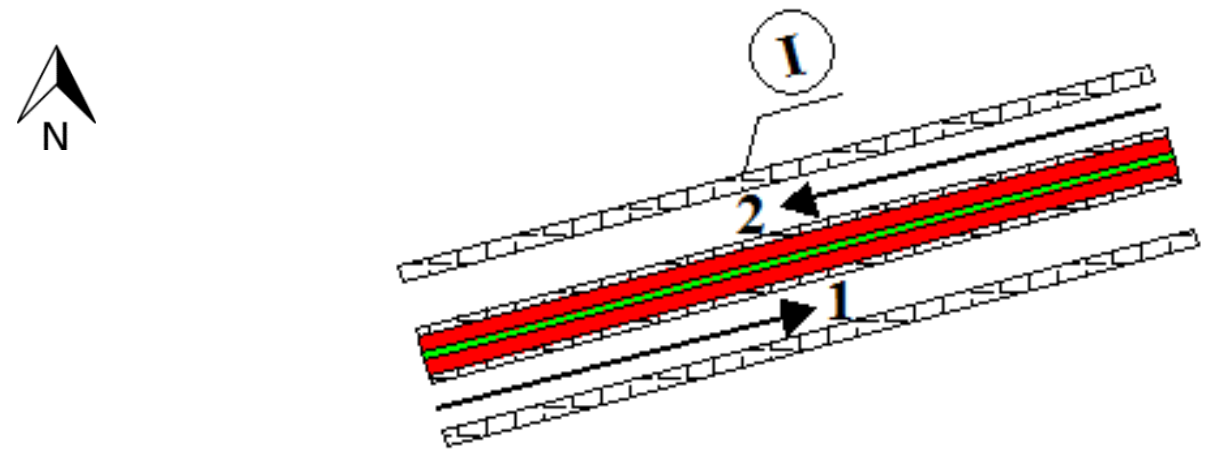

Fonte: Elaborado pelo autor.

Desenho sem escala.

Legenda:

Canteiro central

Infraestrutura cicloviária

\section{CONTAGENS:}

$$
\mathrm{V}_{\mathrm{p}}=1,0 *(\mathrm{~A})+1,0 *(\mathrm{M})+1,5 *(\mathrm{O} / \mathrm{C})
$$

Tabela B39: Estrada Perimetral Pref. Domingos Antônio Fortunato (I).

\begin{tabular}{c|c|c|c|c|c}
\hline \multirow{2}{*}{ Movimento } & \multicolumn{5}{|c}{ Tipo de veículo } \\
\cline { 2 - 6 } & $\mathrm{A}$ & $\mathrm{M}$ & $\mathrm{O} / \mathrm{C}$ & $\mathrm{B}$ & $\mathrm{Vp}$ \\
\hline 1 & 51 & 8 & 8 & 5 & 71 \\
2 & 57 & 24 & 7 & 7 & 92 \\
\hline
\end{tabular}

A=Automóveis; $\mathrm{M}=$ Motocicletas; $\mathrm{O} / \mathrm{C}=$ Ônibus e Caminhões; $\mathrm{B}=$ Bicicletas; $\mathrm{Vp}=$ Veículos de Passeio.

Fonte: Elaborado pelo autor. 
204 | P á g i n a 


\section{APÊNDICE C}

Neste apêndice são apresentados os tempos cronometrados para as amostras de veículos aleatórios em cada trecho selecionado para a estimativa da velocidade média de tráfego.

Tabela C1: Tempos cronometrados para amostras aleatórias de veículos (1).

\begin{tabular}{|c|c|c|c|c|c|c|c|c|c|c|}
\hline \multicolumn{11}{|c|}{ Tempo cronometrado para a transposição dos trechos de extensão conhecida (s) } \\
\hline $\mathrm{n} \% / \mathrm{ID}$ & 1 & 2 & 3 & 4 & 5 & 6 & 7 & 8 & 9 & 10 \\
\hline 1 & 5,5 & 5,3 & 5,2 & 9,6 & 10,6 & 9,6 & 9,1 & 8,2 & 5,0 & 6,4 \\
\hline 2 & 4,9 & 5,9 & 5,6 & 12,3 & 10,6 & 6,6 & 11,8 & 7,2 & 7,2 & 8,8 \\
\hline 3 & 4,4 & 6,4 & 7,2 & 8,6 & 9,2 & 8,0 & 9,7 & 8,8 & 6,4 & 6,6 \\
\hline 4 & 4,9 & 7,0 & 8,1 & 10,1 & 8,7 & 7,1 & 7,8 & 7,7 & 6,7 & 7,0 \\
\hline 5 & 5,5 & 6,1 & 8,5 & 8,3 & 6,7 & 9,8 & 9,7 & 8,3 & 6,6 & 7,5 \\
\hline 6 & 5,2 & 7,2 & 8,2 & 9,8 & 9,9 & 7,2 & 13,1 & 7,1 & 5,0 & 7,2 \\
\hline 7 & 3,6 & 7,1 & 8,1 & 8,0 & 9,7 & 7,5 & 11,3 & 8,3 & 6,4 & 6,7 \\
\hline 8 & 5,9 & 7,6 & 4,8 & 10,0 & 9,9 & 9,9 & 4,9 & 9,9 & 6,2 & 4,4 \\
\hline 9 & 4,5 & 6,0 & 7,5 & 10,1 & 9,9 & 8,2 & 10,6 & 7,4 & 6,3 & 8,3 \\
\hline 10 & 5,2 & 7,4 & 6,1 & 9,6 & 6,8 & 9,6 & 10,2 & 8,7 & 6,9 & 5,9 \\
\hline 11 & 4,7 & 7,5 & 4,9 & 9,7 & 8,7 & 7,5 & 7,4 & 8,1 & 6,3 & 7,3 \\
\hline 12 & 4,7 & 6,2 & 9,9 & 11,9 & 11,4 & 7,5 & 10,0 & 6,4 & 6,5 & 6,8 \\
\hline 13 & 5,4 & 5,7 & 4,6 & 9,9 & 8,4 & 7,5 & 7,9 & 6,7 & 5,3 & 7,0 \\
\hline 14 & 5,3 & 6,4 & 6,5 & 7,5 & 11,4 & 8,0 & 11,3 & 9,0 & 7,7 & 7,3 \\
\hline 15 & 5,0 & 6,6 & 7,4 & 11,9 & 9,4 & 7,1 & 8,9 & 8,1 & 6,8 & 7,0 \\
\hline 16 & 4,6 & 4,1 & 6,0 & 8,9 & 9,1 & 10,6 & 9,7 & 8,9 & 6,0 & 6,9 \\
\hline 17 & 5,1 & 5,2 & 7,3 & 10,5 & 11,2 & 8,5 & 11,9 & 7,2 & 7,9 & 7,1 \\
\hline 18 & 5,3 & 5,9 & 9,3 & 7,7 & 9,1 & 9,1 & 13,4 & 7,9 & 5,8 & 8,1 \\
\hline 19 & 5,7 & 7,5 & 5,4 & 9,1 & 8,9 & 8,1 & 14,4 & 7,1 & 7,0 & 6,4 \\
\hline 20 & 5,8 & 7,4 & 6,7 & 11,2 & 8,6 & 9,4 & 10,5 & 7,6 & 7,1 & 7,4 \\
\hline 21 & 4,7 & 5,6 & 8,2 & 9,8 & 11,2 & 7,1 & 10,0 & 5,9 & 5,4 & 6,8 \\
\hline 22 & 5,1 & 6,1 & 7,0 & 6,9 & 10,5 & 10,7 & 8,9 & 7,8 & 5,6 & 7,8 \\
\hline 23 & 6,9 & 7,6 & 7,4 & 11,4 & 8,3 & 8,4 & 9,7 & 9,9 & 5,9 & 6,4 \\
\hline 24 & 5,3 & 8,6 & 6,1 & 9,1 & 8,7 & 9,0 & 12,8 & 7,7 & 6,7 & 6,7 \\
\hline 25 & 4,5 & 6,3 & 6,2 & 9,2 & 7,5 & 8,9 & 8,1 & 7,6 & 7,5 & 7,0 \\
\hline 26 & 4,8 & 6,6 & 6,9 & 10,5 & 9,1 & 6,3 & 8,8 & 6,6 & 5,9 & 7,3 \\
\hline 27 & 5,7 & 7,5 & 6,6 & 9,4 & 8,4 & 8,0 & 8,9 & 8,3 & 6,3 & 6,3 \\
\hline 28 & 6,2 & 6,2 & 7,1 & 10,3 & 7,4 & 7,6 & 7,3 & 7,7 & 6,7 & 5,2 \\
\hline 29 & 4,3 & 7,1 & 5,9 & 10,3 & 9,0 & 8,1 & 10,8 & 5,7 & 5,0 & 6,0 \\
\hline 30 & 5,0 & 6,6 & 6,7 & 9,1 & 8,7 & 8,5 & 9,6 & 8,0 & 7,5 & 6,9 \\
\hline
\end{tabular}

Fonte: Elaborado pelo autor. 
Tabela C2: Tempos cronometrados para amostras aleatórias de veículos (2).

\begin{tabular}{|c|c|c|c|c|c|c|c|c|c|c|}
\hline \multicolumn{11}{|c|}{ Tempo cronometrado para a transposição dos trechos de extensão conhecida (s) } \\
\hline $\mathrm{n} / \mathrm{ID}$ & 11 & 12 & 13 & 14 & 15 & 16 & 17 & 18 & 19 & 20 \\
\hline 1 & 4,4 & 6,5 & 7,6 & 9,4 & 6,0 & 5,6 & 6,8 & 8,5 & 9,9 & 5,0 \\
\hline 2 & 5,4 & 4,2 & 8,8 & 10,5 & 7,8 & 4,1 & 5,9 & 7,2 & 9,2 & 5,5 \\
\hline 3 & 8,9 & 6,0 & 7,4 & 12,1 & 5,2 & 4,3 & 6,6 & 9,2 & 10,8 & 7,5 \\
\hline 4 & 5,6 & 6,1 & 8,2 & 13,2 & 7,7 & 6,0 & 7,6 & 8,7 & 10,8 & 7,7 \\
\hline 5 & 4,5 & 5,3 & 8,2 & 9,6 & 6,6 & 5,6 & 6,8 & 6,4 & 9,8 & 6,5 \\
\hline 6 & 6,2 & 7,6 & 7,9 & 10,2 & 5,9 & 5,6 & 4,7 & 7,8 & 9,9 & 5,8 \\
\hline 7 & 5,7 & 5,1 & 8,9 & 8,6 & 5,3 & 5,3 & 6,9 & 7,6 & 9,1 & 7,0 \\
\hline 8 & 5,3 & 5,1 & 8,6 & 11,2 & 7,3 & 5,6 & 7,0 & 8,9 & 10,9 & 5,5 \\
\hline 9 & 4,2 & 4,6 & 6,4 & 13,2 & 5,7 & 4,2 & 7,4 & 7,5 & 8,4 & 7,0 \\
\hline 10 & 6,0 & 5,7 & 7,9 & 12,6 & 6,9 & 4,9 & 7,6 & 6,7 & 10,8 & 6,0 \\
\hline 11 & 4,3 & 5,1 & 9,0 & 13,5 & 5,4 & 4,3 & 7,4 & 11,0 & 9,7 & 8,0 \\
\hline 12 & 6,0 & 5,0 & 7,1 & 10,4 & 8,0 & 5,3 & 7,5 & 7,7 & 12,1 & 5,1 \\
\hline 13 & 5,7 & 5,2 & 6,4 & 12,6 & 7,0 & 6,8 & 6,4 & 6,5 & 8,1 & 7,7 \\
\hline 14 & 5,3 & 4,9 & 6,9 & 9,0 & 5,6 & 6,8 & 6,5 & 7,8 & 9,4 & 5,6 \\
\hline 15 & 7,0 & 4,9 & 7,2 & 9,7 & 5,1 & 6,6 & 6,5 & 8,1 & 12,3 & 5,2 \\
\hline 16 & 4,0 & 5,9 & 10,4 & 7,3 & 6,0 & 5,7 & 8,3 & 9,5 & 8,7 & 4,9 \\
\hline 17 & 6,6 & 4,9 & 9,6 & 8,0 & 6,1 & 5,7 & 5,5 & 9,0 & 8,5 & 6,5 \\
\hline 18 & 5,8 & 6,2 & 7,6 & 13,1 & 7,3 & 5,9 & 6,3 & 7,5 & 9,7 & 5,6 \\
\hline 19 & 4,7 & 4,2 & 7,0 & 11,2 & 6,4 & 5,5 & 6,7 & 8,7 & 10,5 & 5,7 \\
\hline 20 & 4,7 & 4,6 & 6,0 & 9,8 & 8,0 & 6,0 & 6,1 & 6,7 & 8,7 & 6,9 \\
\hline 21 & 8,0 & 6,2 & 8,4 & 9,1 & 6,4 & 5,7 & 6,9 & 7,1 & 8,6 & 7,9 \\
\hline 22 & 4,9 & 5,7 & 5,9 & 12,1 & 5,2 & 5,7 & 8,8 & 5,6 & 8,7 & 6,7 \\
\hline 23 & 3,8 & 5,2 & 7,1 & 11,8 & 6,5 & 5,5 & 6,7 & 7,5 & 9,0 & 7,7 \\
\hline 24 & 6,9 & 4,4 & 9,7 & 9,3 & 6,2 & 5,3 & 5,1 & 9,7 & 9,6 & 7,0 \\
\hline 25 & 4,9 & 5,9 & 9,7 & 11,4 & 5,2 & 6,1 & 7,5 & 8,9 & 11,7 & 7,7 \\
\hline 26 & 5,7 & 5,5 & 8,7 & 10,5 & 5,6 & 6,4 & 6,5 & 7,4 & 8,6 & 3,6 \\
\hline 27 & 5,4 & 5,7 & 7,2 & 11,3 & 7,7 & 4,5 & 6,5 & 7,5 & 12,2 & 7,0 \\
\hline 28 & 5,9 & 5,7 & 5,0 & 12,2 & 7,7 & 6,2 & 6,8 & 7,5 & 10,0 & 5,4 \\
\hline 29 & 5,0 & 5,6 & 8,6 & 12,2 & 6,3 & 5,6 & 9,0 & 10,9 & 11,4 & 6,6 \\
\hline 30 & 4,4 & 5,5 & 4,3 & 10,6 & 8,1 & 5,4 & 7,4 & 8,0 & 9,0 & 6,3 \\
\hline
\end{tabular}

Fonte: Elaborado pelo autor. 